\title{
From Condoms to Antiretrovirals: A Posthumanist Performative Account of Men Who Have Sex with Men's (MSM) Condomless Sexual Practices
}

\author{
By
}

\author{
Emerich Daroya
}

A thesis submitted to the Faculty of Graduate and Postdoctoral Affairs in partial fulfillment of the requirements for the degree of

Doctor of Philosophy

in

Sociology

Carleton University

Ottawa, Canada

(C)2021

Emerich Daroya 


\begin{abstract}
Recent biomedical advances in the field of HIV prevention and treatment, including PreExposure Prophylaxis (PrEP) and Treatment as Prevention (TasP), have shifted meanings of "risk" and "safety" concerning gay and other men who have sex with men's (MSM) sexual practices, particularly around "barebacking" or condomless sex. However, public health research continues to be based on the paradigm that gay men misbehave and misuse technologies such as PrEP and TasP to engage in barebacking. Public health discourses frame MSM as culpable for the effects of HIV technologies, reinforcing dominant (neoliberal) narratives of individual autonomy and risk behaviour.

The purpose of this thesis is to challenge these assumptions. By mobilising analytic frameworks from posthumanist performative theories emphasising the active, dynamic, and agentic nature of material and discursive forces, I consider how advances in HIV prevention actively participate in shaping MSM's sexual practices and culture. I examine the impacts of HIV biomedical knowledge and technologies on MSM's conceptualisations of sexual risk, responsibility, morality, and stigma. Drawing on MSM's accounts from online forum posts and in-depth qualitative interviews on the effects of PrEP and TasP, I argue that gay men creatively incorporate harm reduction measures, including biomedical technologies, into their sexual practices, engendering possibilities for condomless sex to become "safer," empowering, and more pleasurable.

This study destabilises the conception of condomless sex as always "risky" and "intentional" by recognising that barebacking practices emerge as complex and multiplesimultaneously safe/unsafe, premeditated/unplanned, and rational/irrational. This work enriches social science's contributions to HIV research by developing a theorised account of the complex considerations taken by gay men in assessing risk through the incorporation of HIV knowledge and biotechnologies. I also contribute to a conceptual rethinking of agency and responsibility beyond human subjects in the materialisation of condomless sexual practices, acknowledging the implication of human and nonhuman forces, including HIV science and public health, in producing a wide variety of effects associated with HIV treatment and prevention technologies.
\end{abstract}




\section{Acknowledgements}

I am forever grateful for the kindness and generosity of my supervisor, Dr. Alexis Shotwell, who took me on as a student and never stopped having faith in me over the years. I cannot begin to express my thanks for always motivating me, keeping me on track, and believing in my intellectual capacities. Her support, guidance, wealth of knowledge, and skilful mentorship is something I will always keep aspiring to.

I would like to express my deepest appreciation to my thesis committee. Dr. Stuart J. Murray's keen interest in the subject and critical insights enabled me to produce this research work in its present form. His careful eye and clear writing style are qualities I hope to carry forward. I am incredibly grateful to Dr. Mike Mopas' thoughtful comments and recommendations on this dissertation. His support to a fellow Filipino scholar in science and technology studies is a source of inspiration. Many thanks also to my thesis examiners, Dr. Barry Adam and Dr. Dale Spencer. It was a pleasure to discuss my work with such esteemed scholars.

I am also grateful to the faculty and staff at the Department of Sociology and Anthropology, especially Dr. Xiaobei Chen, Dr. Aaron Doyle, Paula Whissell, Darlene Moss, and Patricia Lacroix. I would also like to thank The Pauline Jewett Institute of Women's and Gender Studies for trusting me as a TA, especially Dr. Patrizia Gentile, for being such a wonderful mentor and friend. I am grateful to learn from my brilliant and supportive cohortKira Heymans, Vanessa Million, Cihan Erdal, Kory Smith, Leon Laidlaw, Kent Hall, Abigail Curlew, and Gazel Manuel. Thank you to my thesis group, Kat Huybregts, Christine Moreau, River Rossi, Drew Holt, Cheyenne Thomas, and Tarik Kifle, for the insightful suggestios and support.

This thesis would not have been possible without the support and encouragement of my dear friends: Calvin Cheung, Louie Garces, Alvi Dandal, Nicole Watson, Sher Dusoruth, Sesadri Bell, Airish De Leon, and Louis Lafreniere. Dr. Joe Latham, I appreciate your friendship and support. Dr. Madalena Santos, I'm grateful for your brilliance and kindness. Dr. Ryan Conrad, thank you for keeping me sane. Each of you taught me in the most surprising, radical, and beautiful ways.

I would like to extend my sincere gratitude for the generous financial support from the Social Sciences and Humanities Research Council of Canada and the Department of Sociology and Anthropology, Carleton University. I would like to extend my sincere thanks to Dr. Christine Ekholst and Dr. Duane Duncan for writing outstanding recommendation letters. I also wish to thank my interview participants and members of the online forum for sharing their stories.

To my family, especially to my mother and father, Marietta and Ernesto Daroya. I am thankful for the unconditional love and support. My siblings Maidene and Elwyn, thank you for the relentless encouragement. And to Philippe, to whom I owe the completion of my dissertation. Thank you for reading my drafts, asking challenging questions, and allowing me to be silly despite the seriousness of academia. I had endless doubts, but your love, unwavering support, and encouragement sustained me. Merci. 


\section{Table of Contents}

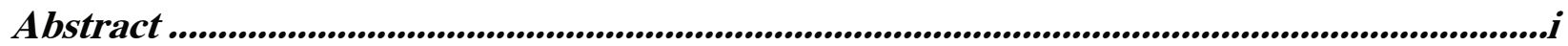

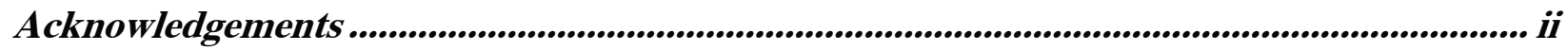

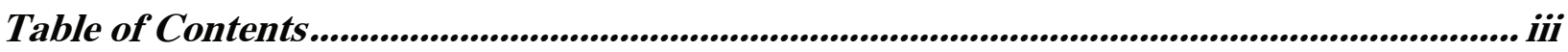

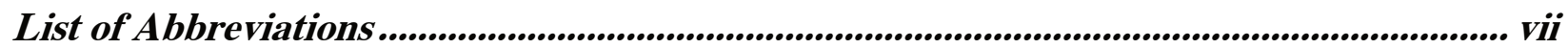

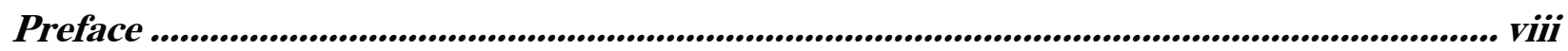

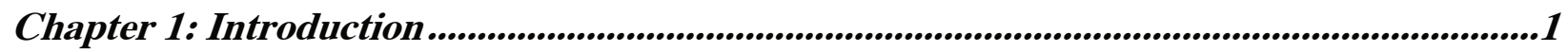

What's in a Term? "Barebacking" Meanings and Practices ................................................................5

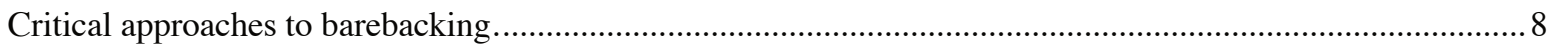

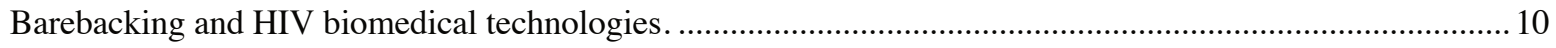

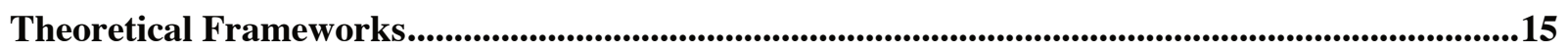

Agential realism and posthumanist performativity ............................................................................. 17

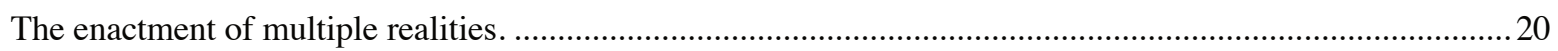

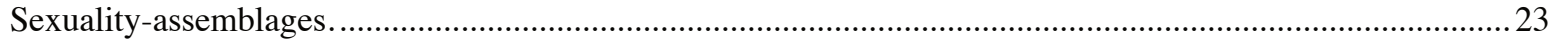

Praxiographic Approach to Foucauldian Discourse Analysis .......................................................25

Cyber or virtual ethnography of online sex environments. ............................................................................... 30

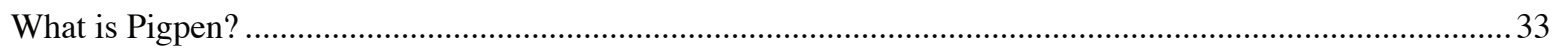

First Phase: Previous Study - Barebacking pre-PrEP (1998-2012) .................................................................. 34

Second Phase: Current Study - Barebacking with PrEP (2012-onwards). ........................................................ 37

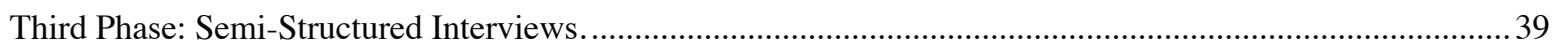

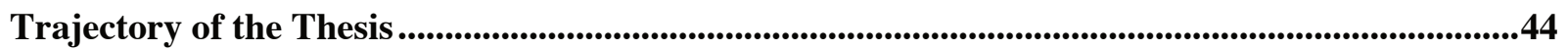


Chapter 2: The Ontological Openness of Barebacking: Shifting Practices in Socio-

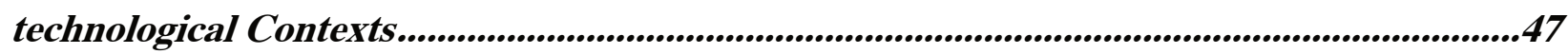

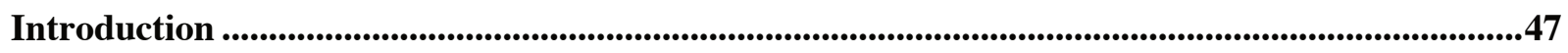

Barebacking as Intentional and Assumptions about MSM's Agency ............................................49

Theorising the Ontological Openness of Barebacking...............................................................53

Barebacking: Socio-Behavioural Evolution from Safer Sex to Greater Sexual Risk-Taking........55

Barebacking: Mitigating Risks through Serosorting and Pharmaceutical Technologies ..............62

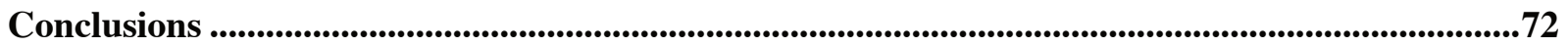

Chapter 3: "Stealthing" and the Emergence of Sexual Morality and Responsibility ...........76

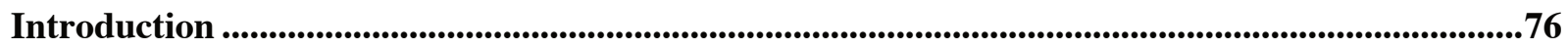

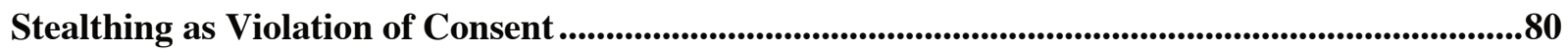

Posthuman Sexuality-Assemblages: Sex in Social and Physical Spaces .............................................83

Conceptualising Stealthing through Liberal and Legal Notions of Consent ....................................87

Limits of Liberal Models of Consent: Anonymous Sex in Bathhouses ...............................................93

(Re)Producing the Responsible Self ....................................................................................................................99

Individual Responsibility among HIV-negative men.......................................................................... 100

Protecting Others (“Altruism”) and HIV-positive men.......................................................................... 104

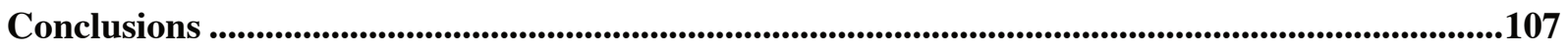

Chapter 4: The Productive Effects of HIV Science and Biomedical Technologies in

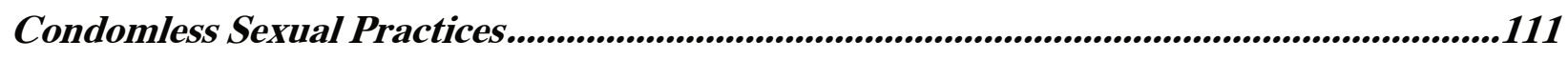

Introduction 
The Productive Functions of HIV Science and Biomedical Technologies .....................................113

Sexual Risk and Pleasure in HIV Science ...................................................................................118

The Implication of Science in Embodied Practices ..................................................................123

Productive Effects of Uncertainties and Limitations ..................................................................130

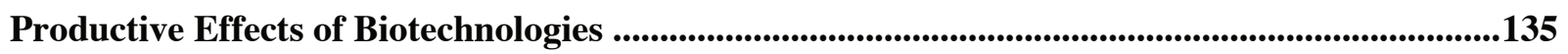

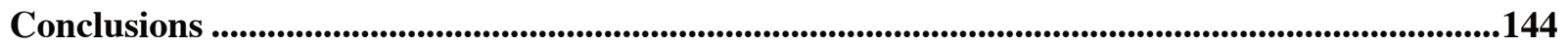

Chapter 5: "I felt judged to be on it": Rethinking Moral Panics and Stigmatisation around

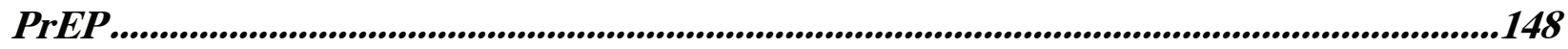

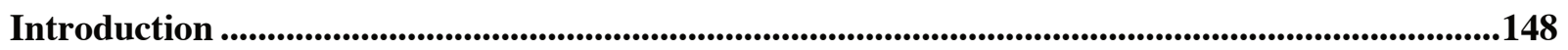

Posthumanist Performativity, Sexuopharmaceuticals and Moral Panics......................................151

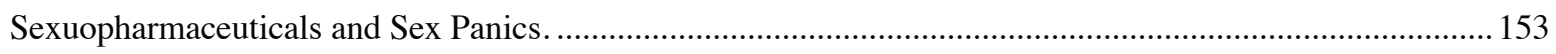

Historical Formations of PrEP Stigma.................................................................................................157

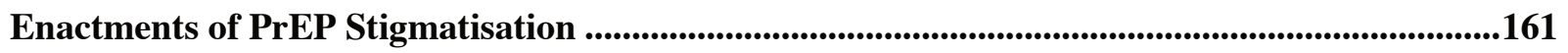

PrEP Stigmatisation in Interpersonal and Intrapersonal Relations................................................... 163

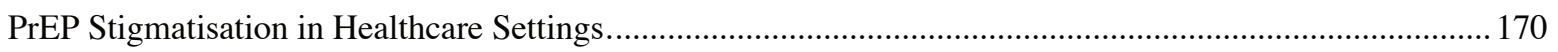

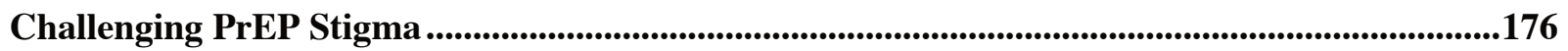

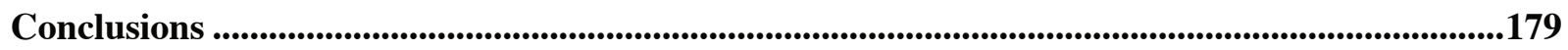

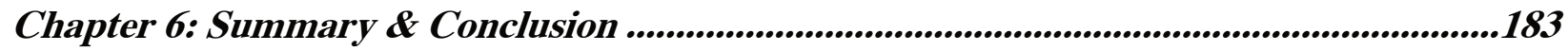

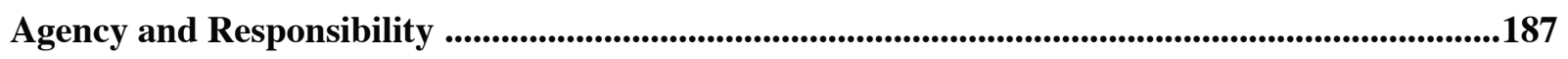

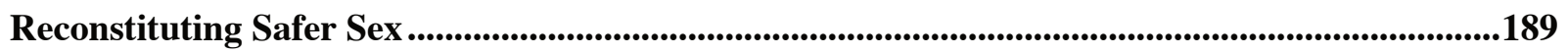

Limitations and Suggestions for Future Research ..........................................................................192 
Epilogue

Bibliography.

Appendix A - Carleton University Ethics Clearance

Appendix B - La Trobe University Ethics Clearance.

Appendix C - Email to Website Moderator

Appendix D - Announcement about Research Posted in the Online Forums.................................238

Appendix E - Interview Guide.

Appendix F - Online Invitation Website

Appendix G - Informed Consent Form

Appendix H - Online Invitation. 249 


\section{List of Abbreviations}

AIDS: Acquired Immunodeficiency Syndrome

ARVs: Antiretroviral Drugs

CDC: Centers for Disease Control

FDA: Foucauldian Discourse Analysis

HAART: Highly Active Antiretroviral Treatments

HIV: Human Immunodeficiency Virus

MSM: Men Who Have Sex with Men

PrEP: Pre-Exposure Prophylaxis

STI(s): Sexually Transmitted Infection(s)

STS: Science and Technology Studies

TasP: Treatment as Prevention 


\section{Preface}

My ex-partner's best friend was diagnosed with HIV ten years ago. At that time, he was in his early twenties, blonde, slim, and, apparently, well-endowed. There was something inherently attractive about him, like a "twink" gay porn actor. As my ex-boyfriend and I pondered the news about someone so young being infected with HIV, my ex said, "I'm shocked, but not surprised." Why did he put himself at risk? In light of knowledge about HIV in the early 2010s, why did he engage in barebacking? Both my ex and I were baffled by these questions. Was it because he had an insatiable sex drive? Could it be that barebacking was simply enjoyable? Upon reflection, I realized I may have been asking the wrong questions. Besides, they were moralising. However, I was curious to learn more. Considering a 20 -something guy could get infected with HIV from barebacking with multiple partners, how many gay men of my age engaged in condomless sex at that time? Moreover, what would this mean for gay men whose sexuality has been devastated by illness and death for thirty-something years (and now forty!) after the AIDS crisis? These questions, among others, were the impetus of my interest in researching barebacking practices.

Around the same time, I had just finished my M.A. I decided to take a break before deciding whether to pursue further studies. My ex and I concluded that Australia was a good option. Our goal would be to obtain a temporary work visa, earn some money, and travel to Southeast Asia. That was at least the plan. Having Australia in mind, I began searching for $\mathrm{PhD}$ programs there. Since our summer was their winter, PhD programs in Australia were still accepting applications. In order to identify potential supervisors, I started writing a proposal about barebacking. Dr. Steven Angelides, who was taking up a position at La Trobe University's Australian Research Centre for Sex, Health \& Sexuality, agreed to supervise me and support my application. And so, in 2012, we moved to Melbourne and I began doctoral research on barebacking.

While my original approach was to investigate the socio-cultural aspect of barebacking, Steven led me to turn to science and technology studies and feminist new materialisms, which were becoming the focus of critical scholarship on HIV. Due to his influence, I also began to shift my thinking toward this body of theory. Fast forward to 2014, and the landscape of gay men's sexuality has drastically changed. Attending the International AIDS Conference that year, the discourse regarding HIV prevention among gay and other men who have sex with men (MSM) moved towards pharmaceuticals, particularly the use of the drug Truvada as PreExposure Prophylaxis (PrEP). In that conference, the World Health Organization even recommended offering PrEP to MSM. For me, the introduction of PrEP raised questions on how long barebacking practices and subcultures could persist. Quickly running out of time and financial support, we packed up our belongings and relocated back to Canada.

At the beginning of 2016, living in Toronto, and working part-time, I was still working towards my Ph.D. thesis. There was a sinking feeling, however, that PrEP was having a profound impact on gay men's sexuality. To talk about barebacking in 2016 without taking PrEP into consideration was already anachronistic. Should I continue working on my thesis even though the topic was, quite simply, out of style? At the beginning of 2017, I had an existential crisis and 
decided to withdraw from my thesis, find suitable work, and maybe make up my mind about the Ph.D. later on.

Since I was unable to find suitable employment, I decided to salvage my $\mathrm{PhD}$, but I would remain in Canada this time. It may be possible for me to pick up on my old work, collect some new data, add new analysis, and produce a new thesis. Gathering some strength, I determined that I had nothing to lose in asking. The only institution that came to my mind was Carleton, where I finished my M.A. Fortunately, Dr. Xiaobei Chen, who was a member of my M.A. thesis committee, was the Graduate Program Coordinator in Sociology at that time. She already knew me and had an idea of my work ethic and capabilities. I sent her an email detailing my situation. This was July 2017 and the admission deadline for Ph.D. program had already passed. And yet, she encouraged me to apply. I did and a couple of weeks later, I got an offer. I accepted and started my Ph.D. (again) in September 2017.

The following thesis is the culmination of this challenging and exciting personal and academic journey. 
This page was left intentionally blank. 


\section{Chapter 1: Introduction}

The AIDS epidemic is cultural and linguistic as well as biological and biomedical. To understand the epidemic's history, address its future, and learn its lessons, we must take this assertion seriously.

Paula Treichler (1999, p. 1)

[T] he virus is more or other than a biological entity [...]. [D]espite the enactment by science of the virus as a stable object, its effects reveal it to be already a mix of phenomena beyond simply semiotic (symbolic or cultural) and material (biological).

Marsha Rosengarten \& Mike Michael (2010, p. 178)

Since Acquired Immunodeficiency Syndrome (AIDS) was first recognised in the 1980s in North America among people with haemophilia, injection drug users, racialised communities and, most severely, gay, bisexual and other men who have sex with men (MSM), knowledge about and technological advancements in the management of the human immunodeficiency virus (HIV) has continually shifted. ${ }^{1,2}$ Developments in the scientific and medical understandings of HIV as primarily transmitted through sexual contact helped in the emergence of safer sex cultures

\footnotetext{
${ }^{1}$ According to Young \& Meyer (2005), the term "men who have sex with men (MSM)" was adopted in the 1990s as a behavioural category in HIV/AIDS literature. The term was coined due to the perceived stigma attached to "gay" and "homosexual." The authors, however, problematise the use of the term, noting that "MSM" erases the identity of gay men, which could be problematic for political and social recognition. By contrast, "MSM" could be useful in contexts where talking about sex between men is difficult (Gafos et al., 2019). It is also noted that the term is limited, for "MSM" does not differentiate between penetrative and non-penetrative sex (which could entail different identities in different cultures) and sex with/between transmen (Khan \& Khan, 2006). Conversely, the term "gay" refers to both identity and practice, yet it can also be limiting. "Gay" is considerably Westernised, and applies mostly to white homosexual men. Men of colour who have sex with other men may not necessarily recognise themselves as "gay," and neither do bisexual men. While I acknowledge that these terms are problematic, I nonetheless utilise "gay" and "MSM" interchangeably in this thesis, both as a recognition that some men selfidentify as "gay," but also being cognizant that not all MSM are "gay." The use of "gay" and "MSM" as identical may be thought of as simultaneously a sexual identity and practice.

${ }^{2}$ The onset of AIDS in North America in the 1980s mostly affected marginalised communities - gay men, black and Latinx drug users, and others who were considered to be engaging in "immoral behaviours." For Treichler (1999, p. 20), the original list of "high risk" categories, the " $4 \mathrm{H}$ " (homosexuals, haemophiliacs, heroin addicts, and Haitians) were linked to a particular kind of person engaging in doing particular things. By connecting AIDS to specific types of people, "propelled by homophobia, racism, and drug phobia, allowed and even promoted indifference toward the deaths of people with AIDS" (Cohen, 1999, p. 20).
} 


\section{2 | Chapter 1}

among gay men, relying on condoms to prevent the spread of HIV. The breakthrough in the biomedical treatment of HIV/AIDS came about in the mid-1990s when highly active antiretroviral treatments (HAART) effectively suppressed the progression of the AIDS virus, helping improve life expectancy and quality of life of people infected with HIV. The introduction of HAART changed HIV management, transmission, and acquisition, impacting the sexual practices of MSM, especially seropositive men. As more HIV-positive men could suppress their viral loads and reduce the likelihood of transmission, they also started declaring their refusal to wear condoms with other seropositive men, calling their practice "barebacking," or condomless anal sex. More recently, the introduction of Truvada, a retroviral medication manufactured by Gilead Sciences, in 2012 as pre-exposure prophylaxis (PrEP) has radically changed HIV prevention. This thesis is concerned with the implications of HIV pharmaceutical and other prevention technologies in MSM's sexualities, focusing on the practices of condomless sex.

Since the introduction of HAART in the mid-1990s, there have been discussions about the effects of biotechnologies on sexual risk behaviours. Researchers have suggested that HIV complacency, or the reduction in perceptions of HIV/AIDS threat following treatment optimism, played a role in the decision of some MSM to engage in barebacking (Berg, 2009; Valdiserri, 2004). Likewise, PrEP provision was predicted to influence the intentions of some MSM to decrease condom use, or to discontinue them altogether in favour of barebacking (Golub et al., 2010). While much research on barebacking assumes that MSM engage in "risky" behaviours in response to biotechnologies, my aim in this research is to focus on the productive force of biomedical technologies and challenge the notion that MSM are somehow culpable for the negative effects of biotechnologies. How is condomless sex understood and practised differently 
due to the reduction of risk that stems from advances in HIV prevention? What role do these different suites of technologies play in transforming how MSM conceive sexual risk, responsibility, morality, and stigma? How do MSM co-constitute subjectivities emerging from the use of such technologies? These questions, among others, drive this research. By drawing insights from posthumanist performative theories, I aim to rethink agency and responsibility as collectively achieved through a wider field of material-discursive relations, connections, or assemblages.

Based on relational ontology, posthumanist performative frameworks emphasise the mutuality of discourse and matter in the process of materialisation by rejecting "the assumption that bodies and things are already-existing entities" (V. Squire, 2015, p. 150). Exemplary works in the development of posthumanist performativity are Karen Barad (2007) and Annemarie Mol (2002), feminist Science and Technology Studies (STS) scholars who coined the terms "agential realism" and "enactment," respectively, to signify the relationality and inseparability of material and discursive forces in the formation of different realities. ${ }^{3}$ I augment these frameworks by bringing in the concept of "sexuality-assemblages" inspired by the works of Deleuze and Guattari (1987) to think differently about sexuality as a grouping of elements coming into

\footnotetext{
${ }^{3}$ In spite of some scholars' claims that Barad and Mol, as well as Deleuze and Guattari, are "new materialists" (e.g., Fox \& Alldred, 2017), I believe their configurations indicate an approach independent of either the "materialist turn" or the "discursive turn." The term "new materialism" is used in the humanities and social sciences to describe the "turn to matter," "the ontological turn," "the posthuman turn," or the "more-than-human approach" (Fox \& Alldred, 2017). According to Coole and Frost (2010), new materialisms emerge out of the critiques of dominant constructionist orientation (what is sometimes called the "cultural turn," "linguistic turn," or "discursive turn"), believed to privilege language, discourse, and culture but inadequate "for thinking about matter, materialism, and politics in ways that do justice to the contemporary context of biopolitics and global political economy" (p. 6). New materialism "conceives of matter itself as lively or as exhibiting agency" and that humans are "immersed within materiality's productive contingencies" (Coole \& Frost, 2010, p. 7). The problem with new materialist approaches, as Vicki Squire (2015) maintains, and I agree with her, is that they risk falling into materialist determinism to the disadvantage of discourses. A crucial component of Barad's and Mol's (as well as Deleuze and Guattari's) posthumanist performative perspectives is their emphasis on the impossibility of separating the material from the discursive, rejecting the divide between the "materialist turn" and the "discursive turn." Rather, they stress the mutual imbrication of matter and discourses in ways that contrast to some new materialist perspectives that focuses on the vitality of matter. I discuss these issues further in the section "Theoretical Frameworks" of this chapter.
} 


\section{4 | Chapter 1}

relation through connections that are in continuous process of change and production (Alldred \& Fox, 2015; Allen, 2015; Fox \& Alldred, 2013). ${ }^{4}$ Combining these theoretical approaches allows for a reconceptualisation of sexuality as a material-discursive phenomenon that is endlessly “done," enacted, or constituted in a "posthuman field of power relations" (Garland-Levett, 2020, p. 701). In this introduction, I explain how these theoretical approaches contribute to understanding the relationality and active role of HIV prevention pharmaceuticals in MSM's sexual cultures and practices. My main argument is that scientific knowledge and pharmaceutical technologies, alongside other discursive and material forces, actively enact barebacking as more than a risky and dangerous practice. Drawing on empirical findings, I demonstrate that through the creative integration of harm reduction measures by MSM into their sexual practices, including biomedical technologies, barebacking can simultaneously emerge as safe, pleasurable, and empowering. This thesis disrupts both a conception of barebacking as always intentional and risky, as well as the dominant public health conception of barebackers as promiscuous people misusing biomedical technologies solely for the purpose of enjoying condomless sex.

Theoretically, this study departs from conventional notions of agency and responsibility that remain confined to individuals in some public health discourses by showing that the effects of biomedical technologies in gay men's sexual practices are collectively achieved by a variety of discursive and material forces, including scientific knowledge and pharmaceutical technologies. Concretely, this thesis offers a challenge to public health to update current prevention and treatment campaigns by emphasising that barebacking practices can sometimes be "safer," empowering, and pleasurable.

\footnotetext{
${ }^{4}$ According to Deleuze and Guattari (1987), thinking with assemblages focuses on what sexualities (or other phenomena) do: "what it functions with, in connection with what other things it does or does not transmit intensities," instead of asking what it means (p. 4). I explain this further in this chapter's "Theoretical Frameworks" section.
} 


\section{What's in a Term? 'Barebacking” Meanings and Practices ${ }^{5}$}

Scott O'Hara, credited to have introduced the term, described "barebacking" in 1997 in his book Autopornography as condomless sex between HIV-positive men. In the same year, Stephen Gendin also wrote that HIV-positive men engaged in "unprotected" anal intercourse, for they believed that there were no longer medical concerns about sharing semen between them (Halkitis, Wilton, \& Drescher, 2005). To explain why some MSM engaged in "barebacking," it was first necessary to define what barebacking referred to so that factors that seemingly persuade gay men to forego the use of condoms may be studied and proper interventions could be created. In general, researchers agreed that barebacking was poorly defined (Carballo-Dieguez et al., 2010; Halkitis, Wilton, \& Drescher, 2005). The commonly accepted definition among researchers contained one element: condomless or unprotected sex, regardless of serostatus. Beyond this definition, there was disagreement about intentionality, acceptance of risk, attitudes about HIV, and responsibility.

In an attempt to operationalise barebacking as a theoretically coherent practice, some researchers examined how MSM conceptualised "barebacking." Foremost was a qualitative study done by Carballo-Dieguez et al. (2010) of men who self-identified as barebackers or who engaged in barebacking in New York. Their findings suggested that a broad agreement among MSM existed, referring to barebacking as anal intercourse without condoms. However, there was a lack of consensus beyond this definition, and participants embraced no single description. Conversely, Carballo-Dieguez and colleagues differentiated between intentional and unintentional condomless sex, and also those practices that carried potential risks and those that did not. The study's authors proposed that barebacking be recognised as "intentional condomless

\footnotetext{
${ }^{5}$ I borrow this from Halkitis, Wilton and Galotowitsch's (2005) article in the Journal of Gay and Lesbian Psychotherapy, with the title: "What's in a Term? How Gay and Bisexual Men Understand Barebacking."
} 
intercourse in HIV risk contexts" to clear the confusion in producing effective public health interventions (Carballo-Dieguez et al., 2010, p. 209). Carballo-Dieguez et al. further distinguished barebacking from condomless sex that may involve accidental infection and from intentional or unintentional condomless sex that was risk-free. Operationalising barebacking as intentional and risky has significant implications for MSM's agency and responsibility vis-à-vis HIV risk: barebackers are framed as "agents who consciously decide to forego condoms despite potential danger" (Harvey, 2011, p. 173). In this configuration, MSM are shaped as "intrinsically risky" and "responsible for their own HIV infections," failing to adhere to the public health imperative to engage in rationality and calculation (Junge, 2002, p. 196).

The operationalisation of barebacking as intentional is generally accepted in the literature, mainly describing the practice as "conscious," "premeditated," "deliberate," or “voluntary” (Carballo-Dieguez et al., 2010, 2011; Gauthier \& Forsyth, 1999; Grov, 2007; Mansergh et al., 2002; Parsons \& Bimbi, 2007; Reisner et al., 2008; Suarez \& Miller, 2001). By producing barebacking as intentional, researchers could consider risk factors contributing to some MSM's willingness to forego condoms. Some argue that sexual pleasure, sensationseeking, and the need for intimacy, which may derive from various psychological states, including depression and poor mental health, influence gay men to bareback (Bancroft et al., 2003; Carballo-Dieguez et al., 2011; Cheuvront, 2002; Elam et al., 2008; Mansergh et al., 2002; Shernoff, 2006a). Drug use is also found to have a strong correlation with sexual risk-taking and a predictor in identifying as "barebacker" (Elam et al., 2008; Halkitis \& Parsons, 2003; Mansergh et al., 2002; Parsons \& Bimbi, 2007; Reisner et al., 2008). While these bodies of research suggest that risk factors are intrinsic to individuals, others proposed that contextual and environmental factors contribute to the tendency to engage in barebacking. 
One of the most cited structural factors in the increase of barebacking is the introduction of HAART. Some maintain that barebacking emerged as a direct result of HAART, responsible for a widespread idea among MSM that the AIDS epidemic was over (Berg, 2009; Halkitis, Parsons, \& Wilton, 2003; Halkitis, Wilton, \& Drescher, 2005; Mansergh et al., 2002; Shernoff, 2006b; Ven et al., 2005; Wolitsky et al., 2001). Likewise, the barebacking subcultural practices of "bugchasing" (i.e., HIV-negative men actively seeking HIV infection) and "giftgiving" (i.e., HIV-positive men willing to infect the former) are also attributed to HAART and other effective HIV treatments. ${ }^{6}$ Ian Young, Toronto-based writer, activist, and founder of the University of Toronto Homophile Association, the first post-Stonewall gay organisation in Canada, even linked the introduction of HAART to the rise of an "AIDS culture" in North America, replacing the image of HIV-positive men as deteriorating with an image of being positive as desirable (I. Young, 1996, 1997). On account of the formation of a "positive lifestyle," HIV-positive men started "being noticed and admired by other men, desirable once again, sometimes more than ever" (Alvarez, 2008, p. 144).

The internet is also considered a significant technological advancement underpinning barebacking, facilitating opportunities to meet new sexual partners online, introducing some men to barebacking practices (Gauthier \& Forsyth, 1999; Moskowitz \& Roloff, 2007a, 2007b;

Mowlabocus, 2007; Tewksbury, 2006). While contextually informed research highlights the role of technologies in influencing barebacking and subcultural practices, some of these studies are fixed on the notion of technologies as subject to the actions of gay men to misuse them. In other

\footnotetext{
6 "Bugchasing" and "giftgiving" are concepts used to refer to the barebacking subcultural practices of intentional HIV seroconversion. Bugchasers are understood to particularly desire semen that contains the virus: "poz cum" as it is colloquially known (Dean, 2009). By contrast, giftgivers are HIV-positive men who "give" HIV ("the bug") to HIV-negative men.
} 
words, much like the epidemiological studies that they purportedly depart from, these investigations subscribe to a normative view of agency as a strictly human affair.

Critical approaches to barebacking. On the one hand, the studies cited above are predicated on identifying risk factors that ostensibly lead MSM to engage in barebacking; on the other, this body of research does not explain how these practices are meaningful for barebackers. Instead, such studies seek to identify barebackers as a risk group, producing MSM as irrational and irresponsible. Critically viewing public health approaches to barebacking, queer theorist Tim Dean (2009) points out that the introduction of HAART did not simply cause "barebacking." Rather, antiretroviral drugs (ARVs) allowed for the transformation of HIV and how gay men have sex. By reconstituting knowledge about HIV, ARVs enabled gay men to think differently about barebacking as formative of connection through the exchange of semen (Dean, 2009; Holmes \& Warner, 2005; E. Reynolds, 2007). Other studies suggest a link between condomless sex and notions of masculinity, where barebacking is associated with what it means to be "real men" who are not afraid to take risks (Adam, 2016; Dowsett et al., 2008; Holmes et al., 2008; Ridge, 2004). Finally, some others maintain that barebacking is a form of resistance against the dominant public health imperative to protect oneself against infections and diseases (Ávila, 2015; Crossley, 2001, 2002, 2004; Tomso, 2008).

In exploring the implication of HIV prevention campaigns in the production of a social context where barebacking becomes possible, Ávila (2015) draws on Foucauldian critical approaches, where barebacking may constitute what Foucault calls a "response to configurations of power" (Foucault, 1990, p. 271). Picking up on this notion, Tomso (2008) argues that the field of public health, as a form of neoliberal governmentality based on health promotion and risk management, produces barebacking as a form of defiance. For these theorists, barebacking is a 
form of resistance against the aims of biopower. ${ }^{7}$ While safer sex discourses centred on condom use offer safety by providing a barrier against possible HIV infection, fulfilling the imperative to be healthy, barebacking, by contrast, offers an opportunity to resist these discourses precisely by abandoning the use of condoms and practising semen exchange. According to Tomso, practising barebacking in the context of a neoliberal biopolitical regime is to expose oneself to disease and be irresponsible and irrational (Tomso, 2008). ${ }^{8}$

However, with the increasing use of HIV biomedical technologies, HIV prevention has shifted from self-governance towards biopolitics by regulating populations and managing masses through pharmaceuticals (Giami \& Perrey, 2012). Giami and Perrey argue that pharmaceutical use is more advantageous because it relies on individual compliance with a medication regimen rather than behavioural changes, like condom use (ibid). The use of PrEP is, in Tim Dean's (2015) view, merely a new method of biopower persuading gay men to regulate their sexual health. As he explains, MSM embody biopower by ingesting PrEP: "If panopticism still functions in the 21 st century, it is because we have swallowed it whole in the name of health" (Dean, 2015, p. 238). While Dean (2009) earlier hailed barebacking for its capacity to resist the biopolitical imperative to remain healthy, he criticises PrEP because it makes it difficult for

\footnotetext{
${ }^{7}$ Biopower is a term first used by Foucault (1990) in the first volume of The History of Sexuality to refer to the techniques used (not only by political authorities but also by medicine, public health and other regulatory mechanisms) to discipline bodies and populations. It is closely related to the term "biopolitics" which he refers to as the management of an entire population including births, deaths, reproduction and illnesses (Rose, 2007). While Foucault (2003) says that disciplinary power (associated with "anatomo-politics") is distinct from biopolitics (which is about regularisation), he states that sexuality exists at both points. Although the former deals with individuals and the latter with populations, he insists that sexuality "is a matter for discipline but also a matter for regularization" (p. 251-252). It can also be argued that pharmaceuticals as biopolitical entities do not only target sexuality at the individual level but also at the level of populations. What I mean to say here is that HIV prevention technologies and strategies circulate between disciplinary and regulatory flows of power.

${ }^{8}$ According to Tomso (2008), neoliberal rationality demands individuals to be efficient, rational and calculative. These ideas combine well with biopolitical regimes, with the aim of optimising population to ensure productivity. "In other words," writes Tomso, "neoliberalism helps to naturalize biopolitical aims" (p. 270). By contrast, "viral sex" presents a challenge to neoliberal biopolitics "by calling into question the meanings of health and survival, mobilizing those concepts in direct opposition to the state-supported aims of public health" (p. 277).
} 
MSM to resist biopolitics: "adopting Truvada risks defeating the purpose of bareback as a practice of resistance to mainstream health norms" (Dean, 2015, p. 233).

Similarly, queer theorist Octavio González (2019) echoes Dean by asserting that PrEP removes the transgressive qualities of condomless sex by disrupting the relation between barebacking and HIV risk. Indeed, the introduction of PrEP changes the history of barebacking: "It could be argued that as PREP $[$ sic $]$ increasingly becomes available to barebackers $[\ldots]$, the era of 'bareback proper' is now drawing to a close" (O. Davis, 2015, p. 123). The advent of PrEP prompts further analysis and evaluation of barebacking, for biomedical technologies have introduced "the possibility that condomless sex does not necessarily mean exposure to HIV" (Girard et al., 2019, p. 489). How have barebacking's meanings shifted in light of different suites of technologies (condoms, HAART, and PrEP, among others)? To put it differently, how have biomedical technologies actively transformed and challenged the meaning of HIV risk in condomless sex practices?

Barebacking and HIV biomedical technologies. As with the introduction of any new HIV prevention technology, healthcare providers and other HIV stakeholders raise concerns regarding the potential for risk disinhibition in condom abandonment favouring condomless sex. For instance, the introduction of HAART in the mid-1990s produced a moral panic arising from a feared "second wave" of new HIV infections across major cities in North America (Rofes, 1998). In very similar ways, PrEP also generated fears about risk compensation, which endure up to the present, that gay men will simply abandon condoms in favour of PrEP when it was first introduced (Duran, 2012; C. Moore, 2020; Weinstein, 2010). ${ }^{9}$ However, some published research

\footnotetext{
${ }^{9}$ Within HIV/AIDS literature, "disinhibition" and "risk compensation" are often times used interchangeably. For Hogben and Liddon (2008), it is important to distinguish these concepts, for they entail different intervention strategies. On the one hand, the former is a "psychological terminology," which "occurs when people stop trying to avoid risk to themselves or others" (p. 1000). Perhaps the most popular examples of disinhibition are alcohol and
} 
thus far points to contradictory and inconclusive effects concerning sexual risk-taking. For example, Hojilla and others' (2016) analysis of counselling notes from San Francisco’s PrEP Demonstration Project established that with very few exceptions, most men did not abandon existing risk reduction strategies upon initiation of PrEP. However, Van Laarhoven and colleagues (2017) reported an increase in high-risk sexual behaviours in Amsterdam after the first six months of PrEP use. By contrast, Freeborn and Portillo (2017) concluded that they did not find any conclusive evidence of any increase in sexual risk behaviours among PrEP users in their review of the literature.

While some studies are interested in investigating the impacts of PrEP on sexual risk behaviours, others focus on understanding the different psychosocial and sociocultural effects of PrEP among MSM. For example, examining the experiences of PrEP users in England, Martinez-Lacabe's (2019) findings suggest that the drug allowed some MSM freedom to navigate complex sexual situations, such as condom failures and sex with multiple partners, instead of being seen as a technology of control (as Tim Dean theorised). Sun and others (2019) also describe that, among Oregon participants, PrEP provides a feeling of empowerment, and is viewed as an additional layer of protection that made some users more comfortable with their sexuality. The PrEP protocol for testing every three months was also not experienced as

\footnotetext{
drugs, where an inebriated person is seen to "no longer care" when under the influence of these elements. On the other hand, risk compensation is "a more cognitive perspective." Hogben and Liddon explain: "The term applies to those whose diminished susceptibility via a given preventive intervention permits them to increase risk behaviours" (ibid). Ranjit et al. (2019), however, argue that these theories are too simplistic, for decision-making in terms of sexual behaviours are more complicated. Additionally, they contend that the theories of disinhibition and risk compensation "negatively labels MSM" as "risk-seekers who desire unrestrained sexual behavior" (Ranjit et al., 2019 , p. 535). I agree with these assessments. As I show throughout this thesis, disinhibition and risk compensation are effects arising out of complex relations, rather than simply MSM behaving badly. As I maintain, such effects are creatively achieved, where MSM adapt HIV knowledge and biotechnologies into sexual practices to make sense of "safety" and "risk."
} 


\section{2 | Chapter 1}

controlling but as a form of self-empowerment (Martinez-Lacabe, 2019). ${ }^{10}$ Other studies seem to concur with these findings. Specifically, men who experienced the AIDS crisis in the 1980s welcomed the positive impacts of PrEP on public health. In contrast, younger gay men stressed the impact of PrEP in their sexual culture, identifying it as characterised by less anxiety and greater pleasure (Hammack et al., 2019). Moreover, while critical theorists have emphasised the individualisation of responsibility through the use of PrEP (Sandset, 2019; Thomann, 2018), Martinez-Lacabe's research participants viewed PrEP not as individualising but pointing towards collective responsibility by preserving the health of the community.

Although these studies reveal that HIV-negative gay men view PrEP positively, others also experienced adverse social effects. Primarily, many PrEP users reported experiencing stigma because other MSM accused them of being uninhibited for using PrEP, using the formulation of "Truvada Whores” (Grimm \& Schwartz, 2018; Pawson \& Grov, 2018). This stigmatising effect is related to barebacking, on account of the belief that PrEP users take prevention shortcuts by foregoing condoms, and the interpretation of using PrEP as communicating desire for condomless sex (Jaspal \& Daramilas, 2016; Spieldenner, 2016). Additionally, stigma is identified as a potential barrier to PrEP access because potential users may feel ashamed for being labelled "promiscuous" (Golub, 2018), leading to some health care providers' discomfort in discussing sex with patients (Calabrese et al., 2019). Nevertheless, though stigma can be an obstacle to PrEP uptake, it may also provide opportunities for fighting and exposing stigma surrounding sex and HIV. For example, some PrEP users have

\footnotetext{
${ }^{10}$ According to the CDC's guidelines for clinicians providing PrEP, PrEP users are required for follow-up every 3 months to repeat HIV and STI testing in order to provide a prescription (valid for 90 days) and ensure adherence. At least every 6 months, clinicians are also obligated to test patients' urine to check for serum creatinine levels. Finally, at least every 12 months, clinicians are instructed to evaluate the need to continue prescribing PrEP to patients. See: https://www.cdc.gov/hiv/pdf/risk/prep/cdc-hiv-prep-guidelines-2017.pdf
} 
reappropriated the term Truvada Whore by emphasising its effectiveness in preventing HIV while offering possibilities for sexual pleasure through barebacking (Haire, 2015). Moreover, PrEP also enabled some HIV-negative men to consider having sexual relations with HIVpositive people (Sun et al., 2019).

These discussions show that the introduction of PrEP in the sexual practices of MSM generates multiple effects beyond its consideration as a useful biomedical tool. The uptake of PrEP produces anticipated and unanticipated outcomes: on the one hand, PrEP creates fear about risk compensation and disinhibition, resulting in stigmatisation. On the other, PrEP cuts the link between HIV risks and condomless sex, opening possibilities for sexual choices, freedom, and pleasure. This thesis adds to these critical conversations by arguing that these various effects are emergent from the coming together of pharmaceuticals, HIV, human bodies, and other entities. My approach here slightly differs from some of the literature discussed above. Specifically, this thesis diverges from some public health research, which focuses mainly on investigating causal relations by relying on simplification and framing a direct relation between PrEP and condomless sex. ${ }^{11}$ Instead, I analyse the implication of HIV knowledge and biotechnologies and other discursive and material forces in the production of effects in the embodied practices of MSM, with the aim of destabilising normative conceptions of individual agency and responsibility.

By contrast, social science and humanities research's focal point is to highlight the complex relations between pharmaceutical technologies and condomless sex, with a particular focus on sexual freedom and pleasure. However, like those inspired by public health, such

\footnotetext{
${ }^{11}$ For example, Golub's (2018) study aimed to provide data for behavioural disinhibition and risk compensation concerning PrEP use, predicting that HIV-negative men who use PrEP intend to decrease condom use by thirty-five percent.
} 


\section{4 | Chapter 1}

studies subscribe to a model of human agency that frames MSM as responsible for the effects of PrEP. For example, a content analysis of Facebook data conducted by da Silva-Brandao and Ianni (2020) found that "individuals play a positive and conflicting ethic towards sex while on PrEP" (p. 1400). To move away from the idea that individuals are culpable for the various effects of biomedical technologies, I argue for a posthumanist performative approach to HIV science and technologies to recognise their implication in co-producing sexual practices. Adapting such a framework, inspired by Barad (2007) and Mol (2002), provides a complex and richer account of the effects of biomedical technologies as historically, socially, culturally, and materially situated and co-constitutive of MSM's sexual practices. In so doing, notions of culpability shift from individual to shared responsibility for the (un)intended effects of HIV science and biomedical technologies.

Further, focusing on the role of technologies in the sexual practices of MSM enables an understanding of "barebacking" as a complex and relational practice beyond its current understanding as intentional condomless anal sex in HIV risk contexts. The notion that barebacking is a single coherent practice can be disrupted by theorising barebacking as relational. As I argue throughout this thesis, condomless sex mediated by HIV biomedical technologies is other than merely risky and dangerous; it can also emerge as protected and safe. I will demonstrate how MSM creatively incorporate harm reduction measures, such as serosorting in conjunction with biomedical technologies, that engender possibilities for condomless sex to become "safer" and more pleasurable. Finally, centring analysis on the active force of biotechnologies enables the recognition of biopower's materiality in producing different kinds of subjects concerning safer sex discourses, further opening possibilities for novel understandings of sexual responsibility as collectively achieved. In what follows, I discuss how posthumanist 
performative frameworks, based on Karen Barad's and Annemarie Mol's theorisations alongside interpretations of Deleuze and Guattari's notion of assemblages, help conceptualise HIV prevention technologies as active participants in shaping MSM's sexual practices and subjectivities.

\section{Theoretical Frameworks}

Much existing research in the field of sexualities in feminist and queer theorisations build upon poststructuralist approaches "that attends to language and meaning-making," in which subjects are framed as "always already saturated with sexual norms, differentials of power, and reigning discourses" (Murray et al., 2018, p. 4). In this configuration, discursive apparatuses of power form identities through performative practices (Parisi, 2009). Judith Butler's work on performativity has been highly influential in helping scholars understand how subjectivities and subjectification are constituted through performative repetitions of norms (Ringrose \& Rawlings, 2015). For Butler, performativity is neither wilful nor arbitrary; instead, "the historicity of discourse and, in particular, the historicity of norms [...] constitute the power of discourse to enact what it names" (1993, p. 188). Building upon this theory, Butler considers the body not "an independent materiality that is invested with power relations external to it" (p. 34). Instead, bodies are neither discursive nor material, but both: "language and materiality are not opposed, for language both is and refers to that which is material" (p. 68). Arguably, Butler's intervention in performative theory maintains the co-constitutive relation between discourse and materiality.

However, from the perspective of some new materialist scholars, Butler's focus on discourse is "ultimately unable to account for the material activities of sign-bodies" (Parisi, 2009, p. 77). As Sara Ahmed (2008) describes in her critique of the emerging field of feminist new materialisms, much scholarship produced thus far gestures towards Butler and other 
poststructuralist feminist and queer theorists as reducing "everything" to language and culture.

Feminist new materialist scholar Myra Hird (2009, p. 331) maintains that " $[\mathrm{m}]$ aterial feminism is not convinced that culture entirely either produces and/or constrains materiality or culture and matter are isolated events." Butler's intervention in arguing that "[the body] bears on language all the time" (Butler, 1993, 68), argues Vicky Kirby (2008, p. 278), is limited to the surface "because she assumes that differentiation of contouring [of the body] is given by/in signification." From the perspective of feminist new materialisms, Butler's reliance on "culture" risks the reinstallation of hierarchies between "ideality and matter, culture and nature, and mind and body" (Kirby, 2002, p. 269).

In repeating these criticisms, I do not wish to take sides in the discourse/materiality debate as most poststructuralist feminists and queer theorists have long rejected such a divide. ${ }^{12}$ Instead, I approach the different positions carefully while reflecting on how new materialisms are continuous and reconfigure a long trajectory of scholarship that emphasises the inseparability of matter and discourse. Just as the "discursive turn" risked overemphasising the importance of culture, the "materialist turn," in my view, may also carry an overinvestment in matter. While questioning the emphasis on culture and language, I do not seek to prioritise "matter" nor reject the insights from the "discursive turn." Instead, I maintain that while Butler introduces groundwork for questioning the relationship between discourse and matter, Karen Barad (2007) builds upon these interrogations by providing analytical frameworks in thinking through and

\footnotetext{
${ }^{12}$ It is important to note that Butler aimed to deconstruct the perceived binary between matter and discourse/culture at length in her early works (Ahmed, 2008). Ahmed (2008, p. 27) also maintains that the new materialist criticisms about poststructuralist feminism as having reduced everything to language is an act of forgetting previous feminist works on biology: "you can only argue for a return to biology by forgetting the feminist work on the biological, including the work of feminists trained in the biological sciences. In other words, you can only claim that feminism has forgotten the biological if you forget this feminist work." Ahmed also points out that Donna Haraway, in her earlier works, explored the relation between nature/biology and culture through her classic term "material-semiotic," which has been picked up by Karen Barad through their concept of "material-discursive."
} 
addressing the relationship between discourse and matter through her theory of "agential realism." This section lays the groundwork for a posthumanist performative analysis of the biomedicalisation of gay men's sexualities through ARVs and their roles in the co-constitution of subjectivities, practices, identities, and other sexual effects.

Agential realism and posthumanist performativity. In her ground-breaking interrogations of the sex/gender distinction, Butler (1993, p. 34) claims that the body is not "an independent materiality that is invested with power relations external to it.” Instead, as Butler (2004) maintains:

there is no easy way to distinguish between what is 'materially' true, and what is 'culturally' true about a sexed body. I don't mean to suggest that purely cultural signs produce a material body, but only that the body does not become sexually readable without those signs, and that those signs are irreducibly cultural and material at once (p. 87).

In other words, Butler indicates that matter is irreducible to language because matter and language are mutually constituted and constitutive. Despite this insistence, Barad (2007) criticises Butler on account of her theorisation that discursive practices constitute matter: “Unfortunately, however, Butler's theory ultimately reinscribes matter as a passive product of discursive practices rather than as an active agent participating in the very process of materialization" (Barad, 2007, p. 151). Refining Butler's theorisations of performativity, Barad draws on the works of feminist STS scholar Donna Haraway and the philosophy-physics of scientist Niels Bohr to develop their theory of "agential realism," which they believe provide an "understanding of materialization that goes beyond the anthropocentric limitations of Butler's theory" (ibid). According to Barad, while Butler's performativity emphasises that language and body are mutually implicated, constituted and constitutive - put simply, bodies emerge through, rather than prior to, reiterative processes-Butler's account is bound up with "regulatory power 


\section{8 | Chapter 1}

and discursive practices, which are limited to the domain of human social practices" (Barad, 2007, p. 145). Importantly, Barad claims, Butler's idea of agency "belongs only to the human domain" and does not "address the nature of technoscientific practices and their profound productive effects on human bodies [...], and more generally the workings of power" (p. 145-6). Barad attempts to address these concerns by developing a theory of agential realism to open possibilities for recognising matter's dynamism, an "active 'agent' in its ongoing materialization" while acknowledging that matter is not determining, for it is always already co-constituted by language (p. 145).

Whereas Butler's notion of performativity helps understand how discursive practices constitute matter, Barad refines Butler's theory by drawing attention to the performativity of objects, bodies, discourses, and other nonhuman things in the production of realities through her notion of "intra-action" (Ringrose \& Rawlings, 2015). In other words, while Butler interrogates the relation between discourse and matter by emphasising that culture and nature are inextricably linked and co-constituted, Barad provides analytical frameworks in thinking through Butler's performativity into direct engagement with matter (Rosengarten, 2004). The concept of intraaction is crucial to Barad's agential realism and reconfiguration of performativity. According to Barad, intra-action signifies the entanglement of matter and discourse ("material-discursive") in the constitution of phenomena: "in contrast to the usual 'interaction,' which assumes that there are separate individual agencies that precede their interaction, the notion of intra-action recognizes that distinct agencies do not precede, but rather emerge through their intra-action" (2007, p. 33). Put simply, phenomena (or the "basic units of reality" [ibid]) materialise through the intra-action of matter and discourse, where matter is considered constitutive of and constituted by discourse. These ideas form the basis on which Barad develops their conception of 
agential realism, where matter and materiality are reconceptualised as agentive and intra-active. Barad explains: "[Agential realism] goes beyond performativity theories that focus exclusively on the human/social realm. Agential realism takes into account the fact that the forces at work in the materialization of bodies are not only social and the bodies produced are not all human" (2007, p. 225). Through agential realism, Barad develops an approach they call "posthumanist performativity," which "complements and extends the thinking offered by Butler around how the performativity of discourses work in intra-action with material agents" (Ringrose \& Rawlings, 2015, p. 87).

To understand Barad's reconfiguration of performativity further, I turn to their discussion of the materialisation of gender through ultrasound technology. For Barad, ultrasound technology should be conceived as productive, and part of the materialisation of gender and not merely a technological hardware that reflects or passively observes a foetus. Barad explains that ultrasound technology is part of the constitution of gender as an effect of the intra-action between discourses, objects (for example, among other things: foetus, placenta, the woman's abdomen and pelvic cavity, the gel used for ultrasound, soundwaves), and "agencies of observation" (that is, a transducer). In this example, Barad argues that ultrasound technology does not innocently observe the foetus; instead, "it helps to produce and is part of the body it images" (Barad, 2007, p. 202). As they further explain, ultrasound technology helps enact the foetus as gendered, where technology is made up of material-discursive forces (Barad, 2007, p. 66).

According to Barad's account, gender is not only a discursive product but also material, where matter is also rendered active in its constitution. While Butler's performativity infers that gender is constituted through discursive practices, Barad's posthumanist performativity extends 
this by accounting for the implication of matter in practices. Indeed, the constitution of gender via ultrasound emerges through several heterogeneous elements where obstetric ultrasonography is understood not as a single practice but as an amalgamation of different practices "involving a myriad of material configurations and discursive formations" (Barad, 2007, p. 204). Barad's posthumanist performativity attempts to offer a “new account of matter's dynamism [...], as well as a posthumanist elaboration of the notion of performativity" (2007, p. 66).

In this dissertation, I take up Barad's conception of matter as dynamic, "not a thing, but a doing" (2007, p. 151), in analysing the potential effects of HIV prevention technologies in MSM's sexual practices to move away from normative conceptualisations of culpability. That is, while MSM are rendered responsible for the (mis)use of biotechnologies in some public health scholarship, drawing attention to the performance of a whole range of human and nonhuman forces by adapting Barad's posthumanist performativity allows me to consider the implication of HIV science and biotechnologies in the production of sexual effects, shifting understandings of responsibility from the individual to shared accountability for the (un)intended effects of such technologies. Additionally, I invoke Barad's posthumanist performativity to attend to the emergent effects of complex yet intertwined sexual practices that involve HIV biotechnologies, bodies, and subjectivities through which multiple realities of condomless sex emerge. To help me further articulate this, I draw on some of the arguments made by feminist and actor-network theorist Annemarie Mol (2002), who maintains that realities are enacted through practices consisting of diverse material-discursive elements.

The enactment of multiple realities. While Barad's intervention provides insights into the intra-active and distributed agencies of both subjects and objects in the production of realities or phenomena, the work of Annemarie Mol (2002) extends these views by attending to how 
different practices tend to produce not only different perspectives but also different realities. For Mol, realities are enacted through practices and, if practices are multiple, then reality is not singular. ${ }^{13}$ The implication is that ontology is not fixed: because realities come into being through practices, then there are also multiple ontologies. Thus, Mol's approach in paying attention to how diseases are made and enacted through practices takes us from a focus on epistemology towards an emphasis on ontology (V. Squire, 2015). According to Mol, while epistemological approaches offer the notion that there are many ways of knowing a disease, the assumption is that there is one single coherent entity called a "disease," albeit with different perspectives. Although paying attention to knowledge multiplies perspectives about an object, epistemological approaches, argues Mol (2014), leave the object being observed untouched. ${ }^{14}$ By contrast, attending to questions of enactments (of realities or ontologies) rather than knowledge (or epistemologies) is different because " disease' becomes a part of what is done in practice" (Mol, 2002, p. 13). In paying attention to how objects are enacted in practices, "what we think of as a single object may appear to be more than one" (Mol, 2002, p. vii). In effect, Mol takes us from the idea that there are not just many ways of "knowing" an object but also many ways of practising it. And each way of practising enacts a different version of the object (Mol, 2014).

\footnotetext{
${ }^{13}$ Instead of "performance," Mol (2002) uses the term "enactment" because she believes it carries less intellectual baggage. For Mol, the performance metaphor suggests that there is a backstage, where a reality is hiding or that what is being done in the present have effects beyond that particular moment. By contrast, "enactment" entails that realities are produced and created through practices. It is important to note, however, that Mol does not imply any conceptual difference between enactment and performativity. Indeed, in a 2018 interview, she says: "There is not much difference between the way I use enact and the way Judith Butler writes about the 'performance' of reality" (Martin, Spink and Pereira, 2018). Nevertheless, the use of the term enactment may be helpful in avoiding conceptual misunderstandings about Butler's performativity. For Vicki Squire (2015), "the concept of enactment might be strategically invoked as a means to distinguish constructivist analyses that focus on meaning construction and representational practices from a material-discursive analysis that focuses on the co-constitution of 'subjects', 'objects', and 'environments"” (p. 153).

${ }^{14}$ Focusing on questions of how a disease is known rather than what is a disease maintains the reality of an object stable, coherent, and singular. Mol explains that an emphasis on epistemology maintains that there are differing ways in which the body can be viewed; however, the body "ultimately remains the same regardless of the practices of enactment that it involves" (V. Squire, 2015, p. 153).
} 


\section{2 | Chapter 1}

For Mol, like Barad, paying attention to practices is important because it is through practices that materialisations happen: "It is possible to say that in practices objects are enacted" (Mol, 2002, p. 32-33). In The Body Multiple, Mol investigates how atherosclerosis (a disease of the leg) is “done," practised, or enacted in a Dutch hospital to demonstrate that objects ("phenomena" in Barad's language) and realities come into being within practices. The disease turns up to be different in various places and practices: in the outpatient clinic, it materializes as pain in walking; in pathology, it is visible through a microscope as a thickened wall of blood vessels; in the operating room, it appears as a plaque taken out of the body. Each of these practices generates its own material reality of atherosclerosis: "And since the object of manipulation tends to differ from one practice to another, reality multiplies" (Mol, 2002, p. 5).

In sum, Barad and Mol push for a posthumanist performative approach that recognises the mutuality and dynamism of subjects and objects in practices by rejecting the assumption that discourse and matter are independent of and pre-existing each other (Barad, 2007). This theoretical move enables the possibility for understanding sexual effects and realities as enacted through sexual practices. Adapting Barad's and Mol's posthumanist performativity helps analyse the complexities of sexual practices, mediated by pharmaceutical technologies, where barebacking emerges as more than risky and dangerous and condomless sex can also be safe, pleasurable, and empowering. These theorisations introduce a new mode of thinking that challenges the separation between discourse/matter by emphasising the constitutive role of practices, which have important implications for a critical analysis of sexualities as emergent via intra-active entanglements in practices that are always already inseparable from biopower. It is here that I turn to some interpretations of French philosophers Gilles Deleuze and Felix 
Guattari's works to augment Barad's and Mol's frameworks and bring it closer to the analysis of sexualities through the concept of assemblages.

Sexuality-assemblages. Although Barad's and Mol's theories of posthumanist performativity help understand sexuality as discursive and material, where HIV prevention technologies are rendered dynamic, complementing these with the concept of "sexualityassemblages" (Alldred \& Fox, 2015; Allen, 2015; Fox \& Alldred, 2013) inspired by the works of Deleuze and Guattari allows for a better understanding of the effects of biotechnologies as multiple and collectively achieved through connections where sexual desires, identities, and other sexual phenomena are emergent and always already co-constituted by (bio)power. The notion of sexuality-assemblages further reconfigures responsibility, agency, and subjectivities as relational achievements.

The English word "assemblage" is customarily understood to be derived from the French agencement from Deleuze and Guattari's works, which refers more to the arrangement of connections (Phillips, 2006). "Any body or thing is the outcome of a process of connections," writes feminist scholar Claire Colebrook (2002, p. xx), clarifying further that for Deleuze (and Guattari): "A human body is an assemblage of genetic material, ideas, powers of acting and a relation to other bodies" (ibid). Similarly, as Murray, Holmes, and Foth (2018) argue, sexuality can be conceptualised as a series of connections, encouraging a way of thinking differently about sexuality as a grouping of different elements, where matter and meaning are rendered coconstitutive of sexual desires and other phenomena. Consequently, in understanding sexuality-asassemblage, sexuality becomes unpredictable as assemblages are "unexpected, disparate and productive connections," capable of creating "new ways of thinking and living," and of desiring and becoming (Colebrook, 2002, p. 76). 


\section{4 | Chapter 1}

According to Fox and Alldred (2013), conceptualising sexuality as assemblages decentres sexual agency from bodies to individuals by recasting it as an effect of the relations of discursive and material elements. The notion of sexuality-assemblages also reconfigures sexual agency as emergent in relation, further "supplying an ontological basis for resistance" that moves away from notions of free will (Fox \& Alldred, 2013, p. 782). The concept of agency as emergent also provides a better understanding of Barad's notion of agential realism, where agency is understood as only possible through intra-actions: "agency is a matter of intra-acting; it is an enactment, not something that someone or something has [...]. It is not an attribute whatsoever. Agency is 'doing' or 'being' in its intra-activity" (Barad, 2007, p. 178). ${ }^{15}$ The reconfiguration of agency as a relational achievement allows me to draw attention to the co-constitutive roles of a whole range of human and nonhuman forces when determining responsibility for the potential effects of HIV prevention technologies in sexual practices (Race, 2012).

In combination, these theoretical frameworks contribute towards a reconfiguration of agency by highlighting the significance of material forces, including HIV biotechnologies and physical spaces, without reducing the importance of discourses, such as HIV science, consent, and responsibility in analysing sexual practices. Notably, a posthumanist performative approach opens possibilities for rejecting the public health framing of MSM as promiscuous for improperly using biomedical technologies by demonstrating that sexual capacities, such as the possibility for condomless sex to become "safer" and more pleasurable, emerge through practices that involve material-discursive forces. Additionally, highlighting the enactment of realities through practices seeks to offer a re-conceptualisation of condomless sex as never singular but multiple, seriously challenging the dominant public health messaging about

\footnotetext{
${ }^{15}$ Edenheim (2016) argues that Barad's move to redefine agency as enactment serves her posthumanist performativity well in ascribing agency not only to humans, but also to technologies.
} 
barebacking as always risky and dangerous. By emphasising the enactment of HIV knowledge and biomedical technologies, alongside other material-discursive forces, these interventions contribute to the reshaping of various effects of biomedical technologies as collectively achieved, further destabilising normative notions of agency and responsibility that remains restricted to individuals. Moreover, by attending to practices, the multiplicity, complexity, and relationality of condomless sexual practices can be revealed. In this research, I adopt Mol's (2002) ethnographic strategy of "praxiography" to attend to how objects, such as HIV pharmaceuticals and condomless sex, are done, or enacted. To fully appreciate the enactment of objects in practices as entangled with power relations, it is crucial to combine these approaches with Foucauldian Discourse Analysis (FDA), which I discuss further in the next section.

\section{Praxiographic Approach to Foucauldian Discourse Analysis}

In The Body Multiple, Mol undertakes a "praxiographic" approach by deconstructing and reconstructing practices, paying attention to "everything and everyone that is active while it is being practiced," while also attending to the materialisations of different effects (Mol, 2002, p. 31-32). According to Bueger and Gadiner (2018), praxiography shares commonalities with ethnography; however, while ethnography is concerned with culture, praxiography focuses analysis on practices. That is, while ethnography may be described as providing an account of some aspects of a community or culture (Hammersley \& Atkinson, 2007), praxiography shifts attention to material practices by stressing on multiplicity instead of singularity through a focus on materialisations of objects in practices (Clever \& Ruberg, 2014). As Mol suggests, a praxiographer investigates objects, like diseases, as never isolated "from the practices in which they are [...] enacted" (2002, p. 33). Further, a praxiographic approach shifts focus from a 
variety of perspectives about an object "to following them as they are enacted in a variety of practices" (ibid, p. 152).

A praxiography inspired by Mol engages in "disentangling" practices by focusing on the involvement of "molecules and money, cells and worries, bodies, knives, and smiles" (Mol, 2002, p. 157), which are "permeated with the legacy of past practices" (Trowler, 2014, p. 23).

Put simply, praxiography follows the entanglement of material forces in practices that are always already embedded within discourses, which are productive of different subjectivities and capacities to act, among other effects. Adapting praxiography to my current research to investigate the emergence or enactments of condomless sex vis-à-vis HIV biomedical technologies, I pay attention to the implication of MSM's sexual practices with the history of HIV/AIDS, safer sex culture, HIV science, and public health discourses, among others. To help me contextualise socio-material practices as embedded within discourses, I bring Foucauldian Discourse Analysis (FDA) together with Mol's praxiographic approach because practices whether sexual practices or knowledge-production practices - are situated within power relations. As Bueger and Gadinger (2018) note: “[A]ny practice and any relation is always one of power [...]. Power is an effect of practice, and is produced within it" (p. 120).

In studying barebacking as an effect of disciplinary power, Ávila asserts that it is “essential to pay attention to the context of power in which [barebacking] takes place," i.e., the arena of sexual health (2015, p. 525). According to Ávila, HIV prevention discourses calls on HIV-negative MSM to incorporate safer sex practices as a moral obligation to avoid HIV infection. Ávila argues that by shaping certain sexual acts as "risky," health promotion campaigns create an environment in which bareback fantasies and practices can be fostered. In analysing HIV prevention campaign discourses as co-constitutive of desires, practices, and 
subjectivities, Ávila exemplifies Foucault's critical work on discourses. As Halperin (1995)

explains, Foucault "teaches us to analyze discourse strategically, not in terms of what it says but in terms of what it does and how it works" (p. 30). In my view, this approach aligns with the posthumanist performativity frameworks discussed above, which centre on the productive force of scientific practices.

Foucauldian scholars understand discourse as "socio-historical forms of practice that are constitutive of the subjects and objects that make up the world" (Hammersley, 2005, p. 3).

Broadly, FDA is "concerned with the way in which texts have been constructed [and constitutive] in terms of their social and historical "situatedness"' (Cheek, 2004, p. 1144). FDA focuses on available discourses (“discursive economy”), which are believed to affect how we see the world and inform our ways of being. In other words, as Willig (2008, p. 113) indicates, discourses offer subject positions by constituting how "people think or feel [...], what they may do (practices) and the material conditions within which such experiences may take place." For Foucauldian scholars, including queer theorists, (sexual) subjectivities are understood to be effects of power relations (Jagose, 1996). ${ }^{16}$

Some new materialist scholars believe that Foucauldian discourse analysis widely used in feminist and queer theorisations falls short in understanding how technologies, or matter, are co-

\footnotetext{
${ }^{16}$ In this thesis, I mainly draw on Foucauldian approaches to discursive analysis (FDA) devised mainly by Carla Willig (2008) and Michael Arribas-Ayllon and Valerie Walkerdine (2008) in critical psychological research. While "discourse" has a variety of meanings and many ways to analyse, I differentiate my approach to discursive analysis (that is Foucauldian) from critical discourse analysis (CDA) as formulated by Norman Fairclough (2001). Arguably, CDA approaches discourse merely as language and its objective therefore "is to show how language figures in social processes" (Fairclough, 2001, p. 229). By contrast, Foucault's understanding of discourse is more complex. As Arribas-Ayllon and Walkerdine explain, Foucault refers to discourse as a particular body of knowledge: as both "discipline" (e.g., psychiatry, medicine, biology, sociology, public health) and practices (through which objects and subjects are formed). Thus, while CDA's focus is on how language is involved in social relations, FDA goes further by analysing how and why discourses change over time and, most important for my purposes, how discourses as mechanisms of power offer possibilities for talking about the self and objects (Arribas-Ayllon \& Walkerdine, 2002). I argue that the notion of discourses as constructive of subjects and objects is what sets FDA apart from CDA.
} 
constitutive of subjectification processes. However, I suggest that incorporating Foucault's notion of dispositif pays attention to how sexuality is an "assemblage," or more specifically an "apparatus," which "refers to a heterogeneous body of discourses, prepositions [...], institutions, laws and scientific statements; the dispositif itself is the network that binds them together, that governs the play between the heterogeneous strands" (Macey, 1993 as cited in Halperin, 1995, p. 189n6). Arguably, Foucault provides tools to analyse how discursive practices constitute an array of connections or assemblages that organise and produce knowledge. Complementing praxiography with FDA therefore is an ideal method for examining the real-world impact of the biomedicalisation of HIV prevention. First, a praxiographic approach to FDA sets the stage for a complex exploration of the role of HIV biotechnologies as intra-active biopolitical entities altering capacities and influencing the desires and subjectivities of MSM. Second, these frameworks help connect MSM's biomedically-informed sexual practices "with economic, sociohistorical and political surfaces" (Beckman, 2011, p. 11) by paying attention to the entanglements of history, mechanisms of power, and subjectification (Arribas-Ayllon \& Walkerdine, 2008).

After laying out these methodological frameworks, the following section asks: what techniques are available to produce or collect data for a praxiographic approach to FDA? It is important to acknowledge that neither praxiography and FDA have set rules or procedures, for they are both analytic strategies (Arribas-Ayllon \& Walkerdine, 2008; Bueger \& Gadinger, 2018). On the one hand, praxiography may be explicitly understood as "practice-focused ethnography" (Trowler, 2014, p. 18). For Bueger and Gadinger (2018), data collection using praxiography may be conducted by following established ethnographic methods, such as observation, conversations (interviews), and textual analysis. On the other hand, FDA "can be 
carried out on any symbolic system," which may include a wide range of materials (Willig, 2008). Accordingly, both praxiography and FDA emphasise the significance of texts. In what follows, I outline the use of internet forums for research - in particular the study of "virtual sex environments" (Ashford, 2009) — as a data collection strategy that lends itself to a praxiographic approach to FDA for its focus on texts as "observational data" (Paechter, 2012, p. 79). First, I explain the study of virtual sex environments, particularly the use of online forums as sources of data. Second, I introduce the online community I call "Pigpen" (a pseudonym) as the leading site for my data collection for the first and second phases of my study. Following these discussions, I note how virtual ethnography may be limited in picking up the complexity of experiences that can be available via face-to-face interactions. Thus, to supplement my online data, I used semistructured interviews in the third phase of this research. I consider virtual ethnography and semistructured interviews as interrelated and interdependent methods aligning with my praxiographic approach to FDA. Combining these methods allow participants to describe their own realities and experiences, while also capturing the messiness and complexity of sexual practices.

Throughout my research, I approached data collection as emergent and mutually informative. While the phases of my research were somewhat "linear," they overlapped and informed each other. For example, though I started the formal research process through virtual ethnography, I often had conversations with friends and sexual partners about their concerns regarding barebacking and PrEP. These conversations informed my understandings about the topic. During the initial analysis of the data I collected from the online forums, I was already able to generate ideas about important themes, as well as some questions I wanted to ask during the third phase (semi-structured interviews) of my research. Throughout the analysis of my interview data, I constantly referred back to the online data to compare and contrast some of the 
ways in which the men in the forums and my interview participants converged and diverged with issues around sexual practices, identities, and pharmaceutical technologies. The experiences I gained throughout this research process became significant, as they shaped and informed how I came to understand my topic, what questions I asked to my interview participants, and how I have chosen to "write up" the data. The analysis of the data also happened during the writing process, which was followed by an extensive process of editing, re-writing, and refining. In the next sections, I provide a summary of my research design and discuss how I operationalised posthumanist performative frameworks and praxiographic approach to FDA throughout the research process.

Cyber or virtual ethnography of online sex environments. The proliferation of virtual spaces that enable the exploration and expression of sexual desires, like barebacking, is inseparable from the development of the internet. As Ashford (2009) identifies, the internet facilitated interaction among sexual minorities, including MSM, in creating "virtual sex environments": such as "bulletin boards, chat rooms, profile-based sites and, with new technologies such as Grindr," a geosocial networking application (“app”) geared towards MSM (p. 298). In these online spaces, members connect and form relationships, developing online communities: "social aggregations emerg[ing] from the Net" as a result of people carrying on "public discussions long enough, with sufficient human feeling, to form webs of personal relationships in cyberspace" (Rheingold, 1993, p. 5). Online communities are specifically crucial for LGBTQ+ individuals as they provide a "safe space," where they can connect, create groups, and facilitate opportunities to discuss and experiment with each other about their sexual desires and practices, and develop a sense of shared or collective identities (Ashford, 2009; Darwin, 2017). While marginalised individuals and communities, such as "gender queers" (Darwin, 
2017) and barebackers (for example Carballo-Dieguez, et al., 2006) are "traditionally difficult to access and study," the emergence of virtual sex environments help researchers to access and interact with individuals (Ashford, 2009, p. 303).

In studying virtual sex environments, approaches inspired by "virtual ethnography" (Hine, 2008, 2015) and “cyber-ethnography” (M. Davis, 2009) are advantageous, for such methods aid researchers in exploring norms and languages that are integral for online communities, specifically in online sex environments (Ashford, 2009). Virtual ethnography and cyber ethnography, in this thesis, are considered similar approaches with a focus on analysing experiences and meanings constructed by participants online. Specifically, virtual ethnography pays attention to the identities and subjectivities that emerge from the discussions (M. Davis, 2009; Mowlabocus, 2010). For Ashford, investigating these identities and subjectivities requires contributions from queer theorisations in critically challenging normative practices and paying attention to the fluidity of identities. ${ }^{17}$ Queering cyber ethnography also entails awareness and reflexivity of how research "constitute the object it investigates" (Ashford, 2009, p. 309). Virtual ethnographic research and other methodological frameworks produce their objects of study from the researcher's perspective instead of presenting an empirical truth or reality (Pink, 2007). ${ }^{18}$

\footnotetext{
${ }^{17}$ Jagose (1996) maintains that any attempt to identify queer theory as a fixed school of thought is a futile endeavour, for "queer" resists stabilisation as a fixed identity. Queer is committed to the deconstruction of categories, including sexual identities. As Angelides (2001) writes: queer theory functions "as a philosophic and self-reflexive force of critique of essentialized notions of gender and sexual identity" (p. 165). In other words, queer theory's project aims at destabilising identities as a principle of social organisation.

${ }^{18}$ By inviting virtual ethnographers to be critical of their role as researchers in the production of knowledge, the appeal to reflexivity further subscribes to the notion of "situated knowledge" by feminist STS scholar Donna Haraway (1988) where the researcher's role as neutral observer is rejected. Instead, the acknowledgment of social locations as informative of knowledge-making practices are brought to the fore. Situated knowledge also encourages researchers to pay attention to the role of objects and technologies in research practices. By emphasising the situatedness of knowledge-making practices, including becoming aware of one's social location, and focusing on the inseparability of humans and nonhumans in research, feminist philosopher-physicist Karen Barad (2007) builds on Haraway's work to develop and push reflexive approaches further towards diffractive methodologies. To think diffractively, according to Barad, means acknowledging that research practices are boundary-making apparatuses, where researchers and objects of study emerge, rather than pre-existing each other. In adapting diffractive
} 
One advantage of cyber, or virtual ethnographic approaches is that it allows researchers to study sexualities "at close quarters without engaging in corporeal acts of sex" (Ashford, 2009, p. 304), primarily conducted through "looking in upon a particular discussion board or reading an online profile" (p. 303). Covert observation, also known as "lurking," or observing without participating or contributing within the online community, is one out of the many ways of "looking in" that offers researchers to access detailed social data will little to no actual participation (Scaramuzzino, 2012). Some have even argued that disclosing a researcher's presence might compromise participants' anonymity and disturb the "naturalism" of online contexts (Snodgrass, 2014). Due to these advantages, purely observational methods are seen as far more advantageous "over more participatory methods" (ibid, p. 443). In this study, I follow these strategies by collecting data from a publicly accessible barebacking online community I call "Pigpen" and situate the forums within the context of HIV prevention discourses and technologies.

Notwithstanding the advantages associated with cyber ethnography, lurking presents significant ethical challenges. While studying publicly available web pages may be exempt from ethical guidelines, for such online spaces are not considered "human subjects" (Walther, 2002), I chose to respect the privacy of Pigpen and confidentiality of its members by using pseudonyms for both the online forum website and its participants. Although Pigpen is publicly available, which does not require the creation of a username and password to access the forums, and may be exempt from Research Ethics Board review, the sensitivity of the research topic and the data required that I submit a proposal to Carleton University's Research Ethics Board-A (CUREB-A). Doing so ensures that this research aligns with the University's ethical protocol and the Tri-

methodology, the researcher is invited to become aware of learning, knowing, measuring, theorising, and observing as material practices that are performative in the production of knowledge (Barad, 2007). 
Council Policy Statement on the Ethical Conduct for Research Involving Humans (TCPS) (see Appendix A for ethics clearance certificate).

What is Pigpen? Pigpen is a New York-based website launched in 2010 claimed by its creators as the number one discussion forum for the barebacking community. Here, I choose the pseudonym Pigpen because it reflects the types of discussions on the website. As its creators maintain, Pigpen is a space where members share their sexual conquests, discuss sexual health issues, and encourage each other to have more uninhibited sex lives. Pushing boundaries of normative sexuality is one of the main themes in the discussions on Pigpen, as I discussed in the article "Online 'Barebacking' Community and the Creation of Sex Pig Desires, Identities, and Practices" (Daroya, 2020). As I described, participants engaged in discussing "pig play": a range of sexual activities considered "dirty" and "raunchy." "Pigpen" is apt as a pseudonym because it mirrors the general characteristics of the website as an enclosed space where "pig sex" can be discussed and explored (ibid).

The website is produced and maintained by a web development company that creates and runs various websites for the LGBTQ+ community. In January 2019, Pigpen had over 59,000 registered active and non-active members. Although American-based, its members are located in vast geographical locations, covering North America, Europe, Asia, Africa, and Oceania. There are no demographic data available to provide more information about Pigpen's members. Nevertheless, discussions within this community likely reflect men's views and experiences from the industrialized West, particularly from Anglophone countries (USA, UK, Canada, and Australia) and others who have a good understanding of English as it is the only language used on the website. 
Pigpen is different from other websites, such as barebackrt.com, a "hook up" site where MSM find others for sex as its primary purpose. By contrast, Pigpen is more forum based. "Forums" (or "discussion boards" or "message boards") are online discussion sites where members hold conversations in the form of posted messages. Unlike chat rooms, which are based on real-time conversations, the messages in forums are archived. As such, they can be viewed and even responded to days, weeks, months or years after they were posted. Bareback.com is another website that also features forums. However, it is not as extensive as Pigpen and does not attract as many discussions and members. Moreover, Pigpen has significantly more members than bareback.com, which has only more than 16,000 members, which means that it is more popular and offers richer data for analysis. In this study, I investigated texts collected from publicly accessible forums on Pigpen, including data previously gathered for my barebacking research at La Trobe University, which I discuss next.

First Phase: Previous Study－Barebacking pre-PrEP (1998-2012). In my previous doctoral study at La Trobe, data were collected between September 2013 and February 2014. While there were 43 forum categories on Pigpen, the primary data collection concentrated on two main sections of the forums where most members were actively engaged in discussions: “General Discussions" and "The Backroom." While the former was publicly accessible, membership was required to access the latter, which contained what could be considered more sensitive discussions related to the intentional passing of HIV. Before starting the study, approval was first sought from the Human Ethics Committee of the Faculty of Health, La Trobe University (Appendix B). After receiving authorisation, an e-mail was sent to the owner of Pigpen, identifying myself, describing the research, and asking his permission to carry out the research (Appendix C). Although it is argued that obtaining consent from the owner or 
moderator is inadequate for obtaining consent from the whole community (Eysenbach \& Till, 2001), I considered the owner as a gatekeeper who has the most knowledge about group norms and who can grant or refuse access to researchers wishing to conduct or recruit participants from the website.

However, after obtaining consent from the website's owner, I did not just immediately gather data from the message board. Instead, following the lead from LeBesco (2004), I negotiated my presence on the message board by creating myself an account with the username "bbckresearch." Following this, I posted an announcement in the General Discussions forums about the research (Appendix D). Part of my introduction was to explain my interest in studying their online conversations about barebacking as stemming from my sexuality. I gave the option to members who wish not to be quoted in the study to send me a private message to withdraw their consent. This announcement was re-posted once a month for five months to remind members that I observed and gathered data from their exchanges for my study. In total, five active members have withdrawn their consent from the study and their posts were not included in the analysis.

During the five months of data collection, I downloaded 222 forum discussions, forty per cent ( 89 of 222) from the General Discussions, while sixty per cent (133 of 222) were from The Backroom category. After downloading, the data were transferred to Nvivo (version 10) to manage and code all discussion threads. A thematic approach described by Braun and Clark (2006) was adapted to identify significant themes in the discussions. First, I familiarised myself with the data by subjecting it to multiple readings, taking notes, and making ideas for coding. Next, I produced initial codes from the data, such as "attitudes about barebacking," "barebacking as evolution," and "use of HAART." When I finished the initial coding, I collated the different 
codes identified across the data set and sorted them into potential themes. For example, codes describing "consent," "lying about serostatus," and "morality" were grouped under the theme of "stealthing": the removal or alteration of condoms when consent was only negotiated for condom-protected sex. However, instead of simply stopping at coding and thematic analysis, I engaged further in a diffractive analysis of the data. For Barad (2017), a "diffractive methodological approach" involves "reading insights through one another" (p. 25). ${ }^{19}$ In their project, Barad situates their diffractive analysis by "draw[ing] on the insights of some of our best scientific and social theories," providing Barad with the theoretical tools to acknowledge the active force of discourses and matter in the production of knowledge. Likewise, instead of simply stopping at thematic coding, I approached my analysis diffractively by "reading-the-datawhile-thinking-the-theory" (Mazzei, 2014, p. 743). For example, if I stopped at coding, I would have interpreted the data about stealthing simply by affirming the role of normative discourses around consent as informative of the participants' views. However, by bringing in posthumanist

\footnotetext{
${ }^{19}$ Diffractive methodology encourages researchers to be attentive to the research process as creative, rather than merely positioning research as a means to observe. This is similar to Donna Haraway's (1988) notion of "situated knowledges," which emphasises that researchers are not neutral observers, but their social locations (gender, race, class, sexuality, etc.) are informative of knowledge-making practices. In addition, the role of "objects as actors" in knowledge production are also recognised, where technologies are conceptualised as active in the generation of meanings in embodied experiences, as well as in the co-constitution of research and knowledge (Haraway, 1988, p. 591). Utilising diffractive methodology in research, Taguchi (2012) advances the notion of thinking differently about the construction of knowledge as inseparable from other materialities. In practice, as she continues, "becoming and knowing are understood as in a state of interdependence" (p. 271), with both humans and nonhumans.

Diffractive methodology augments the notion of reflexivity. Conventionally, reflexivity is a critical scholarly practice that "aims to reflect on, and systematically take account of the investigator's role as an instrument in the construction of evidence," or knowledge (Barad, 2007, p. 86). Researchers are encouraged to think about their research practices as creative and constitutive of knowledge, alongside the acknowledgement of the role of their subjectivities throughout the research process (Pink, 2007). While these reflexive practices offer invaluable strategies for critical self-reflection, for Barad, this scholarly exercise is limited because it focuses on representations of subject matter by researchers where the knower is considered separate from the known "objects" of inquiry. Instead of reflection, Barad suggests that we adopt "diffractive methodology," which "attends to specific material entanglements" rather than separate entities, to account for the intra-action between humans and different forms of matter, including knowledge practices themselves (2007, p. 88).
} 
performative approaches, praxiography, and FDA, I was able to pay particular attention to the material-discursive forces at play in the data, such as sexual spaces and situations.

Within this research apparatus, the textual data and the use of NVivo can further be understood as co-constitutive, helping me determine what materialises as important. For example, the capacity of the forum discussions around stealthing to continually haunt me throughout the coding process might be understood as matter making itself intelligible to the researcher. By recognising textual data and NVivo as active forces during the analysis of the data means that there is no division between the researcher and the object of investigation. As Barad (2007) explains: “practices of knowing cannot fully be claimed as human practices, not simply because we use nonhuman elements in our practices but because knowing is a matter of part of the world making itself intelligible to another part" (p. 185). Other materials, such as Microsoft Word, my computer, tables, chairs, articles, and books, among others, were also part of the analysis and the writing process.

Chapters 2 and 3 present findings from this phase of the study, which shed some light on the complexities of barebacking when condoms were the normative mediator of safer sex. However, the emergence of PrEP has warranted a new understanding of barebacking that needs to be further investigated. As such, a new set of data were gathered from Pigpen to trace this shift in the history of barebacking. In what follows, I outline how I collected this data.

Second Phase: Current Study - Barebacking with PrEP (2012-onwards). In the current study, I mainly focused on the "HIV/AIDS \& Sexual Health Issues" forum on Pigpen, which contained the sub-forums: Making The Decision to Bareback; HIV Risk \& Risk Reduction; PrEP Discussion; and What's It Like to be Poz? I chose these forums and sub-forums mainly for the participants' concentration on PrEP and other biomedical interventions. This forum had an 
enormous total of 18,984 posts when data collection was started. After obtaining clearance from CUREB-A in June 2019, I picked the first 50 most commented threads in the larger HIV/AIDS \& Sexual Health Issues forums and the first 50 most commented threads in the four sub-forums in order to avoid data overload. Between June 2019 and September 2019, a total of 250 threads were gathered.

After collecting data for three months, I transferred the forum threads to NVivo (version 12) and used similar coding and thematic approach outlined above. First, I read through all the online forums and decided which ones were to be included in the analysis. Forum discussions that did not directly relate to biomedical technologies were excluded from the analysis. Second, I re-read the online discussions following the "cleaning up" process, and coded them according to codes I created a priori, based on the research questions and what I learned from the literature. These included "sexual pleasure," "taking greater sexual risks," "changes in risk assessment," "responsibility," and "side effects," among others. Third, I conducted another reading of the data, which involved inductively attempting to deduce the codes emergent from the data. Codes from this step included "PrEP effectiveness," "PrEP on demand," and "viral load and undetectability." I then grouped the codes into themes. For example, I put the codes "sexual pleasure" and "taking greater sexual risks" under the theme "PrEP benefits." Additionally, the codes "PrEP effectiveness," "PrEP on demand," and "changes in risk assessment" were put under the theme "creation of knowledge." It is important to note, however, that these themes and codes overlapped and some of codes were organised under several themes-e.g., "PrEP effectiveness" was simultaneously found under the themes "PrEP benefits" and "creation of knowledge." Analysis did not stop during this stage. Further analysis also occurred during the writing process. 
Findings from this phase of the research are featured in Chapters 3 and 4 of this dissertation. Although some argue that textual analysis of threads allows one to learn about an online group's language and norms (Seale et al., 2010), others suggest that using online forums as data risks neglecting complexities and nuances of the community being studied (Snodgrass, 2014). In addition, lurking within the online community is particularly challenging, for the lack of interaction with participants fails to delve deeper into the situated meanings of experiences (Hine, 2000). However, because my approach strictly involves examination of texts without necessarily being obstructive, I elected to supplement these data with semi-structured interviews to explore further the emergent themes from the online forums and pay attention to the complexities of the experiences of PrEP users.

Third Phase: Semi-Structured Interviews. For this phase of my research, I conducted semi-structured interviews to investigate the effects of HIV prevention in altering the sexual desires, capacities, and subjectivities of MSM. Interviews were done to explore the real-world impact of the biomedicalisation of HIV prevention, an assemblage of healthcare systems, sexual health clinics, pharmacies, pharmaceutical companies, and insurance companies, among others. In-depth, semi-structured interviews guided by a schedule was employed consisting of expansive, open-ended questions that attempted to answer the research questions outlined above (Appendix E). To facilitate a comfortable interaction and allow participants to provide detailed accounts of their experiences, I followed feminist and queer interviewing perspectives "based on friendly conversation” rather than an interrogation (Kong et al., 2002, p. 95).

Maintaining consistency with qualitative interviewing principles, I recruited participants through purposive sampling with a small sample size (Weiss, 1994).$^{20}$ Following ethics approval,

\footnotetext{
${ }^{20}$ Purposive sampling is widely used in qualitative research, involving the identification and selection of individuals having experienced the phenomenon of interest (Palinkas et al., 2015).
} 
a research recruitment ad (“Are you taking PrEP? Join my PhD study!”) was posted on Grindr, specifically targeted to users from Toronto and Ottawa areas. I chose this app as the primary recruitment tool for my project because Grindr was widely used by gay, bisexual, and other MSM, with as many as 27 million users in 2017 worldwide, primarily in North America and Europe (“Gay Dating App Grindr to Sell Shares," 2018). The ad appeared at the bottom of Grindr's interface as a clickable link that led potential participants to the research website (Appendix F). The website contained the online invitation and a "Contact Me" button to facilitate easy contact with the researcher. The website also included a link to the consent form to give more information about the research (Appendix G). However, it was not as simple as I had hoped to recruit PrEP users through Grindr. While over 500 individuals clicked on the link and visited the recruitment website, only one volunteered to participate (Diego from Toronto). To recruit more participants, I opted to message PrEP users directly. I contacted individuals who identified their HIV serostatus as "HIV-negative on PrEP" from Toronto and Ottawa through Grindr's direct messaging tool, asking them if they were interested in joining the study. Unfortunately, no individual agreed to be interviewed from Ottawa and only two participants (Derek and Dennis) from Toronto were enrolled in the research.

As the recruitment of participants for the study on Grindr proved to be challenging, I looked for alternative avenues. PrEP Facts is a Facebook group hosting over 20,000 members across the globe to share information about PrEP. I had been a member PrEP Facts for at least two years when I decided to ask the moderators for permission to post a recruitment ad in the group (Appendix H). I posted the ad in July 2019 and three participants (Damien, Daniel, and Darren) from the USA e-mailed me to volunteer as participants. PrEP Facts is largely an American group, so I looked for Canadian counterparts on Facebook. During my search, I came 
across the group PrEP-Canada. This Facebook group has a relatively smaller membership than PrEP Facts (approximately over 900 members). Prior to posting the recruitment ad, I requested permission from the moderators, just as I did in PrEP Facts. After posting the ad in January 2020, three participants (Dawson, Dominic, and Dylan) volunteered to participate in my study from Toronto. Participants were given the option for face-to-face or online interviews. According to Reinharz and Chase (2002), allowing participants to choose the interview modality can facilitate trust and empowerment combined with expressing clearly the expectations and boundaries of the research relationship. There were three participants (Diego, Dawson, and Dylan) who opted to be interviewed face-to-face; five (Damien, Daniel, Darren, and Dominic) who chose to be interviewed online; and one (Derek) who opted to be interviewed by phone. However, due to the COVID-19 global pandemic, interviews with Dawson and Dylan were moved online via Skype. The interviews were conducted between October 2019-April 2020. Signed consent forms were first obtained, and the purpose of the study and expectations were clearly explained to each participant before the interview.

In total, nine HIV-negative MSM who were using PrEP were interviewed. In this study, the small sample size was intended more as an exploratory case study to understand how PrEP affected some MSM's sexual desires, capacities, and subjectivities, and was not meant to generalise findings. The semi-structured interview questions were adapted from the schedule initially developed by Collins, McMahan, and Stekler (2017) in their qualitative study of the impact of PrEP use on the sexual health of MSM in Seattle, having the flexibility to ask further questions that were appropriate to the content and flow of the interview. The informants were invited to describe their broad experiences on PrEP by asking them to talk about their decision to go on PrEP and their encounters with health care providers; the impact of PrEP in their daily 


\section{I Chapter 1}

lives, including side effects; their overall views about the effectiveness of PrEP and their experiences with regular STI testing; and some targeted questions regarding the impact of PrEP in their sexual health and practices. I aimed to be cognizant about any issues or concepts that participants talked about that were not necessarily addressed in the questions. For example, they spoke about empowerment due to PrEP, which was asked to be elaborated on in subsequent interviews (whenever appropriate). I also exercised having strong listening skills without asserting judgements or values, especially when they spoke about their sexual practices.

In general, I found that my participants were open and honest about their experiences and sexual practices. Perhaps this was due to our shared identities as gay and queer men. My online and telephone interviews with participants, however, were more comfortable than my in-person interview with Diego when it came to discussing their sexual practices. My interview with Diego was conducted in October 2019 in Toronto. As Diego felt some of the interview questions could potentially be sensitive, he opted to have the interview outside. Fortunately, the weather was still warm enough at the time. Even though we were outside and very few people were around, Diego's voice lowered when describing his sexual practices. This was in sharp contrast to my online interviews, in which participants generally spoke freely about sex. In line with posthumanist performative theories, it is arguable that the environment and technology used in the interviews had an impact on some of the ways in which the participants discussed their experiences. The online interviews allowed for more open and honest discussions, whereas the in-person interview presented more challenges, especially when it came to discussing sexual practices, as other people might have been listening to our conversation.

Interviews lasted between 30-60 minutes. Interviews were digitally recorded and automatic online transcription services (NVivo and Trint) were used to translate the audio 
recordings to text files. Informants were offered a \$25 Amazon E-Gift card as a token of appreciation for their participation. Participants were given the right to withdraw their consent at any time during the interview and up to one month after the interview. No informant pulled out of the study.

Following Fereday and Muir-Cochran (2006), a "hybrid approach" of deductive and inductive thematic approach was adapted after uploading the transcribed data into NVivo (version 12). NVivo has provided me with unique insights into the experiences of my participants. My ability to consult these transcribed conversations has helped me to guide my research in a way that is relevant to my participants. Additionally, I was able to compare and contrast the interview data with the online forums. I observed that online forum discussions tended to focus more on issues around sex, while interview participants had more to say about PrEP stigmatisation, which was not covered so much by the online forum participants. With the use of NVivo, I was also able to subject the transcripts to multiple readings. I started deductive coding by creating a priori codes inspired by the research questions, aims, and interview questions. These included codes such as "reasons for starting PrEP," "side effects," and "PrEP stigma." Simultaneously, following an inductive approach, I generated codes that emerged from the data - for example: "PrEP empowerment" and "risk calculation." After coding and organising data into themes following some of the steps described in Phases 1 and 2, an intensive qualitative analysis inspired by praxiographic Foucauldian discursive approaches was utilised to consider sexual experiences as spatially, temporally, materially, and culturally situated. Additionally, I analysed the participant's subjective meaning-making as co-constituted by technologies. Raw, unedited data transcripts were only available to my committee members (upon request) and me. Names and any identifying features were removed from the transcriptions 


\section{4 | Chapter 1}

and pseudonyms were used. The data from this phase of the research will be featured prominently in Chapters 4 and 5.

\section{Trajectory of the Thesis}

The task I set out in this research is to destabilise the operationalisation of condomless sex as a theoretically coherent practice and to recast the normative attribution of agency to individuals by recognising the dynamism, or active force of matter and discourses in practices through which condomless sex is enacted. The theoretical approaches inspired by posthumanist performativity described in this chapter will help me untangle the complex sexual practices of MSM as involving material-discursive forces and having the capacity to alter conditions of how to act and what it means to be "gay" in a biomedically-informed sexual context. By adapting praxiographic analysis, we can begin to answer the question of how HIV biomedical technologies change gay men's approach to risk-taking. Complementing praxiography with Foucauldian discourse analysis opens opportunities for highlighting how historical context and subjective positions are co-constituted through material practices that are always already embedded within power relations.

This thesis is organised into four substantial chapters. Chapter 2 develops the Molian approach of praxiography to analyse data from the online forums collected during the first phase of the study. This chapter considers the portrayal of "evolution," where Pigpen participants describe condomless sex as a continuous progression towards taking more significant sexual risks. Guided by the notion of "multiple ontologies," I argue that the accounts reveal barebacking as more complicated - that is, condomless sex is not as linear or continuous. Sometimes condomless sex transpires because barebacking negotiation never came up, while others simply abandon the use of condoms. Notably, some MSM incorporate safer sex strategies to minimise 
risk, drawing attention to the possibility of condomless sex as "safe." I demonstrate that condomless sex cannot be neatly configured within intentionality and risk (Race, 2010), and by extension, negotiation cannot be simply approached as decision-making between rational individuals.

Building on this, Chapter 3 mobilises the concept of "sexuality-assemblages" to challenge the normative notion of individual negotiation, consent, and responsibility. Combining data from the first and second phases of the study, my analysis focuses on Pigpen participants' accounts surrounding the practice of "stealthing": the removal, or alteration of condoms when consent was only negotiated for condom-protected sex. Deploying posthumanist performativity frameworks, I offer a more nuanced understanding of the intra-actions between MSM and socialmaterial contexts where "consent" and stealthing emerges. I show that outside of anonymous sexual encounters, stealthing is conceptualised as morally intolerable by Pigpen participants. By contrast, stealthing in bathhouses appear as morally tolerable, where alternative models of "consent" are remade. Notwithstanding these differences, participants reinforce notions of individual responsibility in managing HIV risks by emphasising the use of biomedical technologies, illustrating that material-discursive relations are embedded within normative discourses.

The dynamic functions of HIV scientific discourses and biomedical technologies is central to my discussions in Chapter 4. Analysing data from the online forums and semistructured interviews, I argue that MSM incorporate scientific knowledge and biomedical technologies in embodied practices to understand the effectiveness and limitations of antiretroviral drugs. I show that the use of HIV pharmaceuticals for Treatment as Prevention 
(TasP) and PrEP create varying effects. ${ }^{21}$ On the one hand, ARVs allow MSM to reconsider HIV risk, eliminating anxieties and facilitating pleasure production. On the other, HIV pharmaceuticals expose men to the dangers of sexually transmitted infections (STIs) and stealthing. Moreover, while men who use HIV biotechnologies for the prevention and treatment of HIV emerge as rational subjects, popular discourses frame PrEP users as "Truvada Whores," who are misusing ARVs by engaging in "risky" sex, engendering sex panics and stigma.

Chapter 5 examines the accounts about stigmatisation and experiences of stigma with friends, families, sexual partners, and healthcare professionals by interview participants who are PrEP users. Drawing on posthumanist performativity theories, I rethink PrEP stigmatisation as enacted or emergent through assemblages and co-constituted by material-discursive forces. I demonstrate that the history of HIV/AIDS and the materialities of the virus, condoms, and PrEP converge in the discussions of MSM to generate different experiences of stigma, including slutshaming, rejection, and internalisation. PrEP stigma also enacts creative responses to confront negative stereotypes.

Chapter 6 concludes the dissertation by providing a summary of key points and arguments. I also reflect on this research's contributions abstractly on the notions of agency and responsibility vis-à-vis biotechnologies and, more concretely, the reconstitution of safer sex within the arenas of public health and HIV criminalisation. I also identify some limitations of the research and suggest directions for future research on the effects of biomedical technologies on MSM's sexual practices.

\footnotetext{
${ }^{21}$ Treatment as Prevention (TasP) is the use of antiretroviral drugs to reduce the viral load in the bodies of HIVpositive individuals to undetectable levels, which means that they cannot transmit the virus ("Undetectable=Untransmissible").
} 


\section{Chapter 2: The Ontological Openness of Barebacking: Shifting Practices in Socio-technological Contexts}

\section{Introduction}

If practice becomes our entrance into the world, ontology is no longer a monist whole. Ontology-in-practice is multiple. Objects that are enacted cannot be aligned from small to big, from simple to complex. Their relations are the intricate ones that we find between practices.

Annemarie Mol (2002, p. 157)

The previous chapter discussed how barebacking was inconsistently operationalised.

Barebacking originally referred to intentional condomless anal intercourse. The term was eventually used to simply describe condomless sex among MSM. Considering this lack of consensus, Carballo-Dieguez and colleagues (2009) proposed that barebacking be recognised as "intentional condomless intercourse in HIV-risk contexts," to distinguish it from condomless sex with accidental transmission and from risk-free intentional or unintentional condomless sex, such as between monogamous seronegative individuals (p. 61). In defining barebacking more precisely, the authors addressed the definitional imprecision that they believed made it difficult to develop evidence-based interventions. Wolitski (2006) also maintained the difficulties in defining barebacking in his review of the literature to identify why some men engage in it. According to him, researchers usually described barebacking as "unprotected" anal intercourse where risk was present. In his opinion, barebacking was distinct from condomless sex that involved risk management practices, i.e., "when practiced by HIV-negative primary partners who maintain a mutually monogamous or negotiated safety relationship with each other" (Wolitsky, 2006, p. 14). In a similar sense to Carballo-Dieguez and colleagues, Wolitsky proposed that barebacking be defined as: "intentional anal sex without a condom" in "risk" 
situations as opposed to "safer" ones (ibid). For Brisson (2017), the intelligibility of barebacking as a theoretically coherent practice - that is "intentional" and "risky"-reduces it as dangerous behaviour that should be controlled by understanding factors leading MSM to refrain from condom use. This chapter aims to challenge and destabilise this theoretical coherence by analysing how MSM in Pigpen online forums understand barebacking to deconstruct the binaries of risk/safety and premeditated/unplanned underpinning definitions of barebacking in HIV prevention messaging.

Using the idea of "multiple ontologies," I demonstrate that barebacking practices are complex and multiple: simultaneously premeditated and unplanned, safe and risky, despite the perceived theoretical coherence of barebacking as intentional and dangerous. The online forum participants claim that barebacking is an "evolution," a linear progression from safer sex to more significant sexual risks. However, closer examination will reveal that barebacking involves much more complexity than participants overtly claim. Barebackers frequently integrate various safety strategies into sexual practices, destabilising the notion that barebacking is risky by emphasising that certain barebacking practices can be "safe." Consequently, barebacking practices cannot easily be defined within the realm of intentionality and risk (Race, 2010). By extension, barebacking negotiation cannot simply be described as decision-making between rational individuals since it involves material and discursive forces as well as nonhuman and human forces.

The first section provides an overview of some critiques of the narrow definition of barebacking as intentional in public health discourses by arguing that such representation produces gay and other MSM agents who deliberately eschew condoms despite awareness of HIV risks. In the second section, I turn to Mol's use of "praxiography" and "multiple ontologies" 
(2002) as analytical frameworks to help me move away from the operationalisation of condomless sex as intentional (understood here as premeditated), implying gay men's agency, to a posthumanist performative account. Mobilising these frameworks, I demonstrate in the third section that MSM's barebacking practices are more complex and do not accurately follow a linear progression or evolution towards taking more significant sexual risks. In the fourth section, I further interrogate the notion of barebacking as risky and unsafe by analysing the different risk mitigation practices by some barebackers, including serosorting and the use of HIV pharmaceutical technologies. Drawing on these examples, I conclude that barebacking practices can take many forms in the face of changing socio-technological contexts, where MSM negotiate with HIV prevention, sexual partners, and technologies.

\section{Barebacking as Intentional and Assumptions about MSM's Agency}

In modern cultural imagination, barebacking is approached by examining the intentions of gay men (Tomso, 2004). Concerns about the rise in barebacking and increased HIV infections motivated some researchers to investigate why some MSM would engage purposely or intentionally in "risky" practices. Cataloguing why some MSM premeditatively choose to engage in condomless sex produces anxieties about gay men's intentions, framing barebacking as a problem of volition. Building on these theorisations, Race (2010) notes that shaping barebacking as intentional involves recognising gay men's agency in sexual risk-taking, producing MSM as more or less adequately informed about HIV risks. Underpinning definitions of barebacking in epidemiological, public health, and social science research is a general agreement that barebacking is "intentional," "premeditated," "sought after," “conscious," "deliberate," “explicit," or "voluntary" condomless anal intercourse (Carballo-Dieguez et al., 2010; Gauthier \& Forsyth, 1999; Grov et al., 2007; Mansergh et al., 2002; Parsons \& Bimbi, 2007; Reisner et 
al., 2008; Suarez \& Miller, 2001). Synthesising peer-reviewed articles on barebacking, Berg (2009) maintains that the practice is generally understood as "intentional unprotected anal intercourse between men where HIV transmission is a possibility" (my emphasis, p. 754). Likewise, in describing the barebacking subcultural practice of "bugchasing," Breitfeller and Kanekar (2012) define it through intentionality: “Amongst some HIV negative gay men, [barebacking] is used as an intentional mode of seroconversion" (p. 112). Framing barebacking practices as intentional have significant implications on queer men's agency concerning HIV risk: barebackers are understood as "agents who consciously decide to forego condoms despite potential danger" (Harvey, 2011, p. 173). Barebackers are rendered irresponsible for ignoring the public health imperative to engage in rationality and calculation in relation to sexual risks (ibid).

As discussed previously, in some public health research, the factors that contribute to risk-taking are thought to be intrinsic to individuals, while other studies examine the contextual factors in which gay men make conscious decisions to engage in barebacking. It has been argued that barebacking developed following the introduction of HAART and the proliferation of the internet (Adam, Husbands, Murray, \& Maxwell, 2008; Berg, 2009; Gauthier \& Forsyth, 1999; Halkitis et al., 2003; Moskowitz \& Roloff, 2007a, 2007b; Shernoff, 2006a, 2006b; Tewksbury, 2006; Wolitsky, 2006). More recently, the introduction of PrEP has also engendered concerns about its potential impacts on MSM's sexual practices by decreasing the use of condoms or abandoning it entirely in favour of barebacking. Nevertheless, though these contextually informed studies acknowledge that barebacking is embedded within specific socio-technological transformations, they contribute towards strengthening the idea that gay men are misusing pharmaceutical technologies, becoming "complacent" and displaying "poor or deficient attitude to risk" (Rosengarten, 2009, p. 61). In other words, this body of scholarship mainly focuses on 
the question "why they do it?" by emphasising barebacking as premeditated, implying wilful intention, but failing to recognise barebacking as a meaningful and complex practice.

Queer theorist David Halperin (2007) argues that inquiring "why gay men do it?" concerning barebacking inevitably produces irrelevant answers, for the question presumes that MSM are "beset by a number of psychological conditions ranging [...] from internalised homophobia, survivor guilt [...], addictive personality syndrome, sexual compulsiveness, and lack of self-control" (p. 12). Asking why gay men engage in barebacking generates the practice as a problem of agency, allowing the scientific (including social science) enterprise to position barebacking as a "psychological concern that requires assessment" and opening possibilities for public health to intervene in MSM's sexuality (Tomso, 2004, p. 93). For example, psychotherapist Michael Shernoff (2006b) writes that it is crucial to understand the "individuallevel processes that drive men to take risks" in order to "implement change [...] to fully understand and address the behavior of concern" (p. xvii). However, approaching barebacking through psychological speculations results in "the unfortunate presumption that there is something wrong with particular groups and individuals" (Halperin, 2007, p. 27). As an alternative, Race (2010) suggests that barebacking should be approached as a complex practice that involves intimate negotiation between individuals and technologies while also acknowledging that barebacking is always already implicated within dominant discourses.

Moving away from moralistic examinations of barebacking, Tim Dean (2009) pays attention to the transformation of HIV and MSM's sexual practices as an effect of the introduction of HAART. Dean maintains that ARVs allowed capacities for thinking differently about condomless sex as formative of connection through the exchange of semen. Some critical theorists view barebacking as a form of resistance against dominant public health imperatives to 
protect oneself against infections and diseases (Ávila, 2015; Crossley, 2001, 2002, 2004;

Robinson, 2014; Rofes, 2002; Tomso, 2004). ${ }^{1}$ For others, barebacking is justifiable by drawing on the rhetoric of individualism, personal responsibility, consenting adults, and contractual interactions (Adam, 2005). In locating barebacking within discourses of individual responsibility, some MSM dispute the idea that barebackers are "lack[ing] rationality" (Harvey, 2011, p. 169), demonstrating that condomless sex is embedded within normative discourses.

The studies cited above refer to experiences of barebacking before the introduction of PrEP; it is essential to ask if these meanings are still relevant in a context where MSM consume ARVs not only to treat HIV infection but also to prevent infection. The approval of PrEP in 2012 has drastically changed HIV prevention among MSM. Tim Dean's (2015) update to his seminal 2009 book Unlimited Intimacy puts into question the capacity of barebackers to resist public health imperatives through the increasing use of pharmaceutical technologies. While Dean argues that barebacking was developed as a challenge against mainstream health norms, PrEP uptake risks "defeating the purpose of bareback as a practice of resistance" (p. 233). Instead, as González (2019, p. 34) explains: "What PrEP does is remove the transgression from barebacking." Indeed, rather than transgression, PrEP offers users possibilities for engaging in more barebacking with less anxiety and greater pleasure (Hammack et al., 2019), providing feelings of freedom (Hughes et al., 2018; Martinez-Lacabe, 2019). However, to enjoy barebacking "safely" through PrEP, users need to accept the risk of catching STIs (other than

\footnotetext{
${ }^{1}$ Exploring the implication of HIV prevention campaigns in the production of a social context where barebacking as resistance becomes possible, Ávila (2015) draws on Foucauldian approaches to theorise barebacking as a "response to configurations of power" (Foucault, 1990, p. 271). Taking up on this notion, Tomso (2008) argues that the field of public health based on health promotion and risk management is incompatible with barebacking. For Tomso, to practise barebacking is rendered unhealthy, inefficient, selfish, and irresponsible. Barebacking provides opportunities for some MSM to resist safer sex practices by exposing themselves to disease and being considered irrational (ibid).
} 
HIV) and must adhere to biomedical monitoring of bodies and assume self-responsibilisation (Thomann, 2018). ${ }^{2}$

By appreciating the meanings of barebacking and the context in which it is practised, intentionality emerges as one possible explanation, out of many, for why some MSM engage in barebacking (Race, 2010). For some, barebacking is formative of masculinity, connections, and intimacy. For others, engaging in condomless sex is productive of feelings of freedom, empowerment, and pleasure - significations that are also meaningful to PrEP users. Focusing on the negotiation of meanings highlights the fluidity of sexual practices and undermines the coherence of barebacking produced by public health as a problem of volition (Kippax \& Stephenson, 2005; Race, 2014). By underscoring the different meanings of barebacking in practices, Race puts into question the ontological claim that barebacking, alongside notions of negotiation, agency, and responsibility, is coherent and singular. In the next section, I explain how Mol's (2002) notion of "multiple ontologies" help destabilise the theoretical coherence of barebacking, augmenting Race's contributions in approaching condomless sex as ontologically open.

\section{Theorising the Ontological Openness of Barebacking}

In this chapter, I build on Race's (2010) work by arguing for the ontological openness of barebacking. To help me articulate this, I draw on the scholarship offered by Annemarie Mol (2002). As discussed in Chapter 1, Mol focuses on the productive role of practices in creating realities to explain how ontologies are multiple - an analytic strategy she calls "praxiography." For Mol, realities are enacted through practices and, if practices are multiple, then reality is not

\footnotetext{
${ }^{2}$ As discussed in the previous chapter, as part of PrEP clinical guidelines, PrEP users' HIV-negative status are continually monitored and confirmed through laboratory testing every three months. Other than HIV, PrEP users are also tested for other sexually transmitted infections.
} 


\section{I Chapter 2}

singular. The implication is that ontology is not fixed: because realities come into being through practices, there are also multiple ontologies. Likewise, situating barebacking within knowledge practices that seek to study it, Race (2010) argues that different scientific practices enact different realities of barebacking:

From this perspective, sex without condoms is multiple. Sometimes it is produced as barebacking. Sometimes it is produced as serosorting [...]. Sometimes it is produced as an erotic transgression of gay community and public health norms. At other times it may be produced as an erotic expression of ingenuity and survival. How it is enacted is a question that is inseparable from the knowledge practices that apprehend and produce it (p. 161).

Following Race, I want to argue that employing a praxiographic approach to how barebacking is practised or "done" in the socio-material practices of MSM (rather than expert knowledge practices, à la Race) generates different versions or realities of condomless sex. In effect, barebacking becomes multiple in that it "takes different forms in different historical and cultural contexts" (Race, 2010, p. 162). Exploring practices of barebacking through praxiography recognises its embeddedness in "specific relations and encounters" that help shape its meanings (Race, 2014, p. 258). Acknowledging the relationality and dynamism of practices helps in recasting barebacking as emergent through assemblages, in which different discursive and material elements are rendered active.

Approaching barebacking through praxiography also decentres agency from individuals and redistributes it to a collective assemblage of human and nonhuman forces. Mol's and Race's respective frameworks assist in understanding barebacking and barebackers as relational, fluid, and multiple, involving "intimate negotiation between two or more persons as well as changing technologies and conditions" (Race, 2010,p. 148). To support these claims, I pay attention to how barebackers understand and explain their sexual practices as a constant negotiation between safety and risk. I focus on a publicly accessible barebacking online community I call "Pigpen," 
where I found that users challenge and destabilise the presumption of theoretical coherence of barebacking in some public health discourses as intentional condomless anal intercourse in HIV risk contexts.

On Pigpen, participants hold conversations in the form of posted messages. The bulk of the data analysed for this chapter were collected during my studies at La Trobe University between September 2013 and February 2014. Thus, the data speaks to when condoms were the normative safer sex strategy, and PrEP was very early in arrival. The analysis was guided by Mol's (2002) praxiographic approach to realities as actively shaped in practices and Race's (2010) consideration of barebacking as multiply enacted to identify the complexity of barebacking in the accounts by Pigpen participants, which are discussed below. In what follows, I turn to the considerations of barebacking as a socio-behavioural evolution by online forum participants. I argue that these responses reveal more complex barebacking practices that are not so linear as suggested by the notion of evolution. Indeed, barebacking simultaneously emerges as safe/risky and premeditated/unplanned in these discussions.

\section{Barebacking: Socio-Behavioural Evolution from Safer Sex to Greater Sexual Risk-Taking}

This section pays attention to the accounts by Pigpen participants describing barebacking practices as socio-behavioural evolution, progressing from safer sex to barebacking and even bugchasing and giftgiving. By demonstrating that barebacking practices emerge simultaneously as premeditated/unplanned and safe/risky, I argue that in practice, barebacking is fluid, multiple, and complex. When condoms were considered normative safer sex practice, barebacking practices were understood by participants as progressing towards taking more significant sexual risks: from practising safer sex measures, such as using condoms, to the total abandonment of any safety practices. However, taking a closer look reveals that the accounts by Pigpen 


\section{6 | Chapter 2}

participants do not neatly follow a linear progression. Indeed, for some participants, certain forms of safety strategies can be incorporated into their barebacking practices. By integrating risk reduction measures, participants engage in what Race (2003) calls a "reflexive mediation between embodied habits and medical opinion," where queer men's agency is understood as "collective and interactive" (p. 377). Alternatively, in the words of feminist science and studies scholar in HIV Marsha Rosengarten (2009), “gay men’s agency is recast as creatively achieved rather than negatively measured against an imagined norm" (p. 61).

While participants generally understand barebacking evolution as a linear progression, analysing these discussions reveals that this evolution is not so straightforward. Barebacking practices are always more than premeditated and dangerous, shifting between safer to risky sex, sometimes unplanned and planned at other times. This fluidity is illustrated by Oliver, a 32-yearold HIV-positive undetectable man from the UK, in the "Young Bugchasers" thread, in which he describes how he became a barebacker:

The first time I had barebacking was when I was 15. Like many people with their first experiences, condoms just never came up [...]. After that, I settled into using condoms because it was the done thing. A few years ago, I dated a guy in New York [...]. He barebacked me and always shot his load inside. It wasn't really discussed and I was too into getting fucked to care. After that, it was much easier to take cock bareback and felt much better. Pretty soon after that, I was only having sex bareback and actively seeking it out. It was a revelation! (Oliver)

Oliver's account attests to the idea of evolution, where barebacking is described as a progression towards taking more significant sexual risks. Nevertheless, while his response seemingly follows a linear trajectory, barebacking emerges as more complex. While his first sexual experience as an adolescent was barebacking, he explains that he later incorporated using condoms into his sexual practices, for it was seen as normative, demonstrating two things. First, barebacking is always already embedded within safer sex practices. Second, primary 
barebacking experiences produce different effects, one of which is the adoption of condoms rather than their complete abandonment. However, his adherence to condom use shifted when Oliver engaged in barebacking again as an adult with a New York man, which further facilitated engaging in condomless anal sex with other men. Significantly, Oliver mentions that his barebacking experiences, both as an adolescent and an adult, were not planned nor discussed, deviating away from the notion of barebacking as premeditated.

The fixation of public health discourses around barebacking as intentional presumes premeditation from active agents in the decision-making process of abandoning condom use. Oliver's response above challenges this assumption precisely by emphasising that condom use "just never came up," "never discussed," or he was too into "getting fucked to care" in his experiences of barebacking. Barebacking as unplanned (that is, not premeditated) can also be read in a post by a participant from Canada. Thomas, 40 years old and HIV-negative, creates a topic in The Backroom section of Pigpen called "My Bareback Evolution," in which he shares his experiences as a barebacker and asks others if they had undergone similar circumstances:

I never really considered myself a bugchaser, and I recently tested HIV-negative again. I'm wondering if I'm on the same road as a lot of others [...]. I've been a full-time barebacker and never been a condom nazi. Sometimes I would use them, and sometimes I wouldn't. Just depended on the guy I was with. If I went raw, I would ask the guy if he was 'safe.' Even then, I usually didn't let them cum inside me. (Thomas)

Thomas' account of barebacking in this post is fascinating because, while he considers himself as a "full-time barebacker," he also identifies as an occasional condom user ("never been a condom nazi"). ${ }^{3}$ By integrating some safer sex measures, Thomas demonstrates that barebacking

\footnotetext{
${ }^{3}$ The term "condom nazi" among men who self-identify as barebackers online is used as a derogatory term to exclude those who promote and comply with safer sex measures through condom use. In their study of barebacking discourses online, Hammond and colleagues (2016) advance that while barebackers view themselves as embracing HIV risks, even to the point of eroticising HIV infection, men who are "condom nazis" are vilified as enemies not only of barebackers but also of the queer community at large, for "enforcing a moral virtue of risk aversion" (p. 268).
} 
practices are complex, shifting between safety and risk by integrating harm reduction measures, such as serosorting and withdrawal before ejaculation. Here, Thomas is offering a challenge to the theoretical stability of barebacking as always practised in HIV risk contexts while also questioning the perceived wilfulness of barebackers. Thomas may be considered as a barebacker who advances the notion that condomless sexual practices are more complex than the narrow definitions offered by some public health messaging. As he continues:

For the last couple of years, I haven't really been using condoms at all. It's not that I decided to stop using them, I just haven't. And also, within the last six months, I've stopped asking guys their serostatus. There is basically no discussion about it at all now. And I fuck and get fucked raw, and the cum is usually shot inside. (Thomas)

Thomas reveals that while he used to integrate some form of safety measures, his barebacking practice shifted to something that involves taking more significant sexual risks. While this account of barebacking evolution follows a linear progression, the motivation for eschewing condoms and other safety measures is unclear. He elaborates that he discarded any safety measures without rationalising it because it simply happened that way. Thomas's post may be read as blurring the attribution of agency to individuals believed to be rational and calculative. Instead, Thomas's (and Oliver's) texts expose barebacking practices as part of a relational context in which humans and nonhumans participate. Moreover, these participants' respective accounts reveal the fluidity of barebacking by highlighting that barebacking practices are simultaneously risky/safe and unplanned/premeditated.

Another participant confirms the consideration of barebacking as fluid and incoherent in his response to the thread called "What influenced you to take poz loads?":

When I started barebacking again (about three years ago), I was only fucking with guys who said they were HIV-negative. When I moved to barebacking at the sauna, I realised that all asking a guy's status achieves is to create an awkward pre-fuck atmosphere. Guys in saunas will lie about their status for a casual anonymous fuck - so there's no point 
asking. I never ask a guy's status, and I believe that someone's status is their own private business. (Brandon)

While Brandon's account, that of a 50-year-old HIV-negative participant from the UK, seemingly supports the notion of barebacking as evolution — from serosorting to casual anonymous fuck - it is evident that this supposedly linear progression is more complicated than simply taking more significant sexual risks. As Brandon indicates, negotiating safety through serosorting used to be necessary; however, he abandoned serosorting as a safer sex strategy when he began visiting gay saunas. In Brandon's experience, some men failed to truthfully disclose their serostatus within anonymous sexual situations like gay bathhouses. Disclosing a seronegative status when diagnosed with HIV, the removal of condoms, or ejaculation during penetration when consent has only been negotiated for condom protected sex is usually referred to as "stealthing." As I discuss in the next chapter, stealthing is centred around the violation of consent, turning a consensual sexual encounter (with condoms) into a non-consensual one (condomless). Primarily understood through the liberal and juridical notions of individual autonomy and rationality, stealthing becomes a legal problem for it entails a violation of sexual agreement or contract (Brodsky, 2016). However, viewing stealthing through the lens of consent, a closed system based on liberal notions of individuality (Butler, 2011), forecloses the complexities of (barebacking) sexual relations (Loick, 2020). As evident in Brandon's text, stealthing may arise in situations where risk reduction measures are adopted-in this case, serosorting.

Consequently, Brandon's barebacking practices in saunas emerge as complex and multiple: it can simultaneously be serosorting, at other times stealthing; it can be "safer," but also “riskier." It can be premeditated/unplanned and even consensual/non-consensual. Importantly, though failure to disclose one's HIV-positive serostatus is perceived as a nullification of a sexual 
partner's consent and "thereby rendering the physical contact an assault as a matter of law" (Adam, Elliott, Husbands, Murray, \& Maxwell, 2008, p. 145), Brandon's account confronts these normative notions by highlighting the limits of consent as sexual negotiation between autonomous individuals in anonymous sexual situations (Loick, 2019). Instead, consent in the form of disclosure of seropositive HIV status is emergent in different relational sexual situations, significant points which I will return to in the next chapter.

Brandon's response further emphasises that social and physical spaces help shape barebacking practices. Indeed, he alludes to the influence of physical contexts in his relinquishment of serosorting. He explains that anonymity is expected in gay bathhouses, substantiating Haig's (2006) conjecture that non-disclosure is significant among barebackers who frequently visit saunas. Here, Brandon even highlights the active role of anonymous sexual situations in mediating enactments of consent, barebacking, and harm reduction practices, which I turn to further in Chapter 3. Brandon also says that one's serostatus is a private matter, and disclosure should not burden HIV-positive men, especially in saunas. Instead, he insists that everyone is responsible for protecting themselves from infection during anonymous and casual barebacking encounters. For this reason, Brandon problematises putting the burden of disclosure on HIV-positive individuals and shifting responsibility to individuals by personally accepting the burden for the prevention of HIV infection (Adam, 2005). In this sense, Brandon echoes previous findings on HIV self-responsibilisation of HIV risk management (Adam, 2005; Offer et al., 2007; Thomann, 2018). ${ }^{4}$ While barebacking in Thomas's account above emerged as

\footnotetext{
${ }^{4}$ Sociologist and HIV researcher Barry Adam (2005) suggests that, by echoing individual responsibility, barebackers "repeat basic propositions of the safe sex message" (p. 344). I discuss the issue of individual responsibility further in Chapter 3, alongside notions of consent in the context of "stealthing."
} 
irrational, Brandon's text here, by contrast, enacts barebacking through notions of individual responsibility — sustaining the argument that barebacking is fluid, incoherent, and multiple.

While the accounts of evolution seemingly destabilise linearity towards taking more significant sexual risks in the responses above, other participants agree with the portrayal of successive exposure to the dangers of barebacking. The following response to Thomas's post speaks to this:

I started as a total safe top until I went to a party one night. As I was buried deep inside someone (always using condoms), another came up from behind me and stuffed their bare cock in my hole. It felt amazing!!!! I was then a bareback convert. I then did everyone bare but craved more bare cock in me. Now, I'm mostly bottom and taking raw loads, no questions asked. From this day on, there are no regrets [...]. It is, in a sense, an evolution. (Brett).

Here, Brett, 64 years old HIV-positive from New Zealand, characterises his introduction to barebacking as a progression towards taking more significant sexual risks. While this account ostensibly shows barebacking evolution as linear, this stability is complicated by the fact that his first barebacking experience was not premeditated. Indeed, barebacking simply happened in the heat of the moment. Importantly, Brett emphasises the role of pleasure (“It felt amazing!!!”), which he attributes to his "conversion" as a barebacker. Brett echoes AIDS activist and defender of barebacking Eric Rofes' (1998) observation that swallowing semen and being fucked raw provide great pleasure, which HIV prevention messages fail to address. As Race (2016) further asserts, HIV science promotes desexualisation by disavowing pleasure: "a principal commitment of the HIV scientific field is to manage and flatten the affective intensities, complications, and disturbances of sex" (p. 7). ${ }^{5}$

\footnotetext{
5 The issue of pleasure and the role of HIV biomedicine will be further explored in Chapter 4.
} 
The accounts described in this section offer valuable insights into how some MSM made sense of the evolution of their barebacking practices in a context when condoms were considered the normative safer sex practice. In these examples, the socio-behavioural evolution of barebacking is portrayed as progressing towards taking greater sexual risks: from practising safer sex measures to the total abandonment of any safety practices. However, taking a closer look reveal that the accounts are more complex than a linear progression. Indeed, for some Pigpen participants, some forms of safety strategies are incorporated in their barebacking sexual practices, demonstrating that barebacking can simultaneously be safe/risky and premeditated/unplanned.

Nevertheless, while avoiding HIV infection remains crucial for some barebackers, other participants choose to completely abandon some risk-reduction strategies and favouring taking more significant sexual risks. Many factors are cited for doing so, including problems with serosorting, especially when engaging in anonymous sex in saunas, and the power of desire and pleasure. However, though some of the examples I described here point towards taking more significant sexual risks, other participants also discuss the possibility of practising barebacking "safely" by using different harm reduction measures: from serosorting to pharmaceutical technologies as I examine further in the next section.

\section{Barebacking: Mitigating Risks through Serosorting and Pharmaceutical Technologies}

The theoretical coherence of barebacking is challenged by some participants who describe their barebacking practices as concurrently premeditated/unplanned. The intelligibility of barebacking as risky is further destabilised by Pigpen participants who adapt serosorting and use biomedical drugs, allowing barebackers to redefine safety. In what follows, I pay attention to the various measures adopted by barebackers in the earlier years of PrEP to manage HIV risks. I 
discuss that barebacking has become "safer" for some participants as an effect of PrEP; by contrast, other participants express concerns that PrEP may have harmful side effects. Notably, some participants oppose the use of PrEP by some barebackers who are "reckless," which further illustrates that barebacking is a dynamic practice emerging from a range of relations that is multiple and constantly shifting between safety/risk.

In the previous section, I presented Thomas from Canada, who indicated that at some point in his sexual history, he only engaged in barebacking if it was deemed "safe" depending on his sexual partner's serostatus. For Thomas, serosorting is a reasonable response to manage the risks of barebacking, a view shared by other Pigpen participants. An HIV-negative man from the USA illustrates this in his reply to the thread "My Bareback Evolution":

I am new here and just started barebacking not long ago. I am negative and hope to stay that way for as long as I can, hopefully forever [...]. Since I now bareback, I know I am putting myself at risk. I currently only play with a regular fuck buddy but recently took a raw load from one of his HIV-negative friends. So, I am going to try serosorting for now. (Alex)

While Alex acknowledges the risks of barebacking, he notes that this is practised under the auspices of safer sex. Engaging in barebacking through serosorting here is a decision made as an effect of a recent sexual encounter that involved the reception of semen from an HIV-negative sexual partner. Although it is unclear whether this barebacking episode is premeditated or not, he hopes that calculating and managing the risk of HIV infection through serosorting would enable him to stay HIV-negative. Following Race (2003), it is possible to contend that the adaption of harm reduction measures by Alex reveals some HIV-negative barebackers' preventive initiatives, moving away from the notion of barebacking as premeditated and risky. While public health discourses presume that gay men behave badly and irrationally, Alex's text reveals that barebackers are responsible and rational by adopting risk reduction measures - a response that 
emerges within intimate and interactive relations. In particular, serosorting is generated through his relations with other HIV-negative men and HIV prevention. Consequently, Alex's approach to risk is "a matter of subjective responsiveness and interpersonal sense-making," embedded within social and environmental contexts (Race, 2010, p. 148).

The significance of serosorting to manage the risks of barebacking is further evident in the following text posted in the thread "Bottoms: Do only poz loads turn you on?":

Since I'm HIV-negative, I prefer neg loads only [...]. I don't want to get pozzed, but realistically since I bareback, it'll happen sooner or later. (Felix)

Felix, 48 years old from the USA, explains that serosorting is a significant prevention measure in his barebacking practices to maintain his HIV-negative serostatus. However, even if serosorting may protect him from becoming infected with HIV, Felix acknowledges that engaging in condomless sex comes with potential dangers and that serosorting may fail. For this reason, Felix's barebacking practices can be interpreted as situated within and embodying discourses of HIV risk. While it is uncertain as to why Felix believes that serosorting can be unsuccessful, the following 65 years old Canadian HIV-positive participant offers his thoughts:

At first, I thought I could 'batch select' the HIV-negative guys. But after a while, you find that just isn't realistic. I was naïve enough to think serosorting achieves protection, not taking into account all those guys claiming to be HIV-negative who rarely, if ever, test. Or even those guys who have converted since their last test. Then there's the poz undetectable guys, arguably the 'safest' ones to fuck with because they know their status and are not likely to infect you with a load of undetectable seed. (Hunter)

In his response to Felix, Hunter insists that serosorting may be inadequate as a risk-reduction measure. Specifically, he mentions that serosorting may be ineffective because some men may engage in stealthing by lying about their serostatus. A new prevention strategy is created in response to this potential exposure to HIV infection: a form of serosorting where he engages in condomless sex with HIV-positive men with undetectable viral loads. This creative response 
may be conceived as a "reflexive mediation" by incorporating scientific knowledge about ARVs and HIV risk into embodied practices. Indeed, Hunter echoes and reiterates the public health message of "undetectable=untransmissible" $(\mathrm{U}=\mathrm{U})$ by saying that engaging in barebacking with HIV-positive men with undetectable viral loads may be safest. ${ }^{6}$ Such resolution reveals that gay men's agency concerning HIV prevention is emergent and produced through a collective assemblage (Race, 2003). Accordingly, Hunter's text alludes to the fluidity and multiplicity of barebacking as constantly shifting between safe/risk. By incorporating harm reduction measures through ARVs and serosorting, the risk of HIV infection becomes minimal, producing "safer" barebacking and destabilising its equation with danger.

Other HIV-positive men of Pigpen affirm the safety of undetectable viral load:

I'm poz/undetectable and have been forever, well, at least 19 years and have never even had a blip on the radar as far as viral load is concerned. I also have chosen not to bareback with anyone I know who is HIV-negative, although I bet there are guys who have said they were HIV-positive just to sleep with me. Yet, the chances of me giving HIV to anyone is pretty much slim to none as my virus has been well controlled for so long. (Peter)

Peter, a 55-year-old HIV-positive man, echoes Hunter in his reply to the thread "Conversion:

Fantasy or Reality?" by insisting that serosorting as a safety measure can fail, for some HIVnegative men may claim that they are HIV-positive simply to engage in barebacking.

Nevertheless, he assures that although serosorting may be ineffective, he has another way of protecting his sexual partners: having an undetectable viral load, maintaining the significance of HIV prevention in the barebacking sexual practices of HIV-positive men. Also, having an undetectable viral load drives the point that "unprotected receptive anal intercourse between men

\footnotetext{
${ }^{6}$ In 2008, four Swiss HIV experts wrote the "Swiss statement", stating that people with HIV with undetectable viral loads and no STIs cannot transmit HIV during sex (Vernazza et al., 2008). Subsequently, international experts adapted the "Consensus Statement" in 2016 declaring Undetectable=Unstransmissible $(\mathrm{U}=\mathrm{U})$, which has been incorporated in many HIV prevention campaigns worldwide.
} 
does not inevitably lead to HIV infection" (Tomso, 2004, p. 93). Consequently, this participant wrestles the authority to define risk away from scientific discourses precisely by emphasising the "safety" of barebacking practices. And yet, to redefine barebacking as safe, Peter needs to use ARVs to maintain his undetectable viral load and allow him to manage HIV risk, especially the risk of infecting others when barebacking. In this regard, Peter's "safer" barebacking practices are intertwined with HIV scientific discourses and biomedical technologies. Additionally, while Klein (2014) insists that stealthing is associated with intentional HIV transmission, shaping HIVpositive men as dangerous, Peter insists that HIV treatments position him as non-infectious and therefore harmless. For this reason, Peter may be viewed as destabilising notions of HIV risks in barebacking practices, moral discourses of stealthing, and HIV-positive men's burden of responsibility to protect others from HIV infection (I return to these issues in Chapter 3).

These discussions allude to HIV pharmaceutical technologies as effective harm reduction practice for some HIV-positive men. Equally, some HIV-negative men turn to ARVs to mitigate the risks of barebacking by using PrEP. Indeed, for some Pigpen participants, PrEP emerges as a useful tool in preventing HIV transmission while practising barebacking. For some HIV-negative men who occasionally bareback and desire to avoid infection, PrEP is seen as offering an additional layer of protection in conjunction with other risk reduction strategies. For one participant, in particular, PrEP is suggested to offer peace of mind when some risk strategies fail:

I usually don't have tons of sex and still use condoms quite often. When I bareback, I almost always top and ask about status. Despite these measures, I recently decided to go on PrEP and here's why: This last weekend, I was having sex with a friend. He was fucking me when the condom broke. While he is negative and recently tested, I still find it hard to trust anyone's word. With PrEP, I'm significantly less worried about that kind of situation. That alone is enough reason for me to do it. (Tobey)

Tobey, a 35-year-old HIV-negative man from the USA, created a thread called "Another one on PrEP" to share his intentions for choosing to take ARVs to prevent HIV infection. Tobey 
portrays himself as a risk-avert subject, and his resolution to take PrEP is not because he decided to eschew condoms, nor because he wished to engage in more barebacking. Instead, the need for PrEP emerges out of his desire to mitigate HIV risks that may arise out of his control (such as condom breakage). By acknowledging that condoms sometimes break during anal sex, Tobey maintains that barebacking practices are not always premeditated.

For Tobey, taking PrEP is reasonable because it transforms the risks of barebacking more manageable. Consequently, by adapting HIV harm reduction measures, Tobey reinforces that barebacking can be "safe." As another participant elaborates, the connection of barebacking with HIV risk is severed by PrEP, which further opens the potential for some barebackers to take more significant sexual risks and become a "slut":

For those of you who are wondering, I started PrEP. I have been taking more sexual risks, like going to sex parties and doing stuff I didn't use to do. I like the fact that I have an additional layer of protection since PrEP sort of balances the additional risks. It's fun to be a slut, and I'd probably do most of it anyway, even without PrEP. (Roger)

Roger, 52 years old from the USA and Pigpen owner, illustrates an HIV-negative subject who is already a risk-taker and taking even more significant sexual risks as an effect of PrEP. Although PrEP seems to be a catalyst in producing the capacity to become a slut, Roger notes that he would still be putting himself at risk regardless of the availability of PrEP. In which case, the pleasure produced by barebacking takes precedence over staying HIV-negative. Nevertheless, PrEP helps Roger to engage in "safer" barebacking practices because the HIV prevention drug "balances the additional risks" of being a slut. Another participant agrees that PrEP opens possibilities for taking more significant sexual risks:

Before PrEP came out, it was condoms only. Then I started taking PrEP, it was anything goes. I became a slut and would do anything. (Joseph) 
Joseph, 24 years old from the USA, illustrates how PrEP is implicated in his barebacking practices. He describes that before taking PrEP, he was only using condoms but has been substituted by the pharmaceutical drug. While Joseph sustains the notion of barebacking as evolution towards taking more significant sexual risks, it is notable that this progression would not be possible without PrEP. Here, Joseph alludes to the transformative power of PrEP in altering sexual capacities. We can understand PrEP in the embodied practices of MSM as a useful tool in preventing HIV and enabling some men to affirm the pleasure of barebacking. In this context, there is some evidence that the use of HIV pharmaceuticals allows some MSM to re-examine fears around HIV, facilitating pleasure, freedom, and empowerment - effects that emerge from the incorporation of medical knowledge about HIV drugs into embodied practices. As Brandon further illustrates in his response to the thread "Daily Pill Lowers HIV Infection Risk":

This [i.e., PrEP] is probably the best news since the success of vaginal gels. I'm a nondiscriminating cum dump. I never ask status, but I'd prefer not to become infected with HIV. I want to be able to take ALL loads - with less anxiety. (Brandon)

Vaginal microbicides ("vaginal gels"), developed specifically for females, are HIV prevention methods in the form of "creams, rings, gels and sponges that women can insert vaginally before having sex" (Van der Zaag, 2017, p. 1). By linking PrEP and vaginal microbicides, Brandon can be read as a subject who is formed and informed by a biomedicalised HIV prevention context. To make sense of PrEP, he draws upon his knowledge about other prevention technologies, integrating them into his embodied sexual practices. In short, Brandon and other PrEP users, as I expand further in Chapter 4, maybe rendered "biomedically informed subjects," acquiring in-depth knowledge about HIV pharmaceuticals and transmission risks and actively rethinking and including such knowledge in their embodied practices (Rosengarten, 
2009). Recognising the fundamental relationality of embodied and scientific practices sustains the argument that MSM are co-constituted by and co-constitutive of HIV/AIDS prevention messages and technologies. Subsequently, gay men's agency can be recast as distributed across various relations, for HIV prevention technologies can alter sexual practices. As Mol (2002) insists, "Interventions [viz, pharmaceutical interventions] have other effects, too. They bring about more than they seek to achieve" (p. 175). In this case, PrEP not only protects against HIV infection but it also enables Brandon and other PrEP users to have less fear when engaging in barebacking and taking "loads."

In this posthumanist performative account of barebacking, HIV prevention technologies can be held partially responsible for enacting barebacking practices. As another participant explains, his “sexual option pool opened up" due to the availability of PrEP:

Once I was comfortable that the chemical condom was indeed going to protect me, I went cock crazy to some degree. Any guy, anytime, anywhere - no questions! (Logan)

From the US in his 50s, Logan underlines the confidence placed on the effectiveness of PrEP in preventing HIV infection. The quote reveals how PrEP contributes towards MSM's capacity to subvert notions of safe and unsafe barebacking, alluding to MSM's agency concerning HIV risk as collective and interactive. Precisely by recognising PrEP's ability to offer protection, Pigpen participants attest to the implication of HIV science and technologies into sexual practices. Arguably, normative beliefs around culpability for the effects of HIV biotechnologies shift from individual to shared responsibility, for the notion of the responsible or irresponsible individual is replaced by a relational account of biotechnologies as dynamic in barebacking practices.

Though some participants cited above understand PrEP as providing an additional layer of protection against HIV infection, it is notable that other barebackers do not share such enthusiasm. While some fear that the provision of PrEP would lead some gay men to take more 
sexual risks (Duran, 2012; C. Moore, 2020; Weinstein, 2010), some participants are wary of the possible adverse side effects of PrEP on the bodies of otherwise healthy HIV-negative men. One participant's response in the thread "Daily Pill Lowers HIV Infection Risk" sums this up:

Short version, I'm not favouring giving healthy people powerful toxic drugs that have serious side effects. If the person doesn't take the meds properly, they can build up resistance to the medication they may need later. (Gary)

Gary's response is a stark contrast to the ones expressed above that positively welcomed PrEP. Here, Gary expresses anxiety over the possible adverse side effects of PrEP, including the nonadherence to the medication, which may lead to long-term complications, especially if PrEP users contract HIV, and side effects. Another participant echoes the latter:

But being used as a 'chemical condom' for your average barebacker - I don't think it's a great idea. The meds can have some nasty long-term side effects [that] you might not tolerate well. Also, you need to be pretty strict on adhering to taking them regularly start missing doses, and you could quickly find yourself ending up HIV-positive and having your strain become resistant to the medication you're taking and complicating your future treatment options. (Tim)

Tim, HIV-positive 35 years old from Canada, shares Gary's apprehension regarding the potential negative side effects of PrEP on its users. Additionally, as shown in other posts made by Tim, some PrEP candidates might be more deserving than others in using the drug: "I think the idea of PrEP would be good for couples where one person is HIV-positive, and the other is HIVnegative." Here, PrEP emerges differently in the moral economy of risks vis-à-vis barebacking: on the one hand, those who are in monogamous relationships are good candidates for PrEP; on the other, average sluts who take PrEP as a chemical condom and engage in barebacking with any men are rendered "bad" PrEP users. By conceptualising some PrEP users as misusing the prophylactic drug simply as a "chemical condom," Tim may be conceived as a subject who reiterates the normative notions of agency — that is, that gay men are wrongly using biotechnologies, which are rendered mainly inert in barebacking practices. 
However, as I have discussed throughout this chapter, HIV pharmaceutical technologies are dynamic entities in barebacking practices, allowing some men to manage risks while engaging in "safer" barebacking. While PrEP makes barebacking safer, it does not render all forms of barebacking acceptable to everyone. Indeed, barebackers who take PrEP and engage in more significant sexual risks are perceived by some to be reckless and irresponsible, demonstrating that PrEP has stigmatising effects (Grimm \& Schwartz, 2018; Spieldenner, 2016). ${ }^{7}$ As Roger argues in another thread, no matter what type of safer sex measures are adapted, including PrEP, barebackers who engage in more significant sexual risks will eventually become infected with HIV:

You can become poz using condoms. You can become poz on PrEP [...]. Take enough risks, and no matter what risk-reduction method you use, you will become poz. (Roger)

Responding to a participant who claimed that PrEP might finally end the inevitability of HIV infection when barebacking, Roger, the website moderator, offers a different view. He notes that while PrEP and other safety measures may mitigate HIV infection when barebacking, transmission risk is always present. Nevertheless, he positively welcomes PrEP as a tool that enables barebackers to manage risk: "PrEP definitely changes barebacking. It puts more power in the hands of sluts." It may be concluded that PrEP opens capacities for MSM to redefine safety and risk and offer feelings of empowerment while engaging in barebacking. ${ }^{8}$

\footnotetext{
${ }^{7}$ The stigmatising effect of PrEP is related to barebacking and risk-taking. According to some PrEP users, their consumption of the prophylactic drug is interpreted by others to communicate a desire for condomless sex. Some men believe that PrEP users will take a prevention shortcut by foregoing condoms (Spieldenner, 2016). I further discuss the concept of stigma in Chapter 5.

${ }^{8}$ Sun and others (2019) describe that, for some PrEP users, the pharmaceutical technology provides a feeling of empowerment. PrEP is considered as an additional layer of protection, making some users more comfortable with their sexuality. The PrEP protocol for testing every three months is also viewed as a form of self-empowerment among users in England (Martinez-Lacabe, 2019). Chapter 4 also discusses how PrEP opens possibilities for the reexamination of fears around HIV, allowing pleasure production, and facilitating feelings of freedom and empowerment for PrEP users I interviewed for this research.
} 


\section{2 | Chapter 2}

These discussions help recognise the shifting practices of barebacking in light of the biomedicalisation of HIV prevention. The availability of PrEP destabilises the coherence of barebacking by rendering condomless sex simultaneously safe/risky. While barebacking, for some, has become "safer" as an effect of PrEP, other participants express concerns that PrEP may have adverse side effects. These may include risks of intolerance to the drug's toxicity and the potential development of viral resistance if PrEP users fail to adhere to taking the drug every day and contract HIV. Notably, some participants oppose the use of PrEP by some barebackers who are recognised as reckless. That is, where serodiscordant couples in monogamous relationships use PrEP, barebacking becomes acceptable. By contrast, when PrEP is consumed as a chemical condom, barebacking becomes irresponsible though HIV risk is mitigated, further illustrating the multiplicity and fluidity of barebacking.

\section{Conclusions}

Following Mol's (2002) multiple ontologies approaches, this chapter has argued that despite the operationalisation of barebacking as a single and theoretically coherent practice by interrogating the intentions of barebackers in some public health research, barebacking in the practices of MSM is fluid, multiple, and incoherent. Previous research has drawn much attention to barebacking as a problem of volition, construing barebacking as premeditated and risky. As Carballo-Diguez and colleagues (2010) advance, "The issue of awareness of appreciable risk is central" and "the risk calculus is done and condomless sex proceeds anyway" (p. 209). Within this literature, gay men are usually portrayed as irrational and irresponsible who consciously decide to abandon condoms despite potential dangers. However, such a perspective is narrow as it reductively construes barebacking as a dangerous behaviour rather than a complex practice in which MSM integrate varied risk reduction practices and ascribe a wide array of meanings. 
Some barebackers in this study described barebacking as linear socio-behavioural progression or evolution from safer sex towards more significant sexual risks. Nevertheless, the reasons for abandoning the use of condoms among some barebackers are not so straightforward. Indeed, a variety of factors are cited: including, but not limited to, problems with serosorting, especially when engaging in anonymous sex in saunas, and the power of desire as well as pleasure. Moreover, a closer examination of barebacking evolution accounts reveals that barebacking practices are more complex and do not follow a linear progression. Barebacking in the online discussions of participants can simultaneously be safe/risky and premeditated/unplanned.

The theoretical coherence of barebacking is further challenged by some participants who described barebacking practices as involving the mitigation of HIV infection risks, including serosorting and the use of HIV biomedical technologies. While serosorting may be a reasonable safety response, Pigpen participants also recognised its potential failures. Some men may simply lie or even disclose outdated serostatus, which may inadvertently expose one to infection. Accordingly, some barebackers rely on biomedical technologies to protect themselves and others. For HIV-positive men, viral load suppression is an integral safety practice to prevent the transmission of HIV in cases when other safety measures fail, suggesting that some HIV-positive Pigpen participants affirm the belief in their responsibility to protect others from HIV infection (Wolitski et al., 2003), further creating possibilities for re-imagining the safety of barebacking practices.

Similarly, HIV-negative men rely on biomedical technologies to manage the potential failure of serosorting and other safety measures through PrEP, allowing them the freedom to navigate complex sexual situations (Martinez-Lacabe, 2019). For this reason, the incorporation 


\section{4 | Chapter 2}

of safety measures into sexual practices further destabilises the notion of barebacking as risky by emphasising that some barebacking practices can be "safe." Barebacking cannot be neatly configured within the arena of intentionality and risk (Race, 2010). By extension, barebacking negotiation cannot be simply approached as decision-making between rational individuals, for negotiation of barebacking is relational.

The discussions in this chapter contribute towards the larger aims of this thesis by disrupting the ontological coherence of barebacking. I demonstrated that barebacking in the socio-material practices of gay men is fluid, multiple, and incoherent, for barebacking practices are concurrently safe/risky and premeditated/unplanned. Notably, the use of biomedical technologies by both HIV-positive and -negative barebackers testify to the relationality of barebacking, where humans and nonhumans are active in its multiple enactments.

Pharmaceutical technologies dynamically shape gay men's capacities to act, especially when traditional risk reduction practices, such as serosorting, may be ineffective. As such, MSM embody the socio-technological and spatial contexts within which barebacking practices are enacted and through which prevention strategies are created and incorporated. Indeed, some participants pointed out that lying about one's serostatus, or stealthing, is always possible in anonymous sexual situations, where sexual partners share erotic encounters without having to identify or explain themselves with each other. In anonymous sexual situations, such as in bathhouses, public washrooms, or parks, the norm of silence and suspension of identities are expected and endorsed (Elwood et al., 2003). In such situations, disclosure of serostatus becomes difficult, rendering the negotiation of consent - understood as a sexual contract where "free individuals say yes or no" (Cowling \& Reynolds, 2004, p. 1) - problematic. In response, some participants turn to ARVs to manage the inadvertent exposure to HIV risks through stealthing. 
How do MSM make sense of issues of consent vis-à-vis stealthing? How are normative ideals on individual responsibility entangled and emergent with/in socio-material (anonymous) sexual practices? What insights might a posthumanist performative account of sexual practices offer in understanding the intra-actions between MSM and their social, technological, and physical contexts in mediating how consent is conceived? In the following chapter, I pursue these questions by paying attention to how consent and responsibility are framed by Pigpen participants in their discussions of stealthing by augmenting feminist theorisations of consent as relational through the concept of sexuality-assemblages. 


\section{Chapter 3: "Stealthing" and the Emergence of Sexual Morality and Responsibility}

\section{Introduction}

When visiting sex-on-premises venues, I grew accustomed to the sting felt by others when I rejected their offer to eschew condoms during sex. It was a particular kind of sting, laced with entitlement, wounded pride, and aggression [...]. Some men would react respectfully to my insistence on using a condom, others would roll their eyes and curse before leaving our makeshift bedroom inside the venue. On more than one occasion, they would try to proceed regardless, pushing behind me in the hopes that I'd either concede or assume they have grabbed some latex from the plastic tub attached to the wall. It was a form of sexual assault, and trying to do it covertly via stealthing didn't negate this.

Matthew Wade (2019)

This chapter explores "stealthing": removing (or altering) condoms, and ejaculating during penetration when consent has only been negotiated for condom protected sex. In the quote above, Matthew Wade, editor of Star Observer, recounts his experiences of stealthing - being fucked "raw" without his consent - in some of his anonymous sexual encounters in bathhouses. For him, stealthing is a form of sexual assault, for it is a clear violation of consent. In the Sydney-based weekly LBTGQ+ newspaper, Wade wrote his opinion piece in light of an ongoing trial in Victoria, Australia. In 2018, a prominent Melbourne surgeon was charged with sexual assault and rape for allegedly lying about using a condom while engaging in anal sex after a dinner date with another male doctor (Chesser, 2019). In 2021, California is set to introduce a law to make the removal of a condom without consent illegal. Similarly, in 2019, Singapore's parliament introduced a law to jail or cane people who remove condoms during sex without consent. As these cases illustrate, the legal and moral debates surrounding stealthing are highly contentious.

Alexandra Brodsky's (2016) paper published in the Columbia Journal of Gender and Law brought the issue of stealthing into the public eye, defining it as "rape-adjacent" and a 
"broken contract" that must be dealt with punitive legal measures. ${ }^{1}$ In her interviews with survivors of stealthing, Brodsky determined that some participants did not consider such encounters as sexual assault. For Brodsky, such a response may be due to the lack of awareness about the practice. To remedy this, she suggests that the non-consensual removal of condom be legislated against as a form of sexual assault. While I agree that stealthing constitutes a violation of consent and may be punishable by law, I also concur with the view that establishing stealthing as a legal problem is oversimplified as it "converts all human interaction into legal and quasilegal matters" (Loick, 2020, p. 412). Besides, Brodsky discusses stealthing primarily in terms of heterosexual consent, failing to recognise the complexity of intimate relations, especially beyond that of heterosexuality. However, by saying this, I also affirm that moral or immoral sexual behaviours are possible regardless of gender and sexual identities, as evident in the Melbourne surgeon's case. This chapter's objective is not to address or contradict Brodsky's concerns and questions regarding the legality of stealthing. Instead, I draw attention to some of the complexities of "sexual consent" as considered by Pigpen participants in their discussions on stealthing by augmenting alternative theorisations and discussions offered by some feminist scholars on consent with posthumanist performativity frameworks.

Legal discourses continue to dominate debates about sexual consent and violence (Carmody, 2004). For Cowling and Reynolds (2004), the normative understanding and legal codification of sexual consent is, by default, "a liberal assumption of the sexual contract" that entails "free individuals say yes or no" (p. 1). Some feminists offer alternative conceptualisations to this liberal assumption of sexual contract by advancing the notion of consent as relational: viewing individuals not as autonomous and self-sufficient but as vulnerable and interdependent,

\footnotetext{
${ }^{1}$ Brodsky's (2016) paper became the basis of numerous international news stories on stealthing. For example, CBC News published a report in May 2017 on stealthing examining its legal status in Canada (see Mullin, 2017).
} 
especially during sexual encounters. Following Judith Butler's (2011) approach to consent as relational, where giving consent always involves entering into a relationship with another person(s), I expand her notion of relational consent through "sexuality-assemblages" frameworks introduced earlier in this thesis to consider the larger relational field of sexual consent: a complex mix of human and nonhuman entities, including condoms, sexual environments/scenarios, pharmaceutical technologies, fantasies, and pleasure. I suggest that this approach offers a more nuanced understanding of the relationships between MSM and their social, technological, and physical contexts, notably anonymous sexual encounters in bathhouses, shaping the enactments of stealthing and mediating how "sexual consent" is negotiated and understood. My task, therefore, is not to make a normative claim about consent and stealthing (what ought to be, à la Brodsky) but to look at how consent is enacted, articulated, and communicated. In short, I explore the ontology of consent by asking how consent is practised or enacted. This troubles the preconceptions of consent law, especially for MSM (but also for anyone, arguably, engaged in sexual relations).

Utilising the concept of sexuality-assemblages, I seek to challenge the normative notion of individual negotiation, consent, and responsibility by emphasising the relationality of barebacking "consent" that extends beyond negotiation between rational adults. Instead, I argue that the process of consent involves negotiating place, time, fantasies, and pleasures. Focusing my analysis on Pigpen participants' accounts around the practice of stealthing, I maintain that discourses on consent and responsibility are always relational, entangled, and emergent with MSM, the materialities of condoms, HIV status, and biomedical technologies in co-constituting stealthing as morally unacceptable. These relations also generate limits of normative discourses. As I show, normative ideals of consent as a communicative transaction are limited in anonymous 
sexual situations, especially in bathhouses where silence is the norm. Instead, "consent" is enacted in bathhouses as passively given before the communicative act of negotiation. For some MSM, stealthing in bathhouses has become morally acceptable, underscoring the implication of sexual scenarios and environments in (re)making alternative models of "consent" and sexual morality. Despite these contradictory views, most participants nevertheless reinforce individual responsibility in their discussions about risk mitigation in sexual situations where a high probability of stealthing is possible. Biomedical technologies, particularly PrEP and TasP, are significant in mitigating risks in environments where a high probability of stealthing exists.

The first section provides a brief literature review to illustrate how some scholars' understandings of stealthing involve dense theoretical conceptualisations of consent. Second, I introduce the notion of sexual consent as relational through the sexuality-assemblages framework taken in this thesis to offer a more nuanced understanding of the intra-actions between MSM and their social and physical contexts in mediating enactments of stealthing and consent. Third, I reflect on the emergence of stealthing as morally unacceptable in Pigpen participants' discussions by considering normative models of consent and HIV criminalisation as entangled with the materialities of condoms and HIV status. Fourth, I argue that these views are not pervasive. Sexual scenarios and environments are implicated in (re)making different models of "consent" and sexual morality that account for silence and suspension of social identities in anonymous sexual encounters. ${ }^{2}$ Finally, I demonstrate that participants reinforce individual responsibility in the management of HIV risks. Drawing on posthumanist performative

\footnotetext{
${ }^{2}$ My approach in recognising the implications of sexual environments in practices of gay public cruising is in line with some geographical theorisations of MSM's sexualities. For example, Junxi Qian's (2014) examination of gay men's cruising practices in public parks in China emphasises the mutual co-constitution of discourses of homo and heterosexualities in enacting anonymous sex as shameful and transgressive. My analysis in this chapter, indeed in this thesis, diverges from some of these theorisations by bringing in posthumanist performative frameworks to highlight not only geographies and discourses but also socio-technological forces that animate sexual practices.
} 
frameworks, where "agency cannot be exclusively contained in human being, nor even in the norms, values, and discourses which are assumed to animate human behaviour" (Race, 2012, p. 332), I maintain that such articulation of individual responsibility is entangled and emergent with sexual environments and pharmaceutical technologies. ${ }^{3}$ I conclude by considering the ethics of anonymous sex as not reducible to conventional notions of autonomy, rationality, and agency.

\section{Stealthing as Violation of Consent}

Central to the act of stealthing is the violation of consent by turning a consensual sexual encounter ("protected”) into a non-consensual one (“unprotected"). For Klein (2014), stealthing is a form of intentional seroconversion, where "an HIV-positive man actively tries to infect an HIV-negative man with HIV, without the latter's knowledge or consent” (p. 54). Importantly, stealthing is considered dangerous because purposely removing or damaging condoms expose partners to HIV and other STIs. Stealthing also refers to the failure to disclose or declining to answer one's HIV-positive status when asked directly by a sexual partner. Arguably, Klein's formulation of stealthing shapes HIV-positive men as responsible for deceiving their sexual partners and pretending to have a condom on, removing it, or damaging it, and exposing them to HIV infection.

Whereas Klein (2014) directly connects stealthing to the deliberate transmission of HIV, Brennan (2017) cautions against equating stealthing with intentional seroconversion. He believes that issues of consent differentiate each of these practices. Expressed consent, according to

\footnotetext{
${ }^{3}$ My argument here is similar to Brown and Di Feliciantonio's (2021) "assemblage" approach to geographies of HIV, where spaces, such as clubs, bathhouses and saunas are implicated in shaping sexual practices. Drawing primarily on theorisations by DeLanda and Deleuze \& Guttari, they argue for adapting assemblage thinking when analysing the effects of HIV biomedical technologies in order to show how "new forms of pleasure and sociality are always part of wider socio-spatial-technological assemblages" (p. 10). In my view, Brown and De Feliciantonio's frameworks correspond to the ones I use here. However, it is important to acknowledge, as they do, that these conceptualisations have already been introduced previously by Marsha Rosengarten and Kane Race, whose respective scholarships are significant in this thesis. Accordingly, my approach follows more the refinements of posthumanist performativity through Barad and Mol proposed by Rosengarten and Race.
} 
Brennan, is implied in bugchasing and giftgiving. At the same time, stealthing involves the violation of consent where: "one party betrays the other's trust that condoms will be used and not tampered with for the duration of penetration, and at the moment of ejaculation" (p. 321). However, though Brennan suggests that stealthing should be rendered a completely different practice, he insists that it is part of barebacking, bugchasing, and giftgiving practices.

While Klein (2014) and Brennan (2017) are concerned with stealthing within MSM's barebacking practices, Brodsky (2016), by contrast, explores stealthing from a legal and gendered perspective. Her findings demonstrate that some women victims of stealthing do not view their experience as sexual assault, despite having been previously raped. Brodsky maintains that the failure to recognise stealthing as sexual assault reveals the limitations of current legal language surrounding consent. She recommends that the non-consensual removal of condoms be viewed as a violation of sexual agreement or contract. For Brodsky, considering stealthing along these frameworks would enable some victims to understand stealthing as breaking an agreement that causes bodily harm in the form of sexually transmitted infections.

Latimer et al. (2018) concur with Brodsky's (2016) findings that although stealthing may be considered a violation of consent, some individuals who experienced it do not consider themselves victims of sexual assault. Latimer and colleagues maintain that this view reveals the limitations of current discourses around sexual assault, which do not cover stealthing and may thus require expansion in order for stealthing to be reported and legislated against. Drawing on criminal and civil laws, Brodsky suggests that adopting the notion of non-consent would enable victims to test their stealthing cases in courts successfully, highlighting the authority of legal discourses in shaping understandings of sexual consent and stealthing practices. 
At the centre of the consideration of stealthing as "a violation of trust and denial of autonomy, not dissimilar to rape" (Brodsky, 2016, p. 184) is the notion of consent, or the lack of it, which shapes it as a legal problem (expressed in the slogan "no means no"). While I agree with the positioning of stealthing as a violation of consent and that is may be considered sexual and bodily harm, constituting stealthing as a juridical problem may be simplistic because it reduces human interactions into legal matters, failing to recognise the complexity of sexual relations (Loick, 2020). Drawing on feminist critiques of the notion of sexual consent, Loick proposes that instead of relying on a contractual model, a relational model provides a more sophisticated analysis of sexual experiences. Rather than understanding individuals as autonomous and self-sufficient, a relational model of consent views sexual actors as vulnerable and dependent beings.

Offering a feminist critique on the legal understanding of consent, Judith Butler (2011) also argues that consent conceptualised as a contract is a closed system that reproduces the liberal notions of individuality, rationality, and autonomy that assumes individuals as merely saying yes or no. Like Loick, Butler also proposes an alternative approach by considering consent as relational. As she argues, giving consent involves entering into a relationship with someone or other persons. Additionally, since we cannot always anticipate what happens when we agree to engage in sexual activities, then liberal and juridical conceptions of consent are limited. Such approaches fail to distinguish sex that did not happen the way one imagined and sex imposed against one's will. Butler further explains that because individuals open themselves to the unpredictability of sexuality during sexual encounters, "then none of us start as fully selfconscious, deliberate, and autonomous individuals when we consent” (Butler, 2011, p. 423). 
In this chapter, I augment conceptualisations of relational consent through the posthumanist performative approaches I outlined in Chapter 1 to consider the materiality and the larger relational field of sexual consent. Specifically, I aim to demonstrate that humans are always in relation to nonhuman forces, including sexual environments, where negotiation of consent emerges. In the next section, I discuss the transformative role of bathhouses in shaping sexual relations and practices among MSM. Utilising sexuality-assemblages makes it possible to complicate normative notions on consent and responsibility: that the negotiation of consent may entail an intra-actional process between individuals and involve negotiation with sexual spaces and pharmaceutical technologies. By introducing posthumanist performative frameworks into the analysis, consent no longer depends on an individual's will, but rather is "generated through material configurations and flows of agency in time and space" (Garland-Levett, 2020, p. 709).

\section{Posthuman Sexuality-Assemblages: Sex in Social and Physical Spaces}

As discussed in Chapter 1, central to the idea of posthumanist performativity by Barad (2007) is "intra-action," signifying the mutuality of matter and discourse in the process of materialisation, without privileging one over the other. Barad's theory of posthumanist performativity proposes that discourse and matter are emergent, agentive, and intra-active through practices rather than pre-existing entities. Similarly, pushing for an analysis of the mutual constitution of social and physical forces, Mol (2002) introduces the concept of “enactment," whereby realities are understood to be produced through practices. Importantly, because there are multiple practices, there are also multiple realities. This refiguring of ontology as relational, multiple, and emergent is also shared by Deleuze and Guattari through their concept of assemblages, where social, physical, and abstract entities are understood to be multiple and collectively achieved through connections. In particular, the concept of "sexuality- 
assemblages" (Allen, 2015; Fox \& Alldred, 2013) is helpful because it renders sexuality a grouping of different elements, and where matter and meaning are co-constitutive of sexual desires, identities, and practices.

What does this mean for the analysis of sexual consent? While social constructivist approaches would likely argue that liberal and juridical discourses shape how stealthing is conceptualised, such frameworks do not address how stealthing is enacted in social and physical contexts that co-construct how "consent" is given and understood. By contrast, this thesis's posthumanist performative approaches seek to offer a more nuanced understanding of the intraactions between MSM and their social and physical contexts - notably anonymous sexual encounters in bathhouses - in mediating how consent is enacted or practised.

Social and physical spaces help shape the sexualities and practices of MSM. The stigmatisation of homosexual sex, as the gay historian Allan Bérubé (2003) describes, forced queer people to become "sexual outlaws" and carve out spaces in society where they could meet up and not get caught. Public spaces, such as parks, restrooms, subways, and public libraries, became attractive in providing relative anonymity, privacy, and the possibility of meeting others for sex. Nevertheless, due to these spaces' public nature, homosexuals risked being arrested, blackmailed, robbed, or worse, killed. Beginning in the late $19^{\text {th }}$ and early $20^{\text {th }}$ centuries, bathhouses became popular as alternatives to these public spaces due to the safety and privacy they afforded (Bérubé, 2003).

Modern bathhouses, Bérubé (2003) claims, evolved around the 1950s and 1960s. These male-only environments catered for the "sexual and social needs of gay men," allowing MSM to sexually experiment with each other with relative privacy, safety, and protection (p. 36). By the 1970s and 1980s, bathhouses also became important sites for community creation and activism 
(Califia, 2000). In particular, the emergence of HIV/AIDS in the early 1980s shifted early understandings of bathhouses and sexual behaviours by teaching "gay men to see themselves as members of a common tribe with similar interests and needs" (Califia, 2000, p. 7). While early bathhouses were always subject to raids due to homophobia (e.g., the Toronto bathhouse raids in 1981), HIV/AIDS intensified these even further. ${ }^{4}$ For example, in 1984, gay bathhouses in San Francisco were ordered to be closed by the Public Health Department as a means to stop the spread of HIV and prevent men from engaging in "high risk” sexual contact (Bérubé, 2003). However, a few of them remained open, and by the 1990s, bathhouses created opportunities for the expansion of safer sex guidelines and STI testing (Disman, 2003).

Though bathhouses became critical sites for HIV prevention interventions, bathhouse culture also precluded negotiations of condom use (Binson \& Woods, 2003; Elwood et al., 2003). Bathhouses afforded MSM to engage in anonymous sex, characterised mainly by "nonverbal discourse, and de-personalized social rituals" (Haubrich et al., 2004, p. 19). However, the focus on silence might have prevented condom use and other safety negotiations (Elwood et al., 2003). Additionally, as I discuss further in this chapter, the norm of silence in bathhouses also renders the negotiation of consent problematic, primarily when consent is conceptualised as a communicative act (Kukla, 2018; P. Reynolds, 2004).

While normative silence in bathhouses may impede negotiations of safety and consent, silence nonetheless serves a critical role. Silence allows for anonymous sex by limiting the need to divulge information about one's serostatus or other biographical details. Silence is critical in the overall sexual experience because men "could engage in depersonalized and somatically

\footnotetext{
${ }^{4}$ In 1981, all six of Toronto's bathhouses were closed by police, arguing that bathhouses were not private spaces but bawdy houses. According to Bérubé (2003), these raids served as turning points in the political organisation of Toronto's gay community, which facilitated a community response to HIV/AIDS. For further historical insights into the Toronto bathhouse raids, see Silversides (2003).
} 
focused social rituals" (Haubrich et al., 2004, p. 23). For Foucault, the affirmation of nonidentity in bathhouses serves an important function "because of the intensity of the pleasure that follows from it" (quoted in Halperin, 1995, p. 94). Silence makes bathhouse sex "hot" because it is intertwined with masculinity ideals, and too much talking is considered ruining the mood (Haig, 2006). The absence of identities through silence further allows men to create fantasies about their sexual partners.

These discussions demonstrate that bathhouses are "agents" in shaping sexual practices among MSM. For this reason, a praxiographic approach to Foucauldian discourse analytical framework, as outlined in Chapter 1, is beneficial for situating bathhouses as always already permeated by reigning discourses that co-produce complex enactments of consent and responsibility. As a reminder, my methodological approach in this thesis brings together Mol's (2002) praxiography, with the aim to deconstruct and reconstruct practices-paying particular attention to the enactments of objects - and discourse analysis inspired by Foucauldian frameworks, which centres on analysing the historical situatedness and performativity of discourses in producing subjectivities (Arribas-Ayllon \& Walkerdine, 2008; Willig, 2008). With these considerations in mind, this chapter presents an analysis of crucial accounts on stealthing from the New York-based barebacking Website I call "Pigpen." The data analysed for this chapter combines those gathered during my studies at La Trobe University and the ones collected for the current study at Carleton University. As I discussed earlier, in my previous studies at La Trobe, data were collected between September 2013 and February 2014 when PrEP was just introduced. The current study, by contrast, were collected between June 2019 and September 2019, when the adoption of PrEP among gay men was well underway. These data will be 
featured more prominently in the latter part of this chapter, where I discuss how Pigpen participants understand responsibility concerning anonymous sexual practices.

In the next section, I consider the generative role of normative discourses of consent and HIV criminalisation in narrowing down possibilities of Pigpen participants' thinking about stealthing. Inspired by a praxiographic approach to Foucauldian discourse analysis, I propose that these discourses are not determining because the broader environment of things and matter, particularly condoms and HIV status, is implicated in meaning-making practices. I show that participants overwhelmingly concur that stealthing is morally unacceptable, for stealthing is construed as a violation of individual autonomy and agency.

\section{Conceptualising Stealthing through Liberal and Legal Notions of Consent}

Undertaking a textual analysis of the barebacking Website iblastinside.com, Brennan (2017) observes that stealthing discourses online connects the practice with rape. At the centre of stealthing, claims Brennan, is the issue of consent violation, for unprotected sex is performed without the knowledge of a sexual partner. This section demonstrates that Pigpen participants articulate stealthing as morally wrong, which has harmful consequences. I argue that the connection between stealthing and violence is co-constituted by MSM by drawing on normative models of consent and HIV criminalisation, entangled with the materialities of condoms and HIV serostatus.

Thomson (2019) claims that until 2017, few people had heard of or even critically thought about stealthing. On the contrary, as early as 2008, a rule against "stealth breeding" can already be found in the Pigpen forums. In the post "What's Allowed Here \& What's Not" created by Roger, the website owner explicitly prohibits the promotion of stealthing:

Do not advocate violence against other people. Among other things, this means you may not advocate for real-life 'stealth-breeding' (intentionally trying to infect someone else 
with HIV without their knowledge). This is a crime in most places, and even advocating it can be a bad idea.

The prohibition against stealthing as violence reveals that Roger relies on normative discourses on consent to frame the practice as morally intolerable. Moreover, by shaping stealthing as criminal, Roger draws on HIV criminalisation to deter participants from encouraging others to engage in stealthing. Stealthing is morally wrong because it exposes victims to HIV infection, and deliberately infecting someone without their consent is a crime. Such constructions are also upheld by participants in their comments posted on the thread "Is stealthing morally okay?":

Knowingly lying or exposing someone who isn't aware of your status is wrong, and I think CRIMINAL.

I agree with those who feel that stealthing is morally wrong, particularly when the other person has asked about HIV status. It is also criminal.

In my opinion, you should be in jail if you deliberately infect someone without the other person wanting or knowing this!

Stealthing is construed as criminal not only because it is physically harmful but also a violation of autonomy. As one contributor on the thread explains: "It isn't okay to stealth. It isn't okay to play with someone else's health because you take their choices away from them." In debating the morality of stealthing, some participants further advance the notion that agreeing to one form of sexual activity does not mean blanket consent to future sexual contact (Brodsky, 2016).

Interestingly, while some of Brodsky's interviews with female victims of stealthing did not see the practice as sexual assault, some men in Pigpen believe otherwise:

Anyone who deliberately violates the conditions under which their partner agreed to have sex is an asshole and is committing sexual assault.

Stealthing is always done without the consent of the person being stealthed. And since it's done without consent, it's sexual assault. 
I know this is probably an unpopular opinion, but frankly, stealthing is no different from rape.

Transforming a safer and protected sex to an unsafe and unprotected one without consent is deception and might be considered a form of rape. Situated within the category of consent as a sexual contract, stealthing is inexcusable because it violates individuals' bodily agency and autonomy to their desires. According to these participants, stealthing is morally problematic because it denies victims control and enjoyment of their sexuality while also exposing them to HIV risks. As another commenter notes:

If you're having sex with someone and you've led them to believe that you're negative and/or that you're using an unaltered condom when in fact, you aren't, that's stealthing! You don't get to decide what your partner 'really' wants/needs/deserves. There are plenty of guys out there actively looking for poz seed. Forcing it on someone who doesn't want it is rape, in my opinion, and that is never okay. (Ian)

Lying about one's serostatus or damaging a condom is disempowering because it deprives individuals of the possibility of giving meaningful consent. Stealthing is considered violence by this participant because it is a forceful nullification of one's choice in having safer sex with an HIV-negative sexual partner or with the use of condoms. Here, shaping HIV-positive men as the main culprit in enacting stealthing reproduces the discourse of HIV-positive men as "evil perpetrators" (Race, 2012). That is, Ian's response shapes HIV-positive individuals as dubious subjects who are responsible for stealthing HIV-negative sexual partners and exposing them to HIV infection. ${ }^{5}$ Mobilising insights from posthumanist performativity, it is possible to argue that more-than-human entities are mutually intra-active with discursive forces in the emergence of

\footnotetext{
${ }^{5}$ One can suggest that there is an implicit responsibilisation of HIV-positive individuals here, which may be an effect of HIV criminalisation discourses. According to some scholars, like Adam, Elliott, Husbands, Murray, \& Maxwell (2008) and Race (2012), HIV criminalisation discourses generate HIV-positive individuals responsible for disclosing their serostatus and culpable for transmitting HIV while potentially absolving HIV-negative individuals of any accountability.
} 
stealthing as morally unacceptable, as illustrated in Ian's testimony. The materiality of condoms and HIV status (determined through blood tests), alongside liberal notions on consent and HIV criminalisation, actively shapes stealthing as immoral, criminal, and a violation of consent. ${ }^{6}$

Additionally, it appears that most Pigpen participants narrowly view stealthing as a practice perpetrated primarily by active partners (“tops”). For example:

I think that it's stealthing when it involves deceit, whether that's lying about your status to a guy whos' trying to serosort (when poz tops claim to be neg when they know they're not), using a compromised condom on a bottom who does not want to play raw, or agreeing to play wrapped and then slipping the condom off.

Stealthing is about the top starting a session with a condom and removing it mid-course or starting a session with a condom that has otherwise been rendered useless, all without the bottom's knowledge or consent.

These participants imply that "tops" have sinister intents by stealthing clueless "bottoms." By removing or damaging condoms without "passive" partners' consent, "active" partners violate consent by making bottoms submit to their will. However, while tops appear to be solely accountable for stealthing bottoms in these discussions, other participants emphasise that stealthing may also be enacted by the latter. The following HIV-positive participant narrates:

I confess there have been a few times (three that I can remember) where a guy has offered me his cock through a glory hole with a condom on it, and I have purposely sucked it [...] just so I could try and bite a hole in the condom. My intent has never been to poz anyone (I'm undetectable). My sole intent was to get his cum inside of me. Even still, I've stopped doing that. I think it's wrong, a violation of his will. (Jerry)

This excerpt from a 63-year-old American participant and self-identified bottom marks a departure from more familiar discourses of stealthing described by some participants above,

\footnotetext{
${ }^{6}$ Rosengarten (2009) provides a helpful account of the materialisation of HIV status through medical technologies. In particular, determining an "undetectable viral load" involves various entities that help enact this status including body matter (i.e., blood), virus, and the test itself. As Rosengarten notes: “'Undetectable viral load,' or even 'HIV positive' or 'HIV negative' status, are not mere 'knowledge' [...], it is an effect of an embodied engagement with biomedical technologies" (p. 74). In other words, the materialisation of an HIV status is an effect of materialdiscursive forces.
} 
where tops are shaped as maliciously infecting bottoms without their knowledge. Positioning his practice within the category of liberal and juridical notion of consent, Jerry recognises that the act of damaging condoms vitiates his partner's will, which is morally unacceptable. However, despite this acknowledgement, he qualifies that this was not enacted with malevolent intent to transmit HIV. Instead, Jerry expresses his motivation for stealthing as a means for receiving semen that the use of condoms would have otherwise prevented. Though Jerry challenges the link made between stealthing and intentional HIV transmission, his views nevertheless reiterate the principle of harm to make sense of his actions. Jerry's text alludes to normative discourses' generative role in narrowing down understandings of moral principles concerning stealthing while highlighting the complexities and possible limitations of the normative models of consent and HIV criminalisation.

The normative model of consent, as Kukla (2018) describes, is based on the idea that "everyone involved must be able to clearly communicate when they want to withdraw consent in order for it to be valid in the first place" (p. 75). In other words, this model places great emphasis on active communication between sexual participants. However, sex through glory holes, as Jerry describes above, reveals that this model is not always practical. Due to the limited physical and visual contact between sexual partners, except for a glance through the hole, the absence of clear communication between sexual partners puts into question the logic of consent as a "communicative transaction" (Kukla, 2009, p. 45). Consequently, glory holes expose the limits of a "request-and-consent-or-refuse model of sexual negotiation" (Kukla 2018, p. 76).

Additionally, sex through glory holes underscores the limitations of HIV criminalisation. The failure to disclose one's HIV-positive serostatus is perceived as a nullification of a sexual partner's consent and "thereby rendering the physical contact an assault as a matter of law" 
(Adam, Elliot, Husbands, Murray, \& Maxwell, 2008, p. 145). However, as communication through glory holes is simply done through glances, the absence of talking makes disclosure of serostatus difficult and problematic. While damaging a condom is morally wrong because it is a violation of consent, it is arguable that Jerry's undetectable viral load status places him in a harmless position and virtually incapable of transmitting HIV. In the absence of HIV infection harm, can the failure to disclose be considered sexual assault? Situating Jerry's actions within normative principles of consent, it is arguable that a moral offence has been committed; yet, one may also suggest that moral principles in anonymous sexual situations, such as glory hole sex, are more nuanced and complex due to the scenario. Drawing on posthumanist performative frameworks, it is notable that different conceptualisations of sexual morals may emerge through different assemblages of sexual environments, sexual apparatuses, bodies, HIV biomedical technologies, discourses, desires, and pleasure. Sexual negotiation is beyond rational humans entering an agreement because it is also made possible by nonhuman forces, including condoms, HIV status, and glory holes. In this case, it is arguable that "consent" is relationally achieved.

In this section, I demonstrated that the lack of consent provides a framework for understanding stealthing as rape and sexual assault, which also works as a norm in shaping moral conduct within sexual encounters as discussed by Pigpen participants. Further, their views about stealthing are also linked to HIV criminalisation, where stealthing is viewed as harmful by exposing someone to HIV risks. These discussions position HIV-positive men as culpable for enacting stealthing and victimising HIV-negative men. However, I also showed that participants inevitably expose the limits of normative discourses despite these views. In particular, the liberal and juridical idea of autonomous individuals giving consent becomes problematic in anonymous sexual encounters, particularly in glory hole sex, due to anonymity and lack of communication. 
In what follows, I further explore how participants talk about the morality of stealthing in anonymous sexual encounters, with particular attention to the role of bathhouses in the emergence of different understandings of "consent."

\section{Limits of Liberal Models of Consent: Anonymous Sex in Bathhouses}

In their introduction to Making Sense of Sexual Consent, Cowling and Reynolds (2004), as mentioned earlier, note that the liberal conception of consent as a sexual contract is based on the assumption of "free individuals say yes or no" (p. 1). Central to this idea, as Reynolds (2004) further suggests, is the understanding of sexual consent as requiring an "act, utterance or communicative process that signifies that a relationship has developed a sexual dimension" (p. 95). The model of consent as "a performative speech act" reveals a narrow conception of sexual negotiation, which is unambiguously rendered as "just saying 'yes' or 'no' to a request for sex" (Kukla, 2018, p. 78). However, this normative consent paradigm becomes problematic in anonymous sexual venues, including bathhouses, sex clubs, public toilets (“tea rooms”), and glory holes, among other places, where silence is the norm. As Elwood, Greene, and Carter (2003) indicate, MSM who patronise bathhouses recognise that "oral communication seldom occurs" because "verbal communication is viewed negatively and discouraged" (p. 286). In this section, I attend to the divergent, complex, and often conflicting enactments of sexual negotiation concerning stealthing in bathhouses. For some Pigpen participants, "consent" works differently in anonymous sexual situations: it is inactively and implicitly given even before any verbal or physical communication; and, stealthing sometimes functions as a pleasurable fantasy, which may exceed normative moral principles. Drawing on posthumanist performative frameworks, I contend that "consent" in Pigpen participants' responses appear to be relational, 
emergent, and dependent, for consent negotiation involves place, time, fantasies, pleasures, and others.

For example, responding to the thread "Is stealthing morally okay?", Roy, 66 years old HIV-positive man from Ottawa, Canada, points out that stealthing may be acceptable in bathhouses because of the culture of anonymity, silence, and de-personalised sex:

For me, whether or not stealthing is wrong depends on the situation. The more anonymous the situation, the more acceptable I find stealthing. If a slutty bottom is on a sling at a bathhouse and before each guy fucks him, he asks them, 'Are you clean?' then I see nothing wrong if the top fucks him and dumps his toxic load in the bottom's hole.

Roy's views may be considered controversial if situated within the normative model of consent, where stealthing is understood as morally unacceptable. For Roy, however, different contexts may demand flexibility or an entirely different conceptualisation of "consent," especially in bathhouses. He writes: "In other circumstances, where guys chat, get together for coffee, and treat each other as human beings [...], then I find stealthing to be inappropriate.” By contrast, in an environment where silence and anonymity rule, "slutty bottoms" should not expect their desires and needs to be respected. As Roy further explains: "Anyone in a dark room with his hole lubed up should not demand this or that. He should take whatever comes his way."

More importantly, Roy asserts that "bathhouse sex is a perfect example of a suspended morality" because he believes that: "As soon as one enters a bathhouse, one is implicitly giving consent but a consent that is not well defined in anyone's mind." Here, Roy conveys that the process of consent in anonymous sexual situations exceeds liberal consent based exclusively on clear communication through "no means no" and "yes means yes." Indeed, Roy implies that a person inadvertently and passively agrees to allow sex to happen upon entering a bathhouse. Following Corteen's (2004) analysis of the use of codes and signifiers among queer people to indicate sexual preferences, it is possible to contend that Roy's conceptualisation of sexual 
consent in bathhouses "had already been communicated and has been established" before a communicative act (p. 184). When getting into anonymous sexual spaces, one accepts a contract that sexual acts are welcome and everyone has the freedom to participate, or not, in whatever way they choose. Arguably, however, this understanding of consent may pose problems with respect to issues regarding assumptions or misassumptions when "consent" is present or absent, for the interpretation of valid or invalid consent "is still reliant upon subjective recognition" by individuals involved (ibid).

For Roy, passive consent is one reason why stealthing may be morally tolerable in bathhouses. Indeed, when rationalising his views, Roy maintains that: "I prefer to protect these anonymous spaces from morality, which is why I reject the idea of anonymous stealthing as immoral." He further explains that bathhouses are dissimilar from the outside world, which is governed by normative rules about consent:

Outside in the street, we all agree and have rules; no one will approach me and grab my cock. In a bathhouse, we give consent to be touched, and some extend that consent in order to fulfil their fetishes and needs. I'm not going to spend money and walk into a place that resembles the outside world! When I'm at a bathhouse or darkroom, I'm not concerned at all about the other guys around me; it's not a two-way exchange. (Roy)

In this excerpt, Roy reiterates his argument that the process of "consent" in bathhouses is different, where sexual negotiation may not necessarily follow the model of saying "yes" or "no," for consent negotiation occurs even before a formal exchange of verbal or physical communication. Roy further alludes that such spaces are governed by fantasies and pleasure, which may afford the possibility of extracting himself from the demands of normative moral norms. Butler's (2011) critique of the liberal and juridical limitations of consent is informative in understanding Roy's comments. Here, Roy may be pointing to the limits of the liberal model of consent by emphasising the complexities of sexuality and the messiness of fantasies in 
anonymous sexual encounters. As Butler writes, the idea of saying yes or no to a contract during sex fails to recognise that "we do not always know what kind of sex we will get when we allow sex to happen" (2011, p. 423). Indeed, Roy further writes about bathhouses: "I'm there to fulfil my fetishes, whatever they are, including stealthing." Another participant explains:

In some venues, lying is just part of the game, the fantasy, the excitement. A bottom guy at a bathhouse should never expect any truth in that kind of environment. Could be part of the fantasy scene [...]. A sauna or any other sex club is to live out fantasies. (Bryan)

Stealthing fantasy scenes mess with normative consent based on the idea of "social contract," which Brennan (2017) describes as "playing" with codes of behaviour that may even be considered "more subversive" (p. 322). Although subversion may not be very explicit in the comments above, these participants emphasise the uncertainty of fantasies and the messiness of sexuality and, in some ways, putting into question "the idea of the fully choosing subject whose sexual choices express a full understanding" of what is going to happen in sexual encounters (Butler, 2011, p. 427). As Roy further conveys, in bathhouses, men are not fantasised about as people, persons, nor subjects but merely as bodies: "I like anonymous sex precisely because the guys in the cruising area are not people, but bodies for me to enjoy." By fantasising about men in bathhouses as bodies, their identities are temporarily suspended and perhaps providing a reason for why "anonymous sex occurs outside the realm of a moral code-in a state of suspended morality," as Bobby, 46 years old participant from Chicago, argues.

Foucault's views on anonymous sex in bathhouses as desubjectifying is instructive here. For Foucault, the deployment of sexuality understands that sex and desire are fundamentally linked: how we have sex reveals our desires, which tells us something about our identities. By affirming our sexual identities, we also reinforce the normative discourses on sex-desire. Consequently, we also place ourselves in a position where power holds us into its grip instead of 
liberating ourselves from it. At the end of The History of Sexuality, Volume 1, Foucault explains that the counterattack against power should not be through the affirmation of sex but through bodies and pleasure (Foucault, 1990). In Saint Foucault, Halperin reveals that the French philosopher theorised anonymous sex in bathhouses as exemplary in inventing ways to use bodies and pleasure insofar as "it detaches sexual pleasure from sexuality" (Halperin, 1995, p. 87). Foucault contends that bathhouses afford men to dispense with social identities by using bodies to invent new possibilities of pleasure:

I think it is politically important that sexuality be able to function the way it functions in saunas, where, $[\ldots]$ one's own identity, $[\ldots]$ one's own past, $[\ldots]$ one's own place [do not matter] [...]. [O]ne can meet people who are to you what one is to them: nothing else but bodies with which combinations, fabrications of pleasure will be possible (Foucault as cited in Halperin, 1995, p. 94).

For Foucault, because the deployment of sexuality locks individuals to sexual identity, gay bathhouses are spaces where identities do not matter. As Foucault further explains, while techniques of power "make use of sexuality" to attach to us a personal identity, pleasure derived from bodies in anonymous sex is an "affirmation of non-identity" (as cited in Halperin, 1995, p. 94). Sex in bathhouses makes it possible to dispense with identities (although not entirely), for sexual participants make use of bodies to produce pleasure and indulge in fantasy. Bodies must make connections with other bodies, both humans and nonhumans, such as the penis to a mouth through a glory hole, in the production of pleasure. As Holmes, O’Byrne and Murray (2010) describe: "At the bathhouse, bodies [...] form connections with each other [...] [which] create connections that can be multiple and intense" (p. 254). In bathhouses, individuals become bodies free from social roles and expectations, and the free play of desire and fantasy becomes possible. This abstraction of bodies and suspension of identities generate bathhouses as places where 
alternative conceptions of sexual morality may be possible. As Pigpen participant Bobby further remarks:

Any presumption that there is a universal moral code for anonymous sex is empirically false, particularly in bathhouses [...] where men gather with a wide range of interests and agendas in pursuit of a broad array of experiences.

In this text, the active role of sexual environments in co-constituting sexual morality comes alive. While the norm of silence and absence of social identities in bathhouses may prevent sexual actors from formally entering a communicative sexual contract (i.e., the process of liberal consent), Bobby reveals that "consent" still works in these spaces, albeit differently: consent is implied and passively given. As he continues: "Anonymity is consent because participants know (and thus are informed) that stealthing is one of the sex acts practised in anonymous encounters." Here, Bobby appears to be contradicting himself by saying that, on the one hand, bathhouses may be exempt from normative moral codes precisely due to the anonymity of the sexual scenario. On the other hand, he affirms that "consent" still works in anonymous sexual spaces, although negotiation works differently. Consequently, the negotiation of consent is extended beyond two or more individuals; instead, negotiation also includes spaces, fantasies, pleasures, and others within the sexual scenario.

However, though anonymous sexual practices in bathhouses may co-produce alternative views on the process of consent negotiation, liberal and juridical notions on sexual morality are always already present. That is, embodied practices of stealthing are embedded within normative discourses. As discussed, while liberal and juridical discourses actively open up controversies and complexities concerning consent, such norms simultaneously foreclose notions of individuality. Specifically, while Roy, Bryan, and Bobby seem to point to anonymous sexual encounters as exceeding moral standards, they nonetheless present stealthing as "highly 
individualised" (Brennan, 2017, p. 323). Insofar as these participants argue for different views concerning "consent" and stealthing in bathhouses, they nevertheless pursue notions of individual responsibility and self-interest.

To put it differently, these participants present contradictory views about sexual morality and responsibility. As Roy says: "To my way of thinking, if I choose to indulge in anonymous sex, I assume all the risks with that, including contracting an STI.” In other words, while MSM in anonymous sexual practices argue for alternate conceptions on the morality of stealthing by emphasising different processes of consent, Pigpen participants nevertheless affirm discourses of individual responsibility concerning how men should manage HIV risks in anonymous sexual encounters, as I discuss in the next section.

\section{(Re)Producing the Responsible Self}

In this section, I interrogate the emergence of notions of responsibility through the reiteration of liberal discourses on individual autonomy, responsibility, and choice, which, as Adam (2005) insists, are not incongruent with HIV prevention messages. Queer theorist David Halperin (2007, p. 49) rightly points out that HIV prevention strategies are primarily premised on individual responsibility, where individuals are expected to protect themselves against HIV: "it is the job of each of us, and no one else, to prevent ourselves from being infected." I argue that discourses on individual responsibility are entangled with sexual environments and pharmaceutical technologies, forming HIV prevention assemblages (Rosengarten \& Michael, 2010) and co-producing ontologically different biomedicalised responsible subjects. A closer examination of the accounts on responsibility reveals that the labour of protection is quite different for HIV-negative and HIV-positive men: on the one hand, HIV-negative men reinforce individual culpability by emphasising self-protection through the use of PrEP. On the other hand, 
men with HIV assume "altruism," believing that they bear the responsibility to prevent others from getting infected by achieving an undetectable viral load status (M. Davis, 2002). However, I maintain that the notion of altruism is not unproblematic because there is an implicit individualisation precisely by adhering to the legal, ethical, and clinical obligation to prevent HIV transmission.

Individual Responsibility among HIV-negative men. Adam (2005) suggests that, by echoing individual responsibility, barebackers "repeat basic propositions of the safe sex message," which includes personally accepting the burden for the prevention of HIV infection, or that "one should treat every new sexual partner as HIV positive" (p. 344). Pigpen participants also embody these discourses in their discussions on stealthing. For example, a participant from San Francisco alludes to personal responsibility in his comment about the morality of stealthing: "due to the fact that I have made the decision to take anonymous loads at a bathhouse, I have opted to take that risk, and I can't blame anyone but myself if I get pozzed." Here, the mutuality of matter (bathhouses) and discourse (self-blame) is evident in forming a morally accountable subject for his behaviours.

The discourse of individual responsibility is prominent in this comment, especially in this participant's acceptance of risk when receiving semen in anonymous sexual encounters. Contrary to Van Kesteren et al.'s (2005) conclusion that personal responsibility is weaker within the context of casual or anonymous sex, it is evident here that there is a strong emphasis on selfresponsibilisation, especially in bathhouses. Shane, 40 years old from New York, confirms this: "People must be responsible for their actions. If one chooses to fuck anonymous strangers unprotected, then one must accept the potential consequences of that behaviour." 
Whereas I argued earlier that some MSM, alongside bathhouses, actively shape alternative conceptions of "consent" and morality in anonymous sexual situations, it is evident here that bathhouses are also co-implicated in the maintenance of normative views on responsibility - specifically, the emergence of neoliberal models of responsibility in the discussions by Pigpen participants. By emphasising the rhetoric of choice and individual responsibility, participant Shane reiterates what Adam (2005) calls the contemporary strands of moral reasoning within neoliberal discourses. For Adam, the "neoliberal sexual actor" is tamed, responsible, and governed by self-interest, which is also conveyed in the following response by a participant who was a victim of stealthing:

As someone who has been stealthed more than a few times, I can say that yeah, it is morally wrong, and I do feel violated. Then again, it's not like I didn't play a part as well. I didn't ask about their status. Now, if a guy lies about their status, that's on them. But, in most cases, the bottom could have done things to stop it. (Dallas)

The comment above conveys a subject who repeats the liberal and juridical model by describing stealthing as a violation of consent. Dallas also demonstrates that some men who experienced stealthing consider themselves "victims," contradicting some claims that most individuals who are stealthed do not consider their experience to be sexual assault (Brodsky, 2016; Latimer et al. 2018). Nonetheless, Dallas reproduces the rhetoric of individualism that everyone is accountable for preventing HIV infections in his reflection on the morality of stealthing. Indeed, whereas he believes that a moral wrong has been committed, he accepts some responsibility for being stealthed, leading to self-blame. Bottoms are construed as personally responsible for managing both the risk of stealthing and HIV infection.

The responses highlighted so far elucidate on anonymous bareback sex as always risky. The perpetual presence of HIV and STI exposure reproduces normative models of responsibility based on self-protection. Pigpen participants and sexual environments are deeply enmeshed in 
neoliberal rationality, where "continual vigilance [...] against a possible infection" is imposed on individuals (Sandset, 2019, p. 662). Another example:

My view of my own individual health and negative HIV status and the responsibility to maintain this falls onto me. I have taken steps to do all I can to ensure I can continue the status quo, so to speak. And if I choose to place myself in a situation where that can be a problem, then that is the only part of it that rests upon my shoulders and mine alone. (James)

James' response is unsurprising in the context of the individualisation of responsibility, which guides the understanding of HIV prevention. In his analysis of HIV prevention campaigns, Sandset asserts that the promotion of safer sex is not only informed by neoliberal ideals but is also infused with notions of desires and choice: "where and when to stay protected and with what kind of protective technologies be that PrEP or condoms" (2019, p. 665). For James, taking PrEP is a way to manage the risk of HIV infection and protect himself from the possibility of becoming a victim of stealthing:

Simply put, I feel comfortable with those I am intimate with, and Truvada helps me bolster my defence and confidence in my continued HIV-negative status and would never intentionally put that at risk by entering into a situation where a person with ill intent has the opportunity to stealth me.

Robinson (2018) notes that HIV prevention programs shape individuals as rational actors who want to protect themselves from HIV infection. This means that individuals are responsible for managing their sexual health and with the advent of PrEP, controlling HIV risk becomes easier. PrEP, as a biomedical tool in the prevention of HIV, is entangled with notions of individual responsibility because it decentralises HIV prevention by taking them out of the clinic and putting them into individuals' hands (Sandset, 2019). In other words, PrEP reconfigures individual MSM as responsible for their own HIV protection precisely by biomedicalising their bodies. Another participant echoes self-responsibilisation through PrEP: 
If you're really serious about not getting the bug, then why don't you just go on PrEP, adhere closely to your drug regimen and fuck happily ever after?

Here, not only does this participant shift accountability to individual sexual actors for the management of HIV risk, but he also reveals what it means to be a good biomedicalised subject through PrEP. Thomann (2018) notes that PrEP constitutes "a pharmaceutical extension of the responsibilised sexual subject" because PrEP users are required to acknowledge their risky practices and take the necessary steps to mitigate these risks (p. 997). PrEP users are coconstituted as responsible because they are rational, calculative, and equipped with pharmaceutical technologies. However, as the participant above conveys, this responsibility is not limited to managing risks because they must also adhere to a drug regimen to take advantage of the benefits of PrEP. For Dean (2015), adherence to PrEP is an example of the disciplining of bodies and the intensification of rationality as "responsibility can now be measured through drug levels in blood" (p. 14-15).

With the availability of PrEP, an ontologically different subject emerges: one who does not rely on others to practise safer sex (through disclosure of HIV status or use of condoms), but a responsible biomedicalised subject who depends on pharmaceutical technologies to personally manage HIV risks. The biomedicalised subject is different because individuals need to acknowledge their risky sexual practices and because they need to comply with a medication regime (Giami \& Perrey, 2012). In other words, PrEP reinforces and increases notions of personal responsibility by placing the onus on HIV-negative men to protect themselves from HIV precisely by adhering to correct dosage. Nevertheless, although the biomedicalisation of HIV prevention instils personal responsibility on the bodies of HIV-negative men, the discourse of HIV-positive men as a risk to others also remains. As the following participants explain, HIVpositive men are obliged to protect others from HIV: 
Poz guys should disclose their status - in many cases, they have a legal obligation — but besides that, if they are exposing their partners to a chronic condition, their partners should be able to weigh the risk so they can give informed consent properly.

When you become POZ, you take on that extra layer of responsibility of having to disclose your status before engaging in any sexual act whatsoever, even if the other person doesn't bring up status. Someone has to take on the burden of responsibility, and that has to fall on POZ guys since they carry a disease that can affect someone for life.

The posts above reveal how HIV-positive men are burdened with the responsibility to disclosean effect of HIV criminalisation permeated with implicit moralism (Adam, 2005; Adam, Elliot, Husbands, Murray, \& Maxwell, 2008; Rangel \& Adam, 2014; Robinson, 2018). As Davis (2002) proposes, the legal sanctioning of HIV-positive individuals to disclose shapes them as a risk to others and are therefore compelled to be responsible. Additionally, by shaping HIV-positive men as culpable, these responses strengthen the discourse that men infected with HIV are "AIDS carriers" (Lupton, 1999) while inadvertently absolving HIV-negative men as not responsible for HIV transmission. For Roy, however, HIV-positive men should not bear the burden to disclose: "Just because someone was courageous and took the HIV test to learn his HIV+ status does not justify putting all the burden on HIV+ guys all the time."

Protecting Others (“Altruism") and HIV-positive men. Some HIV-negative Pigpen participants emphasise self-protection, while others compel HIV-positive men to disclose and protect them from HIV infection in anonymous sexual situations. So how do HIV-positive men view responsibility? Chad, 53 years old HIV-positive participant from the US, expresses the sentiment that the onus falls on him to be responsible not only for his health but also for the health of his sexual partners:

I take anon loads. I'm responsible for it. I get tested beforehand to make sure I'm safe to play, and I get tested regularly to ensure I stay that way. If I catch something, I get it treated immediately and take myself out of circulation until I'm safe [...]. I am HIV+, and in fact, I am a 5-year AIDS survivor, durably undetectable for three years. I very 
much care about the safety, health, and well-being of the men I serve. I am honest, ethical.

Numerous studies exploring HIV-positive men's constructions of responsibility consistently found that they often perceive themselves accountable for protecting others against HIV infection (M. Davis, 2002; Rutledge, 2009; Wolitski et al., 2003). This strong sense of concern for the safety of others is described by Davis (2002) as "altruistic." However, while altruism appears to be unproblematic, it could be argued that there is an implicit individualisation of responsibility in the very idea of protecting others from HIV infection. As Davis proposes, by legally sanctioning HIV-positive individuals who are considered a risk to others, HIV-positive people are compelled to be responsible. This is evident in Chad's post when he describes himself as a responsible subject who is under surveillance and control. Indeed, altruism for Chad involves achieving an undetectable viral load. Consequently, insofar as altruism involves protecting others from HIV, it is inseparable from the embodiment of ideas of being a risk to others, in addition to HIV criminalisation and biomedicalisation.

Another participant invokes the notion of undetectability as a means for providing an additional layer of protection for his HIV-negative sexual partners who may stealth him (by lying about their serostatus):

I'm poz/undetectable and have been forever [...]. I also have chosen not to bareback with anyone I know is neg, though I'll bet there are guys that have said they were poz just to get my cum. [But] the chances of me giving HIV to anyone are pretty much slim to none as my virus has been well controlled for so long. (Glen)

Glen's text reveals that the figure of the stealther is not limited to HIV-positive men because HIV-negative men may also lie about their status. However, thanks to HIV treatments, Glen positions himself as non-infectious because his viral load is undetectable. Accordingly, in addition to being a clinically responsible subject who places himself under ongoing inspection, 
evaluation, and judgement through treatment (Guta et al., 2016), Glenn also portrays himself as a responsible sexual actor for protecting his sexual partners against HIV infection.

Assuming the responsibility to protect others reinforces the rhetoric and practices of individual responsibility precisely by adhering to the legal and moral obligation to prevent the transmission of HIV. The responsible HIV-positive person is forged and achieved through engagement with biomedical technologies, producing an ontologically different human subject subjected to ongoing viral load testing. That is, much like their HIV-negative on PrEP counterparts, undetectable HIV-positive men also need to become biomedicalised in order to be rendered "safe," desirable, responsible, and good. For one participant, these biomedicalised subjects may also be shifting the moral discourses of stealthing and the burden of responsibility:

I understand stealthing as kind of haunting for HIV-positive men who may not disclose. In today's era of PrEP, PEP, and post-conversion treatment, perhaps stealthing is not the criminal act it was in the past because responsibility is more heavily laid upon the bottom, accepting anonymous loads bareback. (Calvin)

For this participant, PrEP and other HIV biomedical technologies are changing what responsibility to protect means. Whereas normative views about stealthing and responsibility reinforce the notion that HIV-positive individuals are accountable for preventing others from getting infected, biomedical technologies are shifting the onus to HIV-negative men. In other words, disclosure may no longer be necessary given that undetectable HIV-positive men are incapable of transmitting the virus due to undetectable viral load, and HIV-negative men on PrEP are protected from viral infection. Consequently, HIV criminalisation also becomes problematic. One participant asks: "if a person is undetectable, are they morally obligated to declare their status since medical science says we're safe from a transmissible viewpoint?"

Inspired by the concept of HIV prevention assemblages and posthumanist performative frameworks, personal responsibility accounts in this section can be understood as an effect of 
material-discursive intra-actions, where HIV prevention messages and technologies and physical environments are productive of responsible subjects. Indeed, by drawing on selfresponsibilisation to make sense of stealthing, Pigpen participants embody the neoliberal sexual actor by describing each person as responsible for protecting oneself against HIV infection. Moreover, if infection were to occur, the blame should be borne only by the individual. The materiality of personal responsibility becomes even more palpable in the biomedicalisation of HIV prevention and treatment. On the one hand, PrEP enables HIV-negative men to manage risks of stealthing and HIV acquisition easily. On the other, having an undetectable viral load through Treatment as Prevention empowers HIV-positive men to protect themselves from stealthing while also preventing infecting others. These technological advancements are also redefining what it means to be a responsible neoliberal sexual actor. Whereas tenets of a neoliberal subject who is rational, calculative, and personally responsible are still reinforced, this subject is thoroughly biomedicalised: where the onus of mitigating stealthing and HIV risks is highly personalised, while individuals are placed under surveillance and control.

\section{Conclusions}

This chapter paid attention to how issues of consent are framed by Pigpen participants and how they understand responsibility in their discussions of stealthing. Augmenting some feminist theorisations of consent as relational through the concept of sexuality-assemblages helped frame my analyses of the entanglement of discourses on consent and responsibility with matter, which are enacted in multiple ways through various assemblages that involve more-thanhuman entities. The materiality of condoms (their removal or alteration) and HIV status (failure to disclose) exist alongside liberal and juridical consent and HIV criminalisation models to produce stealthing as morally unacceptable that has harmful consequences. These views, 
however, are not pervasive. In anonymous sexual situations, especially in bathhouses where silence is the norm, normative ideals of consent as a communicative transaction becomes limited. For some participants, consent in bathhouses is given passively, where stealthing could be considered acceptable. The emergence of stealthing as morally tolerable in bathhouses underscores the implication of sexual scenarios and environments in (re)making alternative models of "consent" and sexual morality. However, regardless of these different views, most participants reinforce individual responsibility in managing HIV risks, specifically in anonymous sexual situations where there is a high probability of stealthing. Pharmaceutical technologies, particularly PrEP and TasP, are vital in mitigating risks by individuals who are also placed under heavy medical surveillance and control. Through these technologies, ontologically different responsible subjects are produced. On the one hand, HIV-negative men are responsibilised via self-protection through the use of PrEP. On the other, men with HIV assume responsibility to prevent others from getting infected by achieving an undetectable status. Together, these analyses demonstrate the implication of different discursive and material forces in producing sexual morality and responsible subjects in stealthing sexual practices.

In light of these divergent views on stealthing and sexual ethics, there is a need for a critical reflection and problematisation on the limitations of purely legal notions of "consent." Suppose we follow Brodsky's (2016) suggestion on expanding the legal language of consent to account for stealthing as violence. In that case, we run the risk of reinforcing the discourse of HIV-positive individuals as "evil perpetrators" who are out to stealth "innocent" HIV-negative people. If we limit understanding stealthing within purely legal notions of consent, we also deny the complexity and dynamic nature of intimate relations (Carmody, 2003), particularly in 
anonymous sexual situations. Perhaps there is a need to reconsider and explore how anonymous sex between MSM is an ethical encounter.

Anonymous sex in restrooms, public parks, gym lockers, and bathhouses is arguably one of the most exciting aspects of urban gay culture. It enables men to share erotic pleasure without having to identify or explain themselves. What is particularly remarkable about anonymous sex, Dean (2009) contends, is that strangers are turned into lovers so briefly that men remain unknown to each other even after the sexual encounter. Instead of fearing the stranger as dangerous because they are unknown and unfamiliar, anonymous sex, as Dean advances, is ethically exemplary because it demonstrates openness to the other: an "intimate encounter with the other that does not attempt to eliminate otherness" (2009, p. 180). That is, anonymous sex may give rise to an ethical relation because it undermines the official rhetoric of fearing strangers due to safety and security. However, some may argue that being open to strangers and taking them as quick lovers is risky and irresponsible. My point here is not to romanticise anonymous sex nor defend the morality of stealthing. Instead, I wish to consider the ethics of anonymous sex by borrowing from Holmes, O'Byrne, and Murray (2010) in their theorisation of the ethics of glory holes and bathhouse sex inspired by Deleuze and Guattari's concept of assemblages.

According to Holmes, O'Byrne, and Murray (2010), the ethics of "faceless sex" in glory holes is based on connections between bodies and sexual environments that respect otherness and movements. It is an ethics based on trust: believing that the stranger will not harm. For the authors, this is not ethics based on autonomy; instead: "It is an ethics of non-autonomy, one that recognizes and enacts the limits of my autonomy, fragile fragmentariness of my identity, virtualized through a hole in the wall" (p. 257). Thus, faceless sex and other anonymous sexual encounters cannot be easily located within the liberal notions of autonomy, rationality, and 
agency because individuals are connected with each other and with other nonhuman forces, producing erotic pleasure through shared vulnerability. This shared vulnerability is based on dependence with strangers, surrendering to the unknowingness of sexuality itself, and being open to transformations (Butler, 2011); transformations experienced through non-identity and bodily connections in anonymous sexual spaces. Moreover, this shared vulnerability also reconstitutes consent as relational because, instead of understanding individuals as autonomous in anonymous sexual encounters, sexual actors are rendered vulnerable and dependent beings.

Brennan (2017) argues that stealthers embody the "bad gay subject" by exposing someone to HIV infection and without the knowledge of sexual partners. However, I demonstrated that stealthing could not be neatly narrowed down to good/bad construction; instead, as I discussed, Pigpen participants have divergent and complex views about stealthing: it is simultaneously unacceptable and irresponsible, but also acceptable and responsible. Thus, this framing moves well beyond the usual assumption that barebacking is bad, dangerous, and risky because it can also be moral and responsible. This chapter contributes to this thesis's larger aims: to emphasise the ontological openness and relationality of barebacking practices. While this chapter sets the stage for considering the morality of stealthing as tricky to pin down, Chapter 4 analyses the multiple effects of HIV science and biomedical technologies in the sexual practices of MSM. What role does HIV scientific and medical knowledge play in MSM's embodied practices of biomedical technologies? How does the consumption of pharmaceutical technologies reshape sexual practices and subjectivities? Focusing on the generative force of HIV science and anti-retroviral drugs enables an understanding of barebacking as a complex practice beyond its current understanding as intentional condomless anal sex in HIV risk contexts. 


\section{Chapter 4: The Productive Effects of HIV Science and Biomedical Technologies in Condomless Sexual Practices}

\section{Introduction}

This chapter examines how HIV science and biomedical technologies transform sexual practices of MSM. In contrast to the previous chapter, which focused on the generative effects of normative ideas of consent and responsibility in conjunction with material forces, this chapter examines the productive effects of HIV science and technologies to attend to their implications in sexual practices. Specifically, I ask: what role does HIV scientific and medical knowledge play in MSM's embodied practices of biomedical technologies, especially in redefining HIV risk calculus; and how does the consumption of HIV pharmaceuticals alter sexual practices and subjectivities?

Guided by posthumanist performative approaches to HIV science and prevention, I argue that the reflexive incorporation of scientific knowledge and biomedical technologies into embodied practices enables MSM to understand the effectiveness and limitations of ARVs, invent different harm reduction measures, and reconstitute notions of "safety" and "risk." Public health research views changes in sexual cultures and behaviours as a result of gay men's misuse of pharmaceutical technologies. That is, with the introduction of ARVs, gay men are believed to have become "“complacent' and display a poor or deficient attitude to risk" (Rosengarten, 2009, p. 61). By contrast, my intervention here is to recast sexual transformations as creatively achieved through the convergence of HIV knowledge and embodied practices. Analysing data gathered from the second phase of the study (i.e., Pigpen online forums) and interviews with nine PrEP users from Toronto (n=6) and the USA (n=3) from the third phase of the study, I demonstrate that using HIV pharmaceuticals for treatment and prevention create varying effects. 


\section{2 | Chapter 4}

On the one hand, HIV drugs allow for the reconsideration of HIV risk, opening possibilities for eliminating anxieties surrounding HIV infection, removing shame and guilt attached to barebacking, and advancing feelings of freedom and empowerment, which further help facilitate pleasure production. On the other hand, the use of PrEP and TasP exposes men to the acquisition of STIs other than HIV and unwanted barebacking sexual acts. Despite these, incorporating pharmaceutical technologies into sexual practices enables queer men to challenge conventional views on barebacking as problematic, disrupting the understanding of barebackers as risky subjects.

The first section provides an overview of the literature on the co-constitutive function of HIV science, with particular attention to Epstein's (1996) and Treichler's (1999) pioneering works. The former attends to the creation of knowledge about AIDS, and the latter examines how knowledge construction, specifically HIV biomedical science, reiterates negative beliefs around homosexuality. While such approaches provide valuable lenses in viewing HIV knowledge as provisional, a richer account is needed to recognise the dynamism of science and biotechnologies in sexual practices, especially as MSM's sexualities are emerging in a context where pharmaceuticals can prevent HIV transmission. I augment these frameworks by drawing on posthumanist performative frameworks to underscore the active role of heterogeneous elements, including discourses and matter, in enacting sexual practices and subjectivities. The second section utilises these frameworks to argue that HIV science turns sex into a measurable object that needs to be predicted and governed while completely disregarding its role in the production of pleasurable sex. In approaching sex as risky and problematic, HIV scientific practices, in turn, shape individuals as responsible for the management of risk. By rendering 
sexual health an individual responsibility, HIV treatment and prevention research emphasise individuals' agency in which MSM bear the onus of responsibility.

To move away from the normative notion of human agency, which views MSM as responsible for the inappropriate use of technologies, I follow the lead of Rosengarten (2009) and Race (2016) in acknowledging the dynamism of HIV prevention technologies and offer a complex and richer account of the effects of ARVs in sexual practices. In the third section, I demonstrate that research participants emerge as "biomedically informed subjects" (Rosengarten, 2009), integrating biomedical technologies and HIV medicine into embodied practices to make sense of the effectiveness and safety of ARVs. Likewise, the embodiment of HIV knowledge informs understandings of uncertainties and limitations by emphasising that biomedical technologies do not wholly provide zero risks. In the fourth section, I suggest that rather than constraining sexual practices, uncertainties about ARVs allow users to invent different harm reduction strategies. Finally, I explore how HIV pharmaceuticals enable MSM to re-examine fears around HIV, open spaces for agency and empowerment, and expose some to additional risks, specifically unwanted condomless sex or "stealthing."

\section{The Productive Functions of HIV Science and Biomedical Technologies}

The approval of Truvada, manufactured by Gilead Sciences, by the Centers for Disease Control and Prevention (CDC) in 2012, was based on growing evidence on the efficacy of PrEP in preventing HIV infection in clinical trials. Foremost of these was the Preexposure Prophylaxis Initiative (iPrEx), which enrolled men and transgender women who have sex with men (MTWSM) from Brazil, Ecuador, Peru, South Africa, Thailand, and the USA. Publishing their findings in 2010, Grant and colleagues concluded that daily PrEP provided 44\% protection from HIV infection. Among participants who had detectable drug levels (i.e., adherent to PrEP), up to 


\section{Chapter 4}

70\% reduced risk was found (Grant et al., 2010). Similarly, the IPERGAY trial conducted in

Canada and France concluded that HIV infection risk was reduced by up to $86 \%$ with high adherence (Molina et al., 2015; Sagaon-Teyssier et al., 2016).

As the success of HIV prevention pharmaceuticals increased, so too did concerns among researchers and providers that users may change their sexual behaviours by taking more sexual risks. Most significantly, fears around "sexual disinhibition" proliferated among medical experts, arguing that with the awareness of PrEP's effectiveness, HIV affected communities “may reduce concern about HIV risk and result in a decline in condom use" (Rosengarten \& Michael, 2010, p. 168). Nevertheless, disinhibition did not materialise in major PrEP studies: iPrEx reported that risk behaviours among participants decreased; likewise, IPERGAY also indicated no increase in at-risk sexual activities. In that study, MTWSM who engaged in anal sex with more than one partner, considered "high risk," were recruited by researchers to participate in the trial (SagaonTeyssier et al., 2016).

Paying close attention to participants' characterisation in IPERGAY reveals that clinical trials imagine and shape the potential user of PrEP. By co-constituting men and trans women who practise anal sex with multiple men as "at-risk," clinical trials inadvertently foreclose possibilities for uptake by others who may not consider themselves as "high risk." Drawing on science and technology studies, Holt (2015) proposes that the criteria through which clinical trials identify the suitable candidate for PrEP impacts uptake. Analysing an early opinion piece written by senior clinical scientists (Youle \& Wainberg, 2003), Holt argues that portraying potential PrEP users as "vulnerable and threatened by HIV" could be a hindrance to those who are thinking about taking PrEP yet hesitant to self-identify as "at-risk" (Holt, 2015, p. 431). By suggesting that trials configure potential users of PrEP, Holt highlights the productive effects of 
research in shaping subjects and objects of HIV prevention, gesturing towards the co-constitutive function of scientific practices. ${ }^{1}$

The pioneering works of Epstein (1996) and Treichler (1999) have been influential in theorising HIV scientific practices as productive, for they offer analytical lenses in examining the differing social effects of AIDS research. Drawing on the sociology of scientific knowledge, Epstein (1996) investigated how AIDS science gained credibility in light of a politically charged environment during the second decade of the epidemic. According to Epstein, obtaining scientific consensus and credibility was a struggle between "experts" and "laypeople": the former expected the latter to be in a position of trusting what they claimed to be true without questioning such assertions. Most importantly, Epstein paid attention to the role of HIV activists who intervened and posed a challenge to the significance of scientific expertise. Epstein demonstrated that by learning the complex language of biomedicine, HIV activists could engage directly with clinical research, establish their credibility, and even change narratives about the effectiveness of treatments and improve access and distribution.

Augmenting Epstein's (1996) earlier work, Treichler (1999) pursues a linguistic analysis of the constructions of AIDS by arguing that the very nature of AIDS is real only when enacted through particular discourses, such as science and medicine. However, rather than taking the objectivity of scientific practices for granted, Treichler looks into the embeddedness of scientific fact-making within cultural and historical contexts, revealing that biomedical discourses reproduce prior social constructions. As an example, the representation of AIDS as a "gay

\footnotetext{
${ }^{1}$ Holt's (2015) suggestion that clinical trials configure users of PrEP is inspired by approaches within Science and Technology Studies (STS) known as the social construction of technology (SCOT), which focuses on the relationship between technologies and users (Pinch \& Bijker, 1984). The SCOT approach, according to Oudshoorn and Pinch (2003, p. 3), understands that different users "could construct radically different meanings of a technology" and that both technology and users change each other as they are brought together. I also incorporate some of these ideas in this chapter.
} 
disease" earlier in the epidemic transformed gay male bodies and "lifestyles" as "high risk," dangerous, and potent: a reproduction of homophobia in biomedical discourses. HIV activists countered the attribution of gay identity with the virus by initiating a dialogue between doctors and patients, scientists and activists, leading to the development and promotion of safer sex. Significantly, while homophobia in HIV research and policy, especially in the USA, delayed the response to the AIDS crisis, activists challenged expertise by scientists, physicians, and drug manufacturers by experimenting with their own drugs, producing their own body of knowledge and technological know-how in developing and distributing treatments.

Writing before the introduction of antiviral combination therapies for HIV treatment, Epstein (1996) and Treichler (1999) highlight the co-constitutive role of scientific practices in producing realities about HIV/AIDS. Both emphasise how HIV activists created and mobilised knowledge to improve treatments by insisting that HIV-affected communities actively participate in the research, testing, and distribution of experimental drugs. Notably, both theorists stress that scientific knowledge-making is a cultural process involving different practices, social actors, interests, and, as I add, HIV biomedical technologies. Now that the biomedicalisation of HIV treatment and prevention is well underway, especially in most resource-rich countries, I suggest that a more robust framework is needed to augment Epstein's and Treichler's contributions. Consequently, I argue for an approach that recognises science's implication in producing objects and the active role of objects in scientific and sexual practices by drawing on Barad's (2007) notion of posthumanist performativity.

Epstein's (1996) and Treichler's (1999) respective theorisations of the creative force of scientific practices are similar to Barad's (2007) conceptualisation of posthumanist performativity, which "focus[es] inquiry on the practices or performance of representing, as well 
as the productive effects of those practices" (p.49). Barad's posthumanist approach, however, pays greater attention to the implication of objects, bodies, discourses, and other nonhuman elements in the production of realities (Ringrose \& Rawlings, 2015). Likewise, Mol's framework advances the notion that diverse (scientific) practices enact different objects and multiple realities. Barad's and Mol's respective approaches to scientific practices as constitutive are consistent with the arguments proposed by scholars of philosophy of science, where research "not only describe but also help to produce the reality that they understand" (Law, 2004, p. 5). These theoretical moves bring forward significant implications for the analysis of HIV medical interventions. $^{2}$

Building on these analytical frameworks, Rosengarten (2009) captures how medical interventions have transformed knowledge about the virus, subjects, bodies, and sexual practices. Indeed, Rosengarten demonstrates that the introduction of ARVs for treatment and prevention altered how HIV works and MSM's sexual cultures. In her consideration of the function of the viral load test, Rosengarten moves away from the notion that the test is simply a device for measuring amounts of HIV in the blood towards analysing its role in the materialisation of other effects. The viral load test, according to Rosengarten, enacts an "undetectable" reading, materialising the presence of the virus and an HIV infected individual with undetectable viral load simultaneously. Thus, the viral load test also co-constitutes a subject position, sustaining Epstein's (1996) argument that the science of AIDS “can make people 'objects' of that

\footnotetext{
${ }^{2}$ The notion of enactment, as I discussed in Chapter 1, is a theoretical move made by Mol (2002) as an alternate to "performance," or "performativity." For Mol, there is no conceptual difference between her notion of "enactment" and Judith Butler's "performativity," where realities are performed or produced through acts or practices. However, due to some misunderstandings about Butler's performativity - where "performance" may connote that there is a "reality" behind a stage-Mol introduces the term "enactment," which carries less intellectual baggage. For Vicki Squire (2005), Mol's conceptual move "opens up distinctions between the concepts of perspective and 'reality', construction, and constitution, as well as pluralism and multiplicity" (p. 153).
} 
knowledge as well as "subjects"” (p. 4). In the same vein, PrEP trials concurrently materialise the efficacy of the drug in HIV prevention by creating the intended user of PrEP (Holt, 2015). Indeed, much like the IPERGAY study, iPrEx also recruited HIV-negative MTWSM who are considered at high risk of HIV acquisition, measured through the number of sexual partners, condomless anal sex, and transactional sex, among others (Grant et al., 2010). At the centre of these trials is the discourse of HIV risk, particularly its prevention, which helps shape the drug's design.

A posthumanist performative account exposes the co-implication of HIV science in producing objects that it presumes separate from research practices. Such a framework recognises biomedical technologies' productive work in materialising the virus, the embodied subject of HIV, and various transformations in sexual practices. However, as far as HIV science is concerned, objects of HIV "exist on the side of nature and not culture," for the virus and biomedical technologies are considered neutral, presumed to be outside of social, political, and ethical questions (Rosengarten, 2009, p. 47). In the next section, I describe how HIV science and biotechnologies' perceived neutrality has crucial implications for the conception of sexual effects and agency.

\section{Sexual Risk and Pleasure in HIV Science}

Advances in biomedical technologies challenged traditional theorisations about sexual risk typically associated with condomless anal sex (Horvath et al., 2020). Condomless sex among MSM emerged as a public health concern due to the perceived increased exposure to HIV infection risk. Accordingly, epidemiological research focused on studying the motivations for why some MSM would intentionally engage in "irrational" behaviour when they should be adequately informed about safer sex (Brisson, 2017). In Chapter 1, I discussed that existing 
research from studies on barebacking were largely based on the notion of "HIV risk." These studies attempted to identify the psycho-social factors that may lead MSM to bareback: gay men were deemed to seek pleasure and intimacy due to various psychological states (CarballoDieguez et al., 2011; Cheuvront, 2002; Mansergh et al., 2002; Shernoff, 2006a, 2006b), including depression (Bancroft et al., 2003). Such studies identified condoms as barriers to intimacy, and condomless sex was equated with greater pleasure by MSM.

For HIV activist and academic Eric Rofes (1998), pleasure is significant for some MSM who engage in condomless sex: "swallowing semen or being fucked have tremendous meaning and provide significant pleasure for individual gay men" (p. 146). However, sexual health campaigns somewhat neglect sexual pleasure by encouraging MSM to practise safer sex through condom use. For Rofes, rather than recognising the desire for barebacking, such campaigns shape MSM as responsible for the mitigation of risk, "expect[ing] them to govern their sexual lives solely upon rational choices" (E. Reynolds, 2007, p. 260). ${ }^{3}$ Instead of addressing the significance of pleasure, HIV prevention co-constitutes pleasure and sex as problematic that needs to be measured and controlled (Race, 2016).

In his analysis of the constitutive function of HIV science, Race (2016) asserts that HIV knowledge promotes desexualisation by disavowing its role in sexual practices and the production of pleasure. As Race notes: "the entire apparatus of HIV clinical and behavioral research $[\ldots]$ is shaped by attempts to manage or otherwise avoid the presumptive negativity of sex” (2016, p. 7). Likewise, Boone and Bowleg (2020) suggest that when it comes to sexuality, public health tends to focus on "problematic" aspects, such as HIV transmission and other STIs. By understanding sexuality through risk-taking, HIV science turns sex into an empirically

\footnotetext{
${ }^{3}$ The juxtaposition of risk and pleasure is identified by Hoppe (2011) as a dilemma, for the understanding of condomless sex as risky by public health contradicts the experiences of pleasure for some MSM.
} 
measurable object, predictable and governable to preserve "sexual health." Such discourses, though, totally evacuate the significance of sexual pleasure. For Foucault (1990), the creation of knowledge about sex demonstrates the mechanisms of power in objectifying and controlling it. ${ }^{4}$ HIV science also creates the impetus for resistance against discourses of risk as a means for "freeing" sex from the grips of biomedicine. Indeed, by shaping barebacking as risky, HIV prevention campaigns inadvertently create the conditions that encourage MSM to resist such discourses and re-establish a sense of freedom. As Crossley (2002) describes: "one of the main reasons why gay men feel attached to certain 'risky' sexual practices is because they provide a psychological 'feeling' of rebellion [...], which, in turn, creates a sense of freedom” (p. 57). However, advances in HIV biomedical technologies interrupt the connection between barebacking and HIV risk while also challenging the link between the foregoing of condoms and resistance against HIV prevention discourses. As González (2019) claims: "What PrEP does is remove the transgression from barebacking," with the potential to returning gay sex to its precondom roots (p. 34). The transformation of HIV prevention from a behavioural to biomedical intervention, González continues, "liberates sex between men from the medical model of HIV/AIDS" traditionally understood within the paradigm of "protected" or "unprotected" sex (p.

\footnotetext{
${ }^{4}$ Foucault (1990) explains that the counterattack against power should not be through the affirmation of sex, but through bodies and pleasure. What does Foucault mean by this? Kane Race $(2008,2017)$ argues that Foucault's notion of pleasure is notoriously vague. In an interview with Jean Le Bitoux, Foucault makes it clear that "pleasure" is open and fluid. He explains:
}

[B]y using the word pleasure, which in the end means nothing, which is still, it seems to me, rather empty of content and unsullied by possible uses - in treating pleasure ultimately as nothing other than an event, an event that happens, that happens, I would say, outside the subject, or at the limit of the subject, or between two subjects, in this something that is neither of the body nor of the soul, neither outside nor inside [...] (Foucault, 2011, p. 389).

In arguing for the conceptualisation of pleasure as an "event," Race (2008) maintains that pleasure might be approached as processual, in which "many actors and concerns, including concerns about safety, are engaged" (p. 421). That is, pleasure can be conceived more productively through posthumanist performativity, in which pleasure is "mutually implicated in [material-discursive] events" (Race, 2017, p. 144). 
36). For González, PrEP and TasP are "rehabilitating" queer sex to its pre-AIDS roots, in addition to making it an "important form of queer kinship" by reducing anxieties around HIV (ibid). This beneficial effect is one of the "unanticipated benefits of PrEP" that includes the enhancement of pleasure and a greater variety of sexual practices among young Black MSM who take PrEP (Quinn et al., 2020, p. 1376). I demonstrate in this chapter that these findings are also evident in my interviews with PrEP users.

Though HIV prevention and treatment pharmaceuticals help mitigate HIV risk and enhance pleasure, acknowledging and discussing sexual pleasure in some public health messaging remains missing or even entirely disavowed. As Boone and Bowleg (2020) suggest, HIV science exclusively views sex through the lens of risk-taking: as "risk, danger, and deficit" (p. 157). While focusing mainly on the constructions of young Black MSM's sexuality, I maintain that negative views around sex, in general, are pervasive in biomedical HIV treatment research and prevention campaigns. For example, interviews with HIV clinicians demonstrate that, while condomless sex is challenging to change, prescribing PrEP allows healthcare professionals to avoid moralising barebacking. PrEP offers a way to manage the potential harms of condomless sex (Nicholls \& Rosengarten, 2019).

Similarly, in a commentary on risk compensation and PrEP, Blumenthal and Haubrich (2014) suggest that clinicians should become "less punitive [...] and more nonjudgmental and understanding" when PrEP users engage in barebacking (p. 912). However, what remains missing is any acknowledgement of pleasure. Instead, the authors guide clinicians to incorporate a comprehensive prevention plan, including promoting condom use and other risk reduction strategies, regular HIV and STI testing, and monitoring PrEP adherence without any mention of pleasure. These studies reveal that biomedical and clinical HIV prevention and treatment remain 
committed to avoiding sex and pleasure by focusing solely on implementing interventions.

Consequently, by approaching sex as dangerous and problematic, HIV scientific practices shape individuals responsible for managing risk (Boone \& Bowleg, 2020).

The management of personal risks, Adam (2005) indicates, is primarily informed by the doctrine of individual responsibility prevalent in HIV prevention campaigns across the Englishspeaking world: "everyone must take responsibility for their own health" (p. 336). Personal responsibility underpins the use of HIV biomedical technologies, where individuals are expected to be continually vigilant against HIV infection (Sandset, 2019). Likewise, individual responsibility reinforces the fear of disinhibition or risk compensation emerging from the use of pharmaceuticals, for technologies are simply seen as "tools" whose effects result from the actions of MSM. In approaching sexual health as an individual responsibility, biomedical HIV treatment and prevention research emphasise individuals' agency. The onus of responsibility is placed on queer men to manage HIV risks.

Though predominant public health messaging maintains that MSM are exercising poor judgment in terms of risk, Race (2003) argues for a different explanation. Race claims that in sexual practices, a "reflexive mediation between embodied habits and medical opinion" is incorporated (2003, p. 377). That is, behavioural changes involving condom use and adaptation of ARVs are, from the outset of the epidemic, an effect of gay men's incorporation of medical knowledge and technologies. Race's intervention here is significant. He emphasises the contribution of biomedicine in sexual practices that moves away from the presumption that MSM are misusing technologies to a recasting of agency as creatively achieved through the embodiment of HIV knowledge (Rosengarten, 2009). 
To move away from the normative notion of human agency, I follow the lead of Rosengarten (2009) and Race (2016) in recognising the implication of HIV science and technologies in co-producing sexual practices and pleasures. Instead of viewing HIV science as a neutral observer that measures relations of cause and effect, I pay attention to its dynamic role in transforming MSM's sexuality emerging from the use of HIV pharmaceutical technologies. As in the previous chapters, I deploy a praxiographic approach to Foucauldian discourses analysis in interpreting the data here, paying close attention to the materiality and historical situatedness of practices in the production of subjects. I also adapt Rosengarten's (2009) approach to HIV prevention technologies as dynamic or agentic to further provide a complex and richer account of the effects of pharmaceutical technologies in MSM's sexual practices. In recognising biotechnologies and MSM as historically situated in, and co-constitutive of a biomedically informed sexual environment, "a form of distributed agency" emerges (Rosengarten, 2009, p. 80). Notions of culpability shift from individual to shared responsibility for the (un)intended effects of HIV science and biomedical technologies. Inspired by these frameworks, I present analyses of the data gathered from the online forums and interviews. In the next section, I demonstrate that participants draw on their embodied experiences with biomedical technologies and HIV medicine to make sense of the effectiveness and safety of ARVs for the treatment and prevention of HIV infection. I suggest that by reiterating the importance of science over "nonscientific" claims and incorporating expert knowledge in sexual practices, PrEP and TasP users emerge as "biomedically informed subjects" (Rosengarten, 2009).

\section{The Implication of Science in Embodied Practices}

This section pays attention to how HIV science and medicine form and inform how some MSM make sense of biomedical technologies. By emphasising the importance of scientific 
evidence, Pigpen and interview participants emerge as biomedically informed subjects acquiring in-depth knowledge about HIV drugs and transmission risks, actively rethinking expertise in their embodied practices, and sometimes challenging medical authority.

For example, Roger, the owner and moderator of the barebacking online community Pigpen, expresses his opinion in the "HIV/AIDS \& Sexual Health Issues" sub-forum regarding the potential harms and issues with early HIV treatment interventions. In this commentary, Roger argues against guidelines set by public health authorities to start ARVs as soon as a person is diagnosed with infection to slow the progression of HIV and prevent further complications (CDC, 2018). Calling the post “My Issue with Early \& Aggressive Treatment of HIV," Roger suggests that a "one size fits all" approach to HIV treatments is problematic because it does not account for individual bodies' response to HIV. He notes that antiretrovirals' potential long-term side effects are unknown, and pharmaceutical companies are primarily interested in earning profit from early biomedical interventions.

While some participants agree with Roger that starting ARVs soon after confirmation of HIV infection is undesirable_- "Drugs are expensive and can do lots of harm to the body"; and: "The important thing to remember about drug companies is that they are out to maximize profits" - others strongly disagree with these opinions. Indeed, some Pigpen members express doubt, describing such views as incongruent with established scientific evidence: "With all due respect $[\ldots]$ your arguments are designed to discredit medicine in general," depicting it as "relying on analogies (like that of a social worker), while not being able to support your thesis empirically." These debates demonstrate the dominant position of the biomedical model throughout the history of the HIV epidemic, marginalising knowledges that are deemed 
"unscientific" (Adam, 2011). The supremacy of scientific knowledge is highlighted further by Jonas, 41 years old from Germany, who invalidates Roger's claims:

The scientific consensus today favours starting early exactly because studies suggest that the damage HIV does to the system significantly outweighs the side effects of ARVs.

This type of response demonstrates the dominance of science in shutting down debates around pharmaceutical interventions, substantiating the argument that expert discourses are implicated in forum participants' embodied practices. By reproducing the authoritative function of science, men from Pigpen also emerge as biomedically informed subjects:

I'm not a doctor. I'm an architect but a reasonably educated person who has become very well informed through my doctor and his entire staff at the Infectious Diseases Department at my local medical centre. This includes other doctors, pharmacologists, researchers and physician assistants. The evidence is becoming overwhelming that starting early is beneficial.

For Aiden, a 60-year-old HIV-positive man from New York, Roger's post is “simply anecdotal and based on experience," not on "the best recommendations of the scientific community" - a community of different experts from the hospital where he gets treated for HIV. While he portrays himself as an architect and thereby does not have the qualifications to produce rigorous medical data supporting his arguments, he nonetheless constructs himself as a biomedically informed subject formed through his experiences as an HIV infected patient. By incorporating acquired medical knowledge, he maintains that early treatments are beneficial.

Other self-identified HIV-positive Pigpen participants further draw on their knowledge obtained via their engagements with HIV experts to express their opinions on the potential benefits of early ARV treatments. For example, Tony, 48 years old from New York, refutes Roger's views by demonstrating his knowledge about viral replication and the effect of HIV on bodies: 
One thing you have all tellingly ignored is that HIV itself has long since been proven to be a SYSTEMIC virus, attacking nearly every system in the body, and does not simply attack the immune system as was previously thought. The mere presence of the virus causes the human body to unleash an overall inflammatory response that further damages itself and that this cycle of progressive damage at deep levels starts from the moment of HIV infection, and for the vast majority will continue until death absent antiretroviral therapy.

Tony's response indicates a subject formed and informed through his engagements with biomedical technologies and HIV science. In supporting early ARV treatments, he embodies much of the expert knowledge he acquired from medicine to stabilise the distinction between authoritative scientific knowledge, on the one hand, and anecdotal opinion, on the other. Nevertheless, though he supports early biomedical interventions, he is also critical of pharmaceutical companies: “A wider appreciation of this is not helped by the undeniable greed and self-interest of the pharmaceutical industry, but the scientific consensus continues to swing in the direction of early treatment being better." On the one hand, Tony says that pharmaceutical companies are profit-driven; on the other, he emphasises the advantages of ARVs-suggesting that forum participants are shaped by complex and competing discourses, though the authority of scientific discourses remains. Additionally, to offer support to starting early treatments, HIVpositive men turn to their embodied engagements with biotechnologies to understand ARVs as efficacious and beneficial. An example:

For reasons only tangentially related to HIV, the doctors started me on meds quite early. The argument detailed by [Tony] for relatively early introduction to antiviral medication is probably the reason why my physician said, when we were speaking this past week, that by all measures, I am in very good health, notwithstanding the presence of the virus in my system (Bryson, 62, HIV-positive, USA).

In articulating his support for early ARV interventions, Bryson draws on his embodied experience with HIV treatments, offering him the capacity to be healthy. Bryson's support for ARVs is informed in part by the medical work done in and around his body via biomedical 
treatments and viral load tests, among others. It suggests that HIV-positive participants are involved in co-constituting the effectiveness of ARVs in the management of the virus.

Like others cited here, Bryson turns to scientific discourses to articulate support for the effectiveness of HIV treatments. Similarly, other Pigpen members reinforce the importance of scientific evidence to make sense of PrEP's effectiveness. For example, in one of the threads found on the "PrEP Discussion" sub-forum, participants mostly agreed that PrEP's success is backed by rigorous scientific research. Contributors in the online forums inadvertently create a dichotomy between rational individuals who trust scientific research and irrational individuals who still doubt its potential side effects. An example:

When I first heard of PrEP in the testing phase in 2011, I was also sceptical. However, study after study after study have proven that fears [of long-term side effects] have no justification. As for the general toxicity of medication, Tenofovir and Emtricitabine (the two medications in Truvada) have been out or in testing for over 20 years and have been successfully used in immunocompromised individuals who are almost always more susceptible to medication side effects. I think at some point, you either trust in science, or you don’t. (Milo, 37, HIV-positive, USA)

Milo can be recognised as a subject who has been contextually shaped by biomedical knowledge on HIV prevention. This knowledge overlaps with the materiality of PrEP, whose safety and effectiveness are proven by science. For Milo, not trusting evidence is unscientific. As he goes on to write: "Don't get me wrong, there are plenty of times science has been wrong, but it literally always beats blind belief, prayer, fear, etc." Another HIV-positive participant from the UK agrees:

Side effects of Truvada are much more common in people using it for treatment than prevention [...]. Don't worry about long term use: the history of PrEP is six or more years old, which is a bloody long time in HIV terms, including all the trials, and Truvada is well tolerated [...]. Don't worry: take the blue pill!

The importance of science is underscored in this testimony. By pointing out that scientific research sustains PrEP's safety and efficacy, this participant maintains that Truvada is shaped by 
science as a stable object. Also, this participant argues that PrEP is multiple by saying that it has lesser side effects for those who use it as prevention than those who utilise it as treatment. Consequently, PrEP's ontological openness is highlighted by describing its two functions: prevention and treatment. Additionally, the varying effects of PrEP are also emphasised: it is simultaneously safe and potentially unsafe.

From the analysis of the online forums, it is evident that some Pigpen participants integrate biomedical knowledge into embodied practices to frame pharmaceutical technologies as effective in the prevention and treatment of HIV. Arguably, this process illustrates what Race (2003) calls reflexive mediation, where gay men actively change techniques concerning HIV risk by incorporating and embodying scientific expertise into sexual practices. Likewise, interview participants emphasise the importance of scientific knowledge with regard to understanding PrEP's safety. In an interview with Dawson, a 34-year-old scientist in Toronto, he explains his concerns with PrEP effectiveness as follows:

I mean, I think the science is fairly robust [...]. But I mean, I know it's not 100 per cent. And I also know that there are a number of people in the world that have seroconverted while on PrEP and while adherent, although they can still count these seroconversions on two hands [...]. So, it's pretty comparable to the risk we take on our day to day lives. You know, you can stay home on your couch and never do anything, but that'll kill you too!

Dawson expresses confidence in PrEP by reiterating the strong evidence offered by science on its effectiveness. Nevertheless, he also acknowledges that certain drawbacks exist: PrEP does not provide complete protection. Despite this, he insists that the risk of seroconversion with PrEP is analogous to quotidian dangers, alluding to the emergence of risk calculation as an effect of PrEP and the scientific evidence that supports its efficacy.

However, in making sense of the success of PrEP, scientific evidence does not always hold primacy. An interview participant Diego, 33 years old PhD Candidate from Toronto, 
describes how his life experiences corroborate PrEP's effectiveness. Diego describes the

following incident with an ex-boyfriend who had seroconverted, potentially exposing him to HIV risk:

I have a story or experience that I want to share with you. A few weeks, maybe one or two months after I started taking PrEP, I started dating someone. I was afraid of telling him that I was on PrEP for the same reasons that I thought he would judge me. But there was something in me that wanted to stop taking PrEP because there were just the two of us. And I thought it made no sense in taking it. At least that's what I thought at that moment. But we broke up just a few months [...]. But what's interesting is that two months or three months after we broke up, this person called me and said that he had been infected with HIV during the time that we were seeing each other. And this was a very powerful experience for me. I wasn't worried about me because I never stopped taking PrEP. And I'm pretty sure that in the sexual interactions we had, there could have been a possibility for me to get infected [...]. And, yeah, that was when I felt that PrEP was efficient. It was working. Because he was with someone else after I left him, and that person was also infected, and so I feel it makes me feel at ease.

PrEP is co-constituted as useful through more than only scientific data. Diego's story demonstrates PrEP's success in preventing HIV transmission through embodied experiences. It appears that PrEP dynamically changes risk calculation among MSM: whether they regard themselves as high or low risk, which may depend on their relationship status but also on how sexually active they perceive themselves to be. When Diego received the news of seroconversion from his ex-lover, he reported that PrEP enabled him to be relaxed and not worry about HIV transmission, thanks to his decision to continue using PrEP.

While the discussion thread I described in this section started with an argument against pharmaceuticals, most online forum participants differed from this view by emphasising the importance of scientific evidence reflexively incorporated into embodied practices. Drawing on accumulated knowledge from their experiences with HIV treatments, HIV-positive men from Pigpen, specifically, defended pharmaceutical technologies' advantages. For these men, starting early ARV treatments has reduced HIV's ability to replicate, enabling HIV-positive men to be in 
"good health." In the same way, forum participants dismissed fears from others who lacked certainty about the potential side effects of PrEP. Combining their knowledge on HIV treatments and embodied practices, most Pigpen participants maintained that ARVs are safe to use, indeed, safer for HIV-negative men. Likewise, one interview participant explained that he was not concerned at all about the effectiveness of PrEP by drawing on the "robust" science that supports it. In addition, a second interview participant described embodied experiences that endorsed PrEP as a highly effective HIV prevention drug, reinforcing evidence already established by scientific research.

Though my focus here was to show how MSM incorporate medical and embodied knowledge to make sense of the effectiveness of ARVs, the next section will demonstrate how HIV science also informs participants' views on the limitations of PrEP. What do these uncertainties do? How does information about PrEP's incapacity to offer $100 \%$ protection transform MSM's risk calculus?

\section{Productive Effects of Uncertainties and Limitations}

The iPrEx and IPERGAY studies, as mentioned earlier, suggest that regular use of PrEP lowered HIV incidence by about 70 to 86 per cent, respectively. By contrast, the CDC estimates that daily PrEP has $99 \%$ protective capacity, by far higher than the clinical trials, with the caveat that one consistently takes PrEP (CDC, 2020). While these trials and statements from the CDC confirm PrEP's effectiveness, HIV science likewise inadvertently exposes some of its limits. As I demonstrate in this section, while participants acknowledge PrEP's advantages in lowering HIV infection incidence, they also recognise some uncertainties concerning eliminating risk. In what follows, I argue that the perceived limitations of ARVs in providing high but not $100 \%$ protection is productive of varying levels and responses to sexual risks. It will be evident that 
PrEP creates acceptable and unacceptable risks, enacting new risk reduction practices, notions of safer sex, and normative expectations and moral economies of risk and subjectivities. Here, unacceptable risk is mainly associated with HIV, and most participants understood sexually transmitted infections as less concerning because they are treatable.

In January 2015, Brad, a 32-year-old HIV-negative on PrEP from the USA, created a Pigpen forum thread to describe his dilemma about engaging in condomless sex. This participant noted that he has been on PrEP for over two weeks, yet still apprehensive about "enjoying sex to the fullest," for he was "still afraid and unsure the medication can protect [him] 99\% even taken every day." Sharing their thoughts about PrEP's protective capacities, some Pigpen participants remarked that although PrEP was not full proof, it was a highly effective HIV risk reduction technology, enabling users to change risk calculus.

For example, responding to Brad's query, Myles, 44, HIV-negative on PrEP from San Francisco, writes: “it's important to be aware that PrEP is not $100 \%$, nothing is, condoms aren't." Consequently, to mitigate these shortcomings, Myles advances the idea that individuals assess risks by acknowledging that some sexual practices may pose higher exposure to HIV infection than others:

The key lies in understanding the risks and being comfortable with them. There's a whole world of difference of risk between going into a bathhouse and getting ten random loads in your ass every weekend to that of fucking raw with a regular FB [Fuck Buddy] that you've talked beforehand about HIV status.

It is possible to observe that PrEP's success as an HIV harm reduction technology produces different risk levels, some more acceptable than others. For Myles, it is pivotal to exercise sound judgement in terms of sexual dangers, which puts the onus of risk calculation and management on individuals. He invites PrEP users to rank sexual practices into greater or lesser risk, being adherent to PrEP ("if you take it daily, it's terribly effective in keeping you negative"), and 
engaging in barebacking with regular sexual partners: "Although I do get a lot of loads, I sort of choose to know who I get them from.” In short, Myles implies that PrEP users should have indepth knowledge about sexual risks and capable of measuring risk incidence. Subsequently, Myles subscribes to the concepts of rationality, calculation, and risk analysis, embodying Adam's (2005) notion of the neoliberal sexual actor, albeit altered by pharmaceuticals.

In his examination of New York City-based PrEP campaigns, Thomann (2018) asserts that the biomedicalisation of HIV prevention "constitutes a pharmaceutical extension of the responsibilised sexual subject" (p. 997): one who acknowledges their own risk and takes necessary steps to reduce risks. In other words, the pharmaceuticalised neoliberal sexual actor is not only pre-emptive but also "biomedically equipped" (p. 1000). As we have seen, some Pigpen participants above arguably emerge as responsible neoliberal sexual actors, for they use pharmaceutical technologies for HIV prevention and are also rational and calculative. But what constitutes an irresponsible neoliberal sexual actor in a biomedicalised sexual context? Dawson, an interview participant, sheds some light on this. Admitting that some sexual risks are higher than others, he inadvertently sets himself apart as a rational sexual actor for not engaging in what he describes as "extremely" risky sexual activities:

I think there is a huge spectrum of things you can be doing, where we can do as we wish, and I don't judge anyone! But then you turn to the odd person, and they're like, 'Oh, I was on the sling last weekend!' And they had, you know, X number of guys. And there's still part of me that is like, 'wow!' But also, they know that it isn't perfect. So, I just don't go to extremes. (Dawson, 33, Toronto)

Dawson appears to be making distinctions between those who are risky, exposing themselves to more significant dangers, and those who are rational, like himself. By shaping some men as more dangerous than others, Dawson points to different types of PrEP users. On the one hand, there are rational, "good" neoliberal sexual actors who understand the complex levels of sexual risks 
and are calculative in making the right choices. On the other hand, some irrational sexual actors take even more significant sexual risks and possibly pushing the limits of PrEP. Notably, the irresponsible sexual actor also emerges as biomedically equipped, although not pre-emptive, for exposing themselves to more significant risks. Additionally, by reiterating that PrEP's preventive capacity in lowering HIV risk is not absolute, Dawson underscores the instability of PrEP in the embodied experiences of some PrEP users. Deploying Mol's (2002) notion of enactment, it becomes possible to recognise that PrEP, in this case, emerges as having multiple realities: simultaneously effective in preventing HIV infection, but also limited in its capacity to protect in “extremely" risky sexual situations.

While these participants recognise acceptable and unacceptable risks, others point out that PrEP users can implement risk management practices to get as close to zero risks as possible. For example, Milo, who earlier commented about the effectiveness of PrEP in the online forums, maintains that while PrEP lowers the threat of HIV infection, the prophylactic drug cannot entirely eradicate HIV risk. Accordingly, PrEP users can incorporate some strategies to make risk "almost non-existent":

Well, PrEP makes that ability pretty damn close. If a top guy is on PrEP and only has a few partners every few months, the risk is almost non-existent [...]. If you are asking and sticking to neg guys recently tested and undetectable guys, there is almost no risk. (Milo, 44, San Francisco)

Milo's response suggests that PrEP users are active in shaping risk management strategies during sexual encounters. Embodying a biomedicalised HIV prevention context, Milo re-shapes the practice of strategic positioning and "serosorting" as providing even more excellent protection from HIV infection with the use of PrEP. Whereas serosorting is commonly understood as HIVnegative men choosing to only engage in sex with individuals they believe to be seronegative, Milo turns serosorting into having sex only with HIV-positive men who have undetectable viral 
loads and other PrEP users. Subsequently, engaging in sexual practices with others who use PrEP or TasP allows biomedicalised MSM to approach HIV prevention as "zero-risk" (MartinezLacabe, 2019). A zero-risk approach is confirmed by another Pigpen participant from Indiana, USA, who agrees with Milo by pinpointing that selecting the "right" barebacking sexual partners is significant in almost eliminating HIV infection risk:

While there is no $100 \%$ surety about anything in life except death and taxes, being on PrEP and some selectivity in partners makes the odds of seroconverting extremely low. This is especially true if you choose to play with poz undetectable men whom you can trust to be taking their meds as directed or other guys on PrEP themselves, and you stay true to taking Truvada daily. (Jared)

According to Martinez-Lacabe (2019), the use of ARVs for treatment and prevention for some men in England engenders the diminishing of non-acceptable risk vis-à-vis HIV transmission. There is some evidence in Jared's response that this is also true for some Pigpen participants. Indeed, "serosorting" and adherence to PrEP emerge as effective harm reduction practices in eliminating the risk of HIV infection, where "the odds get about as close to zero as possible." A zero-risk approach to HIV prevention is partly informed here by the dissemination of information about PrEP's effectiveness and its uncertainties. From this perspective, HIV scientific knowledge and biotechnologies co-constitute new notions of safer sex, risk reduction practices, normative expectations, and moral economies of risk and subjectivities. While men who engage in the use of biomedical intervention are considered safe and responsible, those who cannot or do not want to participate in the biomedicalisation of HIV prevention and treatment are rendered unsafe and irresponsible, excluded from the sexual engagements of some PrEP users.

These discussions demonstrate that PrEP users are also involved in co-constituting uncertainties around PrEP. Yet, rather than constraining, these uncertainties produce ways in which MSM creatively manage risks by calculating and employing some harm reduction 
measures. Contrary to the fears of disinhibition or risk compensation due to PrEP uptake, it appears that PrEP use makes some men more risk-averse by employing measures meant to eliminate HIV risk. By engaging in lesser risky sexual practices, having regular sexual partners, strategic positioning, and "serosorting," these participants emerge as responsible sexual actorsrational, calculative, and accountable. PrEP actively facilitates users to cut their HIV infection rate to zero in making the right risk choices. However, a zero-risk approach to HIV prevention may exclude and marginalise those who do not engage in biomedical prevention.

\section{Productive Effects of Biotechnologies}

HIV science co-creates PrEP as effective while also co-producing some uncertainties about its capacity to offer complete protection, prompting some participants to invent different harm reduction measures and reconstitute notions of "safety" and "risk." This section showcases data from my interviews with PrEP users and aims to demonstrate that PrEP use allows possibilities for eliminating anxieties surrounding HIV infection, removing shame and guilt attached to barebacking, opening more sexual choices, and advancing feelings of freedom and empowerment, helping facilitate pleasure production. Despite these positive effects, PrEP also exposes some users, especially bottoms, to other risks, particularly the risk of unwanted barebacking. Notwithstanding, PrEP enables users to challenge conventional public health and biomedical views on barebacking as problematic, further disrupting the understanding of barebackers as risky subjects.

For example, when I inquired of an interview participant whether there were any changes in his sexual behaviours since starting PrEP, Damien, 50 years old from Los Angeles, who works in education and entertainment, said:

Yeah, I suddenly could be relaxed about having sex. Not that sex was always anxietyprovoking, but there was a little bit of fear. I couldn't let go during sex because I always 
had to be on guard that the other person was not going to do something I didn't want them to do. And once I went on PrEP, I didn't worry about that as much anymore. It took a while! While I worry about what somebody's serostatus was, I didn't worry about any of those things. It made sex a hell lot more pleasurable. Finally, it was just pleasurable.

PrEP allows some MSM to re-examine fears around HIV, which further opens possibilities for more pleasurable sex - an effect of PrEP that other researchers have consistently found (Koester et al., 2017; Sun et al., 2019; Tester \& Hoxmeier, 2020). Dylan, 56 years old from Toronto who works in the health care industry, expresses similar views when I invited him to talk about his thoughts regarding the benefits of PrEP: "Well, not having to worry about contracting HIV while being sexually active.” Besides the reduction of fear around HIV infection, PrEP also permits Dylan to have more confidence: "I'm more confident than I have [been] in the rest of my adult life. So, I think it really is a game-changer. Since going on PrEP, all of a sudden, I could actually engage in sex without being afraid.” Additionally: "Well, I think it has actually made sex less fearful, less risky. I think it has helped reduce the stigma against people with HIV."

Besides the reduction of fear around HIV infection, PrEP also de-stigmatises sex with HIV-positive men. Agreeing with Dylan, Daniel, a 50-year-old interview participant from San Francisco, also conveys that the lessening of stigma opens possibilities for engaging in sexual relations with HIV-positive men. Prompting him to speak about his views regarding the benefits of PrEP, he insists: "Well, obviously, aside from direct HIV prevention, the incredible, really reduced anxiety around sex and the absolute and complete breakdown of an emotional barrier or perceived barrier between positive and negative folks." Similarly, Darren, 26 years old from Connecticut who works in HIV prevention, also attests to easing anxiety around HIV as an effect of PrEP use: 
Obviously, it prevents HIV. There are still other STIs that doesn't protect you against. However, I think the fear of HIV being in the background, either while having sex or after having sex. I think PrEP takes away a lot of that anxiety and extra thinking that has to go into sex or after sex or before sex or whatever.

Just as the participants cited above, Darren elaborates that lesser fear and anxiety help him gain more confidence to engage in casual sex: "I think not as fearful having sexual encounters, hookups or whatever. I wasn't as fearful after starting PrEP.” Likewise, Dominic, a 36-year-old selfemployed participant from Toronto, reiterates that PrEP offers him more confidence to navigate complex sexual situations:

I became more confident in situations where there wasn't a condom available. So, if I'm, for example, in a bathhouse or if I just meet someone like randomly at a bar and we go into the bathroom to have sex, and we don't have a condom. So previously, if I did do something, then I'd feel really guilty and shameful about it. [With PrEP], I wouldn't have the fear as much.

Dominic remarks that PrEP use did not change his sexual behaviour; that is, it did not promote condomless sex, for he was already engaging in the practice before PrEP uptake. Instead, PrEP transformed his feelings about barebacking, making him less fearful and ashamed. What PrEP made possible, as Dominic confirms, is the possibility for engaging in more barebacking: "I would say I probably engaged in more bareback sex [after PrEP use]." Similarly, Dawson also reports that PrEP empowers him to engage in more condomless sex, offering him freedom and pleasure:

I guess the anxiety of HIV risk, which is practically entirely eliminated. And, like I said before, I was engaging to some degree in condomless sex, and I'd say that's continued, probably increased. And that's kind of freedom. (Dawson, 33, Toronto)

When I invited Dawson to speak more about this notion of freedom, he elaborated:

I mean, in some regard, it's kind of like the '70s, again. Not that I was alive in the '70s. Sex among gay men has been so medicalised and institutionalised. And so, with PrEP, I think we're seeing that bathhouse culture can be a thing again. And even sex parties in the city here in Toronto. And obviously, condoms are still an option there. But it can be 
difficult to navigate in those environments, and substances can be relevant. And so, there is a kind of free love idea.

Not only does Dawson embody a biomedicalised sexual environment, but his sexual practices are also historically informed by the entire course of the epidemic: pre-AIDS, during AIDS, and post-AIDS. With the use of PrEP, sex between men, as Dawson conveys, can be returned to what Patrick Moore (2004) describes as "gloriously promiscuous gay male sexual culture" before the onset of AIDS in the 1980s (p. xv). AIDS has devastated sexual cultures and replaced them with a safer sex culture invented by gay men, wherein the promotion of debauchery was thought to be "in poor taste, even potentially destructive to the community" (ibid). However, with the discovery of AIDS as a viral disease in the 1990s, what was then a public health issue (based on clinical care and service) was taken over by "high theory and high science" (Treichler, 1999, p. 34), wherein discourses of "virology, molecular biology, and immunology permeate ways we think and talk about the AIDS epidemic" (ibid, p. 150). Further, with the introduction of ARVs to manage HIV and AIDS in the mid-1990s, gay men's sexuality became even more "medicalised and institutionalised," as Dawson describes. Yet, he is hopeful that with PrEP and TasP, MSM can reclaim the sexual culture lost due to AIDS. ${ }^{5}$

Dawson is nostalgic about a past when gay sex was unrestricted and safe. Concurrently, Dawson's historical positioning living in a biomedicalised sexual environment is enfolded within this nostalgia for a past and hope for a future: "I keep coming back to the idea of sexual freedom. I think it's kind of exciting that we can go to Steamworks [a popular gay bathhouse in Toronto]

\footnotetext{
${ }^{5}$ According to Shernoff (2006a), nostalgia for a bygone era of gay sexuality is a common theme among barebackers, especially among younger gay men who believe in a romanticised vision of pre-AIDS gay sex as liberating. Pocius (2016) picks up on this idea in his analysis of films produced in 2014 addressing the AIDS crisis in the 1980s that evoke certain nostalgia for pre-AIDS gay sexual cultures in Western gay cultural centres, such as New York and San Francisco, which can now be restored by PrEP. Pocius, however, problematizes this in a global context where gay men who have access to PrEP can experience pleasure through condomless sex, while those in the Global South "are treated as forms of bare life" (2016, p. 37).
} 
and have a good time! And the worse thing to worry about is probably gonorrhoea." To reclaim a past when gay sex was uninhibited is not possible without the mediation of biomedical technologies, which may generate a "queer sex freed from the haunting specter of HIV/AIDS" (McNamara, 2013, p. 230).

While some Foucauldian scholars, such as Dean (2015) and Preciado (2013, 2015), claim that PrEP is simply a new technology of biopower that regulates populations (in this case, MSM) and individuals (i.e., PrEP users), participants in this study insist that PrEP allows space for personal freedom. For example, expanding further on his experiences of PrEP as liberating, Dawson testifies:

Now we all have to take daily medication to have the freedom to have sex. But it's nice that there's a separation. You know, you have your three months appointment. Or, you know, every morning when I take my pill, it's medicalized for 10 seconds. In spite of that, you can experience those freedoms. (Dawson, 33, Toronto)

On the one hand, in terms of HIV and sex between gay and other MSM, medicalisation involves naming risky practices as a medical condition, giving medicine authority to "correct" them (Cacchioni \& Tiefer, 2012). On the other, Dawson's idea of medicalisation is limited to the act of swallowing a pill and going to the clinic for STI test. Thus, there appears to be a disjuncture between social theories on the biomedicalisation of HIV and the embodied practices of PrEP users. As Dawson continues: "So maybe this is medicalised differently, but I think it's just less shame involved" in terms of the pleasure of engaging in barebacking.

Race (2016) problematises the rejection of sexual pleasure by HIV science and prevention, which in turn dismisses its entanglement with sexual cultures. Likewise, Calabrese and Underhill (2015) argue that sexual pleasure is often ignored as a benefit of HIV prevention. Instead, the desire to engage in condomless sex is framed as risky. In opposition to this idea, 
however, interview participants in this study found PrEP use as providing greater sexual pleasure from barebacking, corroborating findings by Hughes et al. (2018) and Hammack et al. (2019). ${ }^{6}$

As Dawson further expands on the benefits of PrEP:

I think it's facilitating nature. Public health campaigns work best when they can work in the flow of what is natural, with those kinds of desires. And, in an alternative universe where there is no PrEP, I think I'll just have lesser condomless sex. (Dawson, 33, Toronto)

Dawson claims that PrEP use facilitates sexual desire, an "attraction to condomless sex," which further generates pleasure that is considered “natural." Here, Dawson's views coincide with findings by da Silva-Brandao and Ianni (2020) of a PrEP Facebook group, where participants also emphasise condomless sex mediated by PrEP as pleasurable for it is natural sex, as opposed to "unnatural" sex, or sex with condoms. Interestingly, as a scientist who works in HIV research and prevention, Dawson asserts that PrEP, as a public health intervention, somewhat addresses pleasure. Consequently, Dawson supports Sandset's (2019) analysis of PrEP campaigns in New York, which finds that HIV prevention ads avow desire and pleasure, rather than rejecting it. Seemingly repudiating this, however, is Dawson who later explains that:

You know, as a public health person, it's not ideal [i.e., condomless sex]. But then, as someone who considers sex as a pleasure, there's pros and cons. So that's [i.e., desire for condomless sex and pleasure] just the pros.

\footnotetext{
${ }^{6}$ In a qualitative study by Hughes and colleagues (2018) with the aim of studying potential risk compensation, interviews with PrEP clinical trial participants across the USA reveal that there is a lack of evidence that PrEP use affect sexual risk behaviours. Instead, their findings suggest that PrEP has other benefits beyond HIV prevention, including "pleasure, intimacy, reduced anxiety, and lessened HIV stigma" (p. 396). Specifically, older queer men highlight the positive effects of PrEP in easing anxieties around HIV. Meanwhile, younger participants view PrEP as providing freedom and greater pleasure (Hughes et al., 2018). Likewise, interrogating generational differences in the meanings of PrEP, Hammack and others (2019) maintain that older men ("AIDS-1 generation," born in the 1950s1960s) and younger men ("Post-AIDS generation," born after the 1990s) emphasise the beneficial effects of PrEP in decreasing anxiety and enjoying greater pleasure. By contrast, "AIDS-2 generation" gay men, born between the 1970s-1980s, express ambivalence about PrEP - worrying about increase in condomless sex and promotion of promiscuity (Hammack et al., 2019).
} 
Just as he claims that public health can acknowledge the desire for and pleasure from condomless sex, Dawson also reiterates the pervading notion of barebacking is risky. Yet, Dawson seemingly contradicts this, for he views sexual pleasure as a positive effect of PrEP. Another participant supports this view:

I rarely had anal sex. I always had anal sex with a condom. It wasn't pleasurable whether I was a top or bottom, and I was mostly a bottom. It wasn't as much fun. And once I went on PrEP, that changed. I'm having much more fun now than I was. (Damien, 50, Los Angeles)

Lesser fear of HIV infection due to PrEP use opens possibilities for sexual desire and pleasure and allows users to have more sexual choices. As Damien further points out:

I think the biggest thing is that PrEP allows people to have a lot of choices and how they want to have sex. They can have it with a condom or without a condom. They can have as much or as little sex as they want.

By giving more options to PrEP users regarding sexual practices, PrEP also provides feelings of empowerment. As Damien explains: "It's really going to empower people to have sex the way they want." When I invited him to speak further regarding his views on empowerment, he clarified:

It gives me power. As I pointed out to other people, if you're the bottom, you are trusting the top: whether that is for them to use a condom, whether that is their serostatus, or whatever it is. You're trusting that they're correct. I don't drink, but if you're drunk or high or whatnot, you will not have the wherewithal in that moment to make sure that the top is using the right protection. It [PrEP] allows you to be protected even in those situations. This gives you power.

PrEP offers Damien the capacity to navigate complex sexual situations and to control potential HIV risk exposures, maintaining findings by Sun et al. (2019) that some MSM feel empowered for their capacity to reduce HIV risk. More importantly, for Damien, PrEP empowers bottoms in situations where they rely on others to wear condoms or not lie about their serostatus. In other 
words, PrEP enables bottoms to take greater control of HIV risk management in situations where they can be "stealthed."

In the previous chapter, I discussed that Pigpen participants maintained conventional views around consent concerning stealthing, drawing from liberal and juridical views on individual autonomy. Additionally, in a biomedicalised sexual environment, participants also sustained normative notions of personal responsibility. Taking PrEP is understood as a responsible way of managing risks of stealthing and HIV infection. As I claimed, with the availability of PrEP, individuals no longer need to rely on others for protection; instead, they can depend on PrEP to personally manage sexual risks. For some PrEP users, the notion of selfprotection appears to be empowering to individuals, for PrEP offers capacities to manage stealthing risks, especially for bottoms. As Dawson describes:

And the other aspect is it kind of gives power to bottoms, though I'm not bottoming so much these days. But like with birth control, it gave power to women to control their own fertility, which is why it was so tied to women's rights. But you know, to get the top to put on a condom was a decision of the top. It's probably a huge grey area of sexual assault happening there. So now, a bottom can protect themselves outside of that sexual encounter situation where people can be coerced because it's the bottom who is at a greater risk. (Dawson, 33, Toronto)

Dawson echoes some of the views by Pigpen participants regarding stealthing as a violation of consent. Likewise, Dawson agrees with Pigpen participants on their positive opinions about PrEP's ability to protect in sexual situations where bottoms might be exposed to HIV risks beyond their control. Another participant, Daniel, agrees: "This [PrEP] allows them [bottoms] to have more agency over their sexual health.” Consequently, PrEP uptake allows users to feel empowered in managing HIV risks, confronting previous prevention discourses that rely on others to be responsible for using condoms. Paradoxically, as Martinez-Lacabe (2019) argues, this sense of empowerment is inseparable from self-governance. That is, the feeling of taking 
control of situations that would have been previously uncontrollable entails adherence to PrEP and following testing protocols.

Nevertheless, though PrEP may offer bottoms capacity to control HIV risk management, PrEP may inadvertently expose some users to unwanted sexual acts and behaviours - particularly condomless sex. Dominic pointed out this issue:

I think, and this might be a generalisation, a lot of tops will assume that if you're bottom and you're on PrEP, that you want to be penetrated without a condom.

When I asked him to elaborate further on this, he explained:

It's happened to me when I'm bottoming. I'll say I'm on PrEP and ask them if they had a condom, they'll say: 'Oh, but you're on PrEP.' The assumption is that because I'm on PrEP, that they have free will to just come inside me.

On the one hand, PrEP is empowering for bottoms who might be exposed to stealthing. On the other hand, PrEP use has also made bottoms more vulnerable to undesired sexual acts, such as condomless sex. This is significant, for it points to the varying effects of PrEP not anticipated during clinical trials. That is, though PrEP is recognised as empowering by enabling individuals to self-protect and manage HIV risks, PrEP use inadvertently exposes bottoms to another riskthe risk of unwanted barebacking or stealthing.

In this section, I paid further attention to the possibilities of PrEP in the embodied sexual practices of some PrEP users. PrEP provides benefits, notably in decreasing anxieties around HIV, especially when engaging in barebacking. For some, less fear facilitates pleasure production, further contributing to feelings of freedom and opening more sexual choices. More importantly, PrEP imparts empowerment to PrEP users, particularly bottoms, to experience greater control over HIV risk exposure due to stealthing. Simultaneously, PrEP also creates possibilities for increased risk of infection with HIV and other STIs due to stealthing. In creating both empowerment and vulnerability, PrEP produces different effects on some participants' 


\section{Chapter 4}

embodied sexual experiences. Notwithstanding, PrEP use allows MSM to re-signify what safer sex means. As Dominic continues: "I think we need to redefine what safe sex means because, historically in all the literature and everything else around HIV and AIDS, safe sex meant safe from HIV. I think for me, safe means safe from HIV because that, to me, is the bigger risk."

\section{Conclusions}

By showing that MSM who use PrEP and TasP incorporate accumulated knowledge drawn from their experiences with HIV medicine, this chapter has argued that changes in sexual risk behaviours are always already embedded in and co-constituted by scientific evidence. Participants are formed and informed through engagements with biomedical technologies by supporting and sustaining the safety and effectiveness of ARVs, while simultaneously shaping dissenting views against scientific evidence as anecdotal and irrational. Through the incorporation of HIV knowledge into sexual practices, participants emerge as biomedically informed subjects. Conversely, participants also acknowledge the limitations of and uncertainties about PrEP by reiterating that some sexual practices pose a higher risk of exposure to HIV than others, even with the use of the prophylactic drug. Most PrEP users can manage these limitations by making the right choices and creating different harm reduction strategies to protect themselves against HIV infection. Individuals reworking their sexual behaviours integrate risk reduction measures as well as scientific knowledge and biomedical technologies into their sexual practices .

Paying attention to the productive function of HIV science acknowledges its entanglement in the sexual practices of MSM. For most participants, the use of HIV pharmaceuticals opens possibilities for freedom, offering more choices, and perhaps most importantly, aids in the achievement of pleasure. Despite these positive effects, PrEP also 
exposes some users, especially bottoms, to other risks, specifically unwanted barebacking. Notwithstanding, integrating pharmaceutical technologies into sexual practices allows some men to challenge conventional views on barebacking as risky and problematic. Recognising the implication of HIV science in the materialisation of sexual effects shifts responsibility from individuals to a collective assemblage of technologies and biomedical knowledge. While public health maintains the presumption that MSM are responsible for sexual behavioural changes due to PrEP or TasP misuse, the posthumanist performative approach I utilised here recasts HIV prevention and treatment as active participants in shaping sexual practices. This chapter thus responds to Race's (2016) call to attend to science's active role in shaping sexual practices and forms of pleasure.

Public health approaches to HIV treatment and prevention are based on neoliberal assumptions on personal responsibility and rational calculation of risk, adapted by barebackers who emerge as "neoliberal sexual actors." While Adam (2005) exemplifies MSM who engage in condomless sex deploy neoliberal moral reasonings, other scholars link these discourses to creating a sexual environment where the violation of such norms becomes possible. From this perspective, MSM engage in sexually risky activities, like barebacking, for the practice provides feelings of freedom by transgressing the demands of safer sex. However, the uptake of PrEP risks defeating the purpose of barebacking as resistance against the imperative to optimise health, for the prophylactic drug intensifies biopower's capacity to discipline sexuality (Preciado, 2015). Dean (2015) argues that barebacking mediated by pharmaceuticals is not freedom but an extension of biopower's reach inside human bodies. Yet, contrary to this idea, participants reported experiencing sexual freedom, pleasure, empowerment, and other PrEP use benefits, 
suggesting that PrEP contributes to disrupting the conventional understanding of barebackers as problematic subjects.

In the moral economy of risks, barebacking is considered dangerous, and barebackers are understood as culpable for transmitting HIV (Race, 2003). However, rather than irresponsible, rebellious, or being disenchanted with discourses of rationality and calculability (Robinson, 2014), participants emerged as responsible subjects by using PrEP, TasP, and other harm reduction measures to protect themselves and others from HIV and other STIs. Building on insights from the posthumanist performative approaches I outlined in this chapter, it is possible to argue that participants' appearance as responsible sexual actors is an effect of their relations with HIV science and pharmaceutical technologies. In other words, HIV scientific discourses and the materiality of PrEP co-constitute participants as biomedically informed subjects who integrate both HIV scientific and medical knowledge into embodied practices. The convergence of scientific expertise and sexual practices contest understandings of risk and safety, offering new ways of engaging in barebacking that is worry-free, less risky, more pleasurable and empowering.

In Chapter 2, I argued that despite the operationalisation of barebacking as a single and coherent practice by HIV science, barebacking in MSM's embodied practices was fluid, complex, and multiple. Indeed, as I demonstrated, by adapting some harm reduction strategies, including serosorting and PrEP, condomless sex in the online discussions of Pigpen participants concurrently appeared to be safe/risky, challenging the framing of barebacking as dangerous behaviour. This chapter strengthens these arguments by showing that PrEP disrupts the link between HIV and condomless sex while also challenging the notion of barebackers as "risky" subjects, calling into question the ontological claim that barebacking is coherent and singular and 
contributing further to the thesis's larger aims. By breaking the link between barebacking and HIV, biomedical technologies engender the transformation of sex without condoms between MSM as less fearful, more pleasurable, and empowering. These transformations would not be possible in the absence of proof on the effectiveness of ARVs as established by HIV science. Consequently, the efficacy of biomedical technologies is more than just "objective" knowledge, for ARVs also participate in the shaping of biomedically informed, responsible and safe subjects, as well as sexual cultures and pleasures.

Despite these promising effects, PrEP remains a "reluctant object," for some MSM are uneager to adopt PrEP (Race, 2016). In the final substantial chapter of this thesis, I pay attention to the unexpected effects of PrEP beyond its intended use as an effective HIV prevention by focusing on stigmatisation as an unforeseen effect arising out of PrEP's introduction to the broader population. Why is stigmatisation persistent even though PrEP opens possibilities for dissociating HIV risk from gay sex and condomless sex? How is stigma enacted, especially in PrEP users' relations with others - particularly sexual partners, friends, families, and healthcare professionals? How do PrEP users combat PrEP stigmatisation? 


\section{Chapter 5: "I felt judged to be on it": Rethinking Moral Panics and Stigmatisation around PrEP}

\section{Introduction}

Upon its introduction, PrEP generated some moral debates among queer men. Famously, David Duran, writing for Huffington Post, coined the term "Truvada Whores" to express his opposition against the prophylactic drug. He believed that PrEP would encourage men to engage in barebacking (Duran, 2012). ${ }^{1}$ Other critics, such as Michael Weinstein, President of AIDS Healthcare Foundation, even called it a "party drug" used by people who engage in riskier sex. Truvada Whores, Weinstein believed, were unable to responsibly adhere to taking PrEP every day (Garcia, 2016). According to González (2019), such adverse reactions reflected the rise of "a new gay sex panic" based on the spectacle of promiscuity and spread of STIs, echoing earlier moral panics ensuing from the AIDS crisis (p. 32). ${ }^{2}$ By contrast, some PrEP users reclaimed the label by promoting the hashtag "\#TruvadaWhore" on social media and printing T-shirts as a means of queer appropriation. Reclaiming the label Truvada Whore, aptly described by Haire (2015) as a "subversive new identity category," poses a challenge to PrEP stigma, encouraging PrEP users not to feel ashamed for taking the initiative to prevent HIV infection (p. 243).

In the previous chapter, I showed that embodied practices of biomedical technologies are entangled with HIV scientific knowledge, allowing MSM to reconstitute meanings of "safety"

\footnotetext{
${ }^{1}$ Note that Duran (2017) wrote a follow-up piece in Huffington Post titled "An Evolved Opinion on Truvada," where he acknowledged that his earlier views about "Truvada Whores" were "outdated and a bit prudish."

${ }^{2}$ The AIDS crisis produced moral panics based on the perceived threat of gay men for causing their disease as a result of their sexual practices (anal sex) and habits (promiscuity) (Weeks, 1986). Moral panics are characterised by "flurries of social anxiety, usually focusing on a condition or person, [...], who become defined as a threat to accepted social values" (p. 96). In the case of AIDS, gay men were given the primary role as disease carriers, making it easier to attribute blame to the victims, further intensifying fears leading to stigmatisation and social exclusion (ibid). For more discussions around moral panics and AIDS, see Watney (1994). Specifically, Chapter 1: “AIDS, 'Moral Panic' Theory, and Homophobia" in Practices of Freedom.
} 
and "risk." Mediated by pharmaceutical technologies, barebacking for some MSM becomes pleasurable, liberating, and empowering: co-constituted effects by a collective assemblage of technologies, HIV knowledge, and embodied practices. Equipped with pharmaceutical technologies, PrEP and TasP users assume the position of neoliberal sexual actors by adapting notions of personal responsibility and risk calculation. While MSM who adopt HIV biomedical interventions emerge as rational subjects in the moral economy of risks, in the moral economy of sex, they materialise as imprudent, for pharmaceutically mediated individuals are rendered "sexual deviants," engaging in risky sexual behaviours by using ARVs. This chapter challenges these binaries by exploring the ambiguities of moral panics connected to PrEP and the sites where PrEP stigma is enacted and challenged. I show that moral economies of HIV risk linked with public health discourses and moral economies of sex associated with sexual practices are always already mutually co-constituted and co-constitutive, producing stigmatisation and other effects.

Inspired by science and technology studies, queer theorist Kane Race (2016) argues that such varying effects of PrEP are produced through encounters or events, where material transformations happen. During events or encounters, various human and nonhuman elements are performative, "in the sense that they participate in how the event unfolds" (p. 5), producing different realities. Understanding PrEP as performative or active in events is similar to previous conceptualisations by Rosengarten and Michael (2010) of HIV prevention as an assemblage "composed of drugs [and], inevitably, of bodies, knowledges [...]" (p. 180). PrEP emerges as processual in assemblages, where PrEP is developed as ontologically emergent through practices (Rosengarten \& Michael, 2009). Focusing on moral panics ensuing from the introduction of PrEP, Race develops an understanding of aversion to PrEP as emergent through the connection 
of HIV prevention with the fear of sex and pleasure. In encountering negative attitudes about sex, PrEP emerges as a "reluctant object," despite its proven effectiveness. Some MSM are reluctant to adopt PrEP due to stigma, impacting slow uptake (Race, 2016). From this perspective, HIV prevention, including PrEP, is inextricable from HIV/AIDS knowledge and beliefs, producing unexpected effects beyond PrEP's intended use as an effective HIV prevention. ${ }^{3}$ That is, the materialisation of PrEP as a reluctant object due to perceived stigmatisation is an unforeseen effect arising out of its introduction to the broader population outside of clinical trials. Understanding the materialisation of PrEP as a reluctant object through the lens of events or assemblages enables an appreciation of the co-constitutive roles of technologies, historical, and socio-material contexts in co-producing moral panics and stigma.

Drawing on frameworks of posthumanist performativity, I argue for a reconfiguration of sex panics and stigma as emergent through historical and socio-technological contexts. I demonstrate that PrEP stigmatisation is co-constituted by the history of HIV/AIDS, cultural fears around sex, and normative beliefs around safer sex. Together with the materialities of condoms and PrEP, such discourses generate different enactments of stigma within interpersonal, intrapersonal, and institutional relations of PrEP users. First, citing the examples of oral contraception (“the pill”), HIV treatments, and PrEP, I explain how posthumanist performative frameworks are useful in recognising the active role of sexuopharmaceuticals in shaping sexual panics and stigmatisation. Second, offering an analysis of interview data with PrEP users from Connecticut, Los Angeles, San Francisco, and Toronto, I demonstrate that participants acknowledge PrEP stigmatisation as co-constituted by fears around HIV, sex, pleasure, and barebacking, generating different experiences of stigma. Third, I illustrate that PrEP

\footnotetext{
${ }^{3}$ The notion of unexpected effects is borrowed from Nelson's (2018) piece in Mosaic: "The unexpected effects of the HIV prevention pill".
} 
stigmatisation takes many forms in the embodied practices of PrEP users, commonly encountered as slut-shaming, rejection, concealment, discrimination, internalisation, and contestation-experiences considered as enactments of stigma. I conclude by advancing some potential implications of the reconfiguration of stigmatisation through posthumanist performative frameworks.

\section{Posthumanist Performativity, Sexuopharmaceuticals and Moral Panics}

In the introduction to Moral Panics, Sex Panics, cultural anthropologist Gilbert Herdt (2009) identifies sex panics as culturally constituted and mediated by the state, media, and various interest groups. During sexual panics, he describes: "the cultural imagination becomes obsessed with anxieties about what [...] evil sexuality will do to warp society and future generations" (Herdt, 2009, p. 5). According to this view, normative discourses produce moral panics and panic icons, considered as threats to normative social order and are subjected to stigmatisation and social exclusion (ibid). Foucault's (1990) work is informative here in elucidating the role of discourses in the production of panic icons and moral panics. Foucault argues in the History of Sexuality, Volume 1 that normative discourses around sexuality function to establish sexual deviance or perversions and to create specific individuals - the hysterical woman, the homosexual, and, we might add, the Truvada Whore. By naming these deviants, power activates its mechanisms to control morally, regulate, survey, and discipline individuals and groups (Herdt, 2009).

Augmenting these ideas, queer scholar Paul B. Preciado (2013) argues that the surveillance, disciplining, and control of sexuality is more than just discursive effects, for contemporary sexuality is mediated by pharmaceutical technologies. From the contraceptive pill ("the pill") for women, hormones for trans people, and PrEP for HIV-negative MSM, Preciado 
contends that sexuopharmaceuticals co-constitute "pharmacopower" through technologisation. Drawing on Foucault's works, Preciado develops his concept of “pharmacopower” as a recent iteration of biopower, which now penetrates the molecular level through various pharmaceutical technologies. Similarly, historian and sociologist Johanne Collin (2015) builds on Foucault's theorisations to advance an approach to biomedical drugs as "living objects and actors," actively “transforming perspectives and shaping contemporary subjectivities" (p. 74). Arguably, by recognising pharmaceuticals' transformative power, both Preciado and Collin offer a theoretical shift towards recognising pharmaceuticals' co-constitutive materiality in practices. I argue that this idea is closely related to Barad's (2007) posthumanist performativity.

As discussed earlier, Barad extends post-structuralist theories of performativity by drawing attention to the active role of objects, bodies, discourses, and other nonhuman things in the production of realities, bringing performativity into direct engagement with matter (Rosengarten, 2004). Recall that the concept of intra-action is used by Barad to challenge the assumption that entities pre-exist their relations. Barad's posthumanist performative approach undertakes an ontological shift towards understanding materialisations as emergent through intra-actions (V. Squire, 2015). In my view, Barad's theorisation of posthumanist performativity is related to the concept of "events" or "assemblages," which also offers an account of effects or realities as emergent and enacted through connections of discursive and material forces. Approaching moral panics and stigmatisation through posthumanist performative approaches allows for an analysis of the multiple experiences or enactments of stigma in different contexts. To develop this further, I now demonstrate the productive role of sexuopharmaceutical technologies in creating moral panics and stigmatisation by focusing on the pill, PrEP, and 
antiretroviral treatments. I follow this by illustrating a posthumanist performative analysis of the interview data that speaks to views and experiences of PrEP stigmatisation.

Sexuopharmaceuticals and Sex Panics. Drawing connections between PrEP and the pill, Preciado (2015) suggests that both sexuopharmaceuticals not only operate on the logic of “chemical condoms" designed to prevent sexual risks (whether HIV or pregnancy); but, most importantly, represent the mediation of sexualities by biomedical technologies. Apart from mediating sexualities as chemical condoms, both the pill and PrEP arguably also engender sexual panics. Bringing the concept of assemblages into play, it is possible to conjecture that sexual panics are co-constituted by discursive and material forces, where sexuopharmaceuticals are also active in the production of widespread fear and mass hysteria.

Analysing societal attitudes ensuing from the introduction of the pill and PrEP, Myers and Sepkowitz (2013) inquire if both pharmaceutical technologies represent a case of déjà vu, since both have produced fears concerning promiscuity and sexual risk behaviours. When the pill was first marketed to the American public in the 1960s, conservative media took an alarmist stance by portraying it as a license for promiscuity. It was thought that the pill would encourage women to "sleep around" because sex may no longer have to result in pregnancy. Women, especially unmarried ones, were made scapegoats and regarded as uninhibited and undesirable (Watkins, 1998). The pill, then, through its entanglement with normative sexual codes, actively shaped the production of sex panics concerning women's sexuality. Likewise, the introduction of PrEP has sparked moral debates, most notably among queer men, where the prophylactic drug is linked to promiscuity, irresponsibility, and naïveté (Pawson \& Grov, 2018). The figure of the Truvada Whore has produced a "new moral panic" based on the belief in promiscuity and the 
spread of sexually transmitted infections (González, 2019). ${ }^{4}$ Thus, reminiscent of the introduction of antiretroviral treatments, Race (2016) advances that PrEP has provoked anxieties attributed to the "moral danger" of "gay sexual pleasure" (p. 14), especially as it relates to condomless sex or barebacking.

The introduction of protease inhibitors in the mid-1990s dramatically transformed HIV (at least in industrialised countries) from a terminal disease to a chronic manageable condition, challenging the link between HIV, AIDS, and death, as well as the panic against homosexuality that followed. ${ }^{5}$ The provision of antiretroviral treatments has created the "normalisation of HIV," understood as a turning point, for HIV-positive people began to be recognised as "regular, unremarkable citizens, just like anyone else" (C. Squire, 2010, p. 407). The biomedicalisation of HIV treatment shifted the needs of HIV-positive individuals from disease, dying, and death to “everyday" problems linked to living with HIV (Flowers, 2010). While advances in biomedical treatments resulted in the normalisation of HIV, a new moral panic ensued beginning in the mid to late 1990s based on a feared "second wave" of HIV infections among gay men in major urban centres across North America (Rofes, 1998).

As I have discussed extensively throughout this thesis, one particular practice held responsible for the steady rise in HIV infections was "barebacking" or "raw sex" (Rofes, 1998).

\footnotetext{
${ }^{4}$ Fears around "sexual disinhibition" proliferated among medical experts, arguing that HIV affected communities "may reduce concern about HIV risk and result in a decline of condom use" with awareness about PrEP's effectiveness (Rosengarten \& Michael, 2010, p. 168). However, disinhibition did not materialise in major PrEP studies. For example, Hojilla and colleagues' (2016) analysis of counselling notes from San Francisco's PrEP Demonstration Project suggested that, with very few exceptions, most men did not abandon existing risk reduction strategies upon initiation to PrEP. Freeborn and Portillo (2017) also concluded that they did not find any conclusive evidence of increased sexual risk-taking among PrEP users in their literature review. Likewise, in Chapter 4, I demonstrated that PrEP users in this study might be more "risk-averse" after PrEP initiation by employing measures meant to eliminate HIV risk.

${ }^{5}$ From the proliferation of the term "gay plague" to describe AIDS, queer men have been given the primary role in spreading HIV (Dowsett, 2009). Certain sexual practices (anal sex and promiscuity) were associated with the disease, which further strengthened hostility towards homosexuality (Weeks, 1986), resulting in blaming the victims of the disease. To be diagnosed with HIV meant that one was engaging in unsafe behaviours (Sontag, 1988). In short, people with HIV and AIDS were accused of bringing the disease upon themselves for being irresponsible.
} 
According to some, barebacking became a general practice due to protease inhibitors (Halkitis et al., 2003; Kagan, 2015; Shernoff, 2006a). ${ }^{6}$ The introduction of the term "barebacking" in public (e.g., through Stephen Gendin’s controversial article titled "Riding Bareback” published in 1997) initiated intense debates in gay communities and among HIV/AIDS stakeholders. Some believed the practice was to blame for the continuing epidemic among gay men. In particular, gay activists and writers blamed "circuit boys" and HIV-positive men for causing continuing infections (Rofes, 1998). This sexualised moral panic led to the creation of barebackers as deviant subjects.

As part of the moral economies of risk, public health discourses co-constitute the moralised economies of sex, alongside materialities of condoms and biomedical technologies, helping shape moral panics surrounding barebacking. Indeed, public health messaging coconstruct barebackers as deviant subjects for transgressing normative safer sex practices. McNamara (2013) maintains that MSM who observe safer sex measures are considered respectable because their sexuality is portrayed as mature, responsible, and healthy. By contrast, barebackers are labelled over-sexualised and depicted as defiantly embracing "unsafe sex" (Ashford, 2010). ${ }^{7}$ Such discourses not only shape norms that define "safer sex" practices, but they also produce barebackers as panic icons for breaching these norms (González, 2010). Against this backdrop, barebacking is construed as a dangerous practice, and barebackers are risky and disease-carrying subjects. However, the introduction of PrEP (much like protease

\footnotetext{
${ }^{6}$ It must be noted that gay men were already practising condomless sex even before the nomenclature, known simply as "unprotected anal sex" (Rofes, 1998, p. 196).

${ }^{7}$ According to Grov (2004), risky behaviours are linked to the labeling of barebacking as taboo, leading to the belief that the practice is "wrong." An inappropriate practice that motivates MSM to fulfil negative stereotypes. Critically analysing these explanations, queer theorist David Halperin (2007) argues that such linking of MSM's motivations for risk-taking to "psychological disorders" produces MSM as pathological subjects. Situated within the discourse of AIDS and homophobia, barebackers emerge as symbols of AIDS and destruction, reproducing the notion of gay men as harbingers of disease (González, 2010; Kagan, 2015).
} 
inhibitors in 1996) threatens to break the link between HIV and barebacking, further posing a challenge to the moral panic related to "safe" and "unsafe" sex. While PrEP may be disrupting Leo Bersani's (1987) claim that "the rectum is a grave," the introduction of the prophylactic drug (re)produces an old panic against gay male promiscuity through the Truvada Whore (González, 2019).

Notwithstanding PrEP's interruption of the link between barebacking and HIV transmission, negative beliefs attached to promiscuity, barebacking, HIV and other STIs remain persistent, engendering hostility, fear, and anxiety against sexual practices that violate "safer sex.” Consequently, the panic ensuing from PrEP produces stigmatisation. Indeed, as Grimm and Shwartz's (2018) describe, PrEP users face stigmatisation by being accused of promiscuity for taking PrEP and engaging in barebacking. Pawson and Grov (2018) further maintain that the understanding of barebacking as a social problem has been extended to PrEP users, leading some individuals to conceal their use of the drug. Concealment of PrEP use, "a kind of PrEP closet," is, in fact, widespread among early adopters of PrEP in Toronto, who were terrified of being considered promiscuous or seen as engaging in barebacking (Grace et al., 2018, p. 26).

Negative beliefs about PrEP users are also recurring among some medical providers, who reinforce the stigmatisation of condomless sex by refusing to provide PrEP due to fears in risk compensation or the abandonment of condoms by PrEP users (Golub, 2018). On account of this persistent stigmatisation, some PrEP candidates are reluctant to talk about PrEP with healthcare workers, making this a relevant barrier to access (Eaton et al., 2017), in addition to the cost of PrEP, which remains a significant deterrence (Kay \& Pinto, 2020). Despite these obstacles, some PrEP users have pushed back against stigmatisation by reiterating that PrEP is a useful harm 
reduction tool (Pawson \& Grov, 2018), helping decrease HIV fears and open possibilities for sexual pleasure (Tester \& Hoxmeier, 2020).

These discussions reveal that the introduction of PrEP in the sexual practices of MSM produces different effects beyond its consideration as a useful biomedical tool. The uptake of PrEP inadvertently creates panic and stigmatisation, generating various material effects, such as fear of judgment and slower uptake. These studies attest to the view that PrEP embodies the sex panic about gay men's promiscuity, dating back to the original "gay men's health crisis" (González, 2019, p. 32), through which the prophylactic drug materialises as a social problem with the dynamic potential of creating other effects. In what follows, I expand on this idea by analysing how PrEP users make sense of the historical formation of the Truvada Whore to recognise that PrEP is implicated within different assemblages that help enact sexual panics and stigmatisation. In so doing, I emphasise the mutual entanglement of the object of PrEP and stigma with other social issues, including HIV stigma, negative beliefs around sex and pleasure, as well as barebacking.

\section{Historical Formations of PrEP Stigma}

The rise of the Truvada Whore as a new panic icon in light of the introduction of PrEP echoes fears about gay male promiscuity that initially emerged from the AIDS crisis. As González (2019) maintains:

The Truvada Whore [...] revitalizes an old narrative [...] that anal sex between men is still, first and foremost, a matter of HIV, STIs, and sexual risk-queer eroticism contained within the HIV/AIDS 'contagion narrative,' as it has been for over thirty-five years. (p. 37)

For Race (2016), the aversion to PrEP not only reinforces the contagion narrative but also reveals unease with gay sex: "despite its biomedical lineage, [PrEP] has thus far been unable to shake its contaminating associations with the apparent excesses of sexual pleasure" (p. 12). For these 
theorists, apprehensions of PrEP are actualised through its relations in specific historical contexts co-constituted by HIV/AIDS, sexual risk, and anxieties around sex. Similarly, informants in this study recognise that the historicity of HIV/AIDS and anxieties around sex, intimacy, and pleasure are implicated in the formation of PrEP stigma. ${ }^{8}$

Indeed, some interview participants understand PrEP stigma as informed by the moralism attached to the fear of sex and pleasure. As an example, when I asked Damien, 50 years old from Los Angeles, to comment whether he had any apprehensions telling others about his PrEP use, he confided: "Sure, early on. Then I realised it's just sex. That's just shame over your sexual practices and what you do." Similarly, Dominic, 36 from Toronto, discussed that the stigmatisation of PrEP users "comes from a place of complete lack of education and ignorance," related to their beliefs surrounding sexuality: "I get frustrated because such ignorance [...] probably comes from [...] their fear and misguided projection of their own sexuality."

The discussions above demonstrate that some interview participants connect PrEP stigma with the inherent moralism attached to the fear of sex and pleasure, which they recognise as productive of shame. As an affective response to sex panic, shame is a powerful emotion that establishes "some sexualities as normal and others as disgusting or unspeakable" (Irvine, 2009). ${ }^{9}$ For queer theorist Michael Warner (2000), it should not be surprising that sex has become a source of shame for "sex is an occasion for losing control [...] [which] fills people with aversion

\footnotetext{
${ }^{8}$ For some PrEP users, including study participants from Grace et al.'s (2018) qualitative focus group interviews, the pervasive negative beliefs about PrEP reveal structural-level stigma around sex and gay sexuality.

${ }_{9}^{9}$ While "affect" in Irvine's (2019) work broadly means "emotions," I understand affect in this thesis simultaneously as emotions that move through an "affective economy" and as the capacity of things and bodies to affect one another (Ahmed, 2014). "Affects" (as in emotions) circulate between subject and objects, producing other capacities and potentials. The acknowledgement of objects as productive of affects resonates well with Deleuze and Guattari's notion of "affect," which recognises that things and bodies have the "ability to affect and be affected" (Massumi, 2004, p. xvii).
} 
and shame" (p. 2). ${ }^{10}$ Appearing to agree with these theorisations, Damien explains that PrEP stigmatisation is an effect of negative beliefs around sex: "I understand why some people slutshame. I mean, sex is a really powerful thing." Besides repulsion to sex, Damien also elucidates that the history of AIDS has actively shaped PrEP stigma. He further explains:

Part of why HIV was allowed to hit and strike was because people were ashamed of it and would not talk about it, would not talk about how you could prevent it. You know, going back to the 80s. (Damien, 50, Los Angeles)

Damien acknowledges that aversion to HIV and sex created a negative response to the AIDS crisis, leaving hundreds of young queer men dead.

Likewise, Diego alludes to the implication of the history of AIDS when expressing his opinions about PrEP stigma: "I think that it [PrEP stigma] is closely related to HIV as a historical phenomenon that took the lives of many people. I think that [it] has not been forgotten, or there hasn't been any type of collective healing." Like other participants above, Diego agrees that PrEP stigmatisation emerges in a context where queer men's sexuality is linked to contagion. Diego further implies that the stigmatisation of PrEP is co-constituted by conventional views around safer sex, which, according to him, are due for an update:

I think that we, as a gay community, are just focusing on what happened but not really seeing the evolution of the epidemic in the 80 s to what it is now. I think people are just focusing on what happened and not letting go of the idea that the only type of gay sex is with a condom. (Diego, 33, Toronto)

\footnotetext{
${ }^{10}$ Warner is not the only queer theorist who links shame with sexuality and sexual pleasure. For example, Halperin (2007) argues that due to the abjection of homosexuality in heteronormative societies, homosexuality has become a relentless source of shame and disgust, shaping desires and pleasures. As he writes: "our very desires and pleasures are constituted in relation to parts of ourselves that are causes of irredeemable shame in our social experience of them" (Halperin, 2007, p. 70). Our inability to overcome shame and disgust might be due to their connection with what we consider desirable and pleasurable. Ahmed explains: "disgust is deeply ambivalent, involving desire for, or an attraction towards, the very objects that are felt to be repellent" (2014, p. 84). In other words, disgust and shame are conflicting because they are mutually constituted by pleasure. Sedgwick and Frank (1995) also argue that shame is an exemplary affect on account of its perpetual link to pleasure: "shame is characterized by its failure ever to renounce $[\ldots]$ its relation to the desire for pleasure" (p. 23).
} 
Diego's views about PrEP stigmatisation are strikingly complex, for not only does he contextualise it within the historicity of AIDS but also through safer sex norms mediated by condoms. The use of condoms, Junge (2002) discusses, is a "doctrine" of safer sex, embodying the idea of "protection" by reducing the risk of HIV. Within this framework, practising condomless sex is considered irrational, dangerous, and pathological. For Diego, however, the privileging of condoms as safer sex has become obsolete in light of PrEP. Though he believes that PrEP challenges the close link between HIV risk and barebacking, negative views about PrEP users as irresponsibly skirting normative practices of safer sex remain. Diego reports: "What I have been gathering from my interactions is that every time I say PrEP, it is a synonym for, or used to suggest, bareback sex."

Diego acknowledges the intimate link between barebacking and PrEP, which are entangled with the historicity of AIDS. Taking inspiration from the notion of assemblages, it becomes clear that PrEP stigmatisation emerges from a complex relation of discursive and material forces. Fear of HIV, homosexuality, and sex, mediated by the virus, condoms, and PrEP, converge to generate stigma that manifests locally in the embodied sexual practices of PrEP users. Consequently, PrEP materialises as a social problem in the relational context of HIV, producing anxieties about sex and pleasure, as well as shame, demonstrating that emotions mobilise "intense affect[s] in the service of moral politics" (Irvine, 2009, p. 235). Here, Irvine makes a significant contribution in understanding emotions as political and, indeed, inseparable from sex panics: “Affective conventions of sexuality — in particular, sexual shame, stigma, fear, disgust—enforce and reinforce [...] regulatory system[s] and are therefore political” (p. 236).

Above, I discussed that participants felt some shame using PrEP - an effect of the public fear of homosexuality, HIV, and sex - as an example of affective response. By emphasising the 
materiality of PrEP, however, I also underlined the active role of sexuopharmaceuticals in enacting moral panics and stigmatisation. As such, I also demonstrated that technologies are active forces in the production of emotions in the service of moral panics. Sara Ahmed (2014) writes: "Feelings $[\ldots]$ take the 'shape' of the contact we have with objects" (p. 5). She further clarifies: "The process of attributing an object as being $[\ldots]$ good or bad, $[\ldots]$ involves reading the contact we have with objects in a certain way" (p. 6). Put simply, objects emerge as harmful or beneficial through "contact" or connections with other forces, producing different emotions. Translating this into the language of posthumanist performativity, the object of PrEP is coconstitutive of affective responses, including fear and stigma, which further enact material effects. In the next section, my focus is to consider the multiple effects of PrEP stigma as enacted in the localised practices of PrEP users. However, first, let me explain what I mean by “enacted" stigma.

\section{Enactments of PrEP Stigmatisation}

Erving Goffman (1963) defines stigma as an "attribute that is deeply discrediting" and reduces the stigmatised "from a whole and usual person to a tainted discounted one" (p.3). Goffman's theorisation has been influential, for it advances psychological and sociological explanations for stigma (Brown et al., 2017). Importantly, Goffman argues that stigma is socially constituted. Consequently, as Parker and Aggleton (2003) develop, stigmatisation and discrimination are inseparable from power relations, for they are "social processes that can only be understood in relation to broader notions of power and domination" (p. 16). For this reason, stigma "causes some groups to be devalued and others to feel superior" through social exclusion and rejection (ibid). Such social rejection and discrimination are commonly referred to as “enacted stigma," especially in literature on HIV stigmatisation (Earnshaw \& Kalichman, 2013). 
In this section, I expand on this notion by reformulating the idea of enacted stigma through Mol's (2002) concept of enactment. I argue that enacted stigma is produced through embodied socio-material practices, taking many forms, including slut-shaming, rejection, concealment, internalisation, and discrimination.

According to Earnshaw and Kalichman (2013), in HIV/AIDS stigma research, distinctions are made between "enacted," "felt," “internalised," and "intersectional" stigma. Enacted stigma is understood as: "Experiences of social rejection, violence, employment discrimination, and medical discrimination" (p. 25). Felt, anticipated, or perceived stigma is described as: "expectations of experiencing prejudice, stereotyping, and discrimination" (ibid). Internalised stigma, by contrast, is defined as: "Endorsement of negative beliefs and feelings associated with stigma by stigmatized people" (ibid). Finally, intersectional stigma is said to be: "multiple stigmas interact[ing] to impact the self" (ibid). In my view, the distinctions made between these "types" of stigma cannot be reliably separated. Experiences of "felt" stigma are always already intersectional and intertwined with "enacted" stigma. Enactments, after all, are multiple and interdependent: "They may be added up [...]; and they may include each other" (Mol, 2002, p. 178). Although Mol refers to the enactments of the atherosclerosis disease in this quote, it is possible to replace "atherosclerosis" with "PrEP stigmatisation" and argue that the latter is also enacted differently in different places, interactions, and practices. Accordingly, in keeping with the posthumanist performative approaches outlined earlier, I suggest that enacted stigma does not have to be limited to how it is conventionally understood. Instead, all experiences of stigma should be considered enacted stigma. PrEP stigmatisation, as I show, is experienced through slut-shaming and fear of judgment, concealment of PrEP use, rejection, and internalisation in their interpersonal and intrapersonal relations. In health care settings, stigma is 
experienced via refusal by providers to prescribe PrEP, anticipated judgement from medical professionals, and internalisation of the "high-risk" label. However, PrEP users are not merely at the receiving end of stigmatisation, for they also challenge negative stereotypes to overcome shame and stigma. Here, we begin to see that separation between felt, anticipated, enacted, or intersectional stigma is unreliable for they are all relational — not only because stigma is socially co-constituted but also because sexuopharmaceuticals mediate enactments of stigmatisation. ${ }^{11}$ Additionally, considering stigma as enacted advances the understanding of stigmatisation as always already co-constituted by power and material relations, supplementing the account of stigma as a form of power (Link \& Phelan, 2001; Parker \& Aggleton, 2003).

PrEP Stigmatisation in Interpersonal and Intrapersonal Relations. This section demonstrates that PrEP stigmatisation is materialised and experienced in multiple ways by some PrEP users in their interpersonal and intrapersonal relations. PrEP stigma is enacted through slutshaming; fear of rejection; dismissal by sex partners; concealment of PrEP use; and internalisation. By utilising Ahmed's (2014) notion of contact, I suggest that these enactments of stigma emerge through contacts or relations in an assemblage, comprising the history of HIV, cultural fears on barebacking, the object of PrEP and condoms, MSM, friends, family, and others.

Drawing on queer theoretical frameworks, Spieldenner (2016) argues that slut-shaming is central to PrEP stigma, for it generates the idea that PrEP users deserve to be despised for taking HIV prevention shortcuts, primarily through condomless sex. To add to these discussions, I present an analysis of the material effects of slut-shaming in the embodied practices of PrEP

\footnotetext{
11 This reconfiguration expands on Erving Goffman's (1963) influential account of stigma as more than just a discrediting attribute. Goffman argues for analysing stigma as social and relational, where "a language of relationships, not attributes, is really needed" (p. 3).
} 
users. Specifically, I ask: how is slut-shaming experienced by PrEP users, and what are its effects on their relations with others and themselves?

Slut-shaming, fear of rejection, and dismissal. Slut-shaming, according to some participants, is sometimes experienced as backlash. For example, Damien confides facing antagonism from others, echoing negative beliefs about PrEP when he started using it in 2014:

I think early on it was, you know: 'you're a whore! Just use a condom! If you're good, you shouldn't need to use PrEP, be monogamous! I don't trust doctors! PrEP can't work! I don't believe it works!' [...]. People think that I must like it up the ass barebacking and all that. Just a lot of crazy dumb stuff! (Damien, 50, Los Angeles)

Normative ideas around condoms as safer sex and monogamy as exemplary are persistent in PrEP users' stigmatisation. Additionally, medical scepticism also plays a role in PrEP stigma, alongside doubts about the drug's effectiveness. More importantly, the configuration of condomless sex as irrational and barebackers as immoral for engaging in dangerous sexual behaviours inform how PrEP stigma is enacted and experienced by users. As confirmed by another participant:

I've heard, and I've encountered this a lot: a lot of slut-shaming. So, if I say I'm on PrEP, people automatically think that I have a lot of sex and I have a lot of bareback sex. That's judged negatively. (Dominic, 36, Toronto)

Slut-shaming is not a new phenomenon among queer men. As McDavitt and Mutchler (2014) suggest, gay men who do not live up to the ideals of safer sex norms by engaging in risky sex, especially barebacking, are often criticised by their peers as "sluts," "whores," shameful, reckless, stupid and disgusting. Dominic demonstrates that these beliefs are enduring. Indeed, PrEP users are slut-shamed for being irresponsible and violating norms of what is considered "safer" sexual conduct. Consequently, while the introduction of PrEP challenges the link between HIV risk and barebacking, the prophylactic drug has not completely dissociated negative views about barebacking, now extended to PrEP users. 
Slut-shaming produces different effects. In some cases, slut-shaming engenders fear of rejection. For example, Diego confides:

In the beginning, there was a stigma for me, and there was a fear of rejection. I didn't even list it on my profiles. I felt judged to be on it. I felt that some people would call me things for being on PrEP [...]. If I told them that I was on PrEP, they were going to think that I was a Truvada Whore, and then they won't talk to me. And I've been told that, but not anymore!

Diego alludes to the consumption of PrEP as not something outside of social context but as profoundly entangled with sexual norms and the moral economies of risk and sex. The ingestion of PrEP enacts the consumer into a Truvada Whore, creating feelings of being judged. Following Ahmed (2014), these negative feelings may be conceptualised as emergent through contact between objects and subjects and the "histories that come before the subject" (p. 6). As Diego's testimony above reveals, fear of rejection emerges through the consumption of Truvada and discourses around Truvada Whore partly co-constituted by HIV stigma, negative beliefs around sex, and barebacking. Fear of rejection generates other effects, such as concealment of PrEP use in online dating platforms on account of being associated with promiscuity. Thus, feelings of PrEP stigmatisation may be construed as moving in what Ahmed calls "affective economies": "where feelings [...] are produced as effects of circulation" $(2014$, p. 8$)$. To put it differently: the affective economy between the moral economies of HIV risk and sex, alongside PrEP, users, and others, is productive of stigmatisation, which can be enacted as felt (as in fears of rejection and judgement), and as rejection in the embodied practices of PrEP users.

Another example: Dylan, 56 years old from Toronto, reports being dismissed by a potential sexual partner due to the belief that PrEP users engage in barebacking:

There was one guy I was chatting with on Scruff [a gay app], and we were both interested in each other. But then, he found out that I was on PrEP and I would practise condomless sex. And because of that, he didn't want to get together with me, even though I was willing to use condoms if he wanted to. He just didn't even want to take that chance 
because I have had condomless sex [...]. It wasn't even about PrEP necessarily. It was really just more about condomless sex.

Although Dylan believes that negative stereotypes surrounding PrEP users as "whores" are already anachronistic ("they seem very dated"), his account reveals that the link between PrEP and barebacking has not disappeared. Indeed, on account of Dylan's engagement with condomless sex, he is deemed reckless by potential sexual partners despite his willingness to use condoms. Thinking through PrEP stigma as enacted through relations or assemblages, it becomes possible to see that the materiality of PrEP, together with the moral economies attached to HIV risk and gay sex, enacts users as Truvada Whores, engendering slut-shaming, feelings of rejection, dismissal, and concealment or non-disclosure.

Concealment of PrEP use and internalisation of stigma. Investigating moral debates surrounding PrEP among MSM in New York City, Pawson and Grov (2018) confirm that PrEP users as a group are framed as barebackers who are sexually irresponsible. On account of these negative stereotypes, some participants conceal their PrEP use. Concealment of PrEP use is also acknowledged by the early adopters of PrEP in Toronto (Grace et al., 2018). For these men, fear of stigmatisation related to PrEP or to have multiple partners motivate them not to tell their friends and families. ${ }^{12}$ Likewise, informants in this study report concealing PrEP use for fear of rejection and judgment. Anxieties in facing stigmatisation affect PrEP users' experiences, especially regarding disclosure with friends, families, and even employers.

The prevalence of negative stereotypes around HIV, risk, gay sex, and barebacking may lead to the distrust of friends, where some PrEP users choose not to disclose PrEP uptake for fear

\footnotetext{
${ }^{12}$ Fear of stigmatisation and rejection are also reasons behind the lack of disclosure among HIV-positive individuals in South Africa, playing a significant role in experiences of the disease (Gilbert \& Walker, 2010).
} 
of being labelled promiscuous. As Dennis replies to the question, "Who knows that you're taking PrEP?":

Only the guys I'm sleeping with. My friends don't know. I don't want all my friends to know I'm sleeping around [...]. I don't have any concerns telling them if they are my close friends. But, for my normal friends, I don't think it's a good idea for me to tell them. (Dennis, 26, Toronto)

Slut-shaming can be read in this quote, where negative beliefs about PrEP may lead to distrust of friends. Dennis fears that his peers may judge him and subject him to stigmatisation for having multiple partners. The fear of slut-shaming may even lead others to withhold information and share their PrEP use only with a select few. For example, Derek, 33 years old from Toronto, says that only a few friends who are gay know about his PrEP use because: "They understand my life choices and they know it's a good thing for me to be in control of my sexual health."

Some participants, then, conceal their PrEP use because they do not want to be considered a slut or a barebacker. Other informants divulge that the stigmatisation of HIV also contributes to experiences of anticipated PrEP stigma. As Diego conveys: "I've been asked if I was HIV-positive just because I'm taking PrEP.” Likewise, in my conversation with Darren, 26 years old from Connecticut, he discloses concealing PrEP use with his family because he worries that they might think he is HIV-positive:

I think when [my family] hears the word HIV, or to prevent HIV, they might get it twisted and think that [PrEP] is used to treat HIV.

Although Darren admits that disclosure of PrEP use with his colleagues and friends is more straightforward because he works in HIV prevention, he confesses that he is more apprehensive when it comes to revealing it to his family. PrEP disclosure is still a difficult conversation for some participants, suggesting that users continually deal with the stigma attached to HIV. Indeed, some studies affirm that individuals are uncomfortable about using PrEP or disclosing 
PrEP use for being associated with HIV-positive status (Quinn et al., 2020). Similarly, though Dawson, a 33-year-old scientist from Toronto who also works in HIV prevention, says that slutshaming of PrEP users does not affect him personally, he reports concealing PrEP use to his parents:

So friends, like closer friends [know that I'm taking PrEP]. I also tell most sex partners [...]. Not my parents, though.

In his attempt to explain his motivation for concealing his PrEP use, Dawson points out that it is difficult for him to engage in such conversation: "I just don’t know how to start the conversation, and I don't know what they'll think. It's just simpler." Though Dawson does not further reflect on his reasoning, it is possible to argue that much like Darren above, Dawson is also concerned about HIV stigma and the potential adverse reaction from his family if they were to find out about his PrEP use. Here, we see an example of the productive capacities of PrEP assemblages: through its contact with HIV historicity and fears around sex, PrEP generates anticipation of stigma, affecting some PrEP users to conceal their PrEP use. Such fears of rejection and judgement, following Ahmed (2014), may be seen as "shaped by contact with objects [in this case, the object of PrEP]" and "by cultural histories and memories [of HIV]" (p. 7). Not all PrEP users, however, conceal PrEP use. For instance, one participant reports openly discussing it with his family to ease their anxieties about HIV. Dominic, 36 years old from Toronto, explains that his family should know about PrEP because "I know it's something they wouldn't have to worry about."

While some interview participants experience PrEP stigma through fear of slut-shaming and rejection from friends and family, others, like Dylan, 56 years old from Toronto, admits being anxious about potentially revealing his consumption of PrEP to his employer for insurance purposes. Currently participating in a clinical trial, Dylan worries that, upon the conclusion of 
the study, he might have to start paying for PrEP, claim it with his employment insurance, and potentially face stigmatisation:

Even though I work in a hospital and is one of the top one hundred employers in Canada, I still don't trust them [...]. It's still kind of a concern for me when I have to start putting claims through my employer's provided insurance. I still feel a certain unease around it.

Explaining why he feels anxious about having to demand his employment insurance to pay for PrEP, he concludes:

Maybe it's part of the [...] shame I've internalised over the past five decades. It's weird. It's because I have this irrational fear of my employer just basically accusing me of spending all this money just so that I can be a tramp.

Dylan explains that the internalisation of shame informs his irrational fear of facing stigmatisation due to his PrEP use.

For Ahmed (2014), internalisation is a mechanism of shame: "In experiences of shame, the 'bad feeling' is attributed to oneself, rather than an object or other" (p. 104). Expanding on this, Parker and Aggleton (2003) argue that, on account of the limited resources for challenging powerful discourses of stigmatisation, some groups and individuals "so often accept and even internalize the stigma they are subjected to" (p. 18). Likewise, PrEP users express similar dynamics of shame and internalisation as Dylan explains above: the power of stigmatisation attached to sex, homosexuality, HIV/AIDS, condomless sex, among others, is informative of his understanding of his fear of being judged.

The internalisation of stigma is also expressed by reinforcing negative attitudes about PrEP by some users themselves. For example, when asked to comment on his views about Truvada Whores, Dennis explains:

I think [Truvada Whore] means you're on PrEP and just sleeping around. Well, I mean, that's true; other people do that. I mean, that's just a true stereotype out there. Of course, not everyone taking PrEP is sleeping around, just sleeping with whomever they talk to. But there are enough gay guys doing that. (Dennis, 26, Toronto) 
A fundamental assumption among participants' social and sexual networks is that PrEP is equated with promiscuity and barebacking. PrEP users often link the stigmatisation of PrEP with HIV stigma and negative beliefs based on promiscuity, which continually haunts some participants who are reluctant to disclose PrEP use with friends and families. Significantly, PrEP stigma leads to rejection from others, especially from potential sexual partners. The fear of rejection is so powerful that some participants internalise and reinforce negative beliefs about PrEP. Thus, this section demonstrates that PrEP stigmatisation is enacted and experienced in multiple ways by some PrEP users in their interpersonal and intrapersonal relations - emergent through connections between the object of PrEP, users, lovers, friends, family, and others, coconstituted by moralised discourses about HIV risk and gay sex. In the next section, I explore stigmatisation in healthcare settings to further demonstrate the complexities of PrEP users' experiences of stigma.

PrEP Stigmatisation in Healthcare Settings. In this section, I investigate the enactments of stigma in healthcare settings to shed light on the complexity of PrEP stigmatisation. The analysis will reveal that some healthcare professionals may be sources of harm due to the stigmatisation of PrEP and its potential and current users as "Truvada Whores." Participants recognise these negative beliefs as impediments to having an open dialogue with providers, which may become a barrier to PrEP uptake. Interestingly, while Golub (2018) conjectures that the label of "high risk" employed by healthcare providers when assessing PrEP eligibility may be stigmatising, some participants in this study accept the label by portraying PrEP uptake as responsible and necessary to mitigate HIV risks.

Recruiting individuals from PREPARATORY-5: Canada's first PrEP demonstration project in Toronto, Grace and colleagues (2018) suggest that feelings of discomfort in discussing 
PrEP, sexual risk-taking, and gay sexuality are viewed as barriers to PrEP access. Given that the use of PrEP requires a prescription, clinicians play a significant role in providing access and ensuring adherence, in addition to their role as carers. However, several studies raise concerns about healthcare providers' biases and stigma, which might negatively impact PrEP uptake among MSM. For example, in their interviews with healthcare workers who prescribe PrEP in the USA, Calabrese and others (2019) conclude that some providers believe that several of their colleagues refuse to prescribe PrEP to prospective users due to biases related to sex and HIV. Likewise, in a survey conducted in 2013 of the Infectious Disease Society of America's Emerging Infectious Network, researchers report that $12 \%$ of their respondents $(n=573)$ do not support the provision of PrEP, citing "moral issues" or "concern about irresponsible sexual activity" (Karris et al., 2013, p. 705). By attaching value judgments about sexual behaviours instead of promoting the health interests of patients (Haire, 2015), it appears that some healthcare professionals reinforce stigmatisation of PrEP users, which may have negative consequences, especially concerning access.

As a general trend, however, participants in this research mostly say that accessing PrEP is relatively easy, especially as they obtain care and prescription from community-based sexual health clinics (such as Hassle Free Clinic and Maple Leaf Medical Clinic in Toronto), where stigmatisation may be lesser or even diminished. Community-based clinics play significant roles in the implementation of PrEP, notably in Ontario, Canada, where the provincial government mandates public health units to offer services for HIV and other STIs (Sharma et al., 2018). Staffed primarily by nurses who have expertise in STIs, vaccinations, and counselling, Sharma and others argue that such clinics are ideal for implementing PrEP, whose success is currently under investigation. As opposed to HIV specialist clinics, where physicians may be reluctant to 
prescribe PrEP and HIV-negative individuals may be "misconstrued as "HIV patient," nurses in community-based clinics are trained to provide care for gay, bisexual, and other MSM, including transmen, who may not be "out" to their family physicians (Sharma et al., 2018, p. 3).

Although community-based sexual health clinics in Toronto and elsewhere in Ontario, Canada, are rendered ideal for PrEP implementation, not all clinics specialising in STIs are exemplary. For example, while living in Germany in 2017, Diego confirms facing stigmatisation from healthcare workers while trying to access PrEP:

Even some healthcare workers made comments about it [PrEP], and this happened in Berlin when I went to a sexual health clinic. The comment was pretty much the same: you know, why do you want to take a pill when you can just protect yourself [with condoms]. (Diego, 33, Toronto)

Diego's description reveals that some healthcare providers impose their values by reiterating normative ideas around safer sex centred on condom use. In some health care settings, PrEP stigma is enacted through judgement and sometimes even refuse to provide PrEP to patients. Another participant, Damien, reports encountering moral disapproval from an HIV medical expert, who rejected his request to access PrEP by telling him that PrEP is unsafe and only for individuals who are irresponsible and immoral:

So, I did my research and found out that a prominent doctor was in Los Angeles. So, I went in and visited him to talk about PrEP. And I got slut-shamed. This doctor had all of the worst information about PrEP. He had all the wrong idea about PrEP [...]. He talked about how it was gonna rot my bones. It was going to hurt my liver [...]. He told me that I shouldn't go on it because it was for people who lived on the street, really bad people. People at high, high risk. And I explained that I didn't agree with anything he said! (Damien, 50, Los Angeles)

Damien's testimony reveals that potential candidates for and current users of PrEP face slutshaming in healthcare settings, even among those who are considered experts in the field of HIV. Damien's statement exposes how some providers reiterate and subscribe to notions of responsible and irresponsible biomedical subjects and good and bad candidates of PrEP. As 
Damien continues: "he was convinced that it was just not something that good people were supposed to take and that it was only for people who were irresponsible." Arguably, this healthcare expert reproduces the moralisation of MSM's sexual practices concerning HIV risk, where individuals who engage in sexual risk-taking are seen as "irresponsible citizens who lack self-control” (Ávila, 2015, p. 533). Irresponsible sexual actors are undeserving of PrEP, who use it simply to engage in condomless sex (Thomann, 2018). Fortunately for Damien, another HIV expert in Los Angeles agreed to become his PrEP provider, describing his experience as "totally positive."

These excerpts shed light on the co-constitution of PrEP users as promiscuous and irresponsible by re-enacting negative views around sex and HIV in healthcare settings. Drawing inspiration from posthumanist performative frameworks, the materiality of PrEP and the object of condoms as the normative technology of safer sex can be recognised as active participants in the enactments of PrEP stigma. This pervading stigmatisation of MSM among some healthcare experts is a significant barrier to PrEP access (Thomann et al., 2017). For some gay and bisexual men and transgender women in New York, stigmatisation creates mistrust of medical providers. Sharing these viewpoints, Darren, an interview participant, suggests that fear of stigmatisation in healthcare settings could indeed prevent some individuals from taking PrEP, especially if they live outside of metropolitan areas:

People might feel some stigma, depending on where they live; it might be different for someone who lives in an urban or metropolitan area. But, for someone who lives more remotely could be facing bias or prejudice, some from the pharmacy or their primary care providers [...]. They are just perpetuating stigma. (Darren, 26, Connecticut)

Darren recognises that stigmatisation might impede PrEP uptake and open dialogue with healthcare professionals. Not surprisingly, Darren's testimony supports Grace and others' (2018) findings that the anticipation of stigmatisation is conducive to discomfort, preventing some 
MSM from accessing PrEP with their primary care providers. Similarly, Darren expresses worry about going to his family doctor for PrEP: "I knew that I didn't really want to go to my primary care [provider] for it. So, I tried to find other avenues [...], where I felt comfortable getting PrEP”. Currently, Darren visits Planned Parenthood to obtain PrEP and for other sexual health needs..$^{13}$

Notably, interview participants from Toronto reported experiencing neither discomfort nor stigmatisation directly from providers when accessing PrEP. On the contrary, most confided that providers from community-based clinics recommended PrEP to them while having regular STI tests or getting treated for STIs. For example, Dawson noted: "I had an STI diagnosis at the Hassle Free [Clinic] in Toronto, and they were recommending it. They were very positive about it.” Golub (2018) maintained that clinical guidance and education materials for doctors and patients might be stigmatising, for they revolve around the notion of PrEP as only for "high risk" individuals. Interestingly, Dawson discussed that being labelled "high-risk" was not at all felt as discrediting; instead:

So, I was considered high risk by Hassle Free [for having anal gonorrhoea and occasionally engaging in condomless sex]. I think I had some appreciation of that at that time [...]. Eventually, I realised I needed more than just the diligence that I wasn't coming up with. (Dawson, 33, Toronto)

Dawson's account reveals that being labelled high-risk is not a barrier to PrEP uptake. Quite the contrary. Another participant shares that being considered high risk by a care provider in a community-based clinic in Toronto prompted him to learn more about PrEP and "to be more on top of sexual health." Consequently, by acknowledging their risks and taking steps to mitigate

\footnotetext{
${ }^{13}$ Planned Parenthood is a non-government organisation providing sexual health care services across the USA and globally. Action Canada for Sexual Health and Rights (formerly Planned Parenthood Federation of Canada) is part of the International Planned Parenthood Federation (source: https://www.ippfwhr.org/).
} 
them, these participants not only self-internalise the high-risk label, but they also embody what Thomann (2018) calls the pharmaceutical extension of neoliberal sexual subject. That is, by taking PrEP, users emerge as “calculating, rational, and biomedically equipped," rather than supposedly irresponsible and risky subjects (p. 1002).

Despite the reported ease in accessing PrEP in Toronto, however, one participant felt that his initial appointment to obtain PrEP was too quick, and a more extended discussion would have been preferable:

The only thing I want to point out is probably the discussion could have been a little bit longer. Because I think the total appointment time for me was about fifteen minutes. And I mean, taking PrEP is a big deal for someone like me who's taking it for the first time. So, I kind of needed more information on that. So, I prefer to have a longer discussion with the doctor and a longer appointment. Just to make sure that my decision was right. (Dennis, 26, Toronto)

This is important, for it points to some of the shortcomings of community-based clinics when initiating individuals to PrEP. Though participants interviewed for this study generally reported positive experiences with community-based clinics, one has to wonder whether queer men who are cowed by medical experts, or even slut-shamed, simply walk away and fail to access PrEP; and, how many MSM, for whatever reason, refuse to go these clinics? These issues must be contended with, mainly because clinics serve as primary points of information regarding PrEP.

This section reveals that some healthcare professionals may be sources of harm due to the stigmatisation of PrEP and its potential and current users as "Truvada Whores." Participants recognise these negative beliefs as impediments to having an open dialogue with providers, becoming a barrier to PrEP uptake. Potential PrEP candidates may become uncomfortable explaining their interests due to concerns about moral judgments. Nevertheless, being labelled "high risk" by healthcare providers in community-based sexual health clinics is not experienced as stigmatising. Instead, some participants self-internalise the label and portray PrEP uptake as 
responsible and necessary to mitigate HIV risks. Therefore, PrEP stigmatisation in health care settings is inseparable from normative conceptions on safer sex, negative views about HIV and barebacking, and the materialities of PrEP and condoms, among others. This complex materialdiscursive entanglement generates different experiences of, and responses to, PrEP stigma. As I discuss next, in reconstituting PrEP use as responsible, participants negotiate and challenge stigmatisation by reclaiming the label of "Truvada Whore" and promoting PrEP to normalise its use.

\section{Challenging PrEP Stigma}

Investigating the "real world" effects of PrEP uptake, Sun and others (2019) identify that PrEP users challenge stigma by reconstituting PrEP use as responsible. We had seen some examples of these in the previous chapter and earlier sections here, as when participants remarked that PrEP is "taking control" or "to be more on top" of their sexual health. Additionally, to combat stigmatisation, PrEP users become ambassadors for PrEP, educating others to normalise its use (Sun et al., 2019). Here, I demonstrate that while PrEP assemblages generate stigmatisation, they also produce capacities to disrupt negative stereotypes and enactments of PrEP stigma. As I show, participants in this study challenge negative beliefs by raising awareness about PrEP and its benefits in their interactions with others, further opening discussions about sex and sexuality, especially between MSM.

For example, when I asked Damien to discuss his concerns about disclosing his PrEP use to others, he confided:

I actually do talk to my friends about PrEP. I've talked to parents of people from high school who have gay kids. And I've said, you know, there is this PrEP that you should know about. I've Instagrammed and Facebooked about it. I comment on the stuff whenever I can. And I even told my parents about PrEP and the pills that are out there. It is something that I do talk about. I think it's one of those things where you normalise sex and sexuality and what we're doing. (Damien, 50, Los Angeles) 
PrEP stigmatisation enables the possibility to disrupt negative beliefs by educating others, which plays a significant role in promoting PrEP uptake, as Grimm and Schwartz (2018) suggest. In their study on PrEP users' experiences in the USA, some MSM report that information about the prophylactic drug is mostly obtained from friends, not from healthcare providers (Grimm \& Schwartz, 2018). Similarly, as opposed to some participants, like Derek and Dominic, who attained PrEP awareness through clinics, other informants describe becoming cognizant of PrEP through their peers:

The first time [I heard about it] was from friends in the field. I have a good friend who has a PhD in Epidemiology. So, I think I first heard of it because his partner was on it. (Dawson, 33, Toronto)

[I heard about it] through a university colleague who told me that our health insurance covered PrEP. At that time, it was very expensive. So, I said: I'm going to do it! (Diego, 33 , Toronto)

Zapata et al. (2020) observe that learning from other MSM about PrEP shows the importance of social support in providing an avenue for promoting PrEP to "at-risk" populations. For the authors, open communication between MSM about PrEP "could be a reflection of this important network within the LGBT community" (Zapata et al., 2020, p. 13). The internet is also noted as an essential tool for learning about PrEP by some participants. For example, Dennis reports:

I heard about it a few years ago. I think I saw online articles, or maybe social media. I'm pretty sure it was somewhere online. (Dennis, 26, Toronto)

Daniel, 50 years old from San Francisco, also mentions becoming informed about PrEP "primarily through friends and the internet," as well as Dylan from Toronto: "I'm pretty sure I heard about it either through online or through a friend." Besides the critical role of peers in bringing awareness about PrEP, the internet also contributes to the normalisation of PrEP use by 
facilitating open discussions about sex and sexuality. Importantly, talking about PrEP is one way of challenging the stigmatisation of PrEP, as one participant discusses:

I've tried to create a dialogue with people that I wanted to hook up with. Because in the beginning, there was stigma for me and fear of rejection. (Diego, 33, Toronto)

Another participant from Toronto agrees that educating others and reframing PrEP as an empowering tool in transforming condomless sex as safer and more pleasurable effectively combat negative views on PrEP users. As Derek says: "We should be open about sex and be taking control of sexual health to prevent the spread of HIV and other STIs." Derek further challenges PrEP stigma by focusing discussions about PrEP on its benefits on sexual health, particularly its effectiveness in reducing HIV risk. He even confronts the "Truvada Whore" label by reclaiming the "slut" title: "I wear it proudly to be a slut!" Similarly, Daniel challenges stigma by wearing Truvada Whore T-shirts as a means of reappropriation:

Initially, I was a little weirded out by people reclaiming the Truvada Whore label. And then I went and bought a T-shirt [...]. Eventually, I realised that I, too, was willing to reclaim that title. (Daniel, 50, San Francisco)

Spieldenner (2016) argues that reclaiming the Truvada Whore label can be viewed as a "queer" strategy, echoing the use of tattoos to communicate one's HIV-positive serostatus (Brouwer, 1998), which serves to defy HIV stigmatisation by wearing the disgraced identity proudly. By assuming what Haire (2015) considers a "subversive" identity, these participants encourage others not to feel ashamed for advancing HIV prevention. Indeed, for Derek, rampant slut-shaming of individuals taking PrEP is illogical: for while non-PrEP users accuse PrEP users of being "slutty," the accusers are not so virtuous themselves:

People who call others sluts. Well, at the same time, they're also just dating around and meeting people. Sometimes they lead to sex, hook-ups, and fooling around with other people. So, it's like people are slut-shaming, but, at the same time, they're also making the same choices. (Derek, 33, Toronto) 
As such, it is essential for Derek to promote PrEP use to normalise condomless sex as "safer."

This section demonstrates that PrEP assemblages produce stigmatisation, on the one hand, and different approaches for confronting negative stereotypes about PrEP use, on the other. PrEP users are not merely at the receiving end of stigmatisation, but they are also active in challenging PrEP stigma. Indeed, some informants raise awareness and promote PrEP uptake to normalise and advocate for the notion of "safer" condomless sex. Educating others plays a significant role in promoting PrEP among queer men while also facilitating open communication about sex and sexuality by reclaiming the Truvada Whore label. The reconstitution of Truvada Whore becomes a means for celebrating pleasurable barebacking without the fear of HIV. These responses point out that operations of stigma are contingent on a range of human and nonhuman relations.

\section{Conclusions}

By reconfiguring sex panics and stigma through posthumanist performative frameworks, I demonstrated in this chapter that PrEP stigmatisation is co-constituted by the history of HIV/AIDS, cultural fears around sex, and normative beliefs around safer sex, alongside the materialities of condoms and PrEP. Additionally, in keeping with the posthumanist performative approaches I outlined earlier, whenever felt, anticipated, or internalised stigma is experienced, these experiences need to be considered as enacted stigma, inseparable from the materiality of PrEP and discursive constructs of Truvada Whores. These reconceptualisations of PrEP stigma have at least two important implications. More abstractly, understanding PrEP stigmatisation as emergent and enacted, which appears differently in numerous practices, enables a more complex conceptualisation of its inseparability from other social issues, including HIV stigma, negative beliefs around sex, pleasure, and barebacking. Most concretely: recognising the entanglement 
and emergence of PrEP stigmatisation requires an approach that involves action towards confronting multiple stigmas between MSM and among healthcare providers.

While moral panics are traditionally understood as discursive constructs "representing and demonizing scapegoats in popular culture and media" (Herdt, 2009, p. 7), I argued in this chapter that anxieties ensuing from the introduction of PrEP demands a rethinking of moral panics and stigmatisation as emergent through assemblages, co-constituted by material and discursive forces. Participants highlight that fear of homosexuality, HIV, and sex, mediated by the AIDS virus, condoms, and PrEP, converge to generate stigma. PrEP stigma is manifested locally in the embodied sexual practices of PrEP users as slut-shaming, fear of judgment and rejection, non-disclosure, and internalisation within their interpersonal and intrapersonal relationships. PrEP stigma is also experienced as rejection by providers, anticipated judgement from medical professionals, and internalisation of the "high-risk" label in healthcare settings. Conversely, PrEP users adopt different approaches for confronting negative stereotypes primarily by raising awareness to promote normalisation of its use and encouraging the idea of “safer" condomless sex with PrEP.

Reinscribing the Truvada Whore label as a stigma management practice may be seen as a challenge to the moral judgements attached to PrEP use. More importantly, reclaiming the term disrupts the operationalisation of barebacking as dangerous. As I discussed in previous chapters, the use of biomedical technologies by MSM allows space for challenging the link between condomless sex and HIV risk, transforming barebacking into less fearful, more pleasurable, and empowering practice. Nevertheless, while PrEP disrupts the ontological claim that barebacking is unsafe and dangerous, barebacking's meaning as a social problem remains persistent. As I claimed earlier, in the moral economy of risk, the use of PrEP and TasP emerges as "rational," 
for users are seen to be mitigating harm. By contrast, in the moral economy of sex, pharmaceutically mediated queer men are rendered "irrational," for they are merely using ARVs to engage in risky behaviours. However, as I demonstrated in this chapter, these binaries are not so stable, for such discourses are always already mutually co-constituted and co-constitutive of different enactments of barebacking, inseparable from sexuopharmaceuticals and sexual practices.

At certain times, barebacking is enacted as safe, pleasurable, and empowering. At other times, barebacking is enacted as morally reprehensible, for it is viewed as a vector for the transmission of STIs other than HIV. Each of these practices enacts a different version or reality of barebacking. This chapter contributes to this thesis's broader aims by emphasising the ontological openness of barebacking and paying attention to its enactment as a social problem, contributing to PrEP stigmatisation. According to this perspective, barebacking mediated by PrEP is ontologically open: it is simultaneously safe and unsafe; responsible and irresponsible; and, morally acceptable and unacceptable. Expanding on this notion, I approached PrEP stigma through posthumanist performative frameworks to reveal its mutuality with objects (e.g., PrEP and condoms), affects, and social issues. Additionally, reconfiguring stigma as enacted unravels the complexities of stigmatisation within socio-material relations, producing multiple effects including, but not limited to, expanding awareness and reclaiming the label of Truvada Whore.

Expanding awareness about PrEP use through normalisation, empowerment, and pleasure for Gómez and colleagues (2020) reflect similar features as earlier AIDS activism in "combat[ting] stigma and institutional restrictions on gay sexuality" and for promoting the expansion of its use and community-building (p. 9). Indeed, for Race (2016), reclaiming the Truvada Whore label gestures towards "queer cultural activism" (p. 13). Whereas participants in 
this study did not directly connect their actions with activism, it is possible to construe their practices as a form of grass-roots activism, although more informal. It can be activism for such awareness-building plays a significant role in promoting and normalising PrEP use, disrupting misinformation and stigma, and exposing how healthcare providers are complicit in sexnegativity and slut-shaming. By acknowledging the implication of PrEP, their embodied sexual experiences with HIV/AIDS history, and the current needs in expanding its use, these participants offer practical ways to fight the multiple enactments of PrEP stigmatisation. 


\section{Chapter 6: Summary \& Conclusion}

[D]eciding whether bareback sex is progressive or conservative, radical or compromised, queer or otherwise makes it too easy to elide the complexity of the phenomenon.

Tim Dean (2019, p. 261)

$[\mathrm{H}]$ ow the practice has evolved, with regard to its multiple meanings, across space, time, history, and various socio-political scenes, such that it becomes nearly impossible to find a unified meaning and understanding of it. Barebacking is consequentially shown, then, to be a profoundly malleable, tactile, and tensile category, simultaneously overdetermined and self-contradicting.

Ricky Varghese (2019, p. xxix)

The ontological openness, complexity, and relationality of barebacking practices have been important throughout this thesis. The task I set out in this research was to destabilise the operationalisation of barebacking as a theoretically coherent practice and to recast the normative understanding of agency by recognising the dynamism of practices as involving discursive and material forces having the capacity to alter conditions of how to act and what it means to be "gay" in the twenty-first century. How is condomless sex understood and practised differently as a result of the reduction of risk that stems from advances in HIV prevention? How do these new technologies, from condoms to PrEP and TasP, impact how MSM perceive sexual risk, responsibility, morality, and stigma? How do MSM co-constitute subjectivities emerging from the use of such technologies?

In response to these questions, I developed four key arguments. First, mobilising the notion of "multiple ontologies," I showed that barebacking practices emerge as complex and multiple: simultaneously premeditated/unplanned and safe/risky despite the perceived theoretical coherence of barebacking as intentional and dangerous. In Chapter 2, I maintained that while participants in the online forums described barebacking as "evolution," a linear socio- 
184 I Chapter 6

behavioural progression from safer sex towards taking more significant sexual risks, closer examination of their accounts revealed that barebacking was more complicated. Sometimes barebacking negotiation just never came up. At other times, some men simply decided to stop using condoms. Notably, some barebackers incorporated several forms of safety strategies into sexual practices. Integrating harm reduction measures into sexual practices destabilises the notion of barebacking as risky by emphasising that certain barebacking practices can be "safe." Consequently, barebacking practices cannot neatly be configured within the arena of intentionality and risk (Race, 2010). By extension, barebacking negotiation cannot be simply approached as decision-making between rational individuals, for negotiation of barebacking is relational-involving material and discursive, nonhuman and human forces.

Second, deploying the concept of sexuality-assemblages, I challenged the normative notion of individual negotiation, consent, and responsibility by emphasising the relationality of barebacking "consent" that extends beyond negotiation between rational adults. Instead, as I demonstrated, the process of consent involved negotiating place, time, fantasies, and pleasures. Focusing my analysis on accounts around the practice of "stealthing," the removal or alteration of condoms when consent was negotiated only for condom-protected sex, I maintained in Chapter 3 that discourses on consent and responsibility were always already relational, entangled, and emergent with MSM, the materialities of condoms, HIV status, and biomedical technologies in co-constituting stealthing as morally unacceptable. However, I questioned these conceptualisations by illustrating that such relations also generate limits of normative discourses. Indeed, normative ideals of consent as a communicative transaction were limited in anonymous sexual situations, especially in bathhouses where silence is the norm. Instead, "consent" was enacted in bathhouses as passively given before the communicative act of negotiation. 
For some MSM, stealthing in bathhouses has become morally acceptable, underscoring the implication of sexual scenarios and environments in (re)making alternative models of “consent" and sexual morality. Nevertheless, I also emphasised that most participants reinforced individual responsibility in managing HIV risks, specifically in anonymous sexual situations. Biomedical technologies, particularly PrEP and TasP, are significant in mitigating risks in environments where a high probability of stealthing exists by individuals placed under medical surveillance and control.

Third, guided by posthumanist performative approaches to HIV science and prevention, I argued in Chapter 4 that MSM reflexively incorporate scientific knowledge and biomedical technologies into embodied practices to understand the effectiveness and limitations of ARVs. The emergence of biomedical technologies as simultaneously useful and limited enable MSM to invent different harm reduction measures (including serosorting) and reconstitute notions of "safety" and "risk." Using HIV biomedical technologies for treatment and prevention created varying effects: on the one hand, HIV drugs allowed for the reconsideration of HIV risk, opening possibilities for eliminating anxieties surrounding HIV infection, which further helped facilitate pleasure. On the other hand, PrEP and TasP exposed men to the acquisition of STIs other than HIV and unwanted barebacking sexual acts. Despite these, incorporating pharmaceuticals into sexual practices helped some men challenge conventional views on barebacking as problematic, disrupting the understanding of barebackers as risky subjects. MSM who adopt HIV biomedical interventions emerge as rational subjects. Nonetheless, they also materialise as imprudent, for they are rendered "sexual deviants," misusing ARVs by engaging in "risky" sex, engendering sex panics and stigma. 
Fourth, reconfiguring sex panics and stigma through posthumanist performative frameworks, I maintained in Chapter 5 that PrEP stigmatisation required a rethinking — as emergent through assemblages, co-constituted by material-discursive forces. Indeed, as I have shown in my analysis of the interview data with PrEP users, participants highlighted that fear of homosexuality, HIV, and sex, mediated by the virus, condoms, and PrEP, converged to generate stigma, manifested, or enacted differently in the embodied practices of PrEP users. Enactments of PrEP stigma included slut-shaming, fear of judgment, rejection, non-disclosure, and internalisation within their interpersonal and intrapersonal relations. PrEP users further experienced stigma within healthcare settings as rejection, anticipated judgment from medical professionals, and internalisation of the "high-risk" label. Conversely, PrEP users adopted different approaches in confronting negative stereotypes primarily by raising awareness to promote PrEP use and encourage the idea of "safer" condomless sex.

These four arguments connect with my research's broader contributions, emphasising the complexity of barebacking mediated by pharmaceutical technologies as more than risky and dangerous. Although barebacking can be enacted as morally reprehensible, understood as a vector for the transmission of STIs other than HIV, it may simultaneously emerge as safe, pleasurable, and empowering. By arguing that barebacking is never singular but multiple in the sexual practices of MSM, this form of theorisation seriously challenges the dominant public health messaging about barebacking as risky and barebackers as promiscuous people who are improperly using biomedical technologies simply to enjoy condomless sex. Instead, as I have shown throughout this thesis, MSM creatively incorporate harm reduction measures, including biomedical technologies and serosorting, engendering possibilities for condomless sex to become "safer" and more pleasurable. Engaging in condomless sex with minimised HIV risk is made 
possible in part by HIV science and biomedical technologies, which are incorporated within barebacking sexual practices. By emphasising the co-constitutive functions of scientific knowledge and pharmaceutical technologies in gay men's sexual practices, this work has argued that the various effects of biomedical technologies may be rendered collectively achieved by a range of discursive and material forces, challenging the notions of agency and responsibility that remains restricted to individuals in some public health discourses.

\section{Agency and Responsibility}

More recently, Ranjit and colleagues (2019) sought to investigate the motivations of some MSM to use PrEP. In particular, they examined the relations between condom use attitudes, safe sex fatigue, better sexual experiences, perceived risk, and the intention to take PrEP among MSM in the USA. Their statistical analyses suggest a correlation between higher numbers of sex partners and safe sex fatigue, leading to negative attitudes about condoms. The measurements reveal that MSM who have multiple partners are tired of using condoms and are motivated to take PrEP to reduce the risk of condomless sex and achieve greater sexual experience. Admittedly, this study offers important insights into the complex decision-making processes for PrEP uptake. However, this work also maintains direct and linear causation through what the authors call “The Dual Motivational Model of PrEP use intention” (p. 541). Drawing on the posthumanist performative frameworks pursued in this thesis, it is arguable that Ranjit et al.'s proposed theoretical model perpetuates the notion of agency within individuals, whose intentions can simply be measured by the number of sex partners, perceptions of risk, and expectations about PrEP. In turn, their research shapes MSM's motivations and sexual practices as seemingly predictable. 
Nevertheless, the authors should be commended for their aim to move away from the social behavioural theories of disinhibition and risk compensation. On the one hand, behavioural disinhibition suggests that MSM will engage in riskier behaviours because PrEP is seen as a "substitute for behavioral control” (Ranjit et al., 2019, p. 535). On the other, risk compensation refers to the theory that MSM will engage in more condomless sex with a more significant number of partners due to perceived suppression of HIV risk on account of biomedical technologies' effectiveness. Instead, the authors argue that the decision-making process to engage in condomless sex due to PrEP is more complicated than what these theories propose. This thesis adds to this conversation by emphasising that the effects of PrEP, such as disinhibition and risk compensation, are multiple and implicated within material-discursive relations. By utilising posthumanist performative frameworks, I demonstrated that biomedical technologies, particularly TasP and PrEP, co-constituted by discourses on individual responsibility and consent, the history of HIV/AIDS, and scientific research, among others, are active in generating condomless sexual practices.

The normative notion of human agency concerning HIV biomedical technologies views MSM as culpable for the inappropriate use of technologies. As Rosengarten (2009) maintains: "assessments of biomedical intervention in reference to prevention tend to be underpinned by a conception of risk that is attached to the work of an individual human" (p. 60). Throughout this work, I demonstrated that transformations in MSM's risk calculus, which may appear as disinhibition and risk compensation, are intertwined with HIV science. MSM draw on a shared knowledge about HIV to reconstitute condomless sex as "safe." As I suggested in Chapter 4, to mitigate the limitations of biomedical technologies for their inability to totally eliminate HIV 
risks, some MSM have invented practices to reduce harm. Such risk mitigation measures open possibilities for eliminating anxieties surrounding HIV infection.

Notwithstanding such beneficial outcomes, the use of PrEP simultaneously generated adverse effects in the form of stigma. In Chapter 5, I established that PrEP stigma was experienced, indeed enacted, in multiple ways in different places. And yet, PrEP users have invented approaches to confront PrEP stigmatisation. By framing these responses as emergent through "processes of reflexive mediation between embodied habits and medical opinion," gay men's agency becomes "not as an individual act but rather as taking place within an accessible context of shared concern and practice" (Race, 2003, p. 377). Thus, gay men's agency and responsibility may be conceived as dynamic and relational, demonstrating that capacities to act regarding risk calculation and biomedical technologies are effects of the relations mentioned above that is "well beyond that of an active individual or group of individuals" (Rosengarten, 2009, p. 103). Conversely, the distribution of agency also shifts normative notions of responsibility from individuals to shared accountability for the outcomes of biomedical technologies in sexual practices. That is, an array of human and nonhuman forces is implicated in the production of a wide variety of effects ensuing from TasP and PrEP, including the reconstitution of "safer sex."

\section{Reconstituting Safer Sex}

Condomless sex mediated by HIV treatments - in the form of drugs - is now safe(r) sex, at least as far as HIV transmission goes. This, decades after condoms had become the central technology for preventing the transmission of HIV (and other sexually transmitted infections) as well as decades after the rise of barebacking where condomless sex was purposefully engaged in as a form of opposition to safe(r) sex initiatives. 
In this thesis, I demonstrated that MSM incorporate harm reduction practices to get as close to "zero risks" when engaging in condomless sex. This was evident in Chapter 2, where MSM integrated condoms, withdrawal before ejaculation, serosorting, and PrEP into barebacking sexual practices. In Chapter 3, I noted that using TasP and PrEP was significant in managing risks, especially in anonymous sexual situations. Chapter 4 further revealed that MSM deployed scientific and embodied knowledge to conclude that biomedical technologies were useful in HIV prevention and treatment, contributing to HIV fear reduction. These discussions demonstrate that biomedical technologies have actively transformed and challenged the meaning of HIV risk concerning barebacking. Indeed, biomedical technologies have introduced "the possibility that condomless sex does not necessarily mean exposure to HIV" (Girard et al., 2019, p. 489). Breaking the link between condomless sex and HIV risk has even led the CDC to stop using the term "unprotected sex" in favour of "condomless sex." This shift in language represents an acknowledgement that prevention strategies, including serosorting, strategic positioning, and biomedical technologies, qualify as "protection" against HIV infection, moving away from a “condoms only" model of HIV prevention (Colbert, 2014).

However, though public health discourses may be repositioning discourses of HIV risk and condomless sex on account of the effectiveness of biomedical technologies, Ashford and colleagues (2020) maintain that criminal law has not adapted to HIV science: "Put simply, the science has changed, but the law has not kept pace" (p. 613). Analysing criminal statute in England and Wales on the subject of HIV transmission, they maintain that the framing of HIV transmission as an act of harm, which implicates HIV-positive individuals as a "vector of disease," fails to recognise that the risk of harm has dramatically reduced or eliminated owing to the effectiveness of PrEP and TasP. As they write: "with modern treatment, most cases of HIV 
transmission do not result in harm in the traditional sense of the term, certainly not a harm meeting the threshold of [grievous bodily harm]" (Ashford et al., 2020, p. 606). Meanwhile, in Canada, a criminal statute explicitly requiring the disclosure of HIV-positive status before sex does not exist. Instead, the Supreme Court ruled in 2012 that people with HIV have no obligation to disclose if a condom is used during anal or vaginal sex, and the HIV-positive partner has a low viral load (determined to be less than 1500 copies of the virus per millilitre of blood) (Canadian HIV/AIDS Legal Network, 2019). And yet, despite this decision, “[t]he legal test required sex with a condom, and the person with HIV must have a low viral load" - the absence of both may lead to prosecution (McClelland, 2019, p. 135). In 2018, however, federal prosecutors are no longer able to press charges in cases of HIV non-disclosure, "where a person maintained a suppressed viral load for more than six months" and if the person "engaged in only oral sex, or when condoms were used during sex" (ibid). While doctrinal law in Canada recognises that the risk of harm is reduced or even eliminated when the positive partner has undetectable viral loads, it seemingly sustains a condom-only approach to safer sex. Conversely and more concretely, there is a need for a reform of HIV criminalisation that accounts for the possibility of a safer condomless sex through the use of biomedical technologies. Specifically, non-disclosure from sexual assault laws in Canada must be removed. More abstractly, HIV stakeholders, lawyers, and researchers should engage in rethinking the complexities of consent and negotiation underlying HIV criminalisation that involves an array of sexual practices, biomedical technologies, desire, and pleasure, as I discussed in Chapter 3.

Additionally, as I considered in Chapter 5, stigma continues to be a problem faced by current and potential PrEP users. Some strategies need to be implemented to help decrease HIVrelated stigma and stigma surrounding condomless sex. This may involve raising awareness 
about the neutralisation of epidemiological risk surrounding condomless sex on account of PrEP and TasP, including its benefits in enhancing sexual pleasure in public health messaging. It may also include educating health care providers about the benefits of HIV biomedical technologies, mainly as they serve as primary points of contact for potential PrEP users. Finally, policymakers may also increase support for local HIV/AIDS community organisations to disseminate understanding of TasP and normalising PrEP use by promoting its advantages to sexual health, including but not limited to the reduction of HIV, opening more possibilities for sexual activities and pleasure.

\section{Limitations and Suggestions for Future Research}

Advances in biomedical technologies have dramatically changed how HIV risk can be pharmaceutically controlled. These shifts also impacted how gay men approach risk in their sexual practices by incorporating other harm reduction measures, such as serosorting (in addition to pharmaceuticals). As I discussed in Chapter 4, the form of "serosorting" practised by some men has shifted entirely different. While "serosorting" was commonly understood as HIVnegative men choosing to only engage in sex with individuals they believed to be seronegative, some men have turned serosorting into having sex only with HIV-positive men who have undetectable viral loads and other PrEP users. While PrEP and TasP users may be considered safe and responsible in managing HIV risks, those who cannot or do not want to participate in the biomedicalisation of HIV prevention and treatment are rendered unsafe and irresponsible and even excluded from the sexual engagements of some biomedicalised MSM. One possible explanation for the reluctance to take PrEP is its cost. In the USA, the current list price of PrEP is $\$ 2000 /$ month, in addition to the various expenses associated with laboratory work for the sexual health test required every three months (Kay \& Pinto, 2020). In Canada, where generic 
Truvada is available, individuals without insurance coverage pay between $\$ 250-\$ 280$ per month in Ontario. According to a recent study, these actual and perceived costs significantly impact decision-making for PrEP uptake by young Black gay, bisexual, and other MSM in Toronto (Lee-Foon et al., 2020).

Subsequently, future research should seek to understand intersecting barriers to PrEP access among MSM who are Black, Indigenous, and people of colour who continue to experience disproportionately high rates of HIV infection in Canada (Haddad et al., 2018). In addition, future studies need to investigate experiences of exclusion and discrimination faced by numerous non-white MSM when accessing sexual healthcare services, as the interview participants in this study were mostly white, except for one self-identified Latino and two selfidentified Asian-Canadians. Nonetheless, all of them were highly educated, made over $\$ 40,000$ per year and lived in large urban areas. Therefore, findings cannot be generalised across various cultural, socio-economic, and geographical variations. Furthermore, due to the relatively small sample size, differences in experiences based on age, sexual orientation, and country of origin could not be explored. Similarly, the social characteristics of the participants in the online forums were impossible to obtain. Another significant limitation is that most men in the forums have access to a computer and the internet, so their views were not representative of socio-economic differences. Consequently, more detailed and nuanced explorations of sociocultural aspects of barebacking and HIV biomedical technologies are warranted.

Moreover, as the COVID-19 global pandemic happened during the study's conclusion, only two of the nine interviews occurred one to two months after the lockdowns in Ontario. Accordingly, the study did not get a chance to probe its impacts on PrEP, sexual behaviour and service provision. Researchers in Australia recently found that COVID-19 restrictions had 
194 I Chapter 6

dramatically reduced PrEP use among MSM, coinciding with a reduction in sexual activities (Hammoud et al., 2021). Accordingly, future research should study the long-term impacts of COVID-19 restrictions on sexual practices and HIV infection in Canada. Crucially, it is critical to research the potential effects of the normalisation of telemedicine in accessing sexual health services among MSM in general and non-white queer men in particular.

\section{Epilogue}

In this thesis, I originally set out to inquire about condomless sex among MSM. The introduction of PrEP revolutionised the landscape of HIV prevention, which previously relied on a condoms-only code. To understand condomless sexual practices deeper, I needed to investigate the connections between HIV biotechnologies, normative discourses, and sexual practices. What has become apparent in this research is that condomless sex is an incredibly complex phenomenon-one that can never be pinned down to either notion of "risky" or "safe," for it is always already both.

While I'm not currently on PrEP, I engage in condomless sex with my primary partner, who also does not take PrEP. Before our first condomless sex, we never really discussed ditching condoms. We agreed that we will frequently get tested and always use condoms. Then, it happened. Barebacking, that is. After having steamy sex in our hotel room shower on a trip to Spain in 2018, I noticed that there was cum oozing out of me. "Oh my god, the condom broke!" I exclaimed. But, instead of panicking, my partner and I both reassured ourselves that there was no need to worry. We just got tested (literally two weeks ago!). Since then, we haven’t used condoms. Still, we frequently get tested and use condoms with others. Some may say that our current practice falls under "negotiated safety." 
Indeed, I felt compelled that this is "safe." And yet, whenever I get tested for sexual health, the doctor insists that I should be on PrEP, “and so should your boyfriend." I don't think I should be as I'm engaging in some kind of negotiated safety agreement. But I didn't tell my doctor. I don't want her to judge me. "I can't afford to pay for PrEP," is my usual excuse. This is true. Am I really "at-risk" to justify paying over $\$ 200$ a month? Is the doctor just overly cautious, or is she just doing her job? Is there more to it than simply being "safe"? Does she recommend it to every gay man who admits to engaging in condomless sex, despite their risk mitigation practices? Is she repeating the notion that any form of condomless sex is risky? Is she just trying to achieve "herd immunity" among gay men in Ottawa?

In this thesis, I learned that sex is more complicated and cannot be neatly categorised between "risky" and "safe." Yet, PrEP has somewhat substituted condoms as the primary safer sex tool to manage the complications of gay sex. This begs the question: will PrEP replace condoms as the normative safer sex practice? Almost a decade has passed since PrEP was introduced, and we have yet to see whether this is the case. As well, will PrEP completely transform gay men's sexuality if it becomes the safer sex strategy? What I hope to have accomplished in this dissertation was to provide analytical tools for addressing some of these questions towards recognising the complexities and relationalities of barebacking sexual relations. 
196 | Bibliography

\section{Bibliography}

Adam, B. (2005). Constructing the neoliberal sexual actor: Responsibility and care of the self in the discourse of barebackers. Culture, Health \& Sexuality, 7(4), 333-346. https://doi.org/10.1080/13691050500100773

Adam, B. (2011). Epistemic fault lines in biomedical and social approaches to HIV prevention. Journal of the International AIDS Society, 14(Suppl 2), S2-S2. https://doi.org/10.1186/1758-2652-14-S2-S2

Adam, B. (2016). Neoliberalism, Masculinity, and HIV Risk. Sexuality Research \& Social Policy, 13(4), 321-329. https://doi.org/10.1007/s13178-016-0232-2

Adam, B., Elliot, R., Husbands, W., Murray, J., \& Maxwell, J. (2008). Effects of the Criminalization of HIV Transmission in Cuerrier on Men Reporting Unprotected Sex with Men. Canadian Journal of Law and Society, 23(1-2), 143-159.

Adam, B., Husbands, W., Murray, J., \& Maxwell, J. (2008). Circuits, Networks, and HIV Risk Management. AIDS Education and Prevention, 20(5), 420-434.

Ahmed, S. (2008). Open Forum Imaginary Prohibitions: Some Preliminary Remarks on the Founding Gestures of the "New Materialism." European Journal of Women's Studies, 15(1), 23-39.

Ahmed, S. (2014). The Cultural Politics of Emotion. Edinburgh University Press.

Alldred, P., \& Fox, N. J. (2015). The sexuality-assemblages of young men: A new materialist analysis. Sexualities. https://doi.org/10.1177/1363460715579132

Allen, L. (2015). Sexual assemblages: Mobile phones/young people/school. Discourse: Studies in the Cultural Politics of Education, 36(1), 120-132.

Alvarez, E. (2008). Muscle Boys: Gay Gym Culture. Haworth Press. 
Angelides, Steven. (2001). A history of bisexuality. University of Chicago Press.

Arribas-Ayllon, M., \& Walkerdine, V. (2008). Foucauldian Discourse Analysis. In C. Willig \& W. Stainton-Rogers (Eds.), The SAGE Handbook of Qualitative Research in Psychology (pp. 91-126). SAGE Publications.

Ashford, C. (2009). Queer theory, cyber-ethnographies and researching online sex environments. Information \& Communications Technology Law, 18(3), 297-314. https://doi.org/10.1080/13600830903424734

Ashford, C., Morris, M., \& Powell, A. (2020). Bareback Sex in the Age of Preventative Medication: Rethinking the 'Harms' of HIV Transmission. The Journal of Criminal Law, 84(6), 596-614. https://doi.org/10.1177/0022018320974904

Ávila, R. (2015). Bareback sex: Breaking the rules of sexual health and the assumption of risks. Sexualities, 18(5-6), 523-547. https://doi.org/10.1177/1363460714550903

Bancroft, J., Janssen, E., Strong, D., Carnes, L., Vukadinovic, Z., \& Long, J. S. (2003). Sexual Risk-Taking in Gay Men: The Relevance of Sexual Arousability, Mood, and Sensation Seeking. Archives of Sexual Behavior, 32(6), 555-572.

Barad, K. (2007). Meeting the Universe Halfway: Quantum Physics and the Entanglement of Matter and Meaning. Duke University Press.

Beckman, F. (2011). What is Sex? An Introduction to the Sexual Philosophy of Gilles Deleuze. In F. Beckerman (Ed.), Deleuze and Sex (pp. 1-29). Edinburgh University Press.

Berg, R. (2009). Barebacking: A Review of the Literature. Archives of Sexual Behavior, 38, 754764.

Bersani, L. (1987). Is the Rectum a Grave? (Vol. 43, p. 222). Winter. https://doi.org/10.7208/chicago/9780226043449.001.0001 
198 | Bibliography

Bérubé, A. (2003). The History of Gay Bathhouses. Journal of Homosexuality, 44(3-4), 33-53. https://doi.org/10.1300/J082v44n03_03

Binson, D., \& Woods, W. J. (2003). A Theoretical Approach to Bathhouse Environments. Journal of Homosexuality, 44(3-4), 23-31. https://doi.org/10.1300/J082v44n03_0

Blair, T. R. (2017). Safe sex in the 1970s: Community practitioners on the Eve of AIDS. American Journal of Public Health, 107(6), 872-879. https://doi.org/10.2105/AJPH.2017.303704

Blumenthal, J., \& Haubrich, R. H. (2014). Will risk compensation accompany pre-exposure prophylaxis for HIV? Virtual Mentor, 16(11), 909-915. https://doi.org/10.1001/virtualmentor.2014.16.11.stas1-1411

Boone, C. A., \& Bowleg, L. (2020). Structuring sexual pleasure: Equitable access to biomedical HIV prevention for black men who have sex with men. American Journal of Public Health, 110(2), 157-159. https://doi.org/10.2105/AJPH.2019.305503

Braun, V., \& Clarke, V. (2006). Using thematic analysis in psychology. Qualitative Research in Psychology, 3(2), 77-101. https://doi.org/10.1191/1478088706qp063oa

Breitfeller, G. H., \& Kanekar, A. (2012). Intentional HIV transmission among men who have sex with men: A scoping review. Gay \& Lesbian Issues and Psychology Review, 8(2), 112121.

Brennan, J. (2017). Stealth breeding: Bareback without consent. Psychology and Sexuality, 8(4), 318-333. https://doi.org/10.1080/19419899.2017.1393451

Brisson, J. (2017). Reflections on the history of bareback sex through ethnography: The works of subjectivity and PrEP. Anthropology \& Medicine, 1-15. https://doi.org/10.1080/13648470.2017.1365430 
Brodsky, A. (2016). Rape-Adjacent: Imagining Legal Responses to Nonconsensual Condom Removal. Columbia Journal of Gender and Law, 32(2), 183-210.

Brouwer, D. (1998). The precarious visibility politics of self-stigmatization: The case of HIV/AIDS tattoos. Text and Performance Quarterly, 18(2), 114-136. https://doi.org/10.1080/10462939809366216

Brown, G., \& Di Feliciantonio, C. (2021). Geographies of PrEP, TasP and undetectability: Reconceptualising HIV assemblages to explore what else matters in the lives of gay and bisexual men. Dialogues in Human Geography, 2043820621989574.

Brown, G., Leonard, W., Lyons, A., Power, J., Sander, D., McColl, W., Johnson, R., James, C., Hodson, M., \& Carman, M. (2017). Stigma, gay men and biomedical prevention: The challenges and opportunities of a rapidly changing HIV prevention landscape. Sexual Health, 14(1), 111-118. https://doi.org/10.1071/SH16052

Bueger C., Gadinger F. (2018). Conceptual Challenges of International Practice Theory. In International Practice Theory (pp. 99-129). Palgrave Macmillan. https://doi.org/10.1007/978-3-319-73350-0_5

Bueger, C., \& Gadinger, F. (2018). Doing Praxiography: Research Strategies, Methods and Techniques. In International Practice Theory (pp. 131-161). Palgrave Macmillan. https://doi.org/10.1007/978-3-319-73350-0_6

Butler, J. (1993). Bodies That Matter: On the Discursive Limits of "Sex.” Routledge.

Butler, J. (2004). Undiagnosing Gender. In Undoing Gender (pp. 75-101). Routledge.

Butler, J. (2011). Sexual Consent: Some Thoughts on Psychoanalysis and the Law. Columbia Journal of Gender and Law, 21(2), 2-17.

Cacchioni, T., \& Tiefer, L. (2012). Why medicalization? Introduction to the special issue on the 
medicalization of sex. Journal of Sex Research, 49(4), 307-310.

https://doi.org/10.1080/00224499.2012.690112

Calabrese, S. K., Tekeste, M., Mayer, K. H., Magnus, M., Krakower, D. S., Kershaw, T. S., Eldahan, A. I., Hawkins, L. A. G., Underhill, K., Hansen, N. B., Betancourt, J. R., \& Dovidio, J. F. (2019). Considering Stigma in the Provision of HIV Pre-Exposure Prophylaxis: Reflections from Current Prescribers. AIDS Patient Care and STDs, 33(2), 79-88. https://doi.org/10.1089/apc.2018.0166

Calabrese, S. K., \& Underhill, K. (2015). How stigma surrounding the use of HIV preexposure prophylaxis undermines prevention and pleasure: A call to destigmatize "truvada whores.” American Journal of Public Health, 105(10), 1960-1964. https://doi.org/10.2105/AJPH.2015.302816

Califia, P. (2000). Sexual Outlaws v. The Sex Police. In Public Sex: The Culture of Radical Sex (pp. 3-13). Cleis Press.

Canadian HIV/AIDS Legal Network. (2019). The Criminalization of HIV Non-Disclosure in Canada: Current Status and the Need for Change-HIV Legal Network. http://www.hivlegalnetwork.ca/site/the-criminalization-of-hiv-non-disclosure-in-canadareport/?lang=en

Carballo-Dieguez, A., Dowsett, G. W., Ventuneac, A., Remien, R. H., Balan, I., Dolezal, C., ... \& Lin, P. (2006). Cybercartography of popular internet sites used by New York City men who have sex with men interested in bareback sex. AIDS Education \& Prevention, 18(6), 475-489.

Carballo-Dieguez, A., Ventuneac, A., Bauermeister, J., Dowsett, G. W., Dolezal, C., Remien, R. H., ... \& Rowe, M. (2009). Is 'bareback' a useful construct in primary HIV-prevention? 
Definitions, identity and research. Culture, Health \& Sexuality, 11(1), 51-65. https://doi.org/10.1080/13691050802419467

Carballo-Dieguez, A., Ventuneac, A., Bauermeister, J., Dowsett, G., Dolezal, C., Remien, R., Balan, I., \& Rowe, M. (2010). "Bareback'-Definitions and identity: Constructs" limitation for HIV-prevention research. In P. A. and R. Parker (Ed.), Routledge Handbook of Sexuality, Health and Rights (pp. 202-212). Routledge.

Carballo-Dieguez, A., Ventuneac, A., Dowsett, G., Balan, I., Bauermeister, J., Remien, R., Dolezal, C., Guguere, M., \& Mabragana, M. (2011). Sexual pleasure and intimacy among men who engage in "bareback sex." AIDS Behavior, 15, 57-65.

Carmody, M. (2003). Sexual ethics and violence prevention. Social and Legal Studies, 12(2), 199-216. https://doi.org/10.1177/0964663903012002003

Carmody, M. (2004). Sexual ethics and the erotics of consent. In M. Cowling \& P. Reynolds (Eds.), Making sense of sexual consent (pp. 45-56). Ashgate.

CDC. (2018). Treatment / Living with HIV / HIV Basics / HIV/AIDS / CDC. https://www.cdc.gov/hiv/basics/livingwithhiv/treatment.html CDC. (2020). PrEP Effectiveness / PrEP / HIV Basics / HIV/AIDS / CDC. https://www.cdc.gov/hiv/basics/prep/prep-effectiveness.html Cheek, J. (2004). At the Margins? Discourse Analysis and Qualitative Research. Qualitative Health Research, 14(8), 1140-1150.

Chesser, B. (2019). Case in Victoria could set new legal precedent for stealthing, or removing condom during sex. The Conversation. http://theconversation.com/case-in-victoria-couldset-new-legal-precedent-for-stealthing-or-removing-condom-during-sex-118343

Cheuvront, J. P. (2002). High-Risk Sexual Behavior in the Treatment of HIV-Negative Patients. 
Journal of Gay and Lesbian Psychotherapy, 6(3), 7-25.

Clever, I., \& Ruberg, W. (2014). Beyond Cultural History? The Material Turn, Praxiography, and Body History. Humanities, 3(4), 546-566. https://doi.org/10.3390/h3040546

Cohen, C. J. (1999). The boundaries of blackness: AIDS and the breakdown of Black politics. University of Chicago Press.

Colbert, C. (2014). CDC Updates Term for 'Unprotected Sex'. The Bay Area Reporter / B.A.R. Inc. https://www.ebar.com/news/news//155424

Colebrook, C. (2002). Understanding Deleuze. Allen \& Unwin.

Collin, J. (2015). On social plasticity: The transformative power of pharmaceuticals on health, nature and identity. Sociology of Health and Illness, 38(1), 73-89. https://doi.org/10.1111/1467-9566.12342

Collins, S. P., Mcmahan, V. M., \& Stekler, J. D. (2017). The impact of HIV Pre-exposure Prophylaxis (PrEP) use on the sexual health of men who have sex with men: A qualitative study in Seattle, WA. International Journal of Sexual Health, 29(1), 55-68. https://doi.org/10.1080/19317611.2016.1206051

Coole, D., \& Frost, S. (2010). Introducing the New Materialisms. In D. Coole \& S. Frost (Eds.), New Materialisms: Ontology, Agency, and Politics (pp. 1-43). Duke University Press.

Corteen, K. (2004). Beyond (Hetero)Sexual Consent. In M. Cowling \& P. Reynolds (Eds.), Making Sense of Sexual Consent (pp. 171-193). Ashgate.

Cowling, M., \& Reynolds, P. (2004). Introduction. In M. Cowling \& P. Reynolds (Eds.), Making Sense of Sexual Consent (pp. 1-14). Ashgate.

Crossley, M. L. (2001). 'Resistance' and health promotion. Health Education Journal, 60(3), 197-204. 
Crossley, M. L. (2002). The Perils of Health Promotion and the "Barebacking" Backlash. Health, 6(1), 47-68.

Crossley, M. L. (2004). Making sense of “barebacking”: Gay men’s narratives, unsafe sex, and “resistance habitus.” British Journal of Social Psychology, 43, 225-244.

da Silva-Brandao, R. R., \& Ianni, A. M. Z. (2020). Sexual desire and pleasure in the context of the HIV pre-exposure prophylaxis (PrEP). Sexualities, 23(8), 1400-1416. https://doi.org/10.1177/1363460720939047

Daroya, E. (2020). Online 'barebacking' community and the creation of 'sex pig' identities: Exploring affordances of a Web forum in celebrating sexual excess. First Monday, 25(10). https://doi.org/10.5210/fm.v25i10.10259

Darwin, H. (2017). Doing Gender Beyond the Binary: A Virtual Ethnography. Symbolic Interaction, 40(3), 317-334. https://doi.org/10.1002/symb.316

Davis, M. (2002). HIV Prevention Rationalities and Serostatus in the Risk Narratives of Gay Men. Sexualities, 5(3), 281-299.

Davis, M. (2009). Sex, technology and public health. Palgrave Macmillan.

Davis, O. (2015). A special issue of Sexualities: Bareback sex and queer theory across three national contexts (France, UK, USA). Sexualities, 18(1-2), 120-126. https://doi.org/10.1177/1363460715569144

Dean, T. (2009). Unlimited Intimacy: Reflections on the Subculture of Barebacking. The University of Chicago Press.

Dean, T. (2015). Mediated intimacies: Raw sex, Truvada, and the biopolitics of chemoprophylaxis. Sexualities, 18(1-2), 224-246. 
Dean, T. (2019). Afterword: The raw and the Fucked. In R. Varghese (Ed.), Raw: PrEP, Pedagogy, and the Politics of Barebacking (pp. 257-281). University of Regina Press.

Deleuze, G., \& Guattari, F. (1987). A thousand plateaus: capitalism and schizophrenia. University of Minnesota Press.

Disman, C. (2003). The San Francisco Bathhouse Battles of 1984. Journal of Homosexuality, 44, 71-129. https://doi.org/10.1300/J082v44n03_05

Dowsett, G. W. (2009). The "gay plague" revisited: AIDS and its enduring moral panic. In G. Herdt (Ed.), Moral Panics, Sex Panics: Fear and the Fight over Sexual Rights (pp. 130156). New York University Press.

Dowsett, G.W., Williams, H., Ventuneac, A., \& Carballo-Dieguez, A. (2008). “Taking it Like a Man”: Masculinity and Barebacking Online. Sexualities, 11(1/2), 121-141.

Duran, D. (2012). Truvada Whores. The Huffington Post, 2015. http://www.huffingtonpost.com/david-duran/truvadawhores_b_2113588.html?ir=Australia

Duran, D. (2017). An Evolved Opinion on Truvada / HuffPost. https://www.huffpost.com/entry/truvadawhore-an-evolved-o_b_5030285

Earnshaw, V., \& Kalichman, S. C. (2013). Stigma Experienced by People Living with HIV/AIDS. In P. Liamputtong (Ed.), Stigma, Discrimination and Living with HIV/AIDS: A Cross-Cultural Perspective (pp. 23-38). Springer Science + Business Media. https://doi.org/10.1007/978-94-007-6324-1

Eaton, L. A., Kalichman, S. C., Price, D., Finneran, S., Allen, A., \& Maksut, J. (2017). Stigma and Conspiracy Beliefs Related to Pre-exposure Prophylaxis (PrEP) and Interest in Using 
PrEP Among Black and White Men and Transgender Women Who Have Sex with Men. AIDS and Behavior, 21(5), 1236-1246. https://doi.org/10.1007/s10461-017-1690-0

Edenheim, S. (2016). Foreclosed Matter-On the Material Melancholy of Feminist New Materialism. Australian Feminist Studies, 31(89), 283-304.

Elam, G., Macdonald, N., Hickson, F., Imrie, J., Power, R., McGarrigle, C., Fenton, K., Gilbrat, V., Ward, H., \& Evans, B. (2008). Risky sexual behaviour in context: Qualitative results from an investigation into risk factors for seroconversion among gay men who test for HIV. Sexually Transmitted Infections, 84(6), 473-477.

Elwood, W. N., Greene, K., \& Carter, K. K. (2003). Gentlemen don't speak: Communication norms and condom use in bathhouses. Journal of Applied Communication Research, 31(4), 277-297. https://doi.org/10.1080/1369681032000132564

Epstein, Steven. (1996). Impure science: AIDS, activism, and the politics of knowledge. University of California Press.

Eysenbach, G., \& Till, J. E. (2001). Ethical issues in qualitative research on internet communities. BMJ, 323(7321), 1103-1105. https://doi.org/10.1136/bmj.323.7321.1103

Fairclough, N. (2001). The Discourse of New Labour: Critical Discourse Analysis. In S. Yates, S. Taylor, \& M. Wetherell (Eds.), Discourse as Data: A Guide for Analysis (pp. 229266). Sage.

Fereday, J., \& Muir-Cochrane, E. (2006). Demonstrating Rigor Using Thematic Analysis: A Hybrid Approach of Inductive and Deductive Coding and Theme Development. International Journal of Qualitative Methods, 5(1), 80-92. https://doi.org/10.1177/160940690600500107 
Flowers, P. (2010). HIV Transitions: Consequences for Self in an Era of Medicalisation. In M. Davis \& C. Squire (Eds.), HIV Treatment and Prevention Technologies in International Perspective (pp. 109-125). Palgrave Macmillan UK.

https://doi.org/10.1057/9780230297050_6

Foucault, M. (1990). The History of Sexuality Volume 1: An Introduction.

Foucault, M. (2003). Society must be defended: Lectures at the College of France 1975-1976. Picador.

Foucault, M. (2011). The gay science. Critical Inquiry, 37(3), 385-403. https://doi.org/10.1086/659351

Fox, N., \& Alldred, P. (2017). Sociology and the new materialism : theory, research, action. SAGE.

Fox, N. J., \& Alldred, P. (2013). The sexuality-assemblage: Desire, affect, anti-humanism. The Sociological Review, 61(4), 769-789. https://doi.org/10.1111/1467-954X.12075

Freeborn, K., \& Portillo, C. J. (2017). Does Pre-exposure prophylaxis (PrEP) for HIV prevention in men who have sex with men (MSM) change risk behavior? A systematic review. Journal of Clinical Nursing, 27(17-18), 3254-3265.

Gafos, M., Horne, R., Nutland, W., Bell, G., Rae, C., Wayal, S., Rayment, M., Clarke, A., Schembri, G., Gilson, R., McOwan, A., Sullivan, A., Fox, J., Apea, V., Dewsnap, C., Dolling, D., White, E., Brodnicki, E., Wood, G., ... McCormack, S. (2019). The Context of Sexual Risk Behaviour Among Men Who Have Sex with Men Seeking PrEP, and the Impact of PrEP on Sexual Behaviour. AIDS and Behavior, 23(7), 1708-1720. https://doi.org/10.1007/s10461-018-2300-5 
Garcia, M. (2016). Why Michael Weinstein Gets Blamed for PrEP Myths. HIV Plus. https://www.hivplusmag.com/prevention/2016/2/04/why-michael-weinstein-gets-blamedprep-myths

Garland-Levett, S. (2020). Knowing-in-being: Traversing the mind/body dualism to dissolve sexuality education's 'knowledge/practice gap.' Gender and Education, 32(6), 697-714. https://doi.org/10.1080/09540253.2018.1482414

Gauthier, D. K., \& Forsyth, C. J. (1999). Bareback sex, bug chasers, and the gift of death. Deviant Behavior: An Interdisciplinary Journal, 20, 85-100.

Gay dating app Grindr to sell shares. (2018). BBC News. https://www.bbc.com/news/business45353789

Giami, A., \& Perrey, C. (2012). Transformations in the Medicalization of Sex: HIV Prevention between Discipline and Biopolitics. The Journal of Sex Research, 49(4), 353-361. https://doi.org/10.1080/00224499.2012.665510

Girard, G., Patten, S., LeBlanc, M. A., Adam, B. D., \& Jackson, E. (2019). Is HIV prevention creating new biosocialities among gay men? Treatment as prevention and pre-exposure prophylaxis in Canada. Sociology of Health and Illness, 41(3), 484-501. https://doi.org/10.1111/1467-9566.12826

Goffman, E. (1963). Stigma: Notes on the Management of Spoiled Identity. Touchstone.

Golub, S. A., Kowalczyk, W., Weinberger, C. L., \& Parsons, J. T. (2010). Preexposure prophylaxis and predicted condom use among high-risk men who have sex with men. Journal of acquired immune deficiency syndromes, 54(5), 548-555. https://doi.org/10.1097/QAI.0b013e3181e19a54 
Golub, S. A. (2018). PrEP Stigma: Implicit and Explicit Drivers of Disparity. Current HIV/AIDS Reports, 15(2), 190-197. https://doi.org/10.1007/s11904-018-0385-0

Gómez, W., Holloway, I. W., Pantalone, D. W., \& Grov, C. (2020). PrEP uptake as a social movement among gay and bisexual men. Culture, Health \& Sexuality, 1-13. https://doi.org/10.1080/13691058.2020.1831075

González, O. R. (2010). Tracking the Bugchaser: Giving" The Gift" of HIV/AIDS. Cultural Critique, (75), 82-113.

González, O. (2019). HIV Pre-Exposure Prophylaxis (PrEP), “The Truvada Whore,” and the New Gay Sexual Revolution. In R. Varghese (Ed.), Raw: PrEP, Pedagogy, and the Politics of Barebacking (pp. 27-48). University of Regina Press.

Grace, D., Jollimore, J., MacPherson, P., Strang, M. J. P., \& Tan, D. H. S. (2018). The PreExposure Prophylaxis-Stigma Paradox: Learning from Canada's First Wave of PrEP Users. AIDS Patient Care and STDs, 32(1), 24-30. https://doi.org/10.1089/apc.2017.0153

Grant, R. M., Lama, J. R., Anderson, P. L., McMahan, V., Liu, A. Y., Vargas, L., Goicochea, P., Casapía, M., Guanira-Carranza, J. V., Ramirez-Cardich, M. E., Montoya-Herrera, O., Fernández, T., Veloso, V. G., Buchbinder, S. P., Chariyalertsak, S., Schechter, M., Bekker, L.-G., Mayer, K. H., Kallás, E. G., ... Glidden, D. V. (2010). Preexposure Chemoprophylaxis for HIV Prevention in Men Who Have Sex with Men. New England Journal of Medicine, 363(27), 2587-2599. https://doi.org/10.1056/NEJMoa1011205

Greteman, A. J. (2018). Viral Matters: Barebacking and PrEP. In A. J. Greteman (Ed.), Sexualities and Genders in Education: Towards Queer Thriving (pp. 145-167). Springer International Publishing. https://doi.org/10.1007/978-3-319-71129-4_6 
Grimm, J., \& Schwartz, J. (2018). “It's Like Birth Control for HIV”: Communication and Stigma for Gay Men on PrEP. Journal of Homosexuality, 1-19. https://doi.org/10.1080/00918369.2018.1495978

Grov, C. (2007). Barebacking websites: Electronic environments for reducing or inducing HIV risk. AIDS Care Psychological and Socio-Medical Aspects of AIDS/HIV, 18(8), 990-997. https://doi.org/10.1080/09540120500521137

Grov, Christian, Parsons, J., \& Bimbi, D. (2007). Sexual Risk Behavior and Venues for Meeting Sex Partners: An Intercept Survey of Gay and Bisexual Men in LA and NYC. AIDS and Behavior, 11(6), 915-926. https://doi.org/10.1007/s10461-006-9199-y

Guta, A., Murray, S. J., \& Gagnon, M. (2016). HIV, Viral Suppression and New Technologies of Surveillance and Control. Body \& Society, 22(2), 82-107. https://doi.org/10.1177/1357034X15624510

Haddad, N., Li, J., Totten, S., \& McGuire, M. (2018). HIV in Canada-Surveillance Report, 2017. Canada Communicable Disease Report, 44(12), 324-332. https://doi.org/10.14745/ccdr.v44i12a03

Haig, T. (2006). Bareback Sex: Masculinity, Silence, and the Dilemmas of Gay Health. Canadian Journal of Communication, 31(4), 859-877.

Haire, B. G. (2015). Preexposure prophylaxis-related stigma: Strategies to improve uptake and adherence -a narrative review. HIVIAIDS - Research and Palliative Care, 7, 241-249. https://doi.org/10.2147/HIV.S72419

Halkitis, P. N., \& Parsons, J. T. (2003). Recreational drug use and HIV-risk sexual behavior among men frequenting gay social venues. Journal of Gay \& Lesbian Social Services, 14(4), 19-38. 
Halkitis, P., Parsons, J., \& Wilton, L. (2003). Barebacking among gay and bisexual men in New York City: Explanations for the emergence of intentional unsafe behavior. Archives of Sexual Behavior, 32, 351-357.

Halkitis, P., Wilton, L., \& Drescher, J. (2005). Introduction: Why Barebacking? Journal of Gay and Lesbian Psychotherapy, 9(3-4), 1-8.

Halkitis, P., Wilton, L., \& Galatowitsch, P. (2005). What's in a Term? How Gay and Bisexual Men Understand Barebacking. Journal of Gay and Lesbian Psychotherapy, 9(3-4), 3548.

Halperin, D. (1995). Saint Foucault: Towards a gay hagiography. Oxford University Press.

Halperin, D. (2007). What Do Gay Men Want?: An Essay on Sex, Risk, and Subjectivity. University of Michigan Press.

Hammack, P. L., Toolis, E. E., Wilson, B. D. M., Clark, R. C., \& Frost, D. M. (2019). Making Meaning of the Impact of Pre-Exposure Prophylaxis (PrEP) on Public Health and Sexual Culture: Narratives of Three Generations of Gay and Bisexual Men. Archives of Sexual Behavior, 48(4), 1041-1058. https://doi.org/10.1007/s10508-019-1417-6

Hammersley, M. (2005). Ethnography and Discourse Analysis: Incompatible or Complementary? Polifonia, 10, 1-20.

Hammersley, M., \& Atkinson, P. (2007). What is Ethnography? In Ethnography: Principles in Practice (pp. 1-19). Routledge.

Hammond, C., Holmes, D., \& Mercier, M. (2016). Breeding new forms of life: A critical reflection on extreme variances of bareback sex. Nursing Inquiry, 23(3), 267-277.

Hammoud, M. A., Grulich, A., Holt, M., Maher, L., Murphy, D., Jin, F., Bavinton, B., Haire, B., Ellard, J., Vaccher, S., Saxton, P., Bourne, A., Degenhardt, L., Storer, D., \& Prestage, G. 
(2021). Substantial Decline in Use of HIV Preexposure Prophylaxis Following Introduction of COVID-19 Physical Distancing Restrictions in Australia: Results From a Prospective Observational Study of Gay and Bisexual Men. Journal of Acquired Immune Deficiency Syndromes, 86(1), 22-30. https://doi.org/10.1097/QAI.0000000000002514 Haraway, D. (1988). Situated Knowledges: The Science Question in Feminism and the Privilege of Partial Perspective. Feminist Studies, 14(3), 575-599. https://doi.org/10.2307/3178066

Harvey, D. O. (2011). Calculating Risk: Barebacking, the Queer Male Subject, and the De/fomation of Identity Politics. Discourse, 32(2), 156-183.

Haubrich, D. J., Myers, T., Calzavara, L., Ryder, K., \& Medved, W. (2004). Gay and bisexual men's experiences of bathhouse culture and sex: "looking for love in all the wrong places." Culture, Health \& Sexuality, 6(1), 19-29. https://doi.org/10.1080/13691050310001607241

Herdt, G. (2009). Introduction: Moral Panics, Sexual Rights, and Cultural Anger. In G. Herdt (Ed.), Moral Panics, Sex Panics: Fear and the Fight over Sexual Rights (pp. 1-46). New York University Press.

Hine, C. (2008). Virtual Ethnography: Modes, Varieties, Affordances. In N. G. Fielding, R. M. Lee, \& G. Blank (Eds.), The SAGE Handbook of Online Research Methods (pp. 270_ 287). SAGE Publications.

Hine, C. (2015). Ethnography for the Internet: Embedded, embodied and everyday. Bloomsbury Academic.

Hird, M. (2009). Biologically Queer. In N. Giffney \& M. O’Rourke (Eds.), The Ashgate Research Companion to Queer Theory (pp. 347-362). Ashgate. 
Hogben, M., \& Liddon, N. (2008). Disinhibition and Risk Compensation. Sexually Transmitted Diseases, 35(12), 1009-1010. doi: 10.1097/OLQ.0b013e31818eb752

Hojilla, J. C., Koester, K. A., Cohen, S. E., Buchbinder, S., Ladzekpo, D., Matheson, T., \& Liu, A. Y. (2016). Sexual Behavior, Risk Compensation, and HIV Prevention Strategies Among Participants in the San Francisco PrEP Demonstration Project: A Qualitative Analysis of Counseling Notes. AIDS and Behavior, 20(7), 1461-1469. https://doi.org/10.1007/s10461-015-1055-5

Holmes, D., Gastaldo, D., O’Byrne, P., \& Lombardo, A. (2008). Bareback Sex: A Conflation of Risk and Masculinity. International Journal of Men's Health, 7(2), 171-191.

Holmes, D., O’Byrne, P., \& Murray, S. J. (2010). Faceless sex: Glory holes and sexual assemblages. Nursing Philosophy, 11(4), 250-259.

Holmes, D., \& Warner, D. (2005). The anatomy of a forbidden desire: Men, penetration and semen exchange. Nursing Inquiry, 12(1), 10-20.

Holt, M. (2015). Configuring the users of new HIV-prevention technologies: The case of HIV pre-exposure prophylaxis. Culture, Health \& Sexuality, 17(4), 428-439. https://doi.org/10.1080/13691058.2014.960003

Hoppe, T. (2011). Circuits of power, circuits of pleasure: Sexual scripting in gay men's bottom narratives. Sexualities, 14(2), 193-217.

Horvath, K. J., Lammert, S., Martinka, A., \& Erickson, D. (2020). Defining Sexual Risk in the Era of Biomedical HIV Prevention: Implications for HIV Research and Practice. Archives of Sexual Behavior, 49(1), 91-102. https://doi.org/10.1007/s10508-019-01499-8 
Hughes, S. D., Sheon, N., Andrew, E. V. W., Cohen, S. E., Doblecki-Lewis, S., \& Liu, A. Y. (2018). Body/Selves and Beyond: Men's Narratives of Sexual Behavior on PrEP. Medical Anthropology, 37(5), 387-400. https://doi.org/10.1080/01459740.2017.1416608

Irvine, J. M. (2009). Transient Feelings. In G. Herdt (Ed.), Moral Panics, Sex Panics: Fear and the Fight over Sexual Rights (pp. 234-276). New York University Press.

Jagose, Annamarie. (1996). Queer theory: An introduction. New York University Press.

Jaspal, R., \& Daramilas, C. (2016). Perceptions of pre-exposure prophylaxis (PrEP) among HIVnegative and HIV-positive men who have sex with men (MSM). Cogent Medicine, 3(1), 1256850-1256850. https://doi.org/10.1080/2331205x.2016.1256850

Junge, B. (2002). Bareback Sex, Risk and Eroticism: Anthropological Themes (Re-)Surfacing in the Post-AIDS Era. In E. Lewin \& W. Leap (Eds.), Out in Theory: The Emergence of Lesbian and Gay Anthropology (pp. 186-221). University of Illinois Press.

Kagan, D. (2015). 'Re-crisis': Barebacking, sex panic and the logic of epidemic. Sexualities, $18(7), 817-837$.

Karris, M. Y., Beekmann, S. E., Mehta, S. R., Anderson, C. M., \& Polgreen, P. M. (2013). Are We Prepped for Preexposure Prophylaxis (PrEP)? Provider Opinions on the Real-World Use of PrEP in the United States and Canada. Clinical Infectious Diseases. https://doi.org/10.1093/cid/cit796

Kay, E. S., \& Pinto, R. M. (2020). Is Insurance a Barrier to HIV Preexposure Prophylaxis? Clarifying the Issue. American Journal of Public Health, 110(1), 61-64. https://doi.org/10.2105/AJPH.2019.305389

Khan, S., \& Khan, O. A. (2006). The trouble with MSM. American Journal of Public Health, 96(5), 765-766. https://doi.org/10.2105/AJPH.2005.084665 
Kippax, S., \& Stephenson, N. (2005). Meaningful evaluation of sex and relationship education. Sex Education, 5(4), 359-373.

Kirby, V. (2002). When All That Is Solid Melts Into Language: Judith Butler and the Question of Matter. International Journal of Sexuality and Gender Studies, 7(4), 265-280. https://doi.org/10.1023/A:1020382712385

Kirby, V. (2008). Natural convers(at)ions: Or, what if culture was really nature all along? In S. Alaimo \& S. Hekman (Eds.), Material Feminisms. Indiana University Press.

Klein, H. (2014). Generationing, stealthing, and gift giving: The intentional transmission of HIV by HIV-positive men to their HIV-negative sex partners. Health Psychology Research, 2(3), 54-59. https://doi.org/10.4081/hpr.2014.1582

Koester, K., Amico, R. K., Gilmore, H., Liu, A., Mcmahan, V., Mayer, K., Hosek, S., \& Grant, R. (2017). Risk, safety and sex among male PrEP users: Time for a new understanding Risk, safety and sex among male PrEP users: Time for a new understanding. Culture, Health \& Sexuality, 19(12), 1301-1313. https://doi.org/10.1080/13691058.2017.1310927

Kong, T., Mahoney, D., \& Plummer, K. (2002). Queering the Interview. In J. Gubrium \& J. Holstein (Eds.), Handbook of Interview Research: Context \& Method (pp. 239-268). Sage.

Kukla, R. (2009). Communicating Consent. Hastings Center Report, 39(3), 45-47. https://doi.org/10.1353/hcr.0.0141

Kukla, R. (2018). That's What She Said: The Language of Sexual Negotiation*. Ethics, 129, 7097.

Latimer, R. L., Vodstrcil, L. A., Fairley, C. K., Cornelisseid, V. J., Chow, E. P. F., Read, T. R. H., \& Bradshaw, C. S. (2018). Non-consensual condom removal, reported by patients at a 
sexual health clinic in Melbourne, Australia. PLoS One, 13(12), 1-16.

https://doi.org/10.1371/journal.pone.0209779

Law, J. (2004). After Method: Mess in social science research. Routledge.

LeBesco, K. (2004). Managing visibility, intimacy, and focus in online critical ethnography. In M. D. Jogns, S. Chen, \& G. Hall (Eds.), Online social research: Methods, issues, and ethics (pp. 63-79). Peter Lang.

Lee, B. (2014). It's a question of breeding: Visualizing queer masculinity in bareback pornography. Sexualities, 17(1-2), 100-120. https://doi.org/10.1177/1363460713511099

Lee-Foon, N. K., Logie, C. H., Siddiqi, A., \& Grace, D. (2020). Exploring young Black gay, bisexual and other men who have sex with men's PrEP knowledge in Toronto, Ontario, Canada. Culture, Health \&Sexuality. https://doi.org/10.1080/13691058.2020.1837958

Link, B. G., \& Phelan, J. C. (2001). Conceptualizing stigma. Annual Review of Sociology, 27, 363-385. https://doi.org/10.1146/annurev.soc.27.1.363

Loick, D. (2020). “... as if it were a thing.” A feminist critique of consent. Constellations, 27(3), 412-422. https://doi.org/10.1111/1467-8675.12421

Lupton, D. (1999). Archetypes of infection: People with HIV/AIDS in the Australian press in the mid 1990s. Sociology of Health \& Illness, 21(1), 37-53.

Mansergh, G., Marks, G., Colfax, G., Guzman, R., Rader, M., \& Buchbinder, S. (2002). "Barebacking" in a diverse sample of men who have sex with men. AIDS, 16(4), 653659.

Martin, D., Spink, M. J., \& Pereira, P. P. G. (2018). Multiple bodies, political ontologies and the logic of care: an interview with Annemarie Mol. Interface-Comunicação, Saúde, Educação, 22, 295-305. 
Martinez-Lacabe, A. (2019). The non-positive antiretroviral gay body: The biomedicalisation of gay sex in England. Culture, Health \& Sexuality, 21(10), 1117-1130. https://doi.org/10.1080/13691058.2018.1539772

Massumi, B. (2004). Notes on the translation and acknowledgements. In G. Deleuze \& F. Guattari (Eds.), A thousand plateaus (pp. xvi-xix). University of Minnesota Press.

Mazzei, L. A. (2014). Beyond an Easy Sense: A Diffractive Analysis. Qualitative Inquiry, 20(6), 742-746. https://doi.org/10.1177/1077800414530257

McClelland, A. (2019). “Lock This Whore Up”: Legal Violence and Flows of Information Precipitating Personal Violence against People Criminalised for HIV-Related Crimes in Canada. European Journal of Risk Regulation, 10(1), 132-147. https://doi.org/10.1017/err.2019.20

McDavitt, B., \& Mutchler, M. G. (2014). “Dude, You're Such a Slut!” Barriers and Facilitators of Sexual Communication Among Young Gay Men and Their Best Friends. Journal of Adolescent Research, 29(4), 464-498.

McNamara, M. (2013). Cumming to terms: Bareback pornography, homonormativity, and queer survival in the time of HIV/AIDS. In Breanne Fahs1, Mary L. Dudy1, \& Sarah Stage1 (Eds.), The Moral Panics of Sexuality (pp. 226-244). Palgrave Macmillan. https://doi.org/10.1057/9781137353177_13

Mol, A. (2002). The Body Multiple: Ontology in Medical Practice. Duke University Press. Mol, A. (2014). A reader's guide to the "ontological turn” - Part 4. Somatosphere. http://somatosphere.net/2014/03/a-readers-guide-to-the-ontological-turn-part-4.html Molina, J.-M., Capitant, C., Spire, B., Pialoux, G., Cotte, L., Charreau, I., Tremblay, C., Le Gall, J.-M., Cua, E., Pasquet, A., Raffi, F., Pintado, C., Chidiac, C., Chas, J., Charbonneau, P., 
Delaugerre, C., Suzan-Monti, M., Loze, B., Fonsart, J., ... Delfraissy, J.-F. (2015). OnDemand Preexposure Prophylaxis in Men at High Risk for HIV-1 Infection. New England Journal of Medicine, 373(23), 2237-2246. https://doi.org/10.1056/NEJMoa1506273

Moore, C. (2020). Malevolent depravity: The rise of PrEP. The Spectator (US Edition). https://spectator.us/topic/malevolent-depravity-prep-aids/

Moore, P. (2004). Beyond Shame: Reclaiming the Abandoned History of Radical Gay Sexuality. Beacon Press.

Moskowitz, D., \& Roloff, M. (2007a). The existence of a bug chasing subculture. Culture, Health \& Sexuality, 9(4), 347-357.

Moskowitz, D., \& Roloff, M. (2007b). The Ultimate High: Sexual Addiction and the Bug Chasing Phenomenon. Sexual Addiction \& Compulsivity, 14(1), 21-40.

Mowlabocus, S. (2007). Life Outside the Latex: HIV, Sex, and the Online Barebacking Community. In K. O'Riordan \& D. Phillips (Eds.), Queer Online: Media Technology and Sexuality. Peter Lang.

Mowlabocus, S. (2010). Gaydar Culture. Gay Men, Technology and Embodiment in the Digital Age. Ashgate. https://doi.org/10.1177/0094306112462562m

Mullin, M. (2017). "Stealthing" could be considered assault say experts about secret removal of condom during sex I CBC News. CBC News. https://www.cbc.ca/news/health/stealthingcondoms-legal-concerns-1.4088491

Murray, S. J., Holmes, D., \& Foth, T. (2018). Introduction: RadSex in theory and in practice. In Dave Holmes, S. J. Murray, \& T. Foth (Eds.), Radical Sex Between Men: Assembling Desiring Machines (pp. 1-22). Routledge. 
Myers, J. E., \& Sepkowitz, K. A. (2013). A pill for HIV prevention: Déjà vu all over again? Clinical Infectious Diseases, 56(11), 1604-1612. https://doi.org/10.1093/cid/cit085

Nelson, B. (2018). The unexpected effects of the HIV prevention pill I Mosaic. Mosaic. https://mosaicscience.com/story/hiv-prep-truvada-prevention-sti-std-lgbtqi-gay-condompride/

Nicholls, E. J., \& Rosengarten, M. (2019). PrEP (HIV pre-exposure prophylaxis) and its possibilities for clinical practice. Sexualities. https://doi.org/10.1177/1363460719886556

Offer, C., Grinstead, O., Goldstein, E., Mamary, E., Alvarado, N., Euren, J., \& Woods, W. J. (2007). Responsibility for HIV Prevention: Patterns of Attribution Among HIVSeropositive Gay and Bisexual Men. AIDS Education \& Prevention, 19(1), 24-35.

Oudshoorn, N., \& Pinch, T. (2003). How users matter the co-construction of users and technologies. MIT Press.

Paechter, C. (2012). Researching sensitive issues online: Implications of a hybrid insider/outsider posision in a retrospective ethnographic study. Qualitative Research, 13(1), 1-16. https://doi.org/10.1177/1468794112446107

Palinkas, L. A., Horwitz, S. M., Green, C. A., Wisdom, J. P., Duan, N., \& Hoagwood, K. (2015). Purposeful sampling for qualitative data collection and analysis in mixed method implementation research. Administration and policy in mental health and mental health services research, 42(5), 533-544.

Parisi, L. (2009). The Adventures of Sex. In C. Nigianni \& M. Storr (Eds.), Deleuze and Queer Theory (pp. 72-91). Edinburgh University Press. 
Parker, R., \& Aggleton, P. (2003). HIV and AIDS-related stigma and discrimination: A conceptual framework and implications for action. Social Science \& Medicine, 57, pp. $13-24$.

Parsons, J. T., \& Bimbi, D. S. (2007). Intentional Unprotected Anal Intercourse among Sex Who have Sex with Men: Barebacking —From Behavior to Identity. AIDS Behavior, 11(2), 277-287. https://doi.org/10.1007/s10461-006-9135-1

Pawson, M., \& Grov, C. (2018). 'It's just an excuse to slut around': Gay and bisexual mens' constructions of HIV pre-exposure prophylaxis (PrEP) as a social problem. Sociology of Health and Illness, 40(8), 1391-1403. https://doi.org/10.1111/1467-9566.12765

Phillips, J. (2006). Agencement/Assemblage. Theory, Culture \& Society, 23(2-3), 108-109. https://doi.org/10.1177/026327640602300219

Pinch, T. J., \& Bijker, W. E. (1984). The Social Construction of Facts and Artefacts: Or How the Sociology of Science and the Sociology of Technology might Benefit Each Other. Social Studies of Science, 14(3), 399-441. https://doi.org/10.1177/030631284014003004

Pink, S. (2007). Doing visual ethnography (Second Edition). SAGE Publications, Ltd. https://www.doi.org/10.4135/9780857025029

Pocius, J. (2016). Of Bodies, Borders, and Barebacking: The Geocorpographies of HIV. In H. Randell-Moon \& R. Tippet (Eds.), Security, Race, Biopower (pp. 21-40). Palgrave Macmillan. https://doi.org/10.1057/978-1-137-55408-6_2

Preciado, P. B. (2013). Testo junkie: Sex, drugs, and biopolitics in the pharmacopornographic era. The Feminist Press at CUNY.

Preciado, P. B. (2015). Condoms chimiques. Libération. https://www.liberation.fr/chroniques/2015/06/11/condoms-chimiques_1327747 
Qian, J. (2014). Narrating the trope of abnormality: The making of closeted experiences in gay public cruising. Geoforum, 52, 157-166. https://doi.org/10.1016/j.geoforum.2014.01.010

Quinn, K. G., Christenson, E., Sawkin, M. T., Hacker, E., \& Walsh, J. L. (2020). The Unanticipated Benefits of PrEP for Young Black Gay, Bisexual, and Other Men Who Have Sex with Men. AIDS and Behavior, 24(5), 1376-1388.

https://doi.org/10.1007/s10461-019-02747-7

Race, K. (2003). Revaluation of risk among gay men. AIDS Education and Prevention, 15(4), 369-381. https://doi.org/10.1521/aeap.15.5.369.23822

Race, K. (2008). The use of pleasure in harm reduction: Perspectives from the history of sexuality. International Journal of Drug Policy, 19(5), 417-423. https://doi.org/10.1016/j.drugpo.2007.08.008

Race, K. (2010). Engaging in a Culture of Barebacking. In M. Davis \& C. Squire (Eds.), HIV Treatment and Prevention Technologies in International Perspective (pp. 144-166). Palgrave Macmillan.

Race, K. (2012). Framing Responsibility: HIV, Biomedical Prevention, and the Performativity of Law. Bioethical Inquiry, 9, 327-338.

Race, K. (2014). The difference practice makes: Evidence, articulation, and affect in HIV prevention. AIDS Education and Prevention, 26(3), 256-266. https://doi.org/10.1521/aeap.2014.26.3.256

Race, K. (2016). Reluctant objects: Sexual pleasure as a problem for HIV biomedical prevention. GLQ, 22(1), 1-31. https://doi.org/10.1215/10642684-3315217 
Race, K. (2017). Thinking with pleasure: Experimenting with drugs and drug research. International Journal of Drug Policy, 49, 144-149. https://doi.org/10.1016/j.drugpo.2017.07.019

Rangel, C., \& Adam, B. D. (2014). Everyday moral reasoning in the governmentality of HIV risk. Sociology of Health \& Illness, 36(1), 60-74.

Ranjit, Y. S., Dubov, A., Polonsky, M., Fraenkel, L., Ogunbajo, A., Mayer, K., \& Altice, F. L. (2019). Pre-exposure Prophylaxis Among Men Who have Sex with Men: Dual Motivational Model of Intention to Use Pre-exposure Prophylaxis. AIDS and Behavior, 23, 534-543. https://doi.org/10.1007/s10461-018-2214-2

Reinharz, S., \& Chase, S. (2002). Interviewing Women. In J. Gubrium \& J. Holstein (Eds.), Handbook of Interview Research: Context \& Method (pp. 221-238). Sage.

Reisner, S., Mimiaga, M., Case, P., Johnson, C., Safren, S., \& Mayer, K. (2008). Predictors of Identifying as a barebacker among High-Risk New England HIV Seronegative Men Who Have Sex with Men. Journal of Urban Health: Bulletin of the New York Academy of Medicine, 86(2), 250-262.

Reynolds, E. (2007). "Pass the Cream, Hold the Butter": Meanings of HIV Positive Semen for Bugchasers and Giftgivers. Anthropology \& Medicine, 14(3), 259-266.

Reynolds, P. (2004). The Quality of Consent: Sexual Consent, Culture, Communication, Knowledge and Ethics. In M. Cowling \& P. Reynolds (Eds.), Making Sense of Sexual Consent (pp. 93-108). Ashgate.

Rheingold, H. (1993). The Virtual Community: Homesteading on the Electronic Frontier. Addison-Wesley Publishing Company. 
Ridge, D. T. (2004). "It was an Incredible Thrill”: The Social Meanings and Dynamics of Younger Gay Men's Experiences of Barebacking in Melbourne. Sexualities, 7(3), 259279.

Ringrose, J., \& Rawlings, V. (2015). Posthuman performativity, gender and "school bullying": Exploring the material-discursive intra-actions of skirts, hair, sluts, and poofs. Confero: Essays on Education, Philosophy and Politics, 3(2), 80-119.

Robinson, B. A. (2014). Barebacking with Weber: Re-enchanting the rational sexual order. Social Theory and Health, 12, 235-250. https://doi.org/10.1057/sth.2014.4

Robinson, B. A. (2018). Doing Sexual Responsibility: HIV, Risk Discourses, Trust, and Gay Men Interacting Online. Sociological Perspectives, 61(3), 383-398. https://doi.org/10.1177/0731121417709248

Rofes, E. (1998). Dry Bones Breathe: Gay Men Creating Post-AIDS Identities and Cultures. Haworth Press.

Rofes, E. (2002). Desires as defiance: Gay male sexual subjectivities and resistance to sexual health promotion. Health Education Journal, 61(2), 125-137.

Rose, N. (2007). The Politics of Life Itself: Biomedicine, Power, and Subjectivity in the TwentyFirst Century. Princeton University Press.

Rosengarten, M. (2004). Tha Challenge of HIV for Feminist Theory. Feminist Theory, 5(2), $205-222$.

Rosengarten, M. (2009). HIV Interventions: Biomedicine and the Traffic Between Information and Flesh. University of Washington Press. 
Rosengarten, M., \& Michael, M. (2009). The performative function of expectations in translating treatment to prevention: The case of HIV pre-exposure prophylaxis, or PrEP. Social Science \& Medicine, 69(7), 1049-1055. https://doi.org/10.1016/j.socscimed.2009.07.039

Rosengarten, M., \& Michael, M. (2010). HIV Pre-exposure Prophylaxis (PrEP) and the Complexities of Biomedical Prevention: Ontological Openness and the Prevention Assemblage. In M Davis \& C. Squire (Eds.), HIV Technologies in International Perspective (pp. 167-183). Palgrave.

Rutledge, S. E. (2009). Formation of personal HIV disclosure policies among HIV-positive men who have sex with men. AIDS Patient Care and STDs, 23(7), 531-543.

Sagaon-Teyssier, L., Suzan-Monti, M., Demoulin, B., Capitant, C., Lorente, N., Préau, M., Mora, M., Rojas Castro, D., Chidiac, C., Chas, J., Meyer, L., Molina, J. M., \& Spire, B. (2016). Uptake of PrEP and condom and sexual risk behavior among MSM during the ANRS IPERGAY trial. AIDS Care - Psychological and Socio-Medical Aspects of AIDS/HIV, 28, 48-55. https://doi.org/10.1080/09540121.2016.1146653

Sandset, T. (2019). 'HIV Both Starts and Stops with Me': Configuring the Neoliberal Sexual Actor in HIV Prevention. Sexuality and Culture, 23(2), 657-673. https://doi.org/10.1007/s12119-018-09584-1

Scaramuzzino, G. (2012). Ethnography on the Internet-An overview. In K. J. and K. Sjoberg (Ed.), Pondering on Methods: A Variety of Methodological Concerns (pp. 41-54). Media-Trycl/Lund University.

Seale, C., Charteris-Black, J., MacFarlane, A., \& McPherson, A. (2010). Interviews and internet forums: a comparison of two sources of qualitative data. Qualitative health research, 20(5), 595-606. 
Sedgwick, E. K., \& Frank, A. (1995). Shame in the Cybernetic Fold: Reading Silvan Tomkins. In E. K. Sedgwick \& A. Frank (Eds.), Shame and Its Sisters: A Silvan Tomkins Reader (pp. 1-28). Duke University Press.

Sharma, M., Chris, A., Chan, A., Knox, D. C., Wilton, J., McEwen, O., Mishra, S., Grace, D., Rogers, T., Bayoumi, A. M., Maxwell, J., Shahin, R., Bogoch, I., Gilbert, M., \& Tan, D. H. S. (2018). Decentralizing the delivery of HIV pre-exposure prophylaxis (PrEP) through family physicians and sexual health clinic nurses: A dissemination and implementation study protocol. BMC Health Services Research, 18(1), 513-513. https://doi.org/10.1186/s12913-018-3324-2

Shernoff, Michael. (2006a). Condomless Sex: Gay Men, Barebacking, and Harm Reduction. Social Work, 51(2), 106-113.

Shernoff, M. (2006b). Without Condoms: Unprotected Sex, Gay Men and Barebacking. Routledge.

Silversides, A. (2003). AIDS Activist: Michael Lynch and the Politics of Community. Between the Lines.

Snodgrass, J. G. (2014). Ethnography of Online Cultures. In H.R. Bernard \& C.G. Gravlee (Eds.), Handbook of Methods in Cultural Anthropology (pp. 463-495). Rowman \& Littlefield.

Sontag, S. (1988). Aids and its metaphors. Farrar.

Spieldenner, A. (2016). PrEP Whores and HIV Prevention: The Queer Communication of HIV Pre-Exposure Prophylaxis (PrEP). Journal of Homosexuality, 63(12), 1685-1697. https://doi.org/10.1080/00918369.2016.1158012 
Squire, C. (2010). Being naturalised, being left behind: The HIV citizen in the era of treatment possibility. Critical Public Health, 20(4), 401-427. https://doi.org/10.1080/09581596.2010.517828

Squire, V. (2015). Reshaping critical geopolitics? The materialist challenge. Review of International Studies, 41, 139-159. https://doi.org/10.1017/S0260210514000102

Suarez, T., \& Miller, J. (2001). Negotiating Risks in Context: A Perspective on Unprotected Anal Intercourse and Barebacking Among Men Who Have Sex with Men - Where Do We Go from Here? Archives of Sexual Behavior, 30(3), 287-300.

Sun, C. J., Anderson, K. M., Toevs, K., Morrison, D., Wells, C., \& Nicolaidis, C. (2019). “Little tablets of gold": An examination of the psychological and social dimensions of PrEP. AIDS Education and Prevention, 31(1), 51-62. https://doi.org/10.1521/aeap.2019.31.1.51

Taguchi, H. L. (2012). A diffractive and Deleuzian approach to analysing interview data. Feminist Theory, 13(3), 265-281. http://doi.org/10.1177/1464700112456001

Tester, G., \& Hoxmeier, J. C. (2020). PrEP, TasP and the casual sex scripts among serodiscordant gay men. Journal of HIV/AIDS and Social Services. https://doi.org/10.1080/15381501.2020.1753620

Tewksbury, R. (2006). "Click here for HIV”: An Analysis of Internet-Based Bug Chasers and Bug Givers. Deviant Behavior, 27(4), 379-395.

Thomann, M. (2018). “On December 1, 2015, sex changes. Forever”: Pre-exposure prophylaxis and the pharmaceuticalisation of the neoliberal sexual subject. Global Public Health, 13(8), 997-1006. https://doi.org/10.1080/17441692.2018.1427275 
Thomson, A. (2019). The Stealthing Panic: Gendered Neoliberalism in Online Media. Australian Humanities Review, 64, 24-46.

Tomso, G. (2004). Bug chasing, barebacking, and the risks of care. Literature and Medicine, 23(1), 88-111. https://doi.org/10.1353/lm.2004.0014

Tomso, G. (2008). Viral Sex and the Politics of Life. South Atlantic Quarterly, 107(2), 265-285. https://doi.org/10.1215/00382876-2007-066

Treichler, P. A. (1999). How to have theory in an epidemic: Cultural chronicles of AIDS. Duke University Press.

Trowler, P. R. (2014). Practice-focused ethnographies of higher education: Method/ological corollaries of a social practice perspective. European Journal of Higher Education, 4(1), 18-29. https://doi.org/10.1080/21568235.2013.833485

Valdiserri, R. O. (2004). Mapping the roots of HIV/AIDS complacency: implications for program and policy development. AIDS Education and Prevention, 16(5), 426-439.

Van der Zaag, A. C. (2017). Materialities of sex in a time of HIV: the promise of vaginal microbicides. Rowman \& Littlefield.

Van Kesteren, N., Hospers, G., \& Empelen, P. van. (2005). Sexuality and Sexual Risk Behavior in HIV-Positive Men Who Have Sex With Men. Qualitative Health Research, 15(2), $145-168$.

Van Laarhoven, A., Hoornenborg, E., Achterbergh, R., Vries, H. D., Prins, M., \& Loeff, M. S. V. D. (2017). O09.3 Changes in sexual risk behaviour among daily prep users after 6 months of use in the amsterdam prep project. Sexually Transmitted Infections, 93(Suppl 2), A20 LP-A20. 
Varghese, R. (2019). Introduction: The Mourning After: Barebacking and Belatedness. In R. Varghese (Ed.), Raw: PrEP, Pedagogy, and the Politics of Barebacking (pp. xvii-xxxiv). University of Regina Press.

Ven, P. , Mao, L. , Fogarty, A. , Rawstorne, P. , Crawford, J. , Prestage, G. , Grulich, A. , Kaldor, J. , Kippax, S. \& (2005). Undetectable viral load is associated with sexual risk taking in HIV serodiscordant gay couples in Sydney. AIDS, 19 (2), 179-184.

Vernazza, P., Hirschel, B., Bernasconi, E., \& Flepp, M. (2008). Les personnes séropositives ne souffrant d'aucune autre MST et suivant un traitement antirétroviral efficace ne transmettent pas le VIH par voie sexuelle. Bulletin des médecins suisses/ Schweizerische Ärztezeitung/ Bollettino dei medici svizzeri, 89(5), 165-169.

Wade, M. (2019). "Stealthing” is sexual assault, and we need to talk about it. Star Observer. https://www.starobserver.com.au/news/national-news/victoria-news/stealthing-is-a-formof-sexual-assault-and-we-need-to-talk-about-it/178175

Walther, J. B. (2002). Research ethics in Internet-enabled research: Human subjects issues and methodological myopia. Ethics and Information Technology, 4(3), 205-216. https://doi.org/10.1023/A:1021368426115

Warner, M. (2000). The Trouble with Normal: Sex, Politics, and the Ethics of Queer Life. Harvard University Press.

Watkins, E. Siegel. (1998). On the pill: A social history of oral contraceptives, 1950-1970. JHU Press.

Watney, Simon. (1994). Practices of freedom: Selected writings on HIV/AIDS (1st U.S. e). Duke University Press.

Weeks, J. (1986). Sexuality. Routledge. 
Weinstein, M. (2010). Advancing on AIDS, or giving up on gay men? San Jose Mercury News, 2014. http://www.mercurynews.com/opinion/ci_16967427?nclick_check=1

Weiss, R. S. (1994). Learning from strangers: The art and method of qualitative interview studies. Free Press.

Willig, C. (2008). Foucaudian discourse analysis. In Introducing Qualitative Research in Psychology (pp. 112-131). Open University Press.

Wolitski, R. J., Bailey, C. J., O’Leary, A., Gómez, C. A., Parsons, J. T., Wolitsky, R., Bailey, C. J., O’Leary, A., Gomez, C., \& Parsons, J. T. (2003). Self-Perceived Responsibility of HIV-Seropositive Men Who Have Sex With Men for Preventing HIV Transmission. O AIDS and Behavior, 7(4), 363-372.

Wolitsky, R. (2006). The Emergence of Barebacking Among Gay and Bisexual Men in the United States: A Public Health Perspective. Journal of Gay and Lesbian Psychotherapy, $9(3-4), 9-34$.

Wolitsky, R., Valdiserri, R., Denning, P., \& Levine, W. (2001). Are We Headed for a Resurgence of the HIV Epidemic Among Men Who Have Sex With Men? American Journal of Public Health, 91(6), 883-888.

Youle, M., \& Wainberg, M. A. (2003). Pre-Exposure Chemoprophylaxis (PREP) as an HIV Prevention Strategy. Journal of the International Association of Physicians in AIDS Care, 2(3), 102-105. https://doi.org/10.1177/154510970300200302

Young, D. S., \& Casey, E. A. (2019). An examination of the sufficiency of small qualitative samples. Social Work Research, 43(1), 53-58.

Young, I. (1996). The AIDS Cult and Its Seroconverts: Part 1. Continuum, 14-17.

Young, I. (1997). The AIDS Cult and Its Seroconverts: Part 2. Continuum, 4, 22-25. 
Young, R. M., \& Meyer, I. H. (2005). The trouble with "MSM" and "WSW": Erasure of the sexual-minority person in public health discourse. American Journal of Public Health, 95(7), 1144-1149. https://doi.org/10.2105/AJPH.2004.046714

Zapata, J. P., Petroll, A., de St. Aubin, E., \& Quinn, K. (2020). Perspectives on Social Support and Stigma in Prep-Related Care among Gay and Bisexual Men on PrEP: A Qualitative Investigation. Journal of Homosexuality, 1-23.

https://doi.org/10.1080/00918369.2020.1819709 


\section{Appendices}

\section{Appendix A - Carleton University Ethics Clearance}

Office of Research Ethics

4500 ARISE Building | 1125 Colonel By Drive OVawa, Ontario K1S 5B6

613-520-2600 Ext: 2517

ethics@carleton.ca

\section{CERTIFICATION OF INSTITUTIONAL ETHICS CLEARANCE}

The Carleton University Research Ethics Board-A (CUREB-A) at Carleton University has renewed ethics approval for the research project detailed below. CUREB-A is consZtuted and operates in compliance with the Tri-Council Policy Statement: Ethical Conduct for Research Involving Humans (TCPS2).

Title: From Condoms to PrEP: Exploring Shifting Experiences and Meanings of Sex and HIV Risk among Gay, Bisexual, and other Men Who Have Sex with Men (MSM)

Protocol \#: 111031

Project Team Members: Mr. Emerich Daroya (Primary Investigator)

Dr. Alexis Shotwell (Research Supervisor)

Department and Institution: Faculty of Arts and Social Sciences\Sociology and Anthropology

(Department of), Carleton University

Funding Source (If applicable):

Effective: June 04, 2020 Expires: June 30, 2021.

Please ensure the study clearance number is prominently placed in all recruitment and consent materials:

CUREB-A Clearance \# 111031.

\section{Restrictions:}

This certification is subject to the following conditions:

1. Clearance is granted only for the research and purposes described in the application. 
2. Any modification to the approved research must be submitted to CUREB-A. All changes must be approved prior to the continuance of the research.

3. An Annual Application for the renewal of ethics clearance must be submitted and cleared by the above date. Failure to submit the Annual Status Report will result in the closure of the file. If funding is associated, funds will be frozen.

4. A closure request must be sent to CUREB-A when the research is complete or terminated.

5. During the course of the study, if you encounter an adverse event, material incidental finding, protocol deviation or other unanticipated problem, you must complete and submit a Report of Adverse Events and Unanticipated Problems Form, found here: hVps://carleton.ca/researchethics/forms-and-templates/

6. It is the responsibility of the student to notify their supervisor of any adverse events, changes to their application, or requests to renew/close the protocol.

7. Failure to conduct the research in accordance with the principles of the Tri-Council Policy Statement: Ethical Conduct for Research Involving Humans 2nd edition and the Carleton University Policies and Procedures for the Ethical Conduct of Research may result in the suspension or termination of the research project.

Upon reasonable request, it is the policy of CUREB, for cleared protocols, to release the name of the PI, the title of the project, and the date of clearance and any renewal(s).

In light of the COVID-19 outbreak, The REB has developed guidance for human participants' research at https://carleton.ca/researchethics/. However, the situation is evolving rapidly so please check back regularly to keep up with any ongoing changes to this guidance.

Please email the Research Compliance Coordinators at ethics@carleton.ca if you have any quesZons.

\section{CLEARED BY: Date: June 04, 2020}

Natasha Artemeva, PhD, Chair, CUREB-A Janet Mantler, PhD, Vice Chair, CUREB-A 


\section{Appendix B - La Trobe University Ethics Clearance}

\section{LA TROBE
UNIVERSITY}

\section{FACULTY OF HEALTH SCIENCES}

MEMORANDUM

To: Gary Dowsett, ARCSHS

Student: $\quad$ Emerich Daroya

From: Chair, Faculty Human Ethics Committee

Subject: $\quad$ Review of Faculty Human Ethics Committee Application No. FHEC13/182

Title: Exploring Barebacking Practices Online

Date: 5 September 2013

Thank you for your recent correspondence in relation to the research project referred to above. The project has been assessed as complying with the National Statement on Ethical Conduct in Human Research. I am pleased to advise that your project has been granted ethics approval and you may commence the study now.

The project has been approved from the date of this letter until 30/6/2016.

Please note that your application has been reviewed by a sub-committee of the University Human Ethics Committee (UHEC) to facilitate a decision before the next Committee meeting. This decision will require ratification by the UHEC and it reserves the right to alter conditions of approval or withdraw approval at that time. You will be notified if the approval status of your project changes. The UHEC is a fully constituted Ethics Committee in accordance with the National Statement under Section 5.1.29.

The following standard conditions apply to your project: 
Limit of Approval. Approval is limited strictly to the research proposal as submitted in your application while taking into account any additional conditions advised by the Faculty Human Ethics Committee (FHEC) .

Variation to Project. Any subsequent variations or modifications you wish to make to your project must be formally notified to the FHEC for approval in advance of these modifications being introduced into the project. This can be done using the appropriate form: Ethics - Application for Modification to Project

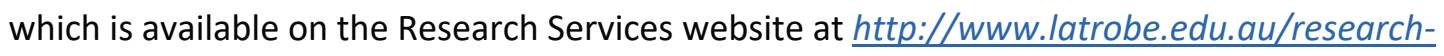
services/ethics/HEC human.htm. If the FHEC considers that the proposed changes are significant, you may be required to submit a new application form for approval of the revised project.

Adverse Events. If any unforeseen or adverse events occur, including adverse effects on participants, during the course of the project which may affect the ethical acceptability of the project, the Chief Investigator must immediately notify the FHEC Secretary on telephone (03) 94793570 or at fhechealth@latrobe.edu.au.Any complaints about the project received by the researchers must also be referred immediately to the FHEC Secretary.

Withdrawal of Project. If you decide to discontinue your research before its planned completion, you must advise the FHEC and clarify the circumstances.

Monitoring. All projects are subject to monitoring at any time by the Faculty Human Ethics Committee. Annual Progress Reports. If your project continues for more than 12 months, you are required to submit an Ethics - Progress/Final Report Form annually, on or just prior to 12 February. The form is available on the Research Services website (see above address). Failure to submit a Progress Report will mean approval for this project will lapse.

Auditing. An audit of the project may be conducted by members of the FHEC. 
234 I Appendices

Final Report. A Final Report (see above address) is required within six months of the completion of the project.

If you have any queries on the information above or require further clarification please contact me at fhechealth@latrobe.edu.au.

On behalf of the Faculty of Health Sciences Faculty Human Ethics Committee, best wishes with your research!

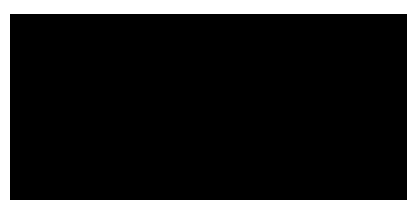

Timothy M Bach, PhD

Acting Chair

Faculty Human Ethics Committee

Faculty of Health Sciences 


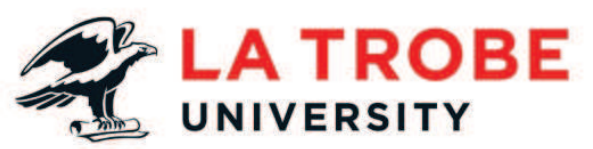

Australian

Research Centre

in Sex, Health

\& Society

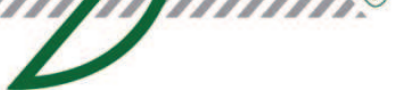

215 Franklin Street

Melbourne, VIC 3000

Australia

T: +61394798760

$\mathrm{F}:+61394798711$

E: arcshs@latrobe.edu.au

www.latrobe.edu.au/arcshs

To Whom It May Concern:

Permission to include (Website 1 or Website 2) for research

My name is Emerich Daroya and I am a PhD candidate at the Australian Research

Centre in Sex, Health and Society (ARCSHS) at La Trobe University, Melbourne, Australia.

My doctoral dissertation explores how gay and other homosexually active men discuss sex-without-condoms in online settings. As a gay man interested in barebacking subcultures, my research aims to move away from the judgemental assumptions about the practice to explore how men describe and understand barebacking in interaction with other men online. I am particularly interested in how men perceive scientific, legal and moral ideas about condom use and balance these with their preferences for condomless sex.

I found your website online and I believe that the discussion board is a great venue for my project as members discuss the issues pertaining to my research interests. I am writing to request permission to include your website in my study. 
If you consent to my request, I plan to announce my presence by creating a post in the General Discussion board containing information about myself and the project. I will then observe the discussion boards for a period of one month to familiarise myself with the forums, the issues and the language used by members. After this, I will collect archived text and visual data (such as forum threads and advertising images, but not content or images from individual profiles) from the discussion boards. Over a period of three months, I will also ask questions in the discussion boards about members' thoughts about barebacking. I can provide you with a list of possible questions before posting them, if you wish.

I concede that there may not be any direct benefit to you or the members of the discussion boards from this study. However, with your kind support, I believe analysis of the message boards (and others I am including in the project) will provide new insights into how gay and other homosexually active men think about ideas, beliefs and fantasies related to HIV and barebacking. This will provide new information about the complexity of barebacking directly from the perspectives of gay and other homosexually active men.

I can understand that you may have reservations about participating in the study, especially with some negative attitudes toward barebacking in society. However, I can assure you that I will protect the privacy of the website, its members and owner(s)/moderator(s) by ensuring that all identifying information is kept confidential, and providing each with pseudonyms when referring to them in reporting of the data in my thesis, and any subsequent outputs such as conference presentations or academic articles. However, as quotations from posts may be quoted in the thesis and subsequent publications, it may be possible for anyone who conducts a search using a 
powerful search engine (such as Google) to link individual quotes back to the website. In this case, the person who is deliberately checking the origin of the quotation is performing the 'detective' operation and it is beyond my control. Although the origin of the quote is traced, the poster is still unidentifiable as usernames are anonymous. I have attached a participant information sheet to this email, which provides some more information about the project and what is involved should you consent to allow me to use the website as a source of data for my research. I would also welcome an opportunity to discuss any aspect of my project with you, either by return email, on Skype, or by phone call. Thank you very much.

Sincerely,

Emerich Daroya, PhD Candidate

E: edaroya@students.latrobe.edu.au

T: +61394798742

Project Supervisors:

Prof Gary Dowsett E: g.dowsett@latrobe.edu.au

T: +61394798708

Dr Duane Duncan E: d.duncan@latrobe.edu.au

T: +61394798709

Dr Steven Angelides E: s.angelides@latrobe.edu.au

$$
\text { T: }+61394798729
$$




\section{Appendix D - Announcement about Research Posted in the Online Forums}
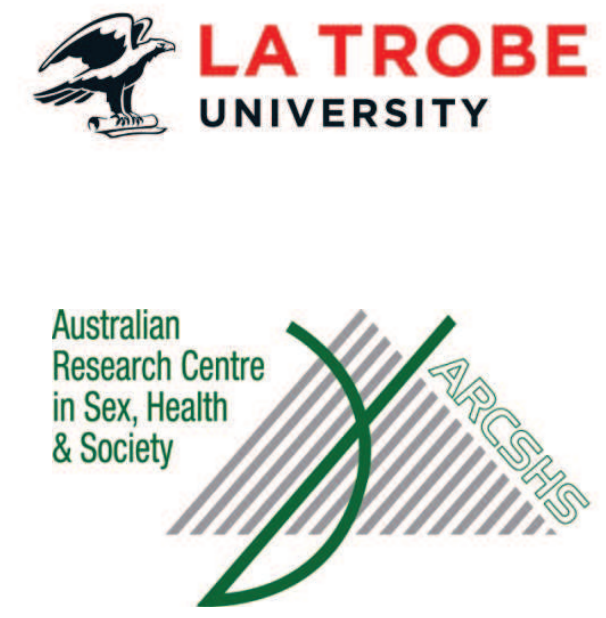

215 Franklin Street Melbourne, VIC 3000

Australia

T: +61394798760

$\mathrm{F}:+61394798711$

E: arcshs@latrobe.edu.au www.latrobe.edu.au/arcshs

Dear members of (Website 1 or Website 2) discussion boards:

Announcement to include (Website 1 or Website 2) in a research study on gay men and barebacking

My name is Emerich Daroya and I am a PhD candidate at the Australian Research

Centre in Sex, Health and Society (ARCSHS) at La Trobe University, Melbourne, Australia.

My doctoral dissertation explores how gay and other homosexually active men discuss issues surrounding sex-without-condoms in online settings.

With the kind permission of the website moderator(s), I am writing to inform you that I am conducting a study of the discussion boards on this website. The research will involve observing and collecting text and visual data from the discussion boards (such as forum threads and advertising images, but not content or images from individual profiles). I will also ask questions in the discussion boards about members' thoughts about barebacking. 
While members of the discussion boards may not receive any direct benefit from this research, I believe analysis of the message boards will provide new insight into how gay and other homosexually active men think about and discuss sex-without-condoms.

I can assure you that I will protect the privacy of the website, its members and moderator(s) by ensuring that all identifying information is kept confidential. I have provided a link to a participant information sheet which provides further information about myself and the study. If you have any questions about any aspect of the project, please send me a message.

If you would prefer for any part of your interaction on the website not to be used as data in the project, you may choose to withdraw by contacting me via private message or email to let me know.

Thank you very much.

Sincerely,

Emerich Daroya, PhD Candidate

E: edaroya@students.latrobe.edu.au

T: +61394798742

Project Supervisors:

Prof Gary Dowsett E: g.dowsett@latrobe.edu.au

T: +61394798708

Dr Duane Duncan E: d.duncan@latrobe.edu.au

T: +61394798709

Dr Steven Angelides E: s.angelides@latrobe.edu.au

T: +6139479872 


\section{I Appendices}

\section{Appendix E - Interview Guide}

1. Can you please tell me something about yourself?

2. What is your age?

3. How would you identify your racial/ethnic background?

4. What is the highest degree or level of school you have completed?

5. What is your current employment status?

6. What is your field of work?

7. What is your income bracket? [ ] below $\$ 40,000 /$ year [ ] between $\$ 40,000-100,000 /$ year [ ] above $\$ 100,000 /$ year

Interview themes, and possible questions*

\section{Background Information on PrEP Use \\ -When did you start taking PrEP? \\ - How did you hear about PrEP? \\ - How have your medical providers talked to you about PrEP? \\ -What was your main reason for starting PrEP? \\ -Did you have any issues finding a doctor who would prescribe PrEP for you? \\ -Where do you currently buy PrEP? Did you have any issues finding a place to access PrEP? \\ - How long do you think you will be on PrEP? \\ -What do you see as the benefits of continuing to use PrEP?}

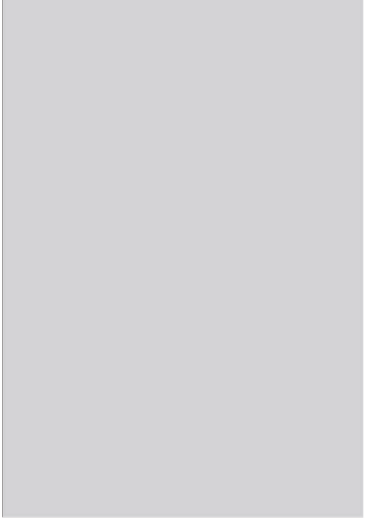

\section{Cost and Side effects of PrEP Use}

- How is your PrEP currently paid for? (i.e., insurance, outof-pocket)

- How much do you pay for PrEP?

-Do you have any concerns about the cost?

-Do you think that PrEP should be made more accessible to those who want it or need it? Why?

-When do you take PrEP? How do you remember to take it each day?

- How do you feel about taking PrEP each day?

- Have you experienced any side effects? Could you tell me more about them?

-Did your doctor discuss these possible side effects with you?

-Did you discuss side effects with your doctor?

-If you're having side effects, how do you managed them? - Have there been times when you stopped taking PrEP? What was the reason for this? -Do you have any concerns about efficacy?

\section{Impacts of PrEP on} personal life

-Who knows that you're taking PrEP? Did you have any concerns about telling them you're on PrEP?

-How did they react?

-What are some positive and negative comments you have heard or read about PrEP in the gay community?

- Have you experienced any stigma or negative reactions as a result of using PrEP? Could you tell me more about it? -Are you familiar with any of the labels commonly associated with PrEP users? For example 'Truvada whore', 'promiscous', 'slut', or 'whore'? What do you think about these?

\section{Impacts of PrEP on sexua} health

-When you started taking PrEP, did you notice a change in your sexual behaviours?

- If your doctor told you it was still important for you to be using condoms with sex partners, what would you think about this?

-Before going on PrEP, what strategies were you using to protect yourself?

-Now that you're on PrEP, are there any other things that you currently do to lower your risk for HIV and other STIs? Are you concerned about other STIs besides HIV?

- How do you feel about undergoing HIV/STI testing regularly now that you're on PrEP?

- How confident do you feel in your ability to protect yourself from HIV since you started PrEP?

-Do you think you're personally responsible for protecting yourself against HIV?

- How do you think PrEP is changing what it means to have safer sex?

-What do you think are some positive and negative effects of PrEP in the gay community? -Is there anything else you would like to add?

Some of these questions are adapted from: Collins, S.P. McMahan, V.M., \& Stekler, J.D. (2017). The Impact of HIV Pre-exposure Prophylaxis (PrEP) Use on the Sexual Health of Mean Who Have Sex with Men: A Qualitative Study. International Journal of Sexual Health, 29(1), 55-68. 
Appendix F - Online Invitation Website

\section{From Condoms to PrEP}

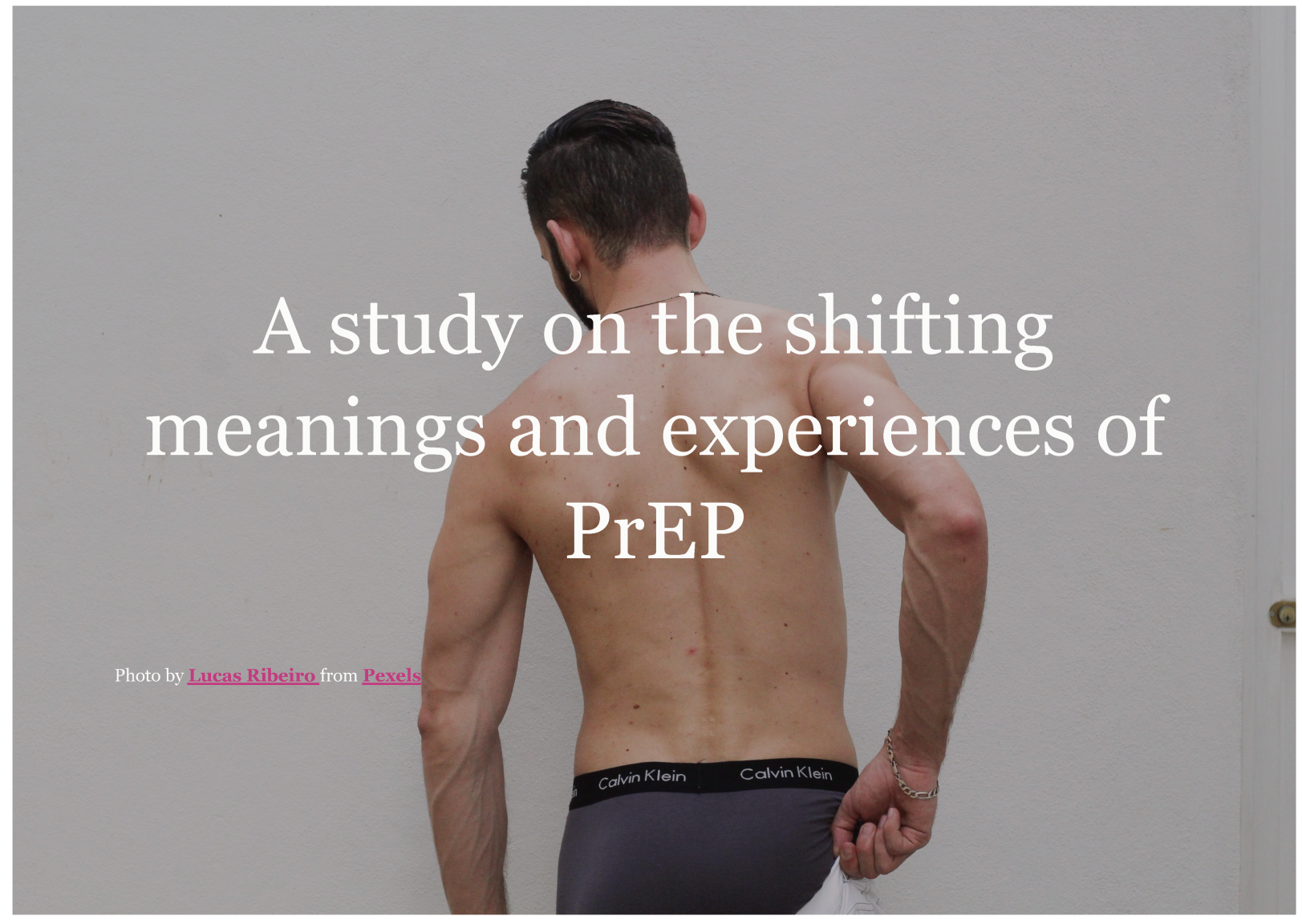

Are you a man who has sex with men taking PrEP?

\section{Join my PhD study!}

PhD Researcher from Carleton University looking for volunteers to take part in a confidential one-on-one, conversational-style interview about their sexual practices and experiences using PrEP. 
The research seeks to investigate the shifting meanings and experiences of sexual practices and identities in relation to HIV risk among MSM who take PrEP.

The specific aims of the research are:

- To explore what PrEP uptake and patterns of HIV testing means to gay, bisexual, and other MSM in and around Ottawa and Toronto areas.

- To explore how HIV-negative gay and bisexual men discuss and incorporate PrEP into their personal lives.

- To understand the impacts of PrEP on sexual health and risk behaviours.

You are eligible to take part if:

- You are English speaking

- You are 18 years or older

- You identify as gay, bisexual, or MSM *trans men who have sex with men are welcome to participate*

- You are currently taking PrEP

- You currently reside in and around Ottawa and Toronto.

I would like to talk to you in person or over Skype, depending on your preference and location. The interview will take about 60-90 minutes and I am able to offer you \$25 Amazon Gift card in acknowledgement for your time and contribution to the project.

The study is a PhD research project conducted by Emerich Daroya, a PhD student based at the Department of Sociology \& Anthropology, Carleton University. This project is supervised by Dr. Alexis Shotwell. For further information, download the Consent Form.

If you are interested, please fill out the form below or contact the researcher at emerich.daroya@carleton.ca for more details on participating.

\section{Contact Me}

Please use the form below to leave your contact details and I will be in touch with you shortly. 
Name (required)

Email (required)

Message

Submit

Carleton

U N I VER S I T Y

The ethics protocol for this research has been reviewed and approved by the Carleton University Research Ethics Board. CUREB A: If you have any ethical concerns with the study, please contract Dr. Bernadette Campbell, Chair, Carleton University Research Ethics Board-A (by phone at 613-520-2600 ext. 2517 or via email at ethics@carleton.ca). 
244 I Appendices

\section{Appendix G - Informed Consent Form}

\section{Carleton}

\section{Name and Contact Information of Researchers:}

Emerich Daroya, Department of Sociology \& Anthropology, Carleton University

Tel.: (613) 295-7062

Email: emerich.daroya@carleton.ca

Supervisor and Contact Information: Dr. Alexis Shotwell, AlexisShotwell@cunet.carleton.ca

\section{Project Title}

From Condoms to PrEP: Exploring Shifting Experiences and Meanings of Sex and HIV Risk among Gay, Bisexual, and other Men who have sex with Men (MSM)

Project Sponsor and Funder (if any)

Social Sciences and Humanities Research Council (752-2018-1774)

\section{Carleton University Project Clearance}

Clearance \#: $111031 \quad$ Date of Clearance: 18 June 2019

\section{Invitation}

You are invited to take part in a research project because you are English speaking, 18 years or older, identify as gay, bisexual, or MSM, and currently taking PrEP, and reside in and around Toronto or Ottawa areas. The information in this form is intended to help you understand what I am asking of you so that you can decide whether you agree to participate in this study. Your participation in this study is voluntary, and a decision not to participate will not be used against you in any way. As you read this form, and decide whether to participate, please ask all the questions you might have, take whatever time you need, and consult with others as you wish.

\section{What is the purpose of the study?}

The research seeks to investigate the shifting experiences and meanings of sexual practices and identities in relation to HIV risk among MSM who take PrEP. The specific aims of the research are: 
To explore what PrEP uptake and patterns of HIV testing means to you.

To explore how you discuss and incorporate PrEP in your personal life.

To understand the impacts of PrEP on sexual health and risk behaviours.

\section{What will I be asked to do?}

If you agree to take part in the study, I will ask you to:

Attend a face-to-face or over Skype, audio-recorded conversation-like interview, which takes approximately 60-90 minutes conducted in English.

Provide your demographic information: age, highest degree or level of education, employment status, field of work, and income group. This information will be used to add context to your responses. The names of people and places you mention in the interview will also be altered during transcription.

During the interview, I will explore 4 themes central to the research with you. They are: (i) background information about your PrEP use; (ii) cost and side effects of PrEP use; (iii) impacts of PrEP on your personal life; and (iv) impacts of PrEP on your sexual health.

\section{Risks and Inconveniences}

If you decide to take part in the research study, you may experience negative emotions during/after the interview. If this occurs, you can pause, skip the respective question, or stop the interview without any adverse consequences. I shall give you a list of supports that you can contact if you wish. You may deliberately or inadvertently disclose sensitive or embarrassing information that could result in stigmatization, embarrassment, loss of respect from your social network, loss of access to insurance benefits, or other negative personal consequences if it became public. To protect your privacy and avoid these risks, your name and any identifying details will be changed or removed as soon as your interview is transcribed.

\section{Possible Benefits}

You may not receive any direct benefit from your participation in this study. However, your participation may allow researchers to better understand the impacts of PrEP on the sexuality of gay, bisexual, and other MSM. Ultimately, this research may prompt reflection from within and beyond LGBQ+ 
communities regarding HIV prevention and may influence culturally appropriate health, education, community support, and policy perspectives both locally and elsewhere.

\section{Compensation/Incentives}

You will receive \$25 Amazon Gift card after the completion of the interview in compensation for your time and contribution for participating in the project.

\section{No waiver of your rights}

By signing this form, you are not waiving any rights or releasing the researchers from any liability.

\section{Withdrawing from the study}

You have the right to withdraw from active participation in this research at any time without consequences. You also have the right to request that your data be removed from the research after the completion of this interview; however, you need to contact the Principal Investigator (named above) $\underline{\text { within four weeks }}$ to start the withdrawal procedure. Once you have withdrawn, your data will be destroyed.

\section{Confidentiality}

By agreeing to participate, you consent to the Principal Investigator collecting and using information about you for the research study. Your participation will be kept confidential. Your name, personal details, and voice recording will also be kept confidential throughout this project and in publications and presentations. Your interview recording will be transcribed by the Principal Investigator as soon as possible. Once the audio recording has been transcribed, verified, and de-identified, the recording will be destroyed. The same will be done if you chose to be interviewed online via chat or Skype. Although my supervisor has access to your interview transcript, she will not be able to recognise you as a chosen pseudonym will be used and personal details altered during the transcription.

We will treat your personal information as confidential, although absolute privacy cannot be guaranteed. No information that discloses your identity will be released or published without your specific consent. Research records may be accessed by the Carleton University Research Ethics Board in order to ensure continuing ethics compliance. 
All data will be kept confidential, unless release is required by law (e.g. child abuse, harm to self or others).

The results of this study may be published or presented at an academic conference or meeting, but the data will be presented so that it will not be possible to identify any participants unless you give your express consent.

You will be assigned a pseudonym so that your identity will not be directly associated with the data you have provided. All data, including coded information, will be kept in a password-protected file on a secure computer.

\section{Data Retention}

After the study is completed, your de-identified data will be retained for future research use. Consent Forms will be destroyed after the completion of the study.

\section{New information during the study}

In the event that any changes could affect your decision to continue participating in this study, you will be promptly informed.

\section{Ethics review}

This project was reviewed and cleared by the Carleton University Research Ethics Board [A or B]. If you have any ethical concerns with the study, please contact Dr. Bernadette Campbell, Chair, Carleton University Research Ethics Board (by phone at 613-520-2600 [ext. 2517 for CUREB A or ext. 4085 for CUREB B] or by email at ethics@,carleton.ca).

\section{Statement of consent - print and sign name}

I voluntarily agree to participate in this study.

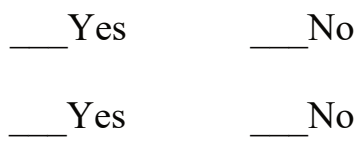

I agree to be audio recorded. 
248 I Appendices

\section{Research team member who interacted with the subject}

I have explained the study to the participant and answered any and all of their questions. The participant appeared to understand and agree. I provided a copy of the consent form to the participant for their reference.

Signature of researcher

Date 


\section{Appendix H - Online Invitation}

\section{Carleton}

\section{Are you a man who has sex with men taking PrEP? Join my PhD study!}

I am looking for volunteers to take part in a confidential one-on-one, conversationalstyle interview about their sexual practices and experiences using PrEP.

The research seeks to investigate the shifting meanings and experiences of sexual practices and identities in relation to HIV risk among men who have sex with men (MSM) who take PrEP. The specific aims of the research are:

To explore what PrEP uptake and patterns of HIV testing means to MSM in and around Ottawa and Toronto areas.

To explore how HIV-negative MSM discuss and incorporate PrEP into their personal lives.

To understand the impacts of PrEP on sexual health and risk behaviours.

You are eligible to take part if:

You are English speaking

You are 18 years or older

You identify as gay, bisexual, or MSM *trans men who have sex with men are welcome to participate*

You are currently taking PrEP

You currently reside in and around Ottawa and Toronto.

I would like to talk to you in person or over Skype, depending on your preference and location. The interview will take about 60-90 minutes and I am able to offer you \$25 Amazon Gift card in acknowledgement for your time and contribution to the project. 
If you are interested, please visit http://bit.ly/2w2yMza (CLICK LINK ON PROFILE) or email Emerich Daroya at emerich.daroya@carleton.ca for more details on participating. The ethics protocol for this research has been reviewed and approved by the Carleton University Research Ethics Board.

CUREB-A: If you have any ethical concerns with the study, please contact Dr. Bernadette Campbell, Chair, Carleton University Research Ethics Board-A (by phone at 613-520-2600 ext. 2517 or via email at ethics@carleton.ca). 